NUREG/CR-6367

SEA 95-554-06-A:8

\title{
Experimental Study of Head Loss and Filtration for LOCA Debris
}

Manuscript Completed: December 1995

Date Published: February 1996

Prepared by

D. V. Rao, F. J. Souto

Science and Engineering Associates, Inc. 6100 Uptown Boulevard N.E.

Albuquerque, NM 87110

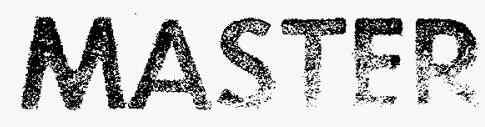

M. L. Marshall, Jr., NRC Project Manager

A. W. Serkiz, NRC Project Manager

Prepared for

Division of Engineering Technology

Office of Nuclear Regulatory Research

U.S. Nuclear Regulatory Commission

Washington, DC 20555-0001

NRC Job Codes L1854 and W6459 


\section{DISCLAIMIER}

Portions of this document may be illegible in electronic image products. Images are produced from the best available original document. 


\begin{abstract}
A series of controlled experiments were conducted to obtain head loss and filtration characteristics of debris beds formed of NUKONTM fibrous fragments, and obtain data to validate the semi-theoretical head loss model developed in NUREG/CR-6224. A thermally insulated closed-loop test set-up was used to conduct experiments using beds formed of fibers only and fibers intermixed with particulate debris. A total of three particulate mixes were used to simulate the particulate debris. The head loss data were obtained for theoretical fiber bed thicknesses of $0.125^{\prime \prime}$ to $4.0^{\prime \prime}$; approach velocities of 0.15 to $1.5 \mathrm{ft} / \mathrm{s}$; temperatures of $75^{\circ} \mathrm{F}$ and $125^{\circ} \mathrm{F}$; and sludge-to-fiber nominal concentration ratios of 0 to 60 . Concentration measurements obtained during the first flushing cycle were used to estimate the filtration efficiencies of the debris beds. For test conditions where the beds are fairly uniform, the head loss data were predictable within an acceptable accuracy range by the semi-theoretical model. The model was equally applicable for both pure fiber beds and the mixed beds. Typically the model over-predicted the head losses for very thin beds and for thin beds at high sludge-to-fiber mass ratios. This is attributable to the non-uniformity of such debris beds. In this range the correlation can be interpreted to provide upper bound estimates of head loss.
\end{abstract}




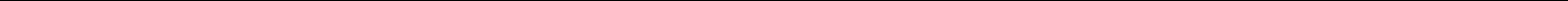




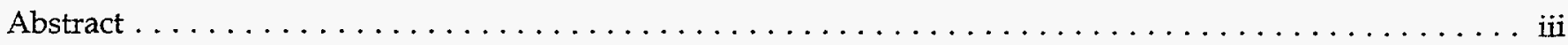

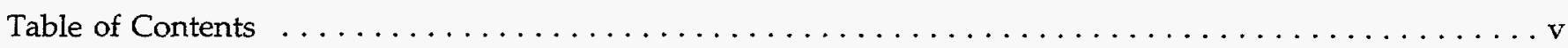

List of Figures $\ldots \ldots \ldots \ldots \ldots \ldots \ldots \ldots \ldots \ldots \ldots \ldots \ldots \ldots \ldots \ldots \ldots \ldots \ldots \ldots \ldots \ldots \ldots$

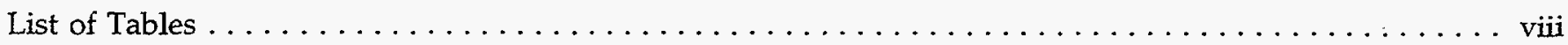

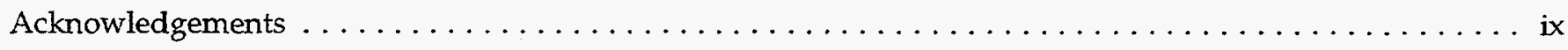

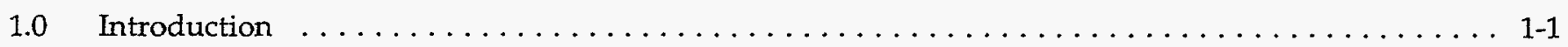

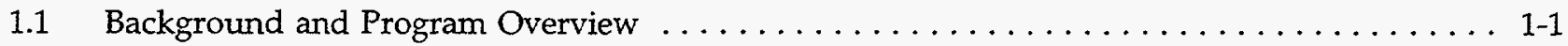

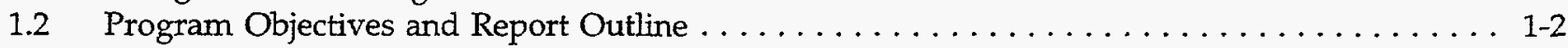

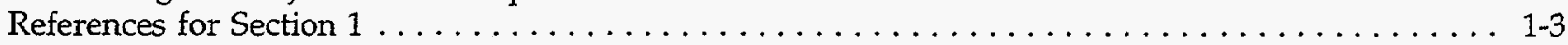

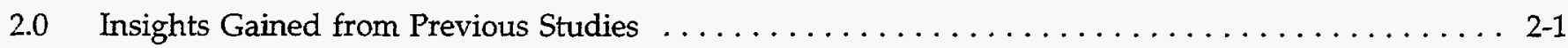

2.1 LOCA Related BWR Suction Strainer Blockage Phenomena . . . . . . . . . . . . . . 2-1

2.2 Review of Head Loss Studies for Pure Fiber Beds . . . . . . . . . . . . . . . . . . 2-3

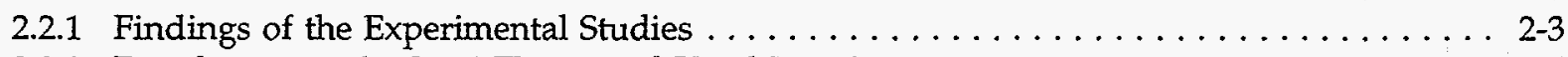

2.2.2 Development of a Semi-Theoretical Head Loss Equation $\ldots \ldots \ldots \ldots \ldots \ldots \ldots \ldots 2-6$

2.3 Effect of Sludge Filtration on the Head Loss $\ldots \ldots \ldots \ldots \ldots \ldots \ldots \ldots \ldots \ldots \ldots \ldots$

2.3.1 Findings of the Experimental Studies . . . . . . . . . . . . . . . . .

2.3.2 Development of a Semi-Theoretical Head Loss Equation $\ldots \ldots \ldots \ldots \ldots \ldots \ldots \ldots$

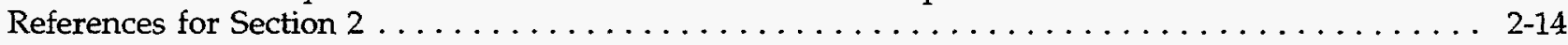

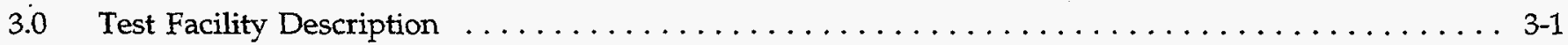

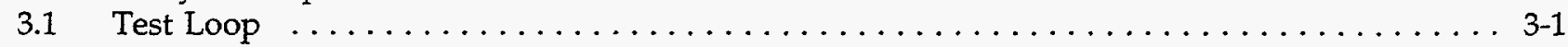

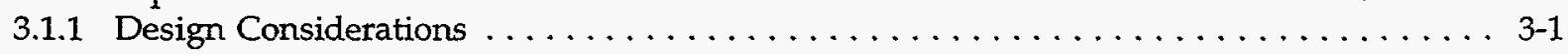

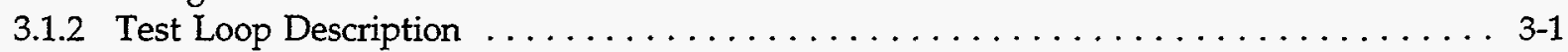

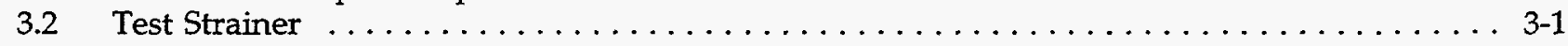

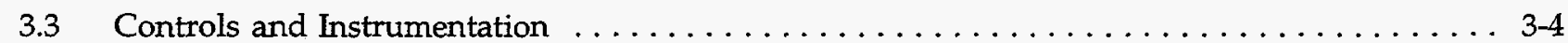

3.3.1 Loop Flow . . . . . . . . . . . . . . . . . . . . .

3.3.2 DP Across Strainer . . . . . . . . . . . . . .

3.3.3 Loop Water Temperature . . . . . . . . . . . . . . . .

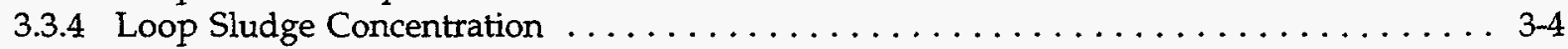

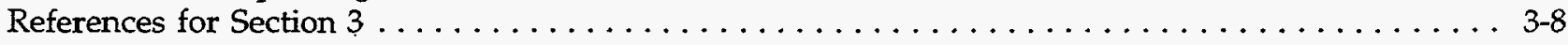

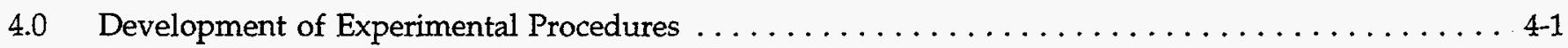

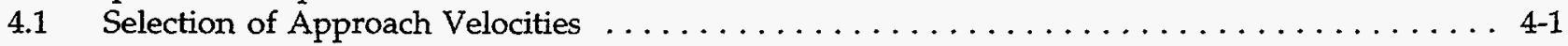

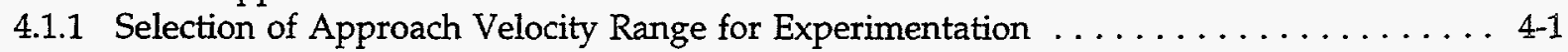

4.1.2 Selection of Approach Velocity at Bed Formation $\ldots \ldots \ldots \ldots \ldots \ldots \ldots \ldots \ldots .4$

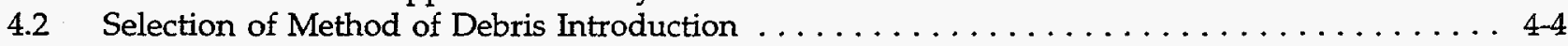

4.3 Selection of Debris Size for Experimentation $\ldots \ldots \ldots \ldots \ldots \ldots \ldots \ldots \ldots \ldots \ldots \ldots \ldots \ldots$

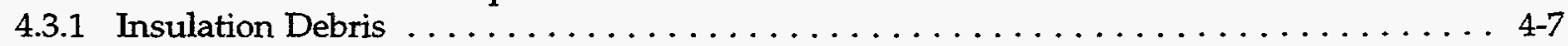

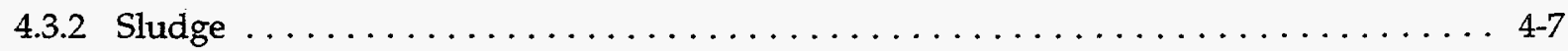

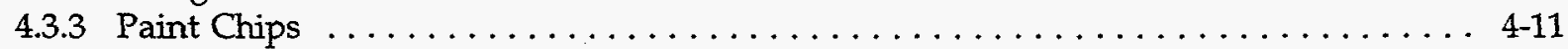

4.4 Selection of Temperature for Experimentation $\ldots \ldots \ldots \ldots \ldots \ldots \ldots \ldots \ldots \ldots \ldots . . \ldots \ldots$

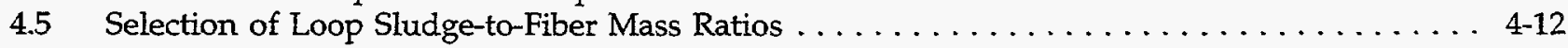

References for Section $4 \ldots \ldots \ldots \ldots \ldots \ldots \ldots \ldots \ldots \ldots \ldots \ldots \ldots \ldots \ldots \ldots \ldots \ldots$ 


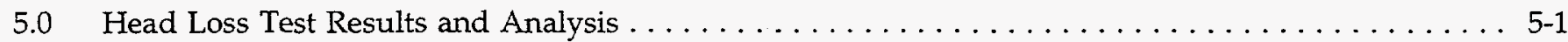

$5.1 \quad$ Experimental Procedures . . . . . . . . . . . . . . . . . . . . . . . $5-1$

5.1.1 Procedure for Insulation Debris Generation . . . . . . . . . . . . . . . . 5-1

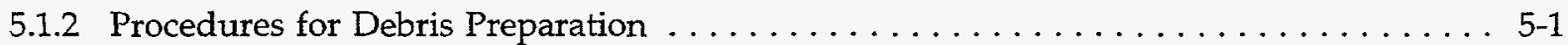

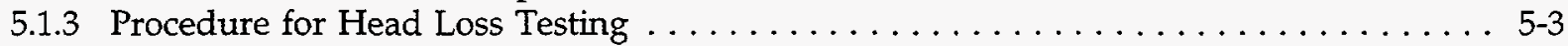

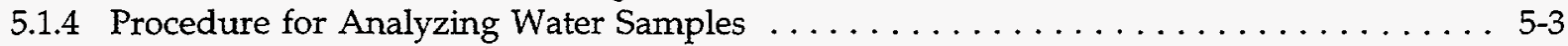

5.2 Test Results . . . . . . . . . . . . . . . . . . . . . . . . . . . $5-4$

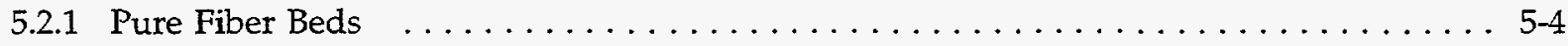

5.2 .2 Mixed Beds . . . . . . . . . . . . . . . . . . . . . . . . 5 .9

5.3 Measurement Uncertainties and Repeatability $\ldots \ldots \ldots \ldots \ldots \ldots \ldots \ldots \ldots \ldots \ldots \ldots \ldots$

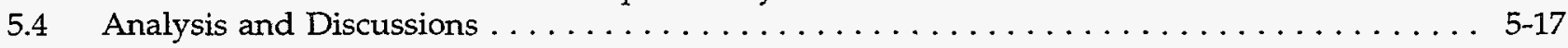

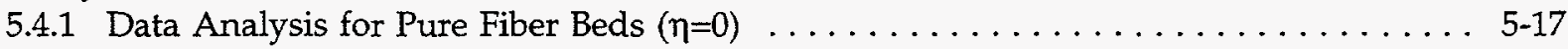

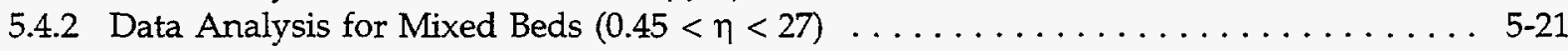

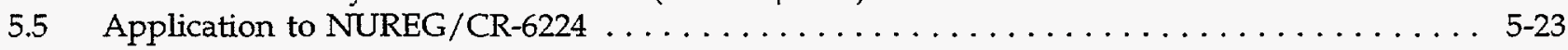

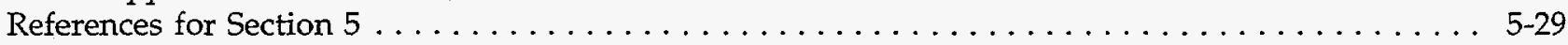

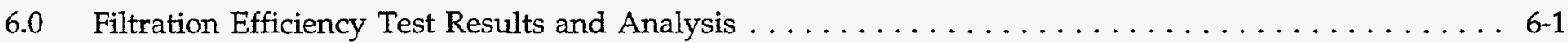

$6.1 \quad$ Experimental Procedure . . . . . . . . . . . . . . . . . . . . . . . . . 6-1

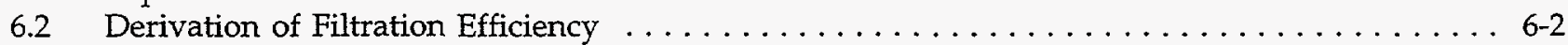

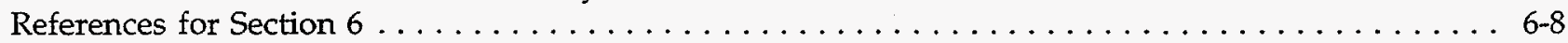

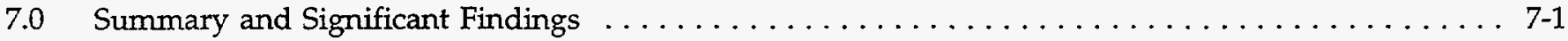

Appendix A Instrument Calibration Sheets $\ldots \ldots \ldots \ldots \ldots \ldots \ldots \ldots \ldots \ldots \ldots \ldots \ldots \ldots \ldots \ldots$

Appendix B Simulated BWR Sludge Characterization $\ldots \ldots \ldots \ldots \ldots \ldots \ldots \ldots \ldots \ldots \ldots$ 


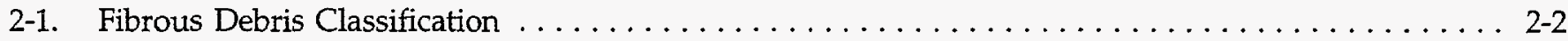

2-2. Comparison of Existing Head Loss Correlations for Pure NUKONTM Fiber Beds.

Shred Sizes Varied From Classes 3 and 4 to Large Pieces. . . . . . . . . . . . . . . . 2-5

2-3. Comparison of Existing Head Correlations for Mixed Beds Formed of NUKON'M and Sludge Simulant. . . . . . . . . . . . . . . . . . . . .

2-4. Comparison of Semi-Theoretical Model Used in Blockage with NUKON ${ }^{\mathrm{TM}}$ Data. . . . . . . . . . 2-11

2-5 Comparison of NUREG/CR-6224 Correlation with the PP\&L Experimental Data . . . . . . . . 2-13

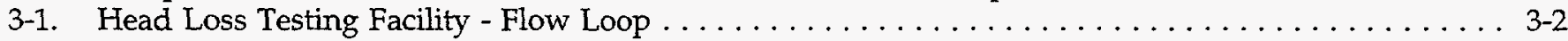

3-2. Planview \& Cross-Section of Strainer . . . . . . . . . . . . . . . . . . . . . . . 3

3-3. Bench Tests Conducted by ARL to Bench Mark the Concentration Measurements . . . . . . . . . . 3-6

3-4. Sludge Only Loop Tests Used to Quantify Uncertainties in Concentration

Measurements .................................... 3-7

4-1. Transient Head Loss Curve for a Typical Pure Fiber Bed Formed on the Strainer . . . . . . . . . 4 4-3

4-2. Effect of Approach Velocity at Bed Formation on the Head Loss. Results from

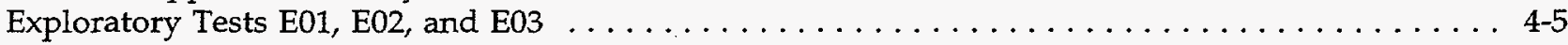

4-3. Effect of Method of Debris Introduction on Head Loss. Results of Tests E18

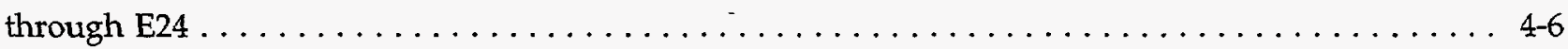

4-4. Representative Sample of Shredded NUKONTM Fibrous Debris - Kernels . . . . . . . . . . . . 4-8

4-5. Representative Sample of Shredded NUKON'T Fibrous Debris - Class 3 \& 4 . . . . . . . . . . . . 4-9

4-6. Representative Sample of Shredded NUKON'M Fibrous Debris - Class 5 \& $6 \ldots \ldots \ldots \ldots$

4-7. Effect of Water Temperature on Head Loss Across a Debris Bed. Results of

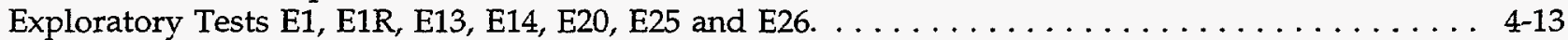

5-1. Typical Transient Head Loss for Pure Fiber Bed - Measurements for Test P-04 . . . . . . . . . . 5-5

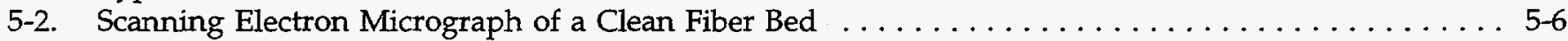

5-3. Experimental Data for Pure Fiber Beds Generated from ARL Tests . . . . . . . . . . . . . . 5-10

$5-4$. Head Loss vs. Time (Type A Sludge $500 \%$ ) . . . . . . . . . . . . . . . . . . . $5-11$

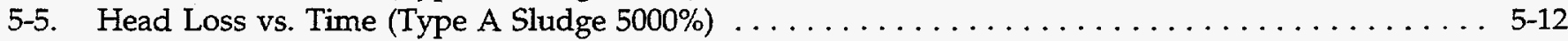

5-6. Typical Cake for Test with Low Sludge-to-Fiber Ratio . . . . . . . . . . . . . . . . . . . . . 5-13

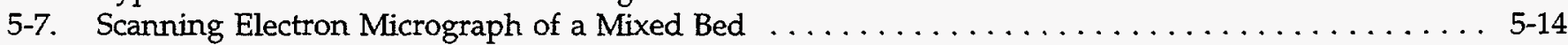

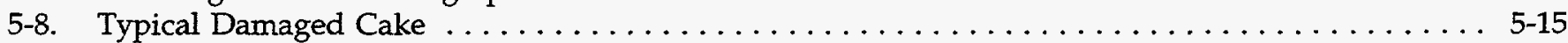

5-9. Experimental Head Loss Data for Selected Bed Thicknesses and Approach

Velocities vs. Sludge-to-Fiber Mass Ratio . . . . . . . . . . . . . . . . . . . . 5-16

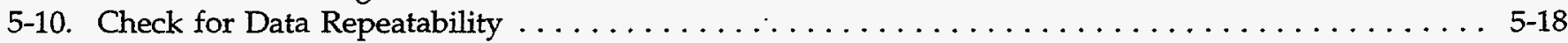

5-11. Comparison of Predictions of BLOCKAGE Head Loss Model (Equation 4-1) with ARL Head Loss Data for Pure Fiber Beds . . . . . . . . . . . . . . . . . . . . . . . . . . 5-19

5-12. Comparison of Predictions of BLOCKAGE Head Loss Model (Equation 4-1) with ARL Head Loss Data for Pure Fiber Beds . . . . . . . . . . . . . . . . . . . . . . . . 5-20

5-13. Comparison of Predictions of BLOCKAGE Head Loss Correlation (Equation 5-5) with ARL Head Loss Data for Undamaged Mixed Beds . . . . . . . . . . . . . . . . 5-22

5-14. Comparison of Predictions of BLOCKAGE Head Loss Correlation (Equation 5-5) with ARL Head Loss Data for Undamaged and Damaged Mixed Beds . . . . . . . . . . . . . 5-28

6-1. Loop Water Concentration as a Function of Time. Data Collected From Two Sampling Ports Located at Top and Bottom of the Strainer Simultaneously $\ldots \ldots \ldots \ldots \ldots \ldots .6 .3$

6-2. Cumulative and Once-Through Filtration Efficiency Measured From Test P27 . . . . . . . . . 6-5

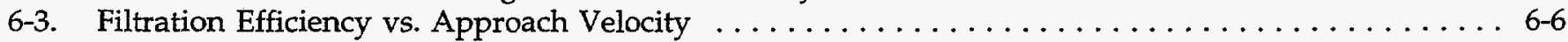

6-4. Cumulative Filtration Efficiencies of the Fibrous Debris Bed vs. Theoretical Thickness . . . . . . . . . . . . . . . . . . . . . . . . . . 


\section{List of Tables}

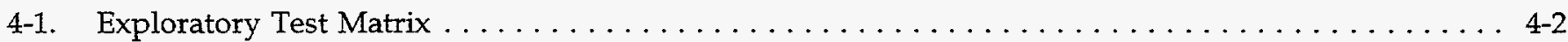

4-2. BWROG-Provided Size Distribution of the Suppression Pool Sludge $\ldots \ldots \ldots \ldots \ldots \ldots \ldots \ldots \ldots 4-7$

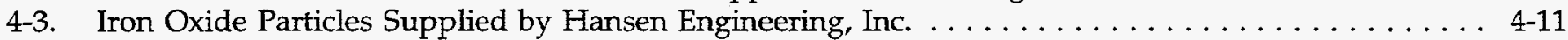

5-1. Parametric Test Matrix . . . . . . . . . . . . . . . . . . . . . . . . . . $5-2$

5-2. Experimental Head Loss Data for Pure NUKON ${ }^{\mathrm{TM}}$ Fiber Beds $\ldots \ldots \ldots \ldots \ldots \ldots \ldots \ldots \ldots \ldots .7$

5-3. Experimental Head Loss Data for NUKON ${ }^{\mathrm{rM}}$ Based Mixed Beds . . . . . . . . . . . . . . . 5-8

5-4. Comparison Between Model Predictions and Test Data for 2" Nominal Thickness

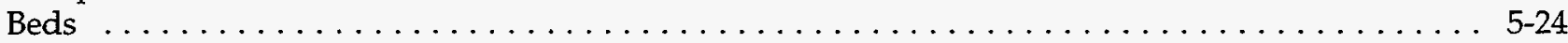

5-5. Comparison Between Model Predictions and Test Data for 1" Nominal Thickness Bed . . . . . . . . . . . . . . . . . . . . . . . . . . . . . . . . . . 5-25

5-6. Comparison Between Model Predictions and Test Data $0.5^{\prime \prime}$ Nominal Thickness Bed . . . . . . . . . . . . . . . . . . . . . . . . . . . . . 5-26

5-7. Comparison Between Model Predictions and Test Data for 0.25" Theoretical Bed Thickness . . . . . . . . . . . . . . . . . . . . . . . . . . . . . . . . 5 5-27 


\section{Acknowledgements}

Several individuals made significant contributions to this study. This study could not have been completed without the technical and management support of the U.S. Nuclear Regulatory Commission. Michael Marshall (RES) was the NRC Task Manager for this effort. He provided critical technical direction, actively participated in all of the experiments, and performed an in-depth review of the technical basis for this study. Aleck Serkiz (RES) provided significant technical insights and review of the experimental and analytical work.

Prahlad Murthy, Mahadevan Padmanabhan, Frank Weber, and George Hecker of Alden Research Laboratory, Inc. (ARL) were instrumental in designing the experimental apparatus, defining the experiments, and conducting the experiments described and analyzed in this report. Their work is documented in the ARL report, "Head Loss of Fibrous NUKONTM Insulation Debris and Sludge for BWR Suction Strainers."

From SEA, Gilbert Zigler was the Project Manager for this task, providing technical direction for the study. Together with Jane Brideau, he also performed a technical and editorial peer review of the report. Debbie Rettig was responsible for the typing and layout of the final document.

Other organizations whose efforts contributed to this study include the BWR Owners' Group ECCS Suction Strainer Committee and the University of New Mexico. Rocky Sgarro was the chairman of the BWROG ECCS Suction Strainer Committee, which provided estimates of the size distribution of the sludge particles present in BWR suppression pools. Toivo Kodas of the University of New Mexico performed the sludge simulant size analysis using a scanning electron microscope. 


\subsection{Introduction}

\subsection{Background and Program Overview}

\begin{abstract}
A loss of coolant accident (LOCA) in a boiling water reactor (BWR) would generate debris from various sources located within the drywell and would transport a fraction of these debris to the suppression pool. Examples of these debris include fibrous or non-fibrous insulation fragments, paint chips and ablated concrete dust. Additional quantities of debris are contained in the suppression pool prior to the LOCA. Examples of such debris include air-filters and suppression pool sludge consisting mostly of iron oxide particles. After a LOCA, all the debris reaching the suppression pool would become intermixed with the pool water and be carried by the water flow to the suction strainers of the emergency core cooling system (ECCS) pumps. A fraction of the debris reaching the strainers would be trapped, forming a debris cake or bed on the strainer surface. Formation of such a debris bed introduces head losses that may exceed the available net positive suction head (NPSH) margin leading to loss of ECCS pumps.
\end{abstract}

In 1979, the NRC established USI A-43, "Containment Emergency Sump Performance," to study safety issues related to the ability of both pressurized water reactors (PWRs) and BWRs to recirculate water back to the reactor core following a postulated LOCA. NUREG-0897, Revision 1, "Containment Emergency Sump Performance," [Ref. 1.1] contained technical findings related to USI A-43, including experimental data obtained from NRCsponsored experiments that studied head loss characteristics of the fibrous debris beds. Based on these experiments, a set of correlations were developed for mineral wool, high density fiberglass, and low density fiberglass (e.g., NUKON ${ }^{\mathrm{TM}}$ ).

Following the Barsebäck-2 and Perry events, several investigations were carried out both in the U.S. and Europe to study head loss across beds formed of insulation fragments. These studies led to the conclusion that the using of NUREG-0897 might underestimate the potential for BWR ECCS strainer blockage because (a) the correlations were developed based on experimental data obtained for relatively larger fibrous shreds compared to the debris that are likely to reach the strainers following a LOCA, and (b) the correlations do not account for increase in head loss due to filtration of particulate debris carried to the strainer by the pool water.

In September 1993, the NRC initiated analyses to evaluate ECCS strainer blockage potential for BWRs to the same detail as was previously done for PWRs. The study selected a BWR $/ 4$, insulated primarily with NUKONTM insulation, and undertook a thorough review of various head loss models available for predicting head loss across beds formed of NUKONTM fragments. The review concluded that there was no general consensus regarding a head loss model or the type and size distribution of the debris likely to reach the strainer following a LOCA that could be used for the reference plant analysis. In response to the need for an applicable head loss model, a semi-theoretical head loss equation was developed. This equation was based primarily on the insights gained from the general field of flow through fibrous medias but was validated with limited experimental data reported for NUKONTM. The head loss model was incorporated into the parametric computer code BLOCKAGE, which was used for estimating potential for loss of NPSH at the reference plant following a LOCA. The model assumed that all the debris reaching the strainer, including the particulate debris, would be trapped in the strainer surface forming a porous debris layer. The results of these initial analyses were documented in NUREG/CR-6224 [Ref. 1.2].

Because the assumptions regarding the head loss model and the filtration efficiency play a vital role in estimating the potential for loss of NPSH, additional experiments were carried out to validate these assumptions. These experiments, termed as head loss tests, were conducted to obtain the experimental data related to head loss and filtration characteristics of the mixed beds formed on the strainer surface. These experiments were conducted at the Alden Research Laboratory, Inc. (ARL). The experimental data obtained from these experiments were analyzed and used to validate the head loss correlation developed in NUREG/CR-6224, and to develop a more appropriate filtration model. 


\subsection{Program Objectives and Report Outline}

The head loss tests were designed and conducted to yield data and insights in the following specific areas:

1. Effect of fibrous debris class (classes $3 \& 4$ versus $5 \& 6$ ) on the head loss across the debris cake.

2. The once-through efficiencies of the fibrous beds to filter/trap micron range sludge particles.

3. The deposition morphology of the debris cake.

4. Head loss across the cake as a function of types and particle size distributions of the bed constituents.

5. The effect of water temperature on the head loss.

The experimental data were used to:

1. Develop a filtration model that was integrated into BLOCKAGE to estimate the fraction of each type of debris that would be filtered at the strainer surface to form the debris bed.

2. Validate/modify the semi-theoretical head loss equation for application with mixed beds formed of low density fiberglass fragments and suppression pool particulates.

The primary focus was to obtain the required experimental data and derive the models that were specifically applicable to the reference plant; i.e., the experiments and the test matrices were designed to obtain the data primarily for debris beds formed of NUKON ${ }^{\mathrm{TM}}$ fragments and simulants of commonly found suppression pool sludge and paint-chips. In contrast, the models were developed in a generalized form, and are applicable to other plants.

Insights drawn from previous studies were effectively used to identify the various phenomena considered in this study. These insights are summarized in Section 2, which also describes the development of a semi-theoretical head loss equation discussed above. Section 3 presents a description of the test set-up, including scaling issues, instrumentation and controls, and associated measurement uncertainties. The experiments were conducted in two phases: (a) exploratory tests, and (b) parametric tests. The data from the exploratory tests was used to develop the test procedures, select material size distribution and finalize the parameter range. These tests and their results are summarized in Section 4. Section 5 presents the experimental head loss data, including a comparison to the semitheoretical model predictions. Section 6 presents the filtration data obtained from the tests and the development of an "approximate" filtration model for integration into BLOCKAGE. Significant findings of the study, along with recommendations for future studies, are summarized in Section 7. 
Introduction

\section{References for Section 1}

1.1 A.W. Serkiz, "Containment Emergency Sump Performance," U.S. Nuclear Regulatory Commission, NUREG-0897, Rev. 1, October 1985.
1.2 Zigler, G., et al, "Parametric Study of the Potential for BWR ECCS Strainer Blockage due to LOCA Generated Debris", Draft Report for Comment, NUREG/CR-6224 (SEA No. 93554-06-A:1), July 1994. 


\subsection{Insights Gained from Previous Studies}

This section provides a brief description of the key post-LOCA suppression pool phenomena for strainer blockage analyses, followed by various experimental approaches used to simulate these phenomena. Considerable experimentation to study the head loss, resulting from debris buildup on ECCS suction strainers, was carried out as part of the USI A-43 study and following the Barseback-2 and Perry events. These experiments provided valuable insights into the significant roles played by selection of debris, experimental set-up design, and experimental procedures. These insights are discussed below.

\subsection{LOCA Related BWR Suction Strainer Blockage Phenomena}

Due to major differences between various U.S. BWRs (e.g., types of insulation and containment layout), it was not practical to identify and study all the phenomena of importance to the reliable operation of BWR ECCS. As a result, this study focused primarily on those conditions and materials that were specifically applicable to the reference plant, a BWR-4/Mark I containment. In the following discussions, it is assumed that the reader is familiar with the LOCA progression scenario and suppression pool phenomenology discussed in Appendix B of NUREG/CR-6224 [Ref. 2.1].

A postulated primary system pipe break located in the drywell generates fibrous insulation debris due to a combination of blast overload forces and jet impingement forces. The generated debris vary in size from individual fibers (or fines) to partially destroyed blankets. The actual size distribution of the debris depend strongly on the type of insulation, duration of exposure to high temperature and radiation (i.e., it's age), mode of encapsulation and distance from the break. These debris are generated at the break location from where a fraction of them would be transported to the suppression pool by the vapor flows during the blowdown phase, followed by water flows during the washdown phase. However, it is likely that larger shreds may not be transported to the suppression pool, and the debris reaching the pool would likely consist of shape (or size) classes 1 through 7 of Figure 2-1. These shape classes were developed based on engineering judgement and limited experimental data [Ref. 2.1]. Moreover, some of these shreds would be further disintegrated by suppression pool hydrodynamics during the high energy phase [Ref. 2.2]. The type of debris that finally approach the strainer after being subjected to various destruction forces would likely consist of a mixture of classes 1,2,3 and 4 .

In addition to the fibrous insulation debris, a sizeable quantity of particulate debris may be generated in the drywell from break jet interaction with the drywell structures and non-fibrous insulation [Ref. 2.3]. Examples of such debris include paint-chips and concrete dust. A fraction of these debris would also be transported to the suppression pool along with the fibrous insulation debris. Additional quantities of particulate debris are known to be present in the suppression pool. These particulate debris, referred to as suppression pool sludge, consist primarily of rust and dust particles. Typically, these particles would be a few microns in size and would most likely be contained at the bottom of the suppression pool prior to a LOCA [Ref. 2.4]. However, as evident from the referenced suppression pool tests, the sludge particles would be resuspended by the high intensity turbulence associated with the suppression pool hydrodynamics during the high energy phase following a LOCA [Ref. 2.2].

Therefore, at the end of the high energy phase, the suppression pool water would be uniformly mixed with classes 1, 2, 3 and 4 fibers and the particulate debris (sludge particles, concrete dust, etc.). For the reference plant, the average concentration of the fibrous debris in the suppression pool water was estimated to be between $6.6 \mathrm{E}-05$ to $1.2 \mathrm{E}-03 \mathrm{lbm} / \mathrm{ft}^{3}$ depending on the break size [Ref. 2.1]. Estimates of sludge concentration were between $2.5 \mathrm{E}-03$ to 0.017 $\mathrm{lbm} / \mathrm{ft}^{3}$ resulting in sludge-to-fiber concentration ratios ranging from 2 to 250 .

This mixture of particulate and fibrous debris would be carried to the suction strainers by the water flow. Based on insights gained from previous studies, almost all of the fibrous debris reaching the suppression pool would be trapped on the strainer surface to form a debris layer that is compressible under the influence of the differential pressure. The thickness of the fibrous bed increases steadily with time as more debris are brought to the suction strainers until the pool is finally cleared of the debris. Based on BLOCKAGE calculations, such a state could be reached within the first few flushing 


\begin{tabular}{|c|c|c|c|c|c|}
\hline \multirow[t]{2}{*}{\begin{tabular}{|l|}
0 \\
0 \\
8 \\
$\frac{\pi}{0}$ \\
0
\end{tabular}} & \multicolumn{2}{|r|}{ Description } & \multirow{2}{*}{\begin{tabular}{|l}
\multicolumn{1}{|c|}{ Settling Characteristics } \\
Drag equations for cylinders are well \\
known, should be able to calculate fall \\
velocity of a tumbling cylinder in still \\
water.
\end{tabular}} & \multirow{2}{*}{\begin{tabular}{|l}
\multicolumn{1}{|c}{$\begin{array}{c}\text { Settling Velocity in } \\
\text { Calm Pools }\end{array}$} \\
$1-3.5 \mathrm{~mm} / \mathrm{s}$ \\
Based on Cal. for \\
$0.5-2.54 \mathrm{~cm}$ long fibers
\end{tabular}} & \multirow{2}{*}{$\begin{array}{c}\begin{array}{c}\text { Strainer } \\
\text { Filtration } \\
\text { Efficiency }\end{array} \\
\text { Unknown }\end{array}$} \\
\hline & & $\begin{array}{l}\text { Very small pieces of fiberglass material, } \\
\text { "microscopic" fines which appear to be } \\
\text { cylinders of varying LD. }\end{array}$ & & & \\
\hline 2 & & $\begin{array}{l}\text { Single flexible strand of fiberglass, } \\
\text { essentially acts as a suspended strand. }\end{array}$ & $\begin{array}{l}\text { Difficult to calculate drag forces due to } \\
\text { changing orientation of flexible strand. }\end{array}$ & Same as above & Nearly 1.0 \\
\hline 3 & & $\begin{array}{l}\text { Multiple attached or interwoven strands } \\
\text { that exhibit considerable flexibility and } \\
\text { which due to random orientations } \\
\text { induced by turbulence drag could result } \\
\text { in low fall velocities. }\end{array}$ & $\begin{array}{l}\text { This category is suggested since this } \\
\text { class of fibrous debris would likely be } \\
\text { most susceptible to re-entrainment in } \\
\text { the recirculation phase if turbulence } \\
\text { and/or wave velocity interaction } \\
\text { becomes significant. }\end{array}$ & $\begin{array}{l}0.04 \mathrm{ft} / \mathrm{s}-0.06 \mathrm{ft} / \mathrm{s} \\
\text { (measured) }\end{array}$ & 1.0 (measured) \\
\hline 4 & & $\begin{array}{l}\text { Formation of fibers into clusters which } \\
\text { have more rigidity and which react to } \\
\text { drag forces more as a semi-rigid body. }\end{array}$ & $\begin{array}{l}\text { This category might be represented by } \\
\text { the smallest debris size characterized } \\
\text { by PCls air blast experiments. }\end{array}$ & $\begin{array}{l}0.08-0.13 \mathrm{ft} / \mathrm{s} \\
\text { (measured) }\end{array}$ & 1.0 (measured) \\
\hline 5 & $S$ & $\begin{array}{l}\text { Clumps of fibrous debris which have } \\
\text { been noted to sink. Generated by } \\
\text { different methods by various } \\
\text { experimenters. }\end{array}$ & $\begin{array}{l}\text { This category was characterized by the } \\
\mathrm{PCl} \text { air test experiments as comprising } \\
\text { the largest two sizes in a three size } \\
\text { distribution. }\end{array}$ & $\begin{array}{l}0.13-0.18 \mathrm{ft} / \mathrm{s} \\
\text { (measured) }\end{array}$ & 1.0 (measured) \\
\hline 6 & (6)D & $\begin{array}{l}\text { Larger clumps of fibers. Forms an } \\
\text { intermediate between Classes } 5 \text { and } 7 .\end{array}$ & $\begin{array}{l}\text { Few of the pieces generated in } \mathrm{PCl} \text { air } \\
\text { blast tests consisted of these debris } \\
\text { types. }\end{array}$ & $\begin{array}{l}0.16-0.19 \mathrm{ft} / \mathrm{s} \\
\text { (measured) }\end{array}$ & 1.0 (measured) \\
\hline 7 & & $\begin{array}{l}\text { Precut pieces (i.e. .25" by .25") to } \\
\text { simulate small debris. Other } \\
\text { manual/mechanical methods to } \\
\text { produce test debris. }\end{array}$ & $\begin{array}{l}\text { Dry form geometry known, will ingest } \\
\text { water, should be able to scope fall } \\
\text { velocities in still water assuming } \\
\text { various geometries. }\end{array}$ & $\begin{array}{c}0.25 \mathrm{ft} / \mathrm{s} \\
\text { (calculated) }\end{array}$ & 1.0 (estimated) \\
\hline
\end{tabular}


cycles, if it is assumed that ECCS pumps were not lost due to loss of NPSH. For the reference plant, the estimates of fiber bed theoretical thickness ${ }^{1}, \Delta \mathrm{L}_{\mathrm{o}}$, varied between 0.5 to 8 inches, assuming a strainer surface area of $37.62 \mathrm{ft}^{2}$; the actual thickness may be considerably lower due to compression of the cake.

One of the deleterious effects of fibrous debris bed build-up is the ability of the bed to filter out particulate debris. During the initial stages when the fiber beds are very thin, only a small fraction of particulate mass would be filtered by the debris bed and a majority of particulates would penetrate the strainer and enter the reactor systems (i.e., ECCS pumps, pipes and reactor vessel). A fraction of the particulate mass entering the reactor systems would be deposited. The remaining fraction would reenter the pool and become available for transport to the strainer. This trend changes with time as the debris bed thickness increases. At higher thicknesses much higher fractions of the particulate debris will be filtered by the bed. Depending on the size distribution of the particulate debris, a filtration efficiency of 1.0 could be reached at higher bed thicknesses.

Due to a combination of debris bed buildup and filtration of particulates by these beds, the pressure drop across the strainer increases steadily with time. Estimation of head loss as a function of time requires: (1) a once-through filtration model that estimates the fraction of each debris species that would be trapped on the strainer surface as a function of the debris bed thickness and the approach velocity, and (2) a model that estimates the head loss as a function of the types and quantities of debris making up the cake.

\subsection{Review of Head Loss Studies for Pure Fiber Beds}

\subsubsection{Findings of the Experimental Studies}

As part of USI A-43 study, a series of tests were conducted under NRC sponsorship to measure head

\footnotetext{
${ }^{1}$ Theoretical thickness, $\Delta \mathrm{L}_{\mathrm{o}}$ also termed as nominal thickness, refers to thickness of the debris layer calculated from the debris mass, $m_{f}$, using 'as-manufactured' packed or packing density of the insulation, $c ; \Delta L_{o}=m_{f} / c A_{s}$ where $A_{s}$ is the cross-sectional area of the strainer.
}

loss for the various fibrous insulation materials most commonly used in PWRs: (1) mineral wool (also referred to as rockwool), (2) high density fiberglass, and (3) NUKONTM [Refs. 2.5 and 2.6]. For all these materials, head loss was measured as a function of screen approach velocity and theoretical thickness for both the "as-fabricated" blankets (without scrims or other blanket covers) and for insulation shreds of various sizes. The insulation manufacturers provided the insulation blankets in their original form (prior to aging) for testing. The blankets were used "as-is" for head loss measurements for asfabricated mats; the blankets were manually shredded into small pieces, ranging in size from $1^{\prime \prime}$ $\times 0.5^{\prime \prime} \times 0.125^{\prime \prime}$ to $3^{\prime \prime} \times 2^{\prime \prime} \times 0.125^{\prime \prime}$, for head loss measurement for shreds. Best fit expressions obtained from these experiments are reported in NUREG-0897 [Ref. 2.5] as:

$$
\begin{aligned}
& \Delta H=123 U^{1.51}\left(\Delta L_{o}\right)^{1.36} \\
& \quad \text { for Mineral Wool }\left(\mathrm{c}=6.2 \mathrm{lbm} / \mathrm{ft}^{3}\right) \\
& \Delta H=1653 U^{1.84}\left(\Delta L_{o}\right)^{1.54} \\
& \quad \text { for High-Density Fiber Glass }\left(\mathrm{c}=10 \mathrm{lbm} / \mathrm{ft}^{3}\right) \\
& \Delta H=68.3 U^{1.79}\left(\Delta L_{o}\right)^{1.07} \\
& \quad \text { for } \mathrm{NUKON}{ }^{\mathrm{m}}\left(\mathrm{c}=2.4 \mathrm{lbm} / \mathrm{ft}^{3}\right)
\end{aligned}
$$

where,

$$
\begin{array}{ll}
\mathrm{U} & \text { is the strainer approach velocity }(\mathrm{ft} / \mathrm{s}) \\
\Delta \mathrm{L}_{\circ} & \text { is the theoretical debris thickness }(\mathrm{ft}) \\
\Delta \mathrm{H} & \text { is the head loss ( } \mathrm{ft} \text {-water) } \\
\mathrm{c} & \text { is the as fabricated packed density. }
\end{array}
$$

Correlations are highly material specific. Attempts have been made by several investigators, with limited success, to eliminate this dependence on the materials through the use of mass spread instead of theoretical thickness [Ref. 2.7].

The major drawback of these equations is that they are based on experimental data obtained for nonuniform beds formed by relatively large shreds of insulation that resemble size class 7 of Figure 2-1. Typical shreds of insulation generated by break jet impingement on the aged fibrous insulation are much finer, as demonstrated by the Heissdampfreaktor (HDR) tests [Ref. 2.5], than the shreds used in the experiments reviewed above. Accumulation of such fine shreds on the strainer followed by 
compression, resulted in formation of much denser beds and thus, higher head losses. Such higher head losses were initially reported by Kermkraftwerk (KKL) after conducting experiments using mineral wool that was aged up to 20 years [Ref. 2.8]. In these KKL experiments, aged mineral wool was stirred in water to simulate the effect of steam jet and subsequent suppression pool turbulence. The fibrous material was then transferred to a small flatplate strainer section via circulating water flows, where it formed a uniform layer. The experiment was started at high velocities to allow for bed compaction before head losses were measured. Measured head loss was correlated using the equation [Ref. 2.8]:

$$
\Delta H=318 U^{1.13}\left(\Delta L_{o}\right)^{1.14}
$$

It can be easily shown that Equation 2-4 results are approximately 2 to 3 times higher than those of Equation 2-1. As mentioned above, this increase can be attributed to smaller size debris used in the KKL experiments compared to the previous NRC experiments. Similarly, larger head losses compared to Equation 2-1 were also reported for mineral wool by several European investigators [Ref. 2.9].

\section{NUKONTM Based Fiber Bed Data}

Since USI A-43 was completed, most of the head loss data for fibrous beds in the U.S. was obtained for NUKON ${ }^{\mathrm{TM}}$ [Refs 2.10, 2.11, and 2.12], and a limited amount of test data were reported for Thermal-Wrap $\AA$, a fiberglass insulation, which possesses a theoretical density close to that of NUKON ${ }^{\mathrm{TM}}$ [Ref 2.13]. Initially, the NUKON'M head loss tests were conducted at ARL [Refs 2.10 and 2.11]. In these tests, finer debris were generated from aged insulation blanket by either manual means or by air jet (blast) impingement. These finer debris, typically $0.25^{\prime \prime} \times 0.25^{\prime \prime} \times 0.125^{\prime \prime}$ in size, were used to simulate LOCA debris and corresponding head loss was measured from a closed loop experimental set-up. Empirical correlations were developed based on the experimental data from these tests:

$$
\Delta H=173 U^{1.94}\left(\Delta L_{o}\right)^{1.46}
$$$$
\text { for NUKON }{ }^{\mathrm{TM}} \text {-- Air-Blast Debris [Ref. 2.10] }
$$

$$
\Delta H=410 U^{1.62}\left(\Delta L_{o}\right)^{1.45}
$$

for NUKON ${ }^{\mathrm{TM}}$-- Manual Shreds [Ref. 2.11]
Another series of head loss tests were conducted at ARL [Ref. 2.12] using NUKONTM insulation fragments. These tests employed an open loop equipped with a small scale semi-conical strainer (surface area of $2.7 \mathrm{ft}^{2}$ ) and a mixing tank (volume of $240 \mathrm{ft}^{3}$ ) to simulate the BWR suppression pool. Reference 2.12 provides a detailed description of the test facility and procedures. The debris used in half of these tests were classified as 'fibers' that were described to be loose clusters of individual fibers, about $0.13 \mathrm{lbm} / \mathrm{ft}^{3}$ in density. The other half of the tests were conducted using 'shreds', which were described as consolidated fibers that retained some of the original strength of the fiber bed. Based on these experiments, the following correlations were developed:

$$
\begin{aligned}
& \Delta H=77.4 U^{1.30}\left(\Delta L_{o}\right)^{0.67} \\
& \quad \text { for NUKON }{ }^{\mathrm{TM}}-{ }^{-} \text {'fibers' [Ref. 2.12] } \\
& \Delta H=84 U^{1.43}\left(\Delta L_{o}\right)^{0.86} \\
& \quad \text { for NUKON }{ }^{\mathrm{TM}}-\text {-- 'shreds' [Ref. 2.12] }
\end{aligned}
$$

The various correlations proposed for debris beds formed of pure NUKONTM fragments (i.e, Eqns. 2-3, $2-5,2-6,2-7$ and 2-8) are plotted in Figure 2-2. As evident from this figure, considerable scatter exists in the head loss predictions by different correlations, which raises questions related to their adaptability to estimate BWR strainer blockage potential.

Careful examination of the experimental data would reveal that scattering can be attributed to:

- $\quad$ Differences in the shape classes of the debris used in the experiments. In general, beds formed of finer debris resulted in larger pressure drops, possibly because of formation of relatively uniform and compact beds. The experiments conducted as part of USI A-43 study generally used larger shreds that resembled shape classes 6 and 7 of Figure 2-1, and resulted in lowest of the measured pressure drops. As a result, Equation 2-3 provides the lowest pressure drop predictions for any given combinations of flow velocity and bed thickness. On the other hand, Equations 2-6 and 2-7 were developed based on the head loss data obtained using debris 


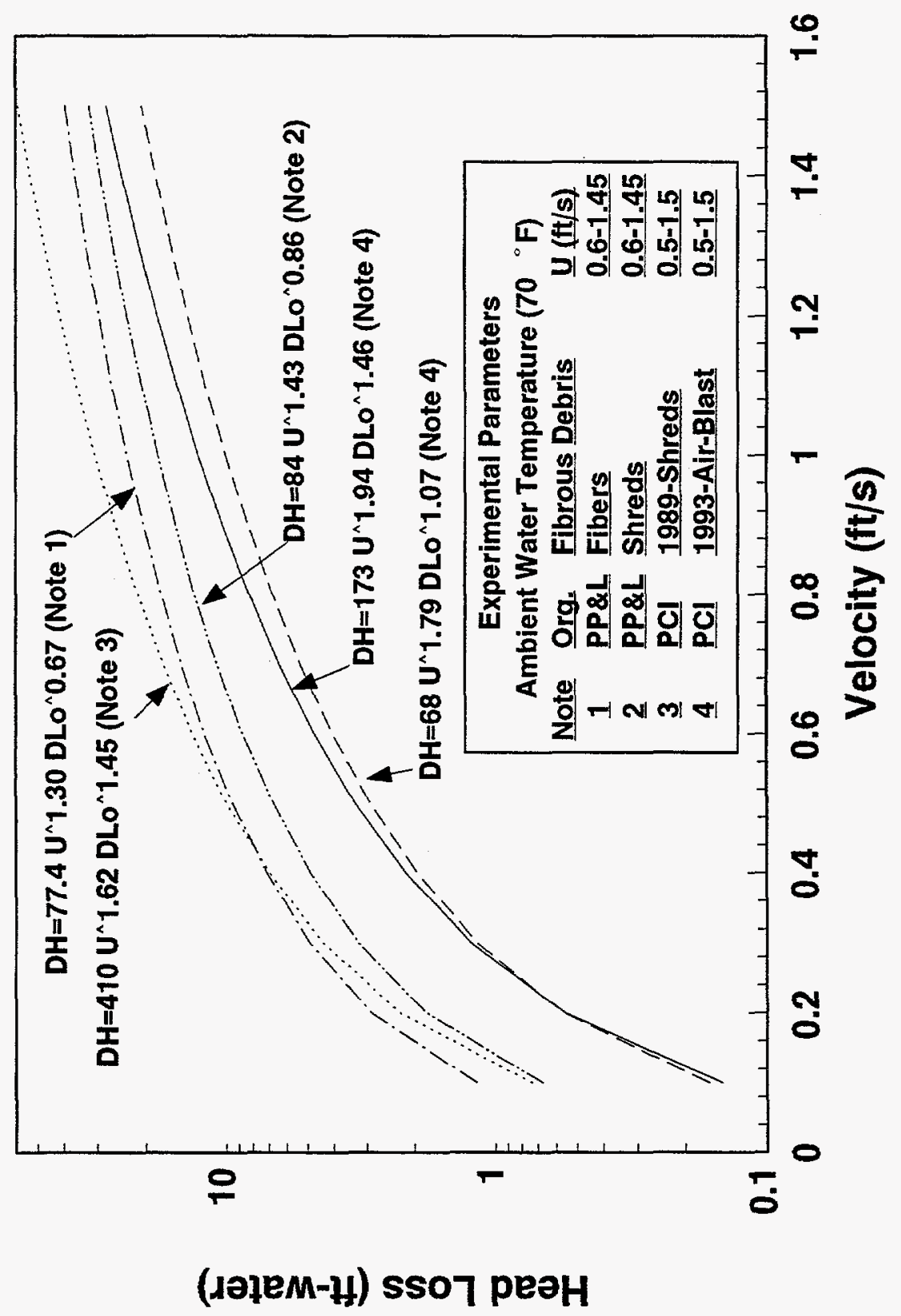


that were closer to classes $3 \& 4^{2}$, which may explain the larger pressure drop predictions provided by these equations. The other debris, which were intermediate in size, provided head losses higher than Equation 21, but lower than Equations 2-6 and 2-7.

- Method of correlating the data. Empirical forms, such as:

$$
\Delta H=A U^{B}\left(\Delta L_{o}\right)^{C}
$$

have been used to correlate the experimental data which were obtained for a limited range of experimental parameters. Multiple regression fit of the experimental data were used to determine the empirical coefficients $A$, $B$ and $C$, without considering the conditions such as water temperature or fiber characteristics. A different set of empirical constants were developed for each experiment; no attempt was made to identify important groups of physical parameters that may collapse the data obtained from different experiments. As a result, the differences in the data caused by variations in the range of parameters studied in each experiment were manifested as scattering of correlations predictions. These drawbacks can be avoided, and the data can be better collapsed if functional forms with a theoretical basis are used instead of purely empirical forms such as those described above. Usage of purely empirical forms for correlating experimental data are strongly discouraged (e.g., Ref. 2.14) since they do not interpret the data in terms of the governing processes or on the basis of previous experimental work in the related fields.

Based on these observations, the following conclusions were drawn:

1. Considerable attention must be paid to ensure that size classes of debris used in the experiments would be representative of the

\footnotetext{
${ }^{2}$ The shape class information was deducted from photographs and other qualitative descriptions provided by the investigators [Ref. 1.5 and 1.8].
}

debris expected to reach the strainer following a LOCA. However, very limited experimental data exist that can provide insights into size class of LOCA debris that reach the strainer. As a result, one must ultimately rely on engineering judgement to arrive at the size class of the debris. This decision in part should be based on the following considerations: (a) debris disintegration would occur not only during generation but also during transport (e.g., suppression pool hydrodynamics), and (b) debris size class is also influenced by other factors such as the effects of aging on the insulation of interest ${ }^{3}$.

2. Methods that possess theoretical basis should be adopted to correlate the data.

\subsubsection{Development of a Semi-Theoretical Head Loss Equation}

The previously developed correlations were purely empirical in nature, a fact that limits their usage. For example, it is difficult to apply any of the correlations listed above to temperatures that are typical of suppression pools. To minimize these shortcomings, a semi-theoretical approach was sought. Such an approach is recommended because it correlates the data in terms of physical theories that are based on previous experimental work in the related fields [Ref. 2.14]. Towards this objective, previous investigations in the general field of flow through compressible fibrous/porous media were reviewed [Ref. $2.15-2.21$ ] to identify groups of parameters, pertinent functional forms and other information that will lead to better correlation of the experimental data. The review findings were used in developing the semi-theoretical head loss equation described below.

The formation of a debris layer on the strainer surface results in a situation similar to flow through porous media, characterized by large pressure drops. As initially suggested by Muskat [Ref. 2.15] and confirmed later by Ward [Ref. 2.16], the pressure drop across a fibrous bed can be expressed as:

\footnotetext{
${ }^{3}$ It is commonly believed that aged mineral wool is susceptible to break up and disintegrates readily under the influence of very small forces.
} 


$$
\frac{\Delta P}{\Delta L}=\alpha(\varepsilon) \mu V+b(\varepsilon) \rho V^{2}
$$

where,

$$
\begin{array}{ll}
\Delta \mathrm{P} & \begin{array}{l}
\text { is the pressure drop due to flow } \\
\text { across the bed (dynes } \left./ \mathrm{cm}^{2}\right)
\end{array} \\
\Delta \mathrm{L} & \begin{array}{l}
\text { is the height or thickness of the } \\
\text { fibrous bed }(\mathrm{cm})
\end{array} \\
\mu & \begin{array}{l}
\text { is fluid dynamic viscosity (poise) } \\
\text { is fluid density }(\mathrm{g} / \mathrm{cc})
\end{array} \\
\mathrm{V} & \begin{array}{l}
\text { is fluid velocity }(\mathrm{cm} / \mathrm{s}) \\
\alpha(\varepsilon) \text { and } \mathrm{b}(\varepsilon)
\end{array} \\
& \begin{array}{l}
\text { are unknown functions of the } \\
\text { bed porosity. }
\end{array}
\end{array}
$$

Since the 1940s, experimental and theoretical efforts have been underway to determine $\alpha(\varepsilon)$ and $b(\varepsilon)$ for beds formed of different porous media. Initial efforts focused on channel flow models for porous media, which resulted in the well-known KozenyCarman Equation for laminar flows:

$$
\frac{\Delta P}{\Delta L}=\frac{a S_{v}^{2}(1-\varepsilon)^{2}}{\varepsilon^{3}} \mu V
$$

where,

$$
\begin{aligned}
& S_{v} \quad \text { is the specific surface area of the porous } \\
& \text { bed }\left(\mathrm{cm}^{2} / \mathrm{cm}^{3}\right) \\
& \varepsilon \quad \text { is the bed porosity. }
\end{aligned}
$$

In the turbulent region, Equation 2-10 becomes equal to [Ref. 2.17]:

$$
\frac{\Delta P}{\Delta L}=\frac{b S_{v}(1-\varepsilon)}{\varepsilon} \rho V^{2}
$$

Based on a comprehensive set of experimental data for flow through granular porous media with porosities between 0.4 and 0.85 , Ergun proposed values of 4.2 and 0.3 for the constants $a$ and $b$ [Ref. 2.17].

A series of later investigators studied flow through fibrous porous media, both theoretically and experimentally. For laminar flow through fibrous porous media, characterized by high porosities, the functional relationship between pressure and porosity expressed above (i.e., $\Delta \mathrm{P} \propto(1-\varepsilon)^{2}$ ) was found not to be valid. The analytical reasoning for this conclusion can be found from the works of Kyan, et al. [Ref. 2.18]. Based on a large data base for flow through fibrous media, Davies [Ref. 2.19] proposed that for laminar flow through fibrous porous media, the functional equation should be:

$$
\frac{\Delta P}{\Delta L}=a S_{\nu}^{2}(1-\varepsilon)^{1.5}\left[1+a_{0}(1-\varepsilon)^{3}\right] \mu V
$$

where,

a and $a_{o}$ are empirical constants.

Based on experimental data for flow through compressible mats made of nylon, fiberglass,

Darcon, and wood pulp, Ingmanson, et al. [Ref. 2.20] confirmed this relationship and suggested 3.5 and 57 for the empirical constants $a$ and $a_{0}$. To date, these constants have been in wide use for laminar flow through fibrous porous media. Using these constants, Equation 2-13 can be rewritten as:

$$
\frac{\Delta P}{\Delta L}=3.5 S_{\nu}^{2}(1-\varepsilon)^{1.5}\left[1+57(1-\varepsilon)^{3}\right] \mu V
$$

Equation 2-14 is proposed for laminar flows. These flows are traditionally referred to as low-velocity flows. For turbulent or high velocity flows, experimental studies of Kyan, et al., and numerous other investigators indicate that the functional relationship expressed in Equation 2-12 is valid for fibrous media as well. The empirical constant is close to 0.66 , instead of 0.3 as suggested by Ergun [Ref. 2.17]. The equation thus becomes:

$$
\frac{\Delta P}{\Delta L}=\frac{0.66 S_{v}(1-\varepsilon)}{\varepsilon} \rho V^{2}
$$

The overall equation, valid for laminar, transient, and turbulent flow regimes, can now be expressed as a sum of Equations 2-14 and 2-15, as shown below: 


$$
\begin{gathered}
\frac{\Delta P}{\Delta L}=3.5 S_{\nu}^{2}(1-\varepsilon)^{1.5}\left[1+57(1-\varepsilon)^{3}\right] \mu V+ \\
\frac{0.66 S_{v}(1-\varepsilon)}{\varepsilon} \rho V^{2}
\end{gathered}
$$

Unlike previously developed correlations (Eqns. 2-1 through 2-8), Equation 2-16 can be used to incorporate the effects of a variety of factors including fiber type, temperature, debris size, compressibility and presence of sludge.

NUREG/CR-6224 presents discussions on how each of these factors can be addressed and proposes approximate forms of Equation 2-16 for several of the selected special cases. Using characteristic properties of NUKON ${ }^{\mathrm{rM}}$ and ambient water temperature, Equation 2-16 can be approximated to be equal to:

$$
\frac{\Delta H}{\Delta L_{o}}=67 U+54 U^{2}
$$

where,

$$
\begin{array}{ll}
\Delta \mathrm{H} & \text { is head loss (ft-water) } \\
\Delta \mathrm{L}_{\circ} & \text { is theoretical thickness (ft) } \\
\mathrm{U} & \text { is fluid velocity ( } \mathrm{ft} / \mathrm{s} \text { ) }
\end{array}
$$

Figure 2-3 compares predictions of this equation with the experimental data reported from the sources listed above [Ref. 2.6, 2.10 and 2.11]. As evident from this figure, Equation 2-17 provides reasonable agreement with the experimental data. In the past, three different correlations (Eqns. 2-3, 2-5 and 2-6) were used to correlate this same set of experimental data. Encouraged by the good comparison, it was decided to adopt this correlation and further validate the equation for debris that was more representative of actual BWR conditions at elevated temperatures. One of the objectives of this study was to obtain the experimental data that could be used to validate Equation 2-16.

\subsection{Effect of Sludge Filtration on the Head Loss}

Following the Perry event, additional concerns were raised regarding increase in pressure drop due to filtration of particulate debris by the fibrous debris bed formed on the strainer surface. The examples of the particulate debris include suppression pool sludge consisting mostly of iron oxide particles, and concrete dust and calcium silicate fragments generated by the LOCA jets. Several experiments were carried out in both the U.S. and Europe to investigate the effect of filtration of these particulates on the head loss [Ref. 2.3, 2.12, 2.22 and 2.23]. Initially, most of these experiments employed 70-200 $\mu \mathrm{m}$ particles to simulate the particulate debris approaching the strainer. However, later surveys of the sludge typically found in the U.S. BWR suppression pools was used to develop a prototypical sludge size distribution [Ref. 2.4].

\subsubsection{Findings of the Experimental Studies}

The experiments conducted in Europe for mixed debris were not released for public usage at the time these experiments were planned, and hence are not reviewed here. Two tests [Ref. 2.3 and 2.12] were conducted in the U.S. to address this concern. The first series of tests used $>70 \mu \mathrm{m}$ rust particles to simulate sludge and NUKONTM fibers to simulate LOCA debris. The debris were added to a large water tank which was equipped with a small-scale truncated cone strainer located at the tank bottom. The head loss across the strainer was measured as a function of time and was correlated as follows [Ref. 2.12]:

$$
\Delta H=1059 U^{1.30}\left(\Delta L_{o}\right)^{0.72}\left(\Delta L_{s}\right)^{0.2}
$$

where,

$$
\Delta L_{s} \text { is the theoretical sludge thickness }{ }^{4}(\mathrm{ft})
$$

A similar set of experimental data were also reported by the BWROG [Ref. 2.3] which used a once-through test column ${ }^{5}$ to obtain the data. These experiments also employed $>70 \mu \mathrm{m}$ rust particles to simulate the sludge, and correlated the experimental data into the following form [Ref. 2.3]:

\footnotetext{
Thickness calculated from the mass using iron oxide density of $320 \mathrm{bbm} / \mathrm{ft}^{3}$

${ }^{5}$ In this set-up a mixture of fiber and sludge contained in the top portion of the column were allowed to drain through the strainer under the influence of the gravity.
} 


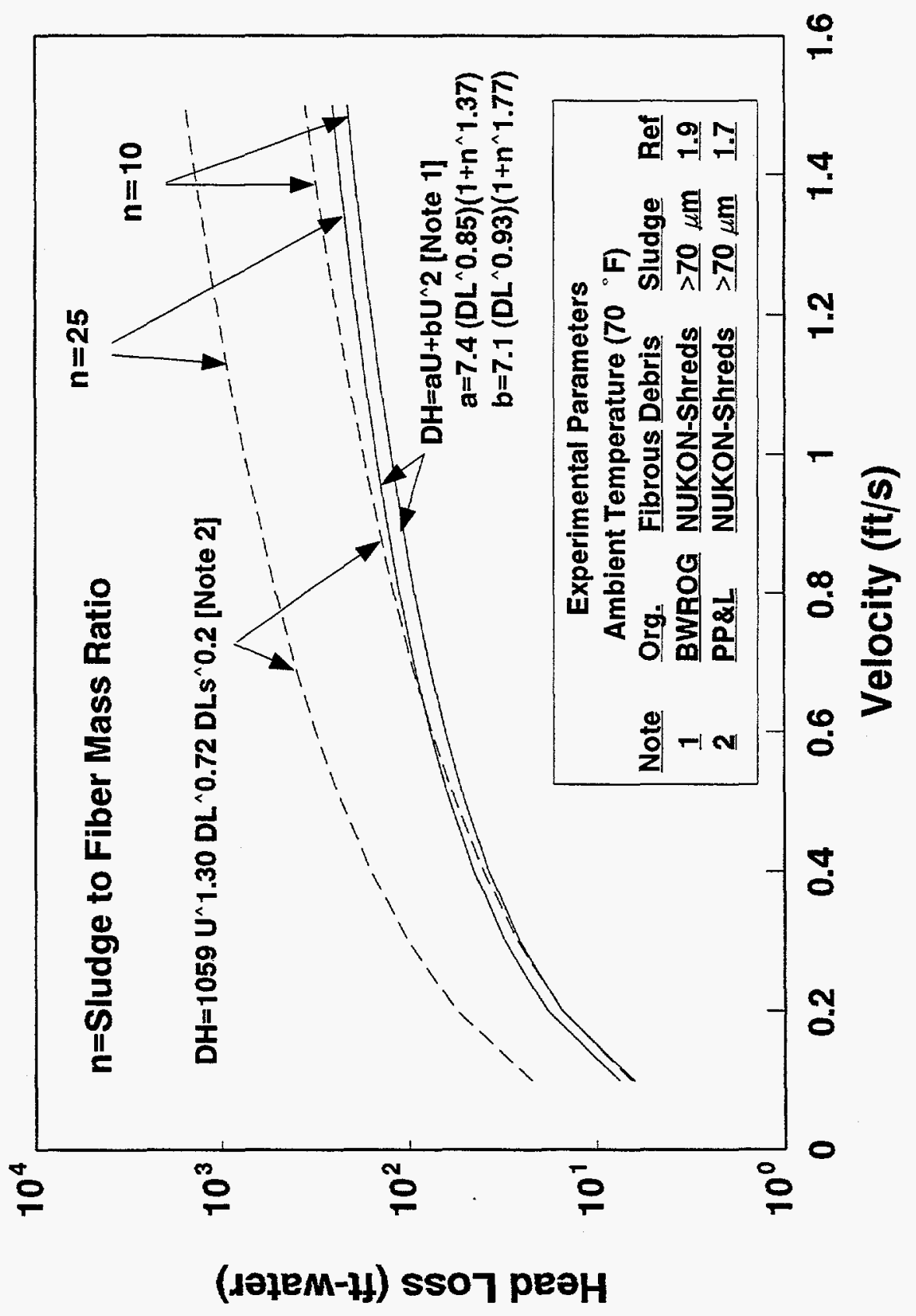




$$
\Delta H=a U+b U^{2}
$$

where,

$$
\begin{aligned}
& a=7.4\left(\Delta L_{o}\right)^{0.85}\left(1+\eta^{1.37}\right) \\
& b=7.1\left(\Delta L_{o}\right)^{0.93}\left(1+\eta^{1.77}\right), \text { and } \\
& \eta=\text { sludge-to-fiber mass ratio } \\
& \quad \text { approaching the strainer }
\end{aligned}
$$

In Equations 2-18 and 2-19, the quantities $\Delta \mathrm{L}_{\mathrm{s}}$ and $\eta$ were estimated based on the amount of sludge added to the test set-up since the visual observations suggested that most of the sludge was trapped by the debris bed. Predictions of Equations 2-18 and 219 are plotted in Figure 2-4. Once again, considerable scatter exists between the predictions provided by these equations, possibly due to a combination of the difference in the experimental methods employed to measure head loss and the purely empirical nature of the correlations proposed.

In a later investigation, the BWROG conducted additional tests to investigate the effect of sludge particle size on the head loss. These tests used 1-3 $\mu \mathrm{m}$ rust particles based on a BWROG survey of the suppression pool sludge to simulate the particulate debris approaching the ECCS strainer, instead of the $>70 \mu \mathrm{m}$ particles used in the experiments reviewed above. The results of these tests clearly indicated that only a small fraction of the smaller debris would be filtered by the fibrous beds in the first pass, unlike in the previous experiments where most of the sludge was noted to have been filtered in the first pass. This resulted in substantially lower pressure drops in the later case compared to Equations 2-18 and 2-19.

The experimental data reported in the open literature provide the following insights:

1. Filtration of particulate debris by the fibrous layer would substantially increase the pressure drop. The increase in some cases was ten-fold depending on the sludge-to-fiber mass ratio.

2. Considerable attention must be paid in selecting the representative sludge particle size. Experiments conducted by BWROG have shown that for the same concentration of sludge particles approaching the strainer, the head loss was considerably higher in the case of larger particles. For example, for a given concentration, the $70 \mu \mathrm{m}$ particles used in the experiments described above always resulted in pressure drops higher than the 1-3 $\mu \mathrm{m}$ particles. In this regard, results of the BWROG survey of sludge particles typically found in suppression pools should be carefully assessed in determining the prototypical sludge particle size distribution.

3. The experimental data should be correlated making use of functional forms that possess sound theoretical basis instead of purely empirical functional forms. For example, Equation 2-18 is based purely on an empirical functional form based on data obtained at relatively higher sludge-to-fiber mass ratios. Usage of this correlation at low sludge-tofiber ratios (e.g., $\Delta \mathrm{L}_{\mathrm{s}}=0$ ) would severely underpredict head loss. Such drawbacks can be avoided if the correlation is developed making use of insights drawn from previous experimental work in the related fields as described in the following sections.

\subsubsection{Development of a Semi-Theoretical Head Loss Equation}

Due to important industrial applications (e.g., process water filtration and high efficiency particulate air filtration), the process of filtration of micron-size particles by fibrous beds was extensively investigated [Ref. 2.24 and 2.25]. The experiments have revealed that filtration efficiency is a strong function of the particle diameter and the bed thickness. Additional factors that appear to influence filtration are fluid approach velocity, bed morphology and fiber diameter. In all cases, considerable increase was observed in the head loss as a result of filtration. These investigations suggest that the semi-theoretical head loss equation described above can also be used to predict head loss across a debris bed made of fibers and sludge if the porosity, $\varepsilon$, in Equation 2-16 can be expressed as:

$$
\varepsilon \equiv \varepsilon_{m}=1-\left(1+\frac{\rho_{f}}{\rho_{\mathrm{p}}} \eta\right)\left(1-\varepsilon_{o}\right) \frac{\Delta L_{o}}{\Delta L_{m}}
$$




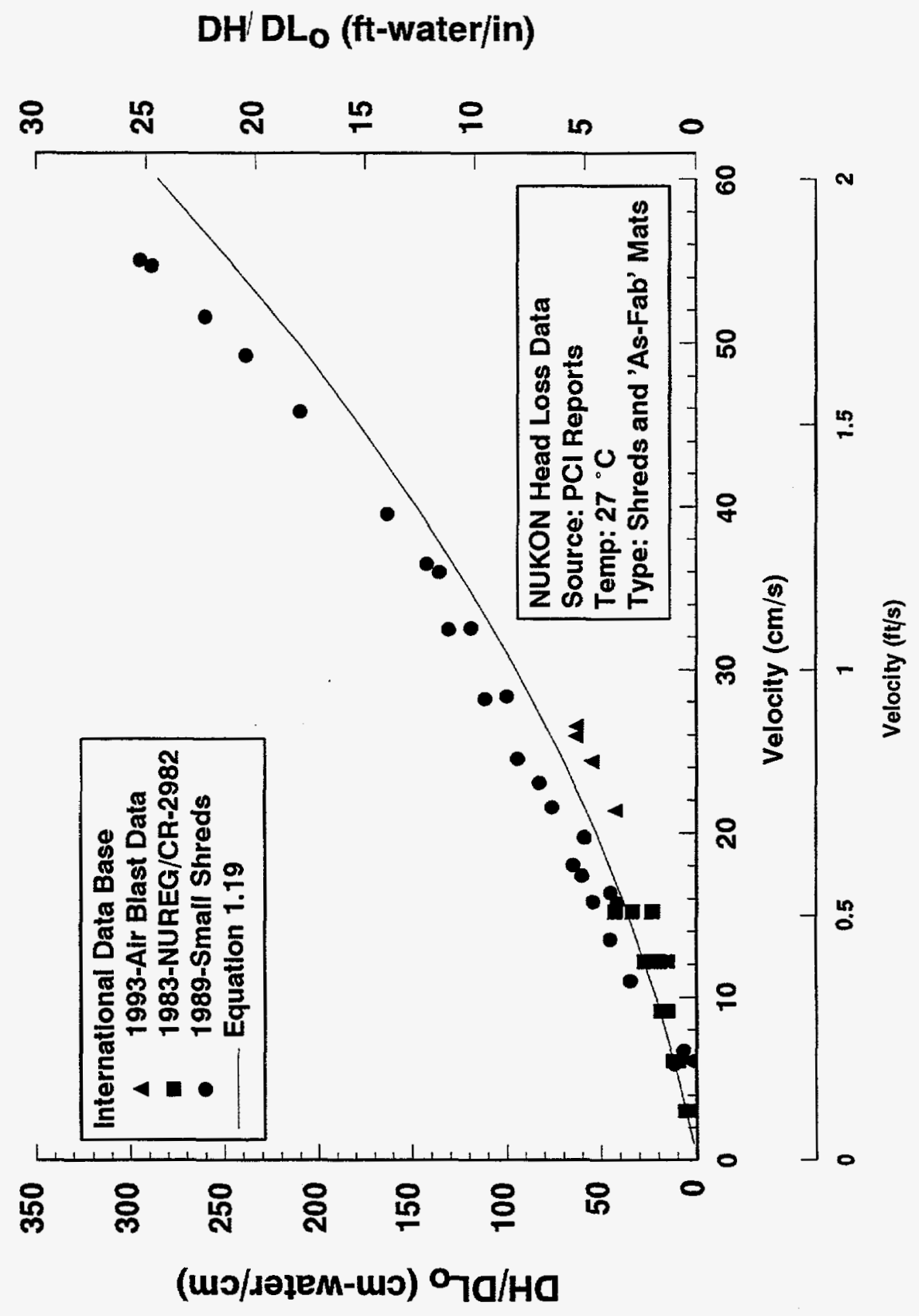

迎

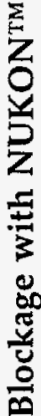

$\Xi$

芯

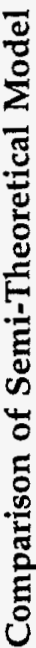

i்

总 


$$
\begin{gathered}
\varepsilon_{o}=1-c_{o} / \rho_{f} \\
\Delta L_{m}=c_{o} / c \Delta L_{o}
\end{gathered}
$$

The sludge-to-fiber ratio $\eta$ in Equation $2-20$ is based on the quantity of sludge filtered by the debris bed; not the quantity approaching the strainer.

Figure 2-5 provides a comparison of this equation prediction with the experimental data of Reference 2.12. As evident from this figure, reasonable agreement was observed. One of the objectives of this study is to further validate this correlation.

Usage of Equation 2-20 to predict head loss across a mixed debris bed requires accurate estimation of $\eta$, the sludge-to-fiber ratio $\eta$ and $\Delta \mathrm{L}_{\mathrm{o}}$, and the nominal thickness of the fiber bed. In Figure $2-5$ both $\eta$ and $\Delta \mathrm{L}_{\mathrm{o}}$ were estimated based on the concentration of sludge and fiber approaching the strainer assuming that all that debris would be trapped on the strainer surface. Such assumptions may be acceptable in the case of fibers and for particulate debris $>70 \mu \mathrm{m}$ [Ref. 2.12 and 2.23]. However, for sludge particles in the range of $1-10 \mu \mathrm{m}$, the assumption of $100 \%$ filtration would considerably overestimate $\eta$ and thus the head loss across the bed. For these cases, estimation of head loss requires accurate estimation of $\eta$ which in turn depends on the filtration efficiency which is defined as the fraction of the particulates removed by the fibrous beds during their passage through the debris bed. Previous experimental studies of filtration demonstrate that filtration efficiency is a strong function of particle size. Other factors that effect filtration efficiency include the bed thickness, bed morphology and the approach velocity. Several semi-analytical models have been developed to predict filtration efficiency as a function of all the parameters listed above. One of the objectives of this study is to measure filtration efficiency of the debris bed. 


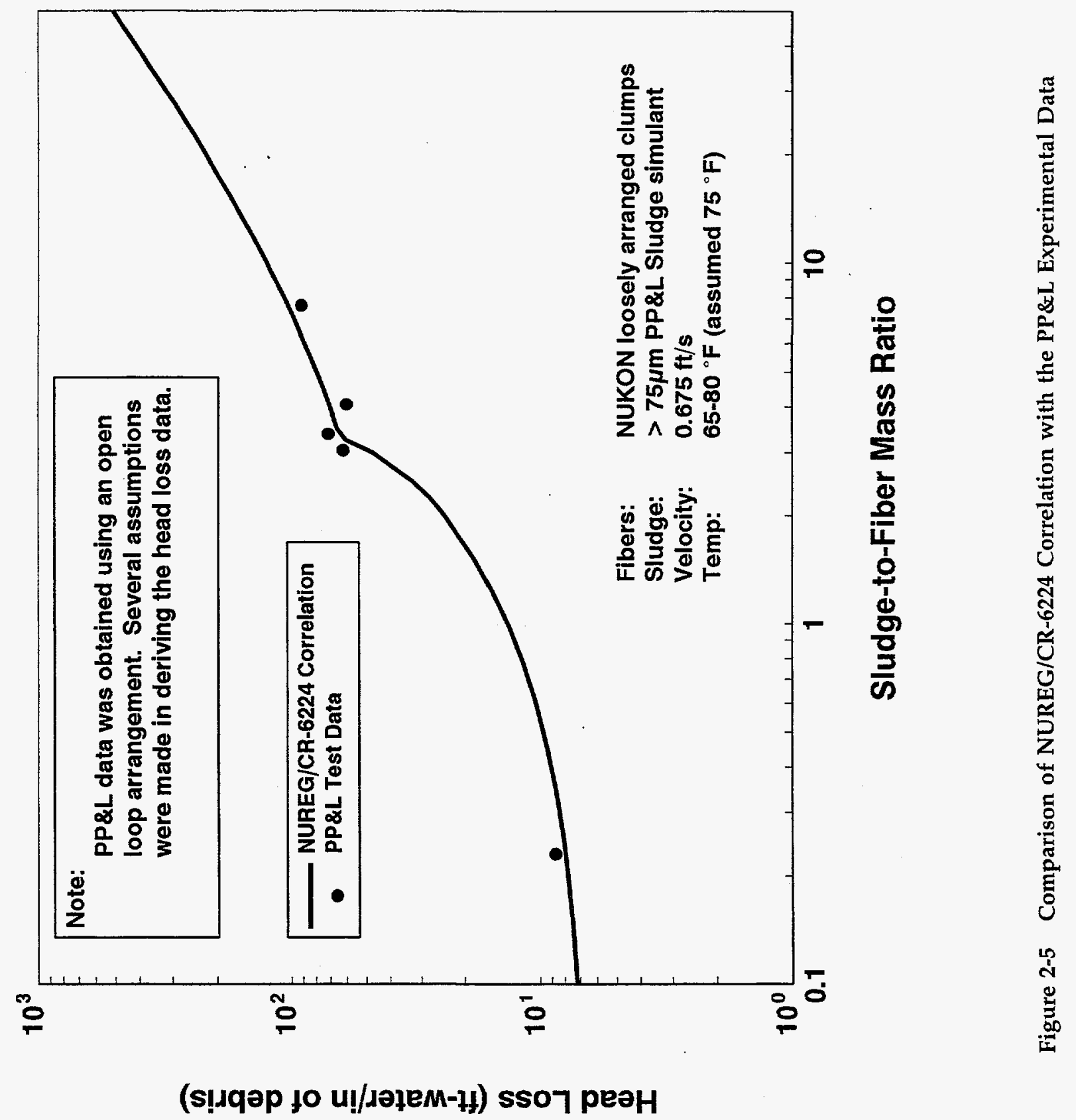


Insights Gained from Previous Studies

\section{References for Section 2}

2.1 G. Zigler, et al, "Parametric Study of the Potential for BWR ECCS Strainer Blockage Due to LOCA Generated Debris", Revised Draft Report, NUREG/CR-6224 (SEA No. 93554-06-A:1), April 1995.

2.2 F. Souto and D.V. Rao, "Experimental Study of Sedimentation of LOCA Generated Debris and Sludge in BWR Suppression Pools," Science and Engineering Associates, Inc., SEA No. 95-554-06-A:9, 1995.

2.3 BWR Owners' Group, "Interim Report of the BWR Owners' Group ECCS Suction Strainer Committee," BWROG-94157, December 1994.

2.4 Letter from T. Green to A. Serkiz, "BWR Owners' Group ECCS Suction Strainer Committee - Suppression Pool Sludge Particle Distribution," General Electric Company, OG94-661-161, September 1994.

2.5 A.W. Serkiz, "Containment Emergency Sump Performance," U.S. Nuclear Regulatory Commission, NUREG-0897, Rev. 1, October 1985.

2.6 D. N. Brocard, "Buoyancy, Transport, and Head Loss of Fibrous Reactor Insulation," Alden Research Laboratory, published as Sandia National Laboratories Report No. SAND82-7205, Rev, NUREG/CR-2982, Rev. 1, July 1983.

2.7 I. Greis, "Pressure Drop in Connection with Fluid Through Insulation Deposited on Strainers," RPD-92-109, ABB Atom, 1992.

2.8 "KKL Specific ECCS Strainer Plugging Analysis According to Regulatory Guide 1.82, Rev. 1 for a Loss of Coolant Accident," Technical Report, Bet/93/031, Kernkraftwerk, Leibstadt, AG.

2.9 D.V. Rao, D. Cremer, E. Cramer and F. Souto, "Review of International Knowledge Base for ECCS Recirculation Reliability," SEA No. 95554-09-A:1, Science and Engineering Associates, Inc., 1994.
2.10 J. B. Nystrom, "NUKONTM Insulation Head Loss Tests," ARL/124-89/M670F, Alden Research Laboratories, Inc., 1989.

2.11 B. J. Pennino and G. Hecker, "Head Loss Tests with Blast-Generated NUKONTM Insulation Debris," ARL/140-93/M670F, 1993.

2.12 K.W. Brinkman and P.W. Brady, "Results of Hydraulic Tests on ECCS Strainer Blockage and Material Transport in a BWR Suppression Pool," Pennsylvania Power \& Light Company, EC-059-1006, Rev. 0, May 1994.

2.13 T. Williams, "Experimental Measurements on the Characteristics of Flow Transport, Pressure Drop and Jet Impact on Thermal Insulation," NRC Reg Guide 1.82, Transco, Inc., May 1992.

2.14 J.P. Holman, "Experimental Methods for Engineers," 4th Edition, McGraw-Hill Book Company, New York, NY, 1984.

2.15 M. Muskat, Physical Principles of Oil Production, McGraw-Hill Book Co., Inc., New York, NY, 1949 , p. 128.

2.16 J. C. Ward, "Turbulent Flow in Porous Media," Journal of the Hydraulics Division, Proceedings of ASEC, HY5, 1964.

2.17 S. Ergun, "Fluid Flow Through Packed Columns," Chemical Engineering Progress, Vol. 48, No. 2, P. 89, 1952.

2.18 C. Kyan, D. T. Wasan and R. C. Kitner, "Flow of Single-Phase Fluids Through Fibrous Beds," Ind. Eng. Chem. Fundam., Vol. 9, No. 4, 1970.

2.19 C. N. Davies, "Proceedings of Institute of Mechanical Engineers," (London), B1, pp. 185, 1962.

2.20 W. L. Ingmanson, B. D. Andrews, and R. C. Johnson, "Internal Pressure Distribution In Compressible Mats Under Fluid Stress," TAPI Journal, Vol. 42, No. 10, 1959. 
2.21 I. F. Mcdonald, M. S. El-Sayed, K. Mow, and F. A. L. Dullien, "Flow Through Porous Media-Ergun Equation Revisited," Ind. Eng. Chem. Fundam., Vol. 18, No. 3, 1979.1.10

2.22 M. E. Henricksson, "Research and Experiment in Support of Back Fitting Measures at the Swedish BWRs," Vattenfall Utveckling AB, January 1994.

2.23 BWROG, "Summary of Current and Potential Future BWR Owners' Group Activities Regarding Resolution of ECCS Suction Strainer Issue," Presented to International Working Group Meeting, Albuquerque, NM, 1994.
2.24 C. Tien and A.C. Payatakes, "Adronces in Deep Bed Filtration," AICHE Journal, Vol. 25, No. 5, 1979.

2.25 N. A. Fuchs, The Mechanics of Aerosols, Dover Publications, Inc., English Edition, New York, NY, 1989. 



\subsection{Test Facility Description}

The test facility developed for these experiments was designed and instrumented to obtain head loss data that can be used in conjunction with BLOCKAGE in plant specific analyses. The test facility was not designed to be used for a strainer design qualification. The following sections describe how various BWR suppression pool features were incorporated into the test facility.

\subsection{Test Loop}

\subsubsection{Design Considerations}

Full-scale simulation of actual suppression pool and ECCS systems was beyond the scope of this study; hence, for these head loss experiments two alternatives were considered to simulate the underlying phenomena: (1) an open loop and (2) a closed loop. Each of these options have relative advantages and disadvantages over the other. The open loop experimental data are easily scalable to actual BWR conditions, and the test set-up would provide a better measurement of once-through filtration efficiencies. However, a realistically sized open loop limits the maximum head loss that can be sustained to very small values (e.g., 10-20 ft-water) compared to a closed loop. This would have seriously limited the range of parameters that could be explored in an open loop facility. A closed loop required much smaller amounts of water, insulation and sludge, resulting in easier facility clean up between tests and less energy required to maintain elevated water temperatures. On the other hand, the closed loop allows particulate debris which pass through the debris bed (cake) on the strainer, to be re-filtered by the cake on subsequent flow cycles. Therefore, the head loss versus time data (i.e., transient head loss curves) in the closed loop are not indicative of what will occur in a plant. This drawback was compensated for by measuring the sludge concentration remaining in the loop, which was used to estimate the quantity of debris contained in the debris bed at the time when steady state conditions were attained. This information was in turn used to correlate the head loss in terms of the actual amounts of debris contained in the debris cake.

\subsubsection{Test Loop Description}

Based on engineering judgement and past experience, a closed test loop was selected as the basic head loss facility. Figure 3-1 shows a schematic of the test loop. The 12 inch vertical test section had an $11 \mathrm{ft}$ long approach upstream and 4.5 $\mathrm{ft}$ downstream of the strainer assembly. The long approach section was needed to achieve a relatively flat velocity profile at the strainer. While the vertical piping associated with the test section was constructed of 12 inch diameter pipe, the rest of the loop was built using 4 inch piping to keep the flow velocities high enough to minimize settling of sludge particles in the loop, especially in the horizontal segments at low flow velocities. Additional details of the test loop are provided in Reference 3.1.

To facilitate operation at a higher than ambient temperature, the steel piping of the flow loop was insulated to minimize heat loss from the loop. In addition, a resistance heater on the pipe walls and the energy loss from the pump were used to maintain water at temperatures as high as $125^{\circ} \mathrm{F}$.

\subsection{Test Strainer}

The ECCS suction strainers used in a BWR are typically semi-conical in geometry as shown in Figure 3-2. In this case the debris is drawn to the strainer by the water flow and is then held compressed to the strainer surface by the differential pressure introduced by the flow. If it is assumed that the flow is fairly uniform, then the primary direction of the flow at any given location would be perpendicular to the strainer surface, except near the edges. In such a case, any segment of the strainer can be approximated by a flat plate located in a direction perpendicular to the primary flow direction. Thus, a flat plate strainer arrangement can be used to simulate the strainers found in the reference plant ECCS. It should be emphasized that these similitude arguments may not be applicable to strainer designs that intentionally introduce nonuniform flows.

\footnotetext{
${ }^{6}$ It is generally suggested that a length-to-diameter ratio of 7 is needed to establish fully developed flow patterns
} 
Test Facility Description

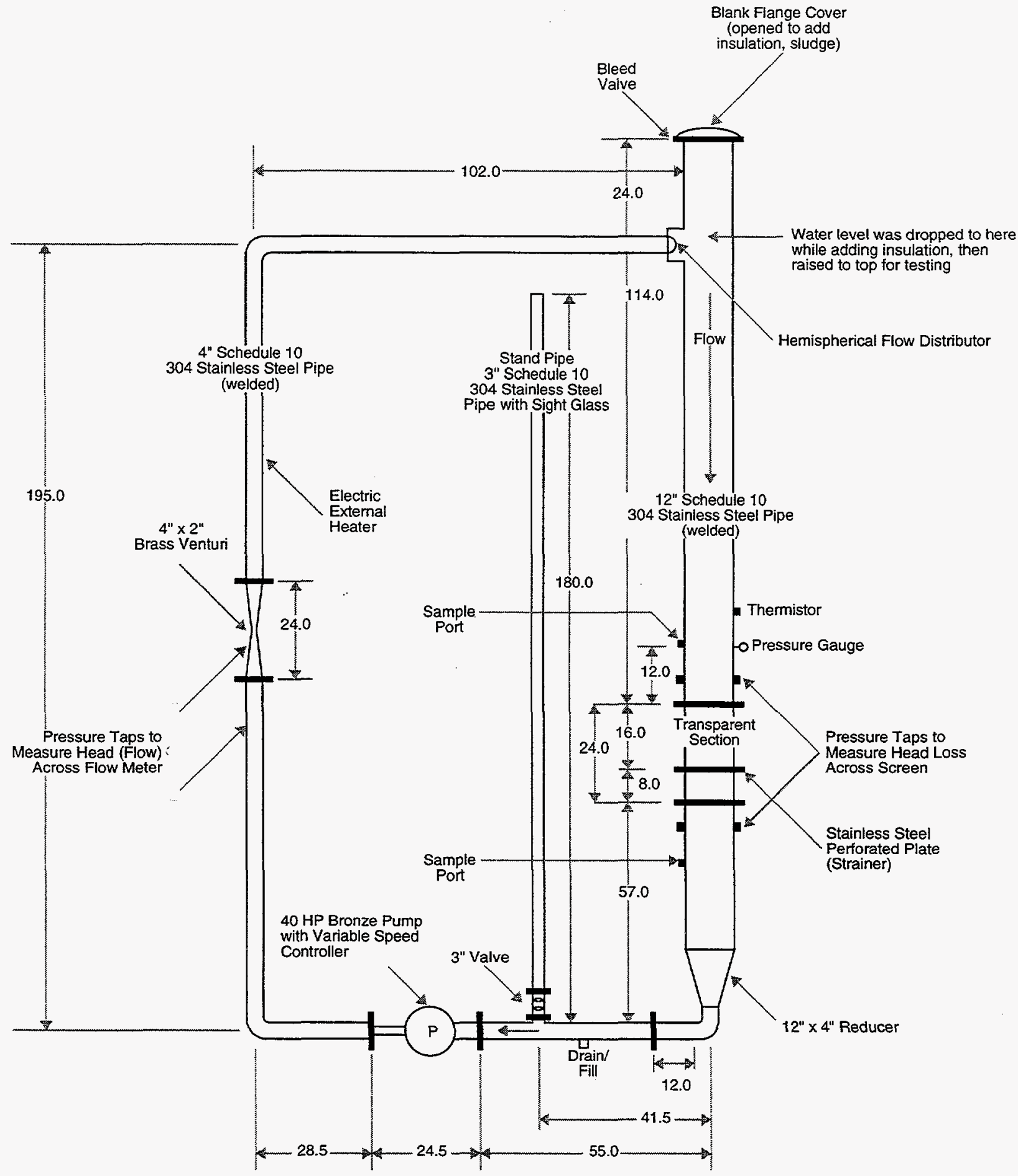

Figure 3-1. Head Loss Testing Facility - Flow Loop 
Test Facility Description
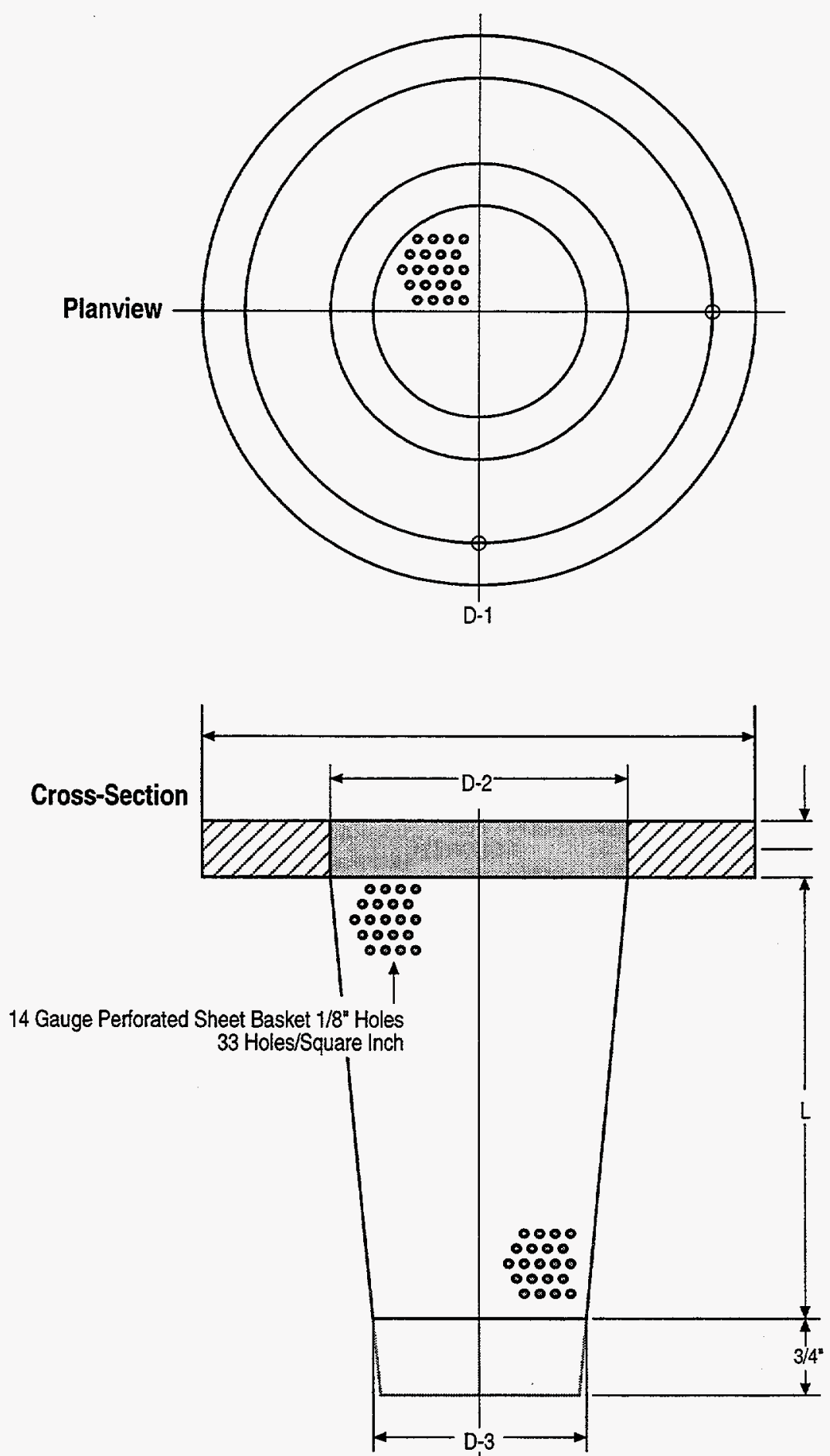

Figure 3-2. Planview \& Cross-Section of Strainer 
The simulated strainer used in this study consisted of a perforated flat plate made from 14 gauge, 304 stainless steel with $1 / 8$ inch holes and 30 holes per square inch. The hole arrangement and size were exactly the same as that of the reference plant strainers and the strainers commonly found in U.S. BWRs. Introduction of the strainer resulted in reduction of the flow area to about $40 \%$ and caused small head loss, typically about $0.2 \mathrm{ft}$-water at a water velocity of $1.5 \mathrm{ft} / \mathrm{s}$. These clean strainer head losses were subtracted from the head losses measured for strainers loaded with debris beds to obtain the head loss resulting from the flow through the debris layer.

The perforated strainer plate was located between two lengths of 12 inch diameter acrylic pipes to facilitate viewing of debris cake formation and compression. This also allowed visual evaluation of the travel time for all introduced insulation debris to reach the strainer plate, the debris distribution on the strainer, and compression of insulation debris at various approach velocities.

\subsection{Controls and Instrumentation}

\subsubsection{Loop Flow}

Loop flow was controlled by a $40 \mathrm{HP}$ variable speed motor-pump combination. A calibrated 4 inch by 2 inch Venturi flow meter was used to measure the flow through the loop; differential pressure cells were used to measure the head difference across the venturi which was then translated to estimate the flow rate. The calibration curves are provided in Appendix A. As evident from these curves, the measurement uncertainties were within $\pm 2 \%$ throughout the velocity range of present interest $(0.15-1.5 \mathrm{ft} / \mathrm{s})$. The DP cell output was fed to a computerized control system which was used in feedback mode to control $A C$ pump drive speed and thus the test loop flow rate. Every ten seconds the system flow was averaged, recorded and checked against the set point. If the difference between the setpoint and the actual flow was more than $2 \%$, then the pump speed was altered appropriately. This ability to accurately control the flow eliminated the need for a valve in the flow loop, thus reducing the possibility of dead zones where the sludge particles can settle out.

\subsubsection{DP Across Strainer}

The head loss across the strainer was measured between piezometric taps located $1.5 \mathrm{ft}$ upstream and $1 \mathrm{ft}$ downstream of the strainer. The calibration curve for the pressure transducer is presented in Appendix A. The tabulated pressures were obtained after appropriately accounting for elevation differences between the two pressure taps and the head loss introduced by a clean (or unloaded) strainer.

\subsubsection{Loop Water Temperature}

Water temperature was measured by a RTD sensor which was also connected to the computer monitoring system. The calibration curves are presented in Appendix A. The water was initially brought to the required temperature by making use of low power heating stripes placed on the stainless steel pipes and the heat losses from the pump. No additional controls were used to precisely control the water temperature, but generally the water temperature did not vary more than $5^{\circ} \mathrm{F}$ from the set point; the maximum variation noted was about $15^{\circ} \mathrm{F}$.

\subsubsection{Loop Sludge Concentration}

Loop concentration of sludge and other particulate debris was measured by drawing water samples from ports located upstream and downstream of the strainer. Usually one liter water samples were drawn after head loss stabilized at each approach velocity. The samples were then filtered through a $0.45 \mu \mathrm{m}$ pore filter paper and the concentration was determined by weighing the filter paper before and after filtration using a precise electronic analytical balance (A\&D).

Due to the important role played by concentration estimates, considerable attention was paid to quantify the uncertainties associated with the concentration measurement. In the first step, 14 bench tests were conducted where a known quantity of sludge varying between $0.03 \mathrm{~g}$ to $0.25 \mathrm{~g}$ was added to 1 liter of water in a glass bottle used for sample collection. The mixture was then filtered through the filter $(0.45 \mu \mathrm{m}$ pores) and the filtrate was dried and weighed. The percentage of weight returned from these tests are plotted versus the original weight in Figure 3-3. As shown in this 
figure, the collected weights were approximately the same as the added weight at large concentrations. However, at low concentrations, the collected weights were up to $12 \%$ lower. Visual observations suggest that these differences are due to measurement uncertainties and sludge adhering to the walls of the sampling bottle. As shown in this figure, a fairly linear correction equation could be developed to compensate for these factors.

In addition to the bench tests, three sludge only loop tests were conducted using the loop set-up. In these tests a pre-determined quantity of sludge was added to the loop and the water was allowed to circulate several times. Samples of water were then drawn and filtered to estimate concentration of sludge in the loop. The measured concentrations were then corrected using the correction equation developed from the bench tests described above. The ratio of measured concentration to the nominal concentration versus the approach velocity is plotted in Figure 3-4. Sludge recovered of $100 \%$ in Figure 3-4 would correspond to the ideal condition. As evident from this figure, very few tests yielded such highly accurate estimates, which was expected considering the uncertainties involved. The individual samples yielded concentrations that varied from $112 \%$ to $85 \%$ of the nominal concentration. Thus, it can be concluded that concentration measurement based on a single sample could be associated with an uncertainty of up to $\pm 15 \%$. This uncertainty can be minimized if the concentration estimates are obtained by averaging data from more than one sample. In Figure 3-4, these averaged values are plotted versus approach velocity. As evident from this figure, uncertainties involved are within $\pm 5 \%$.

Based on these calibration tests, it was concluded that:

1. Each concentration sample could be associated with uncertainties as high as $\pm 15 \%$.

2. To minimize the uncertainties, more than one sample should be drawn whenever possible.

The concentration information was used to estimate the filtration efficiency of the debris bed. 
Test Facility Description

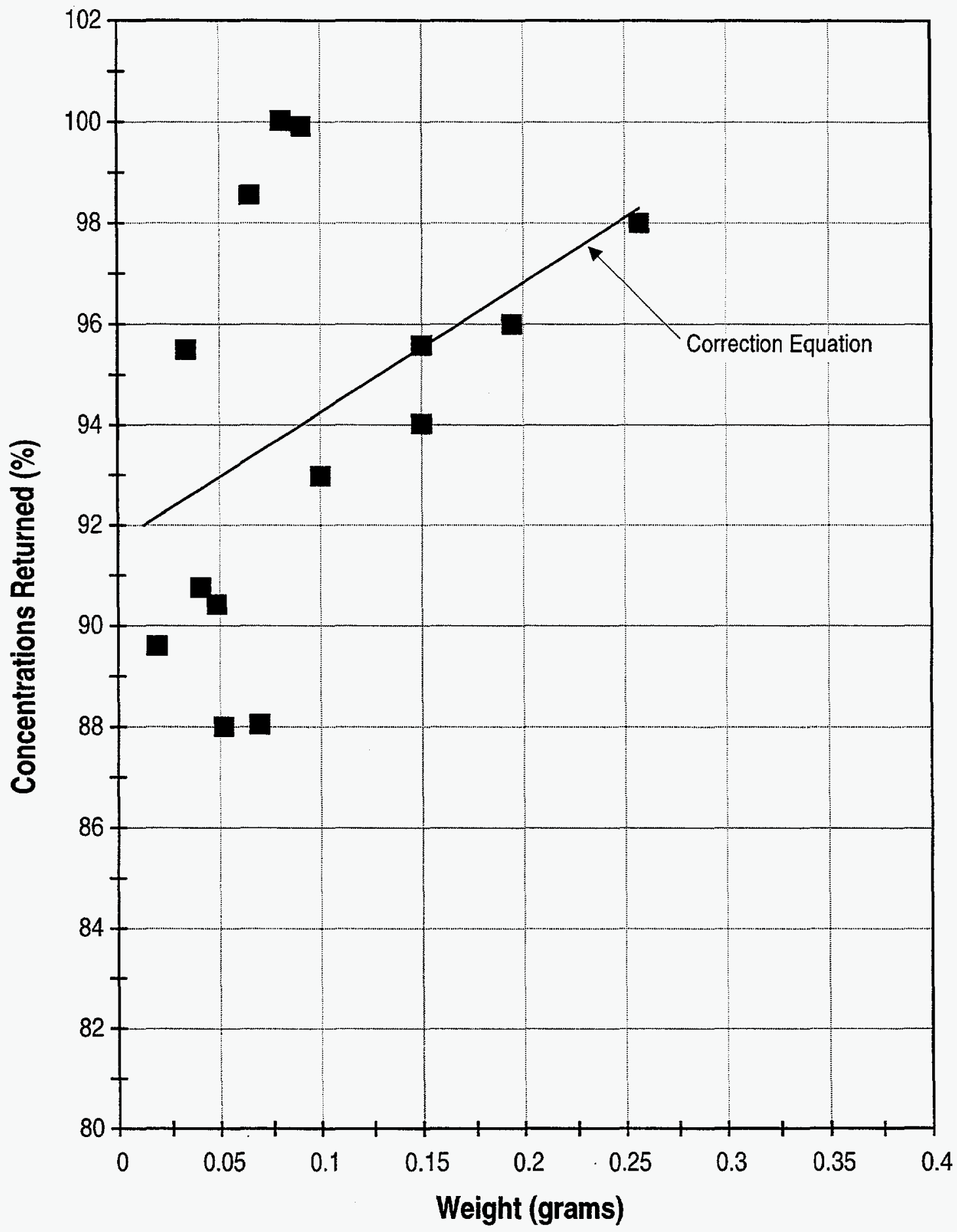

Figure 3-3. Bench Tests Conducted by ARL to Bench Mark the Concentration Measurements 
Test Facility Description

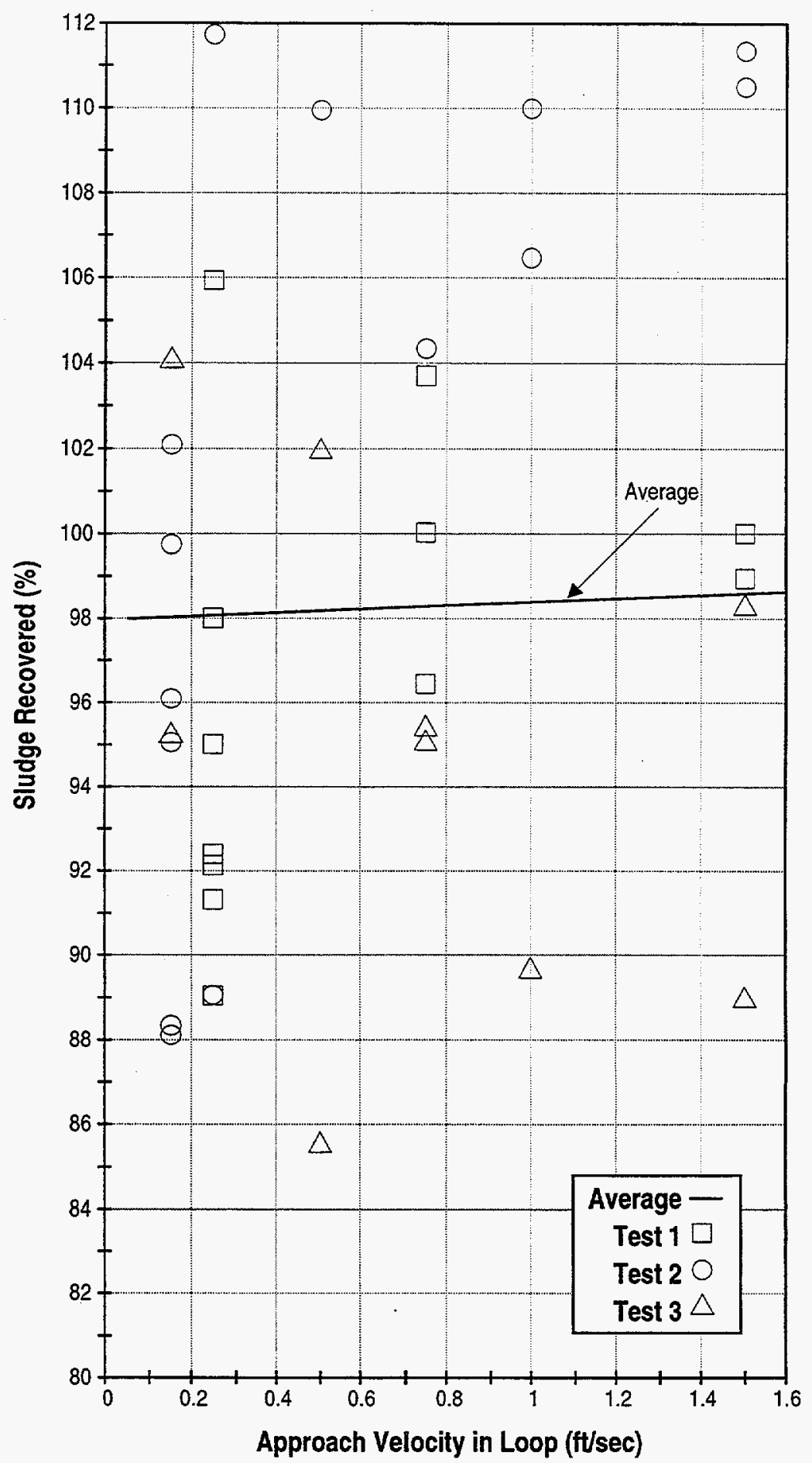

Figure 3-4. Sludge Only Loop Tests Used to Quantify Uncertainties in Concentration Measurements 
Test Facility Description

\section{References for Section 3}

3.1 P. Murthy, M. Padmanabhan, F.J. Weber, G.É. Hecker, "Head Loss of Fibrous Insulation

Debris and Sludge for BWR Suction

Strainers," Alden Research Laboratory, Inc., 1995. 


\subsection{Development of Experimental Procedures}

A series of exploratory tests were conducted to draw insights that could be used to (a) develop the experimental procedure that could be used in the final set of tests, termed as parametric tests; (b) maximize the data that can be collected from each test; and (c) understand the effect of each of the key parameters on the head loss. The following sections summarize how the exploratory test results were used in developing the experimental procedure. Table 4-1 presents the test matrix for the exploratory test.

\subsection{Selection of Approach Velocities}

\subsubsection{Selection of Approach Velocity Range for Experimentation}

The reference plant has a total of 4 low pressure ECCS strainers ( $2 \mathrm{LPCI}$ and 2 core spray) with a total surface area of $37.62 \mathrm{ft}^{2}$. A rated flow of 25,000 GPM translates to an approach velocity of about 1.5 $\mathrm{ft} / \mathrm{s}$. This value of $1.5 \mathrm{ft} / \mathrm{s}$ was selected as the upper bound for experimentation. A lower bound of $0.15 \mathrm{ft} / \mathrm{s}$ was selected for experimentation because maintaining stable flow rates below $0.15 \mathrm{ft} / \mathrm{s}$ was extremely difficult. The selected approach velocity range of $0.15-1.5 \mathrm{ft} / \mathrm{s}$ envelops the ECCS approach velocities in the existing U.S. BWRs, as confirmed by a recent survey undertaken by the BWROG.

\subsubsection{Selection of Approach Velocity at Bed Formation}

Head loss across a filter bed is a strong function of the approach velocity. For incompressible beds, the head loss at any given velocity is independent of the velocity at which the bed is formed. For compressible beds, such as fibrous debris beds, the head loss could be a function not only of the approach velocity at which it is measured, but also of the approach velocity at which the bed is formed. Implicitly, it follows that the approach velocity at which the bed forms may impact the bed morphology (i.e., the internal structure of the bed), which in turn may affect the head loss across the bed at a given velocity. If the head loss is very sensitive to the approach velocity at which the bed is formed, then a separate test should be conducted for each selected approach velocity. On the other hand, if the head loss is proven to be fairly insensitive to the approach velocity, then it is possible to use the same test to obtain head loss data corresponding to several different velocities. Thus, it was important that this issue be further explored experimentally to quantify the effect, if any, of the approach velocity on the resultant head loss. A total of seven experiments were conducted (E-01, E-01R, E-02, E-03, E-20, E-21 and E-22). Important observations from these experiments can be summarized as follows:

1. The head loss is a strong function of the velocity at which it is measured. This trend is evident from the transient head loss curve illustrated for Test E-01 in Figure 4-1. In this test, a pure fiber bed of theoretical thickness of $2 \mathrm{in}$. was allowed to form at an approach velocity of $0.15 \mathrm{ft} / \mathrm{s}$. Thereafter, the approach velocity was increased in steps until a maximum velocity of $1.0 \mathrm{ft} / \mathrm{s}$ was attained.

At each intermediate velocity ample time was allowed for the bed to compress under the influence of increased pressure drop and for the head loss to reach a steady state value. As evident from Figure 4-1, the resultant head loss increased monotonically with increasing velocity.

After a head loss of $36 \mathrm{ft}$-water was reached at a velocity of $1.0 \mathrm{ft} / \mathrm{s}$, the approach velocity was then reduced in steps, finally reaching the initial velocity of $0.15 \mathrm{ft} / \mathrm{s}$. As the velocity was decreased, the head loss followed closely. However, at each subsequent velocity the resultant head loss was about $5-10 \%$ higher than the head loss measured on the way up. This trend is illustrated in the insert of Figure 4-1, which plots head loss as a function of the approach velocity. In this figure, the velocity direction is illustrated with an arrow.

A similar trend was also observed for all the remaining tests and is consistent with previously reported results [Ref. 4.1, 4.2 and 4.3]. This trend can be attributed to the 'hysterisis effect', which refers to the fact that the bed does not fully recover from the compressed state, i.e., beds are not completely elastic. Since the conditions leading to the 
Table 4-1. Exploratory Test Matrix

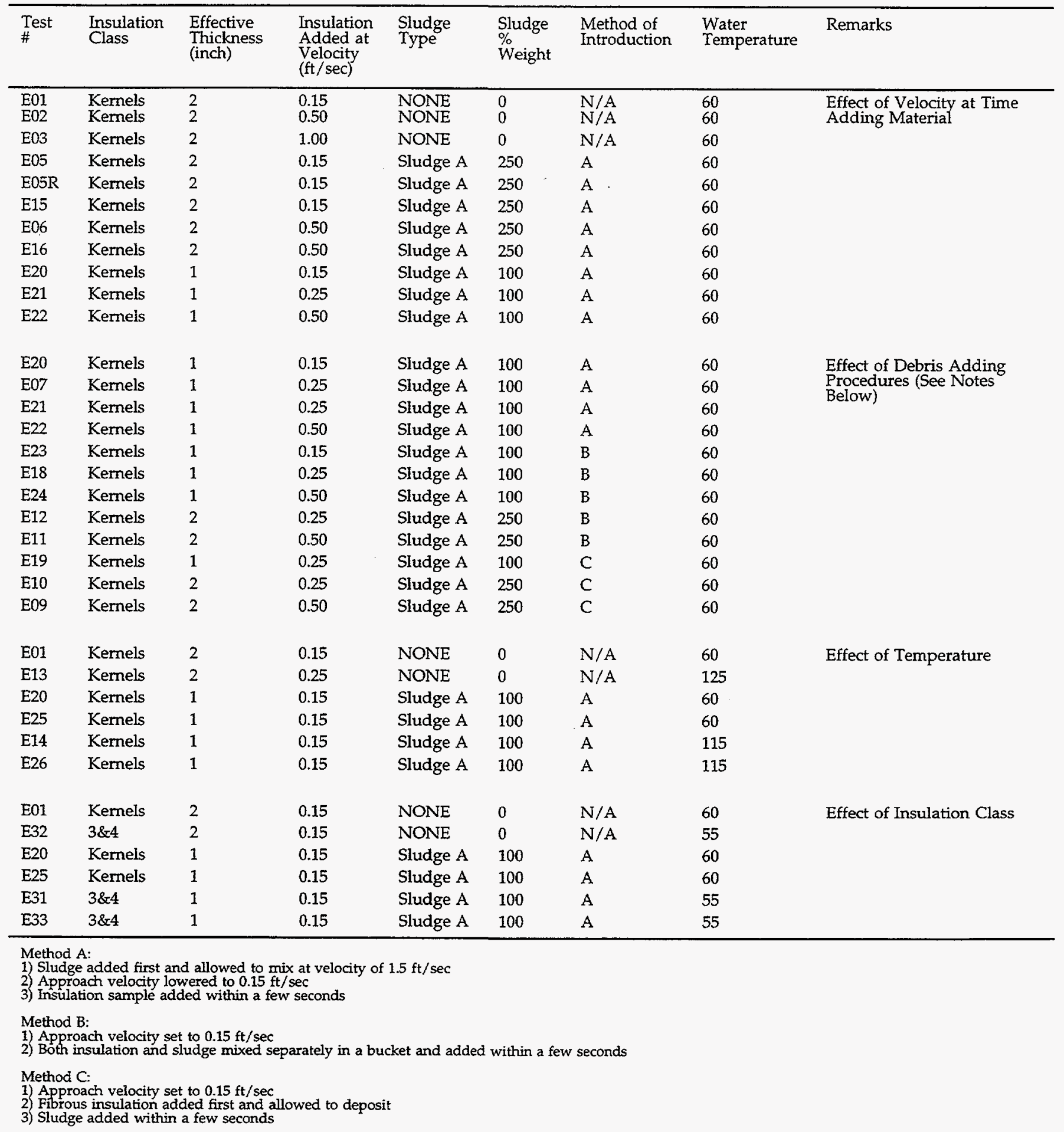




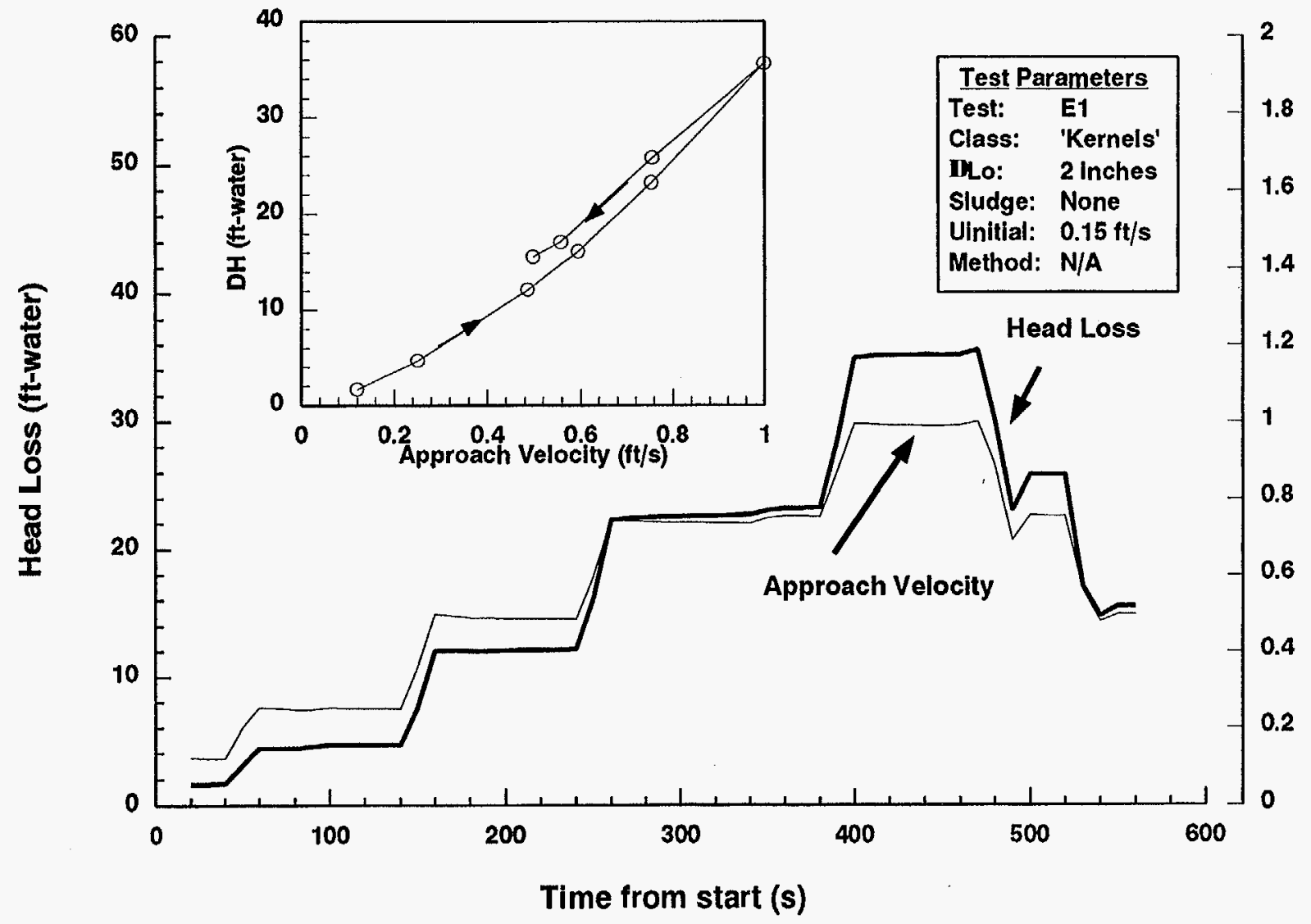


hysterisis effect are not typical for the reference plant, the head loss data obtained while the velocities were decreasing was excluded from further analysis and correlation development.

2. The head loss is only weakly dependent on the approach velocity at which the bed is formed. As evident from Figures 4-2a and $4-2 b$, the final stable head loss at any given velocity is the same (within the random deviation) with no regard to whether the bed was formed at that velocity or it was formed at a lower velocity and then the velocity was increased. This finding is equally valid both for the beds with and without sludge (i.e., pure beds and mixed beds).

The implication of these findings is that a single test can be used to measure head losses corresponding to several velocities; that is, the bed can be allowed to form at the lowest velocity of interest and then can be increased in steps until the maximum velocity was reached. As a result of these tests, it was decided to start each test at the lowest velocity and increase the velocity in steps until the maximum velocity is reached. At each velocity, the head loss was allowed to reach the stable value. After reaching the maximum flow velocity, the velocity would be decreased in steps reaching the initial value of $0.15 \mathrm{ft} / \mathrm{s}$. The corresponding stable head losses were recorded, although they were not analyzed or considered in the development of the correlation.

\subsection{Selection of Method of Debris Introduction}

Previous investigations related to fiber beds loaded with particulate debris suggest that the bed morphology can significantly influence the head loss [Ref. 4.4]. Bed morphology is also influenced by such factors as (a) the sequence in which the debris arrive at the strainer, (b) the mode of deposition, and (c) the affluent concentration. In an open loop it may be possible to simulate the actual BWR suppression pool conditions; fibrous debris and sludge particles arrive at the strainer simultaneously and at low concentrations. However, in a closed loop exact simulation of these conditions is not possible. Instead, the following three different alternatives were investigated:

\section{Method A}

- $\quad$ Sludge is added first at a relatively high approach velocity $(1.5 \mathrm{ft} / \mathrm{s})$ and allowed to circulate through the loop for several minutes to ensure uniform mixing with the loop water and establish a uniform concentration.

- Approach velocity is lowered to $0.15 \mathrm{ft} / \mathrm{s}$ which was selected as the approach velocity at bed formation.

- Insulation debris is added all within a short time (few seconds) while maintaining the approach velocity of $0.15 \mathrm{ft} / \mathrm{s}$.

\section{Method B}

- Approach velocity is set at $0.15 \mathrm{ft} / \mathrm{s}$.

- The insulation and sludge mixture, previously prepared in a bucket, is added together slowly.

\section{Method C}

- Approach velocity is set to $0.15 \mathrm{ft} / \mathrm{s}$.

- Fibrous insulation is added first and allowed to deposit on the strainer and head loss allowed to stabilize.

- $\quad$ Sludge is added at a later time.

Several exploratory tests were conducted to examine the impact of the method of debris addition on the head loss. The measured head losses are plotted in Figure 4-3. As evident from this figure, Method $C$ typically resulted in much higher pressure drops compared to the other two methods. On the other hand, Methods A and B resulted in very similar head loss values; the differences are in the same order of magnitude as random deviations. Visual observations of distribution of materials in the loop and formation of the bed suggest that Method $C$ does not represent actual plant conditions. For example, the beds formed in Method $C$ can be best described as consisting of two separate debris layers, a sludge layer on top of the fibrous layer, which is not expected to occur in the BWR suppression pools. Also, Method B resulted in high sludge concentration at the time of bed formation and resulted in spatially variable sludge concentration in the loop. To avoid these non-typical conditions related to bed formation, it was decided to adopt Method $A$ as the primary method of debris introduction. 


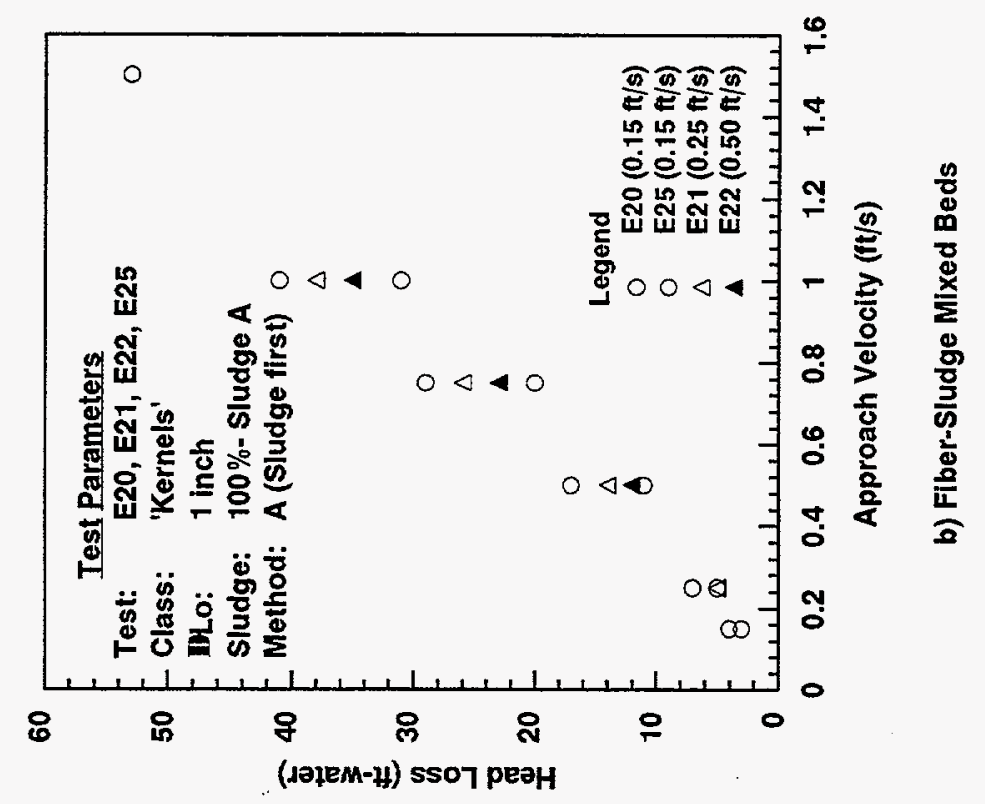


Development of Experimental Procedures

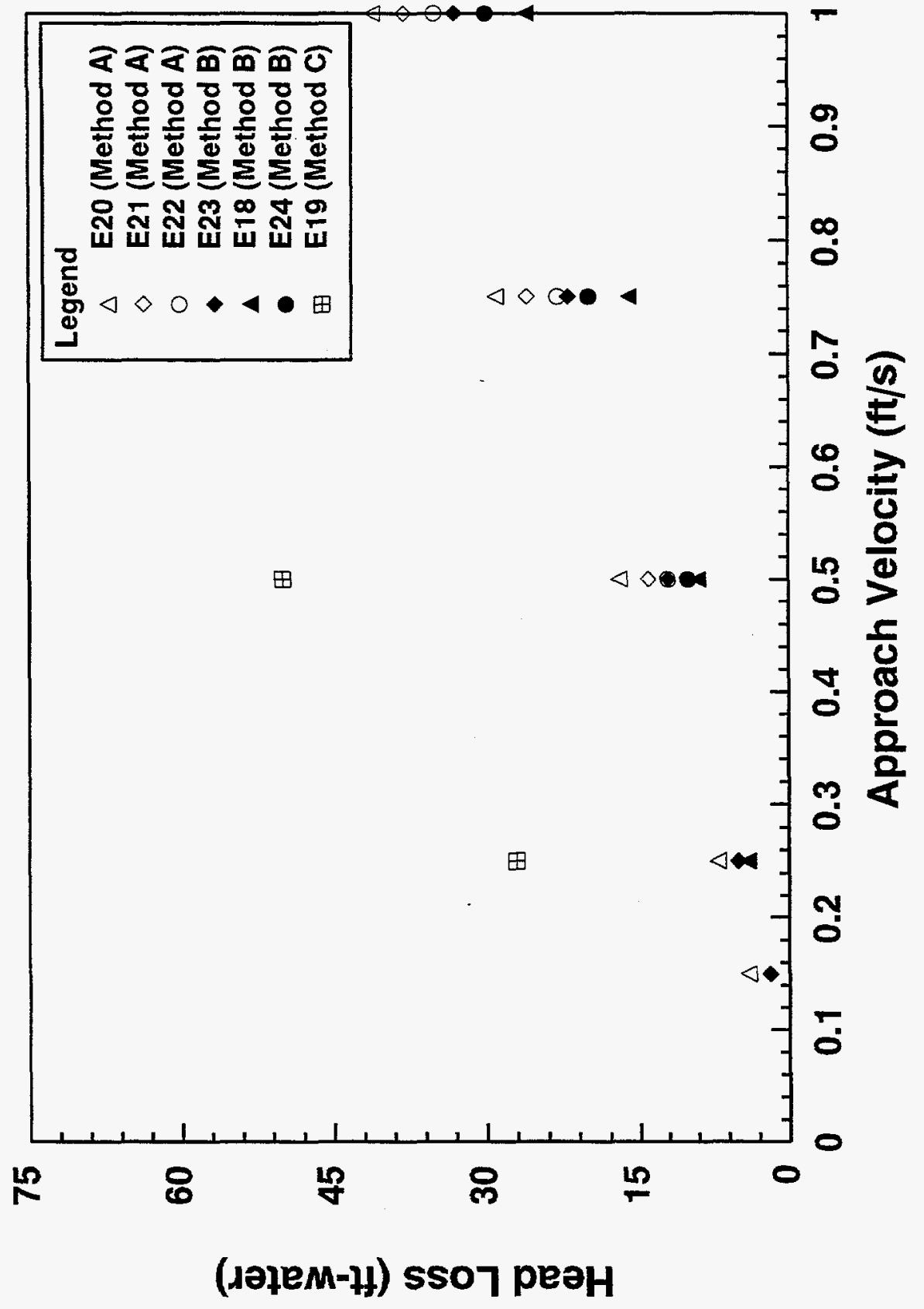

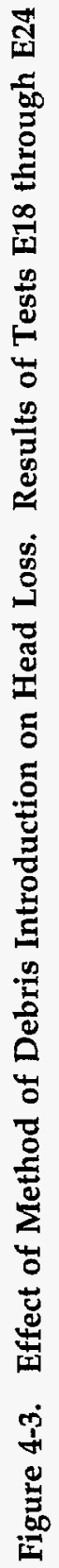




\subsection{Selection of Debris Size for Experimentation}

\subsubsection{Insulation Debris}

The reference plant uses NUKON ${ }^{\mathrm{TM}}$ blankets for primary piping insulation. Thus, aged NUKON ${ }^{\mathrm{TM}}$ was selected as the material for study. The NUKON ${ }^{\mathrm{TM}}$ blankets were aged according to the ASTM standards. Based on practicality considerations, a leaf shredder was selected for shredding the NUKONTM blankets into the representative size classes. As previously discussed, the representative insulation debris would resemble shape classes 1, 2, 3 and 4 of Figure 2-1 due to disintegration caused by debris generation and suppression pool chugging. The debris may possess slightly larger size classes (e.g., classes $5 \& 6$ ) if the debris is not subjected to the suppression pool chugging (i.e., the debris that arrives during the washdown phase). Therefore, the intent of this study was to obtain head loss data for two sets of debris classes: (1) a mixture of shape classes 1, 2, 3 and 4 of Figure 2-1, which was referred to as insulation 'Classes 3\&4'; and, (2) a coarser mixture of classes $1,2,3,4,5$, and 6 , which was referred to as insulation 'Classes $5 \& 66^{\prime}$.

Several exploratory studies were undertaken to generate these insulation size classes using the leaf shredder. Initially, large pieces were added to the shredder and were shredded long enough for the fragments to be rolled up into small balls or 'kernels'. A photograph of the typical kernels used in the experiment is illustrated in Figure 4-4. Later, the method was revised and better controlled to generate insulation debris that closely resembled classes $3 \& 4$ and $5 \& 6$, described above. Photographs of classes $3 \& 4$ and $5 \& 6$ are illustrated in Figures 4-5 and 4-6. Exploratory tests were conducted to examine the impact of the differences in these size classes on the head loss. Although not shown here explicitly for pure beds as well as for mixed beds, the kernels generally resulted in higher head losses [Ref. 4.5]. Visually, the cake formed of kernels was different from that one formed with Classes $3 \& 4$, as the deposition with the kernels appeared more uniform and was flatter or more compressed [Ref. 4.5]. On the other hand, the cake for Classes $3 \& 4$ was slightly uneven and was more springy after drying.
Based on these test results as well as from the visual inspection of the debris, the following conclusions were drawn:

1. Longer exposure to a leaf shredder does not necessarily produce more representative debris. Longer shredding leads to balling up and generation of kernels. Such a ball milling process is not expected to occur following a LOCA and thus kernels are not representative of the debris produced following a LOCA. The NUKON ${ }^{\mathrm{TM}}$ debris produced from the airblast tests did not possess any kernels either [Ref. 4.6]. Based on this reasoning, it was decided not to perform any more experiments using kernels.

2. The parametric head loss tests were conducted using insulation classes $3 \& 4$ primarily. However, a few tests were conducted using insulation classes $5 \& 6$ to examine the effect of insulation class on the head loss.

\subsubsection{Sludge}

The sludge particle size distribution provided by the BWROG, shown in Table 4-2, was used to conduct the experiments [Ref. 4.7]. To create a simulant of this sludge, SEA surveyed various vendors of

Table 4-2. BWROG-Provided Size Distribution of the Suppression Pool Sludge

\begin{tabular}{|ccc|}
\hline $\begin{array}{c}\text { Bin Width } \\
\mu \mathrm{m}\end{array}$ & $\begin{array}{c}\text { Average Size } \\
\mu \mathrm{m}\end{array}$ & \% by weight \\
\hline $0-5$ & 2.5 & $81 \%$ \\
$5-10$ & 7.5 & $14 \%$ \\
$10-75$ & 42.5 & $5 \%$ \\
\hline
\end{tabular}

special powders. The intent of the survey was to identify a vendor who could provide the iron-oxide powders with size distribution that closely resembled the BWROG-provided size distribution. Based on this survey, it was determined that ironoxide powders \#2008 and \#9101-N, sold commercially by Hansen Engineering, Inc., best matched the BWROG sludge size distribution data. As shown in Table 4-3, a mixture of powders consisting of $95 \%$ 
Development of Experimental Procedures

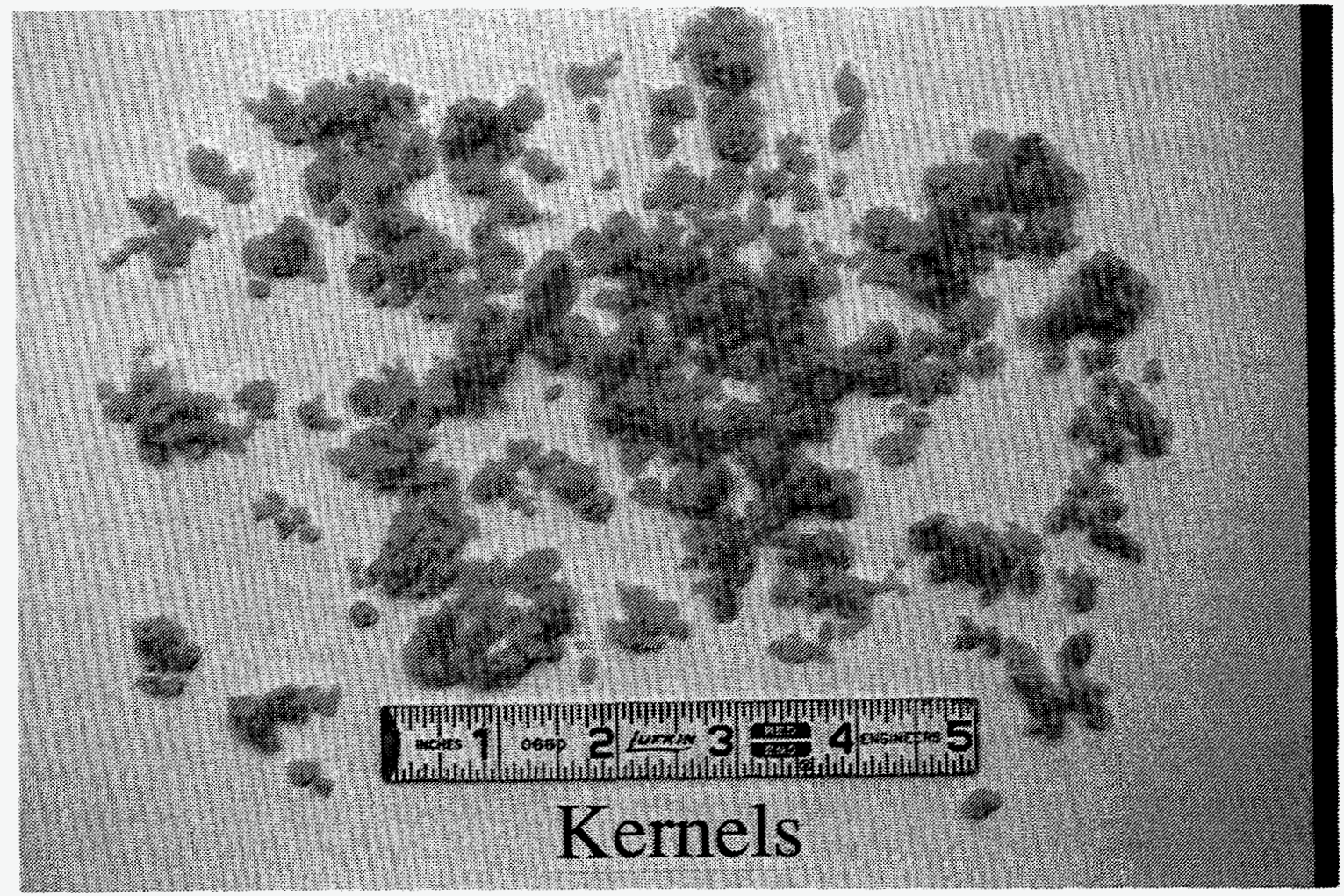

Figure 4-4. Representative Sample of Shredded NUKONTM Fibrous Debris - Kernels 
Development of Experimental Procedures

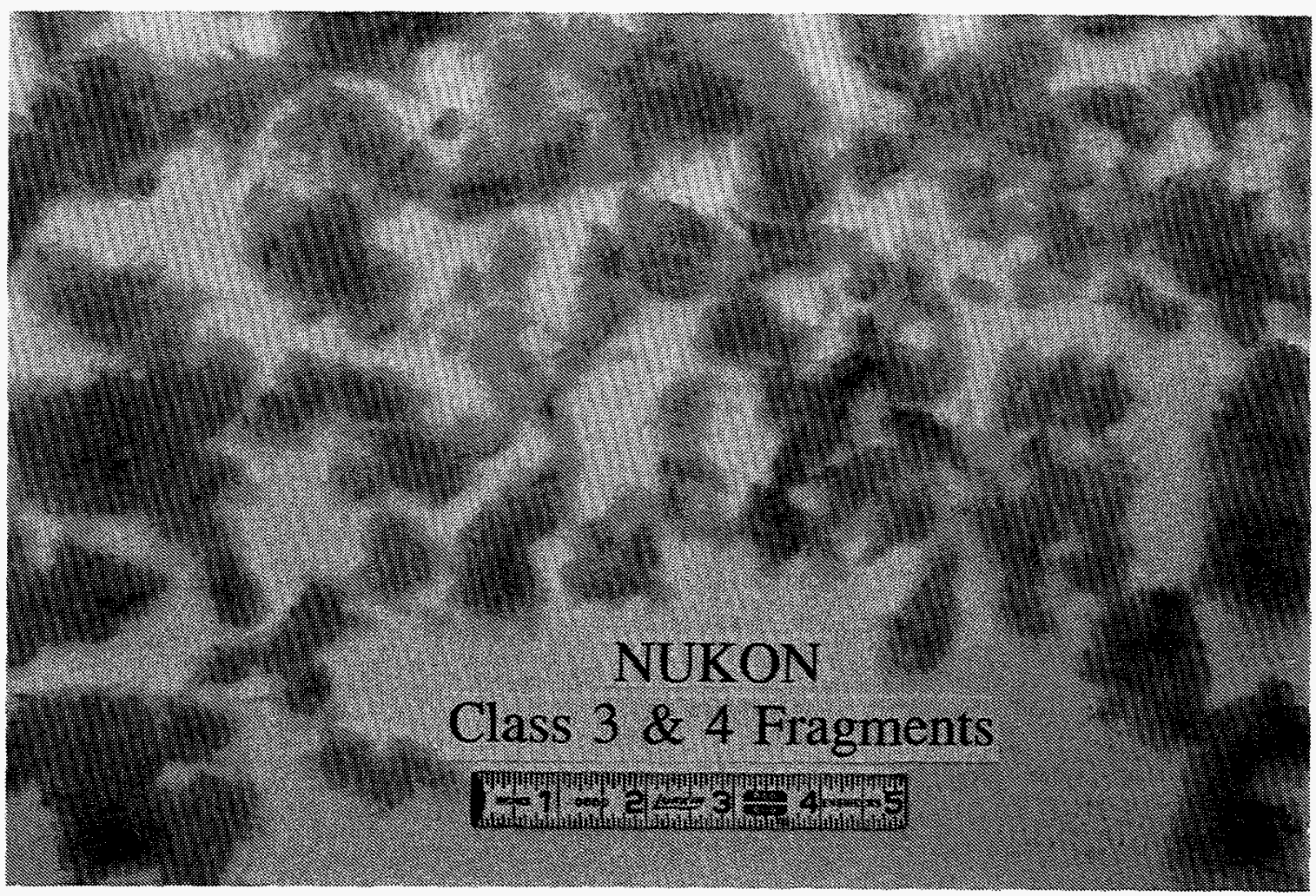

Figure 4-5. Representative Sample of Shredded NUKONTM Fibrous Debris - Class 3 \& 4 
Development of Experimental Procedures

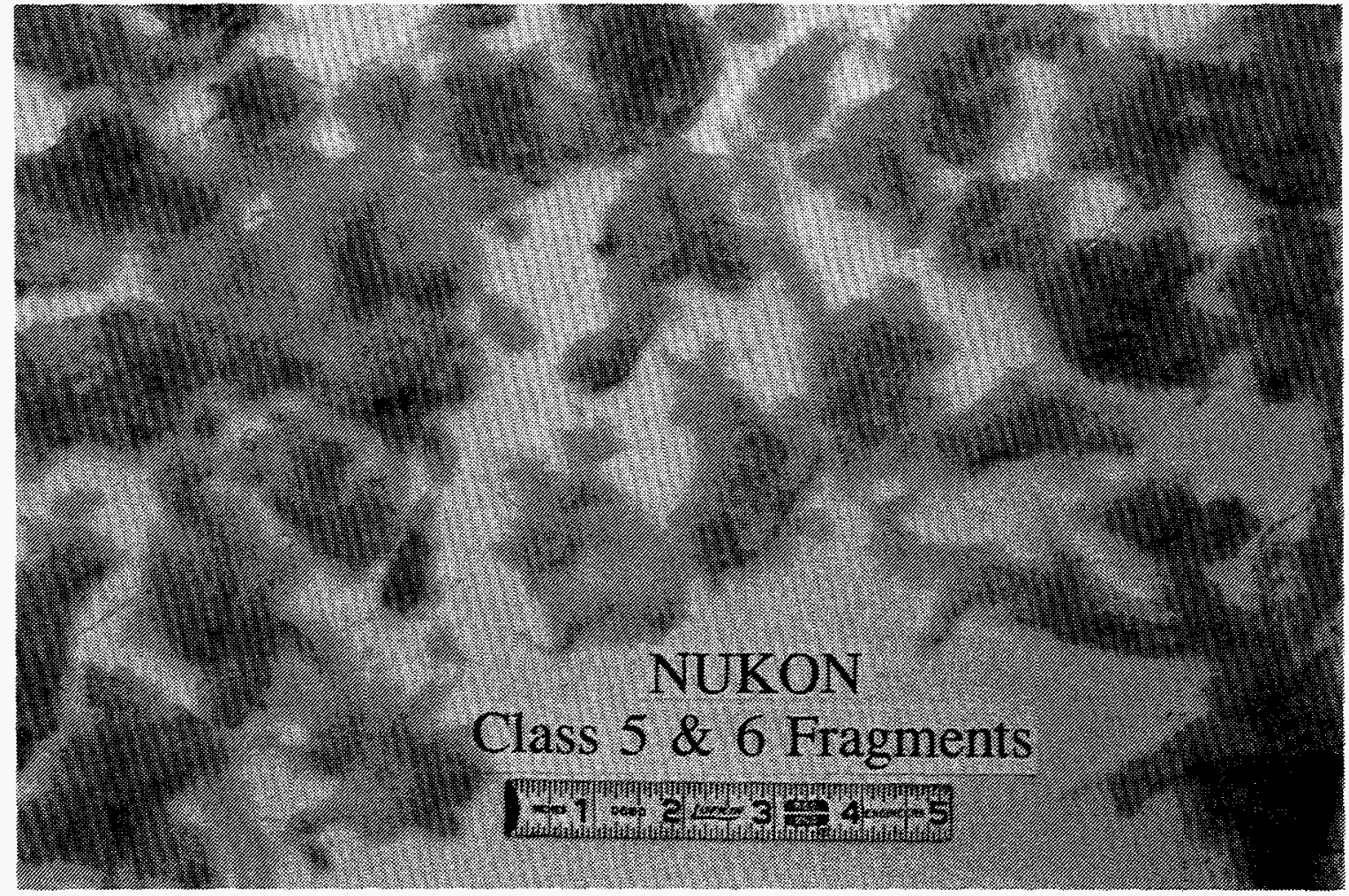

Figure 4-6. Representative Sample of Shredded NUKONTM Fibrous Debris - Class 5 \& 6 
Table 4-3. Iron Oxide Particles Supplied by Hansen Engineering, Inc.

\begin{tabular}{cccccc}
\hline $\mathrm{Fe}_{3} \mathrm{O}_{4}$ Specification & $<2 \mu \mathrm{m}$ & $\mathbf{2 - 5} \boldsymbol{\mu \mathrm { m }}$ & $\mathbf{5 - 1 0} \boldsymbol{\mu m}$ & $\mathbf{1 0 - 3 5} \boldsymbol{\mu m}$ & $>\mathbf{3 5} \boldsymbol{\mu m}$ \\
\hline$\# 2008$ & $5 \%$ & $80 \%$ & $15 \%$ & $0 \%$ & $0 \%$ \\
$\# 9101-\mathrm{N}$ & $-0 \%$ & $-0 \%$ & $-0 \%$ & $82 \%$ & $-18 \%$ \\
$95 \% \# 2008+$ & $4.75 \%$ & $76 \%$ & $14.25 \%$ & $4.1 \%$ & $0.9 \%$ \\
$5 \% \# 9101-\mathrm{N}$ & & & & & \\
\hline
\end{tabular}

by weight of powder \#2008 and $5 \%$ by weight of \#9101-N best simulates the BWROG size distribution. This mixture, termed Sludge $\mathbf{A}$, was used in most of the head loss tests.

In addition to Sludge $\mathrm{A}$, some other head loss experiments were conducted using another sludge mixture, named Sludge B. Sludge B consisted of $100 \%$ \#9101- $\mathrm{N}$ iron-oxide powder and was used primarily to estimate the effects of a different sludge size distribution on the head loss.

Considerable efforts were devoted to characterize Sludge $A$ and $B$, both before and after they were added to the loop and circulated through the pump propeller region. The characterization procedure involved Scanning Electron Microscopy and Sedimentation velocity analysis. Appendix B documents the sludge characterization efforts. Based on these results, it was concluded that, although Sludge A may contain larger agglomerates during dry state, they disintegrate into more representative sizes after being circulated through the loop for several minutes. The size distribution of Sludge A appears to be consistent with the specifications of Table 4-2 at the time when the fiber is added to the loop according to method $A$ of debris introduction.

\subsubsection{Paint Chips}

HDR test results demonstrate that a LOCA would produce a certain quantity of paint debris in the drywell [Ref. 4.8]. A recent BWROG study [Ref. 4.9], which examined various failure modes for epoxy coated zinc based paints found in the BWR containments, classified these paint debris as 'large sheets', 'small sheets', 'chips', and 'particles'. The chips, about 0.125 to 1.0 inch in width were judged to be most common for BWR conditions. This description qualitatively matches the paint-chips previously produced for experimentation at ARL for PP\&L tests [Ref. 4.10]. The weight range for the chips used in the PP\&L experiments was between $0.02 \mathrm{~g}$ and $0.16 \mathrm{~g}$, with an average of about $0.10 \mathrm{~g}$.

According to BWROG estimates, about $86 \mathrm{lbm}$ of such debris may be produced in the drywell. If it is assumed that all these debris would be transported ultimately to the strainer, this may introduce additional head losses. To examine the impact of these paint-chips on head loss, a mixture consisting of $10 \%$ by weight of paint-chips and $90 \%$ by weight of Sludge A, named Mix A, was used in the experiments.

\subsection{Selection of Temperature for Experimentation}

According to the reference plant's final safety analysis report, the suppression pool water temperature varies with time after a LOCA due to the combined effects of the steam dumping and heat exchanger operation. Depending on the break size and reactor power level at the time of the break, suppression pool temperatures as high as $175^{\circ} \mathrm{F}$ are possible. In view of these possible large variations in suppression pool temperatures $\left(60^{\circ}-175^{\circ} \mathrm{F}\right)$, it is essential that the effect of elevated temperatures on the head loss and debris bed buildup be well understood prior to application of the present head loss data to evaluate ECCS strainer blockage potential.

For flow through fiber beds, head loss has been known to be significantly influenced by water temperature, especially in the viscous flow regime. 
In most cases, this effect can be attributed to changes in the viscosity and density. However, it is possible that other effects of temperature may also play an important role. For example, the higher temperature may affect the fiber strength and may possibly lead to formation of more dense beds. The Vattenfall experiments have shown that in the case of mineral wool, variations in head loss caused by temperatures can be accounted for through the use of a viscosity correction factor [Ref. 4.11]. Similar understanding related to effects of temperature on the head loss is presently lacking for NUKONTM.

Three exploratory tests (E-13, E-14, and E-26) were conducted at elevated temperatures to examine the effect of temperature on the head loss. The head loss data from these experiments was plotted in Figures $4-7 \mathrm{a}$ and $4-7 \mathrm{~b}$ for the pure beds and mixed beds, respectively. As shown in these tests, elevated temperature lowers head loss in all cases. This is consistent with the trends exhibited by head loss data reported by Vattenfall for mineral wool. Although not shown here explicitly, approximate analyses have revealed that this head loss variation is attributable to changes in viscosity, i.e., changes in head loss can be accounted for by varying viscosity in Equation 2-16 as a function of temperature. This finding is further confirmed by making use of similar data obtained for pure fiber beds and mixed beds as part of the parametric tests.

Although the majority of the exploratory tests were conducted at the ambient temperature, it was decided to conduct the parametric tests at the elevated temperatures because the lower head losses corresponding to these higher temperatures allow for a larger range over which the rest of the experimental parameters can be varied.

\subsection{Selection of Loop Sludge-to- Fiber Mass Ratios}

For the reference plant, the sludge-to-fiber mass ratios can vary from 2 to 200 depending on the break size and location. Initially, this range was selected for experimentation. However, it was quickly recognized that the experimental apparatus could not sustain head losses introduced by large sludge-to-fiber mass ratios, especially for thicker beds. Typically for thick beds $\left(\Delta \mathrm{L}_{\mathrm{o}} \geq 0.5^{\prime \prime}\right)$, a maximum sludge-to-fiber mass ratio of 20 was achieved. For thinner beds, sludge-to-fiber mass ratios as high as 60 were used. 


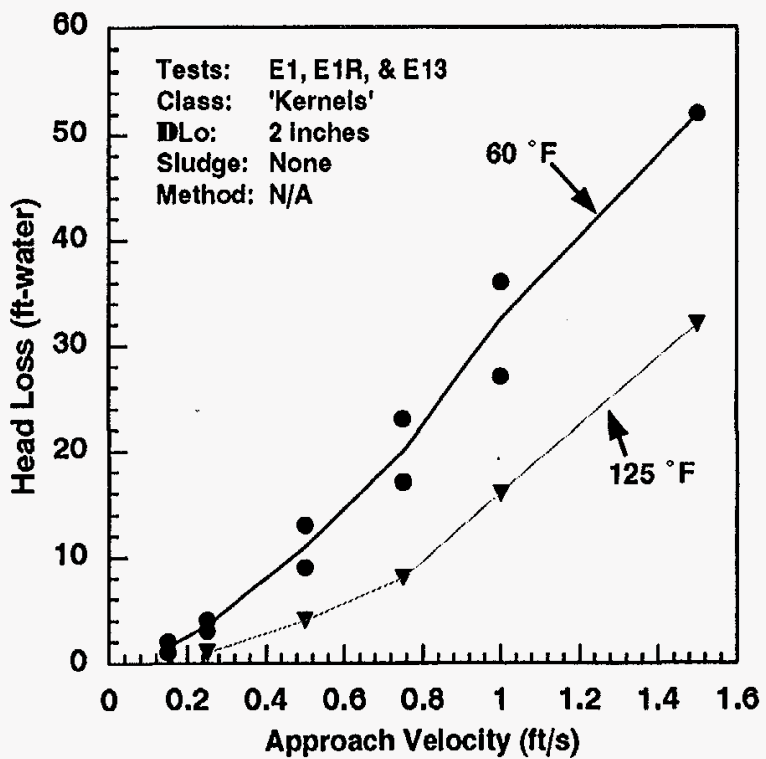

a) Pure Fiber Bed

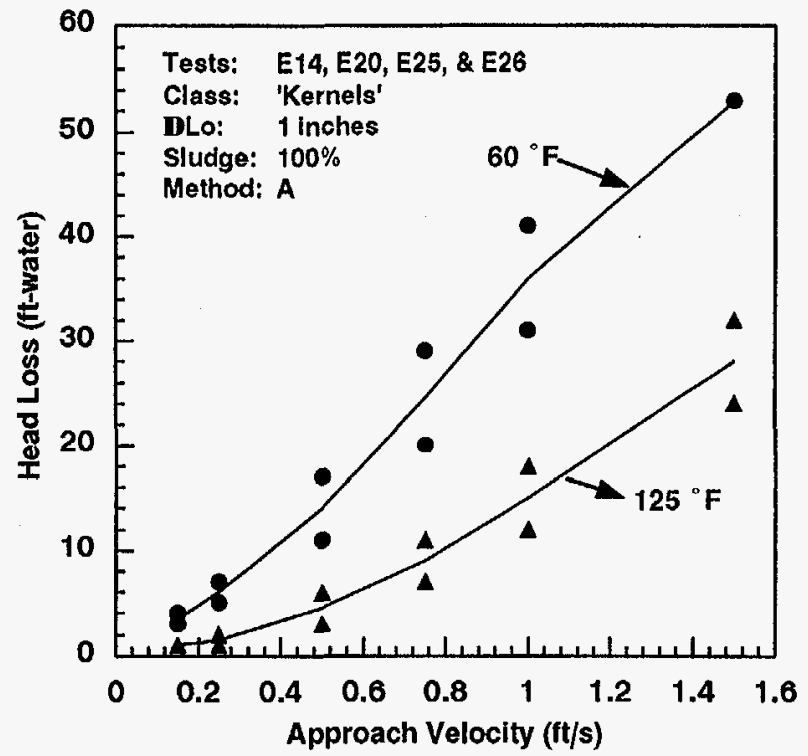

b) Fiber-Sludge Mixed Bed 


\section{References for Section 4}

4.1 D. N. Brocard, "Buoyancy, Transport, and Head Loss of Fibrous Reactor Insulation," Alden Research Laboratory, published as Sandia National Laboratories Report No. SAND82-7205, Rev, NUREG/CR-2982, Rev. 1, July 1983.

4.2 J. B. Nystrom, "NUKONTM Insulation Head Loss Tests," ARL/124-89/M670F, Alden Research Laboratories, Inc., 1989.

4.3 B. J. Pennino and G. Hecker, "Head Loss Tests with Blast-Generated NUKON ${ }^{\mathrm{TM}}$ Insulation Debris," ARL/140-93/M670F, 1993.

4.4 Ives and V. Pienvichitr, "Kinetics of filtration of dilute suspension," Chemical Engineering Science, Vol. 20, pp. 965-973, 1963.

4.5 P. Murthy, M. Padmanabhan, F.J. Weber, G.E. Hecker, "Head Loss of Fibrous Insulation Debris and Sludge for BWR Suction Strainers", Alden Research Laboratory, Inc., 1995.

4.6 T. Kegel, "Air Blast Destructive Testing of NUKON ${ }^{\mathrm{TM}}$ Insulation Simulation of a Pipe Break LOCA," Colorado Engineering Experiment Station, Inc., October 1993.
4.7 Letter from T. Green to A. Serkiz, "BWR Owners' Group ECCS Suction Strainer Committee - Suppression Pool Sludge Particle Distribution," General Electric Company, OG94-661-161, September 1994.

4.8 A.W. Serkiz, "Containment Emergency Sump Performance," U.S. Nuclear Regulatory Commission, NUREG-0897, Rev. 1, October 1985.

4.9 BWR Owners' Group, "Interim Report of the BWR Owners' Group ECCS Suction Strainer Committee," BWROG-94157, December 1994.

4.10 P. Murthy, M. Padmanabhan, and G. Hecker, "Tests of Particle Settling Velocity in Still Water," Report No. ARL/SEA/787/94/ 1, Alden Research Laboratory, Inc., Holden, MA, May 1994.

4.11 J. Wilde, "Strainer Test With Fiber Insulation and Reactor Tank Insulation, Results from Small Model", Vattenfall Development Corp., Sweden, June 1993. 


\subsection{Head Loss Test Results and Analysis}

Based on the results of the exploratory tests and other supporting analyses, a test matrix was developed for the final set of tests conducted as part of this study. The test matrix is presented in Table 5-1. The experimental procedures for the head loss tests and the test results are presented in the following sections.

\subsection{Experimental Procedures}

The experimental procedure for each step of the head loss tests are summarized below. These procedures were extracted from Reference 5.1.

\subsubsection{Procedure for Insulation Debris Generation}

As previously discussed in Section 4, a leaf shredder was used for fibrous insulation debris generation from the blankets of aged (or heat treated) insulation provided by the insulation vendor [Ref. 5.1]. The leaf shredder used for debris generation is a FLOWTROW leaf eater with setting on 5. A total of four (4) plastic strings are exposed to a length each of $3.4^{\prime \prime}$ approximately. Based on a series of exploratory tests, the following procedures were followed to generate the debris:

1. Heat treated insulation blanket is cut vertically into $6 "$ squares.

2. Two squares are processed at a time.

3. Each square is peeled into individual layers, about 10 to 12 per square.

4. All these layers are put into leaf shredder (off). Leaf shredder is covered and a bag is placed beneath. Leaf shredder is turned on and run for 60 seconds.

5. Bag beneath shredder is removed; larger pieces of insulation that remain in shredder are removed and kept separate from material that settles into bag. The material in the shredder consisted of insulation fragments ranging from individual fibers to class 6 fibers as shown in Figure 2-1. These materials were considered to represent insulation size classes
$5 \& 6$. The material collected in the bag consisted of finer debris ranging from individual fibers to small shreds (classes $3 \& 4$ of Figure 2-1). These debris are treated as insulation classes $3 \& 4$. Any 6" $\times 6$ " squares still intact (not shredded) are removed from either sample.

6. Bag is replaced beneath shredder and steps 1 through 5 are repeated until the required amount of insulation for either size class is obtained.

\subsubsection{Procedures for Debris Preparation}

In the experiments, the debris deposited on the strainer surface is quantified in terms of its theoretical (d nominal) thickness which relates to its weight as:

$$
\Delta L_{o}=\frac{W_{\text {fiber }}}{\rho_{o} A_{s}}
$$

where,

$$
\begin{aligned}
& \left.W_{\text {fiber }} \text { is insulation mass ( } \mathrm{g} \text { or } \mathrm{lbm}\right) \\
& \rho_{0} \quad \begin{array}{l}
\text { is theoretical or nominal NUKONTM } \\
\text { density }\left(2.4 \mathrm{lbm} / \mathrm{ft}^{3} \text { or } 0.039 \mathrm{~g} / \mathrm{cc}\right)
\end{array} \\
& \begin{array}{ll}
\mathrm{A}_{\mathrm{s}} \quad \text { is strainer surface area }\left(0.869 \mathrm{ft}^{2} \text { or } 807.7\right. \\
\left.\mathrm{cm}^{2}\right)
\end{array} \\
& \Delta \mathrm{L}_{\mathrm{o}} \quad \text { is bed theoretical thickness. }
\end{aligned}
$$

After numerical substitutions, this equation can be re-written as:

$$
W_{\text {fiber }(s)}=\Delta L_{o}(\text { inch }) \cdot(71.2)
$$

The required amount of fiber was measured using an OHAUS CT6000 Class A Digital scale, with a capacity of $6000 \mathrm{~g}$ and a resolution of $1 \mathrm{~g}$. A container of $200 \mathrm{~g}$ is placed on the scale and the scale is zeroed. After that, shredded NUKONTM is added to the container until desired weight is reached. The NUKONTM debris is then transferred to a container filled with water and thoroughly mixed to completely soak the insulation and remove air bubbles trapped in the shreds. 
Head Loss Test Results and Analysis

Table 5-1. Parametric Test Matrix

\begin{tabular}{|c|c|c|c|c|c|c|c|}
\hline Test & $\begin{array}{l}\text { Nominal Fibrous } \\
\text { Thickness } \\
\text { inch }\end{array}$ & $\begin{array}{l}\text { Insulation } \\
\text { Class }\end{array}$ & $\begin{array}{l}\text { Sludge/ } \\
\text { Insulation } \\
\text { Ratio (\%) }\end{array}$ & $\begin{array}{c}\text { Insulation } \\
\text { Added @ } \\
\text { Velocity } \\
\mathrm{ft} / \mathrm{s}\end{array}$ & $\begin{array}{l}\text { Water } \\
\text { Temp. } \\
\text { omp }\end{array}$ & $\begin{array}{c}\text { Particulate } \\
\text { Type }\end{array}$ & Remarks \\
\hline PO1 & $T$ & $3 \& 4$ & $\sigma$ & 0.15 & 125 & $\mathrm{~N} / \mathrm{A}$ & Head Loss Test \\
\hline P02 & 1 & $5 \& 6$ & 0 & 0.15 & 125 & N/A & Head Loss Test \\
\hline P03 & 2 & $5 \& 6$ & 0 & 0.15 & 125 & $N / A$ & Head Loss Test \\
\hline P04 & 4 & $3 \& 4$ & 0 & 0.15 & 125 & N/A & Head Loss Test \\
\hline P05 & 2 & $5 \& 6$ & 0 & 0.15 & 50 & $\mathrm{~N} / \mathrm{A}$ & Head Loss Test \\
\hline P06 & 1 & $5 \& 6$ & 100 & 0.15 & 125 & Sludge A & Head Loss Test \\
\hline P07 & 2 & $3 \& 4$ & 100 & 0.15 & 125 & Sludge A & Head Loss Test \\
\hline P08 & 2 & $5 \& 6$ & 100 & 0.15 & 125 & Sludge A & Head Loss Test \\
\hline P09 & 0.5 & $3 \& 4$ & 100 & 0.15 & 125 & Sludge A & Head Loss Test \\
\hline P10 & 0.5 & $3 \& 4$ & 250 & 0.15 & 125 & Sludge A & Head Loss Test \\
\hline P11 & 0.5 & $3 \& 4$ & 500 & 0.15 & 125 & Sludge A & Head Loss Test \\
\hline P12 & 1 & $3 \& 4$ & 50 & 0.15 & 125 & Sludge A & Head Loss Test \\
\hline P13 & 1 & $3 \& 4$ & 250 & 0.15 & 125 & Sludge A & Head Loss Test \\
\hline P14 & 1 & $38 \div 4$ & 500 & 0.15 & 125 & Sludge A & Head Loss Test \\
\hline P15 & 1 & $3 \& 4$ & 1000 & 0.15 & 125 & Sludge A & Head Loss Test \\
\hline P16 & 2 & $3 \& 4$ & 50 & 0.15 & 125 & Sludge A & Head Loss Test \\
\hline P17 & 4 & $3 \& 4$ & 50 & 0.15 & 125 & Sludge A & Head Loss Test \\
\hline P18 & 4 & $3 \& 4$ & 100 & 0.15 & 125 & Sludge A & Head Loss Test \\
\hline P19 & 2 & $3 \& 4$ & 50 & 0.15 & 50 & Sludge A & Head Loss Test \\
\hline P20 & 1 & $3 \& 4$ & 100 & 0.15 & 125 & Sludge B & Head Loss Test \\
\hline P21 & 2 & $3 \& 4$ & 100 & 0.15 & 125 & Sludge B & Head Loss Test \\
\hline $\mathrm{P} 22$ & 1 & $3 \& 4$ & 100 & 0.15 & 125 & Mix A & Head Loss Test \\
\hline $\mathrm{P} 23$ & 2 & $3 \& 4$ & 100 & 0.15 & 125 & Mix A & Head Loss Test \\
\hline P24 & 1 & $3 \& 4$ & 100 & 0.15 & 125 & Sludge A & Filtration Test \\
\hline P25 & 1 & $3 \& 4$ & 100 & 0.25 & 125 & Sludge A & Filtration Test \\
\hline P26 & 1 & $3 \& 4$ & 100 & 0.5 & 125 & Sludge A & Filtration Test \\
\hline P27 & 0.5 & $3 \& 4$ & 100 & 0.15 & 125 & Sludge A & Filtration Test \\
\hline P28 & 0.5 & $3 \& 4$ & 100 & 0.25 & 125 & Sludge A & Filtration Test \\
\hline P29 & 0.5 & $3 \& 4$ & 100 & 0.5 & 125 & Sludge A & Filtration Test \\
\hline P30 & 0.25 & $3 \& 4$ & 100 & 0.15 & 125 & Sludge A & Filtration Test \\
\hline P31 & 0.25 & $3 \& 4$ & 100 & 0.25 & 125 & Sludge A & Filtration Test \\
\hline P32 & 0.25 & $3 \& 4$ & 100 & 0.5 & 125 & Sludge A & Filtration Test \\
\hline P33 & 0.5 & $3 \& 4$ & 1000 & 0.15 & 125 & Sludge A & Head Loss Test \\
\hline P38 & 1 & $3 \& 4$ & 750 & 0.15 & 125 & Sludge A & Head Loss Test \\
\hline P40 & 0.5 & $3 \& 4$ & 0 & 0.15 & 125 & Sludge A & Low Debris Thickness \\
\hline P41 & 0.25 & $3 \& 4$ & 0 & 0.15 & 125 & Sludge A & Low Debris Thickness \\
\hline P42 & 0.125 & $3 \& 4$ & 0 & 0.15 & 125 & Sludge A & Low Debris Thickness \\
\hline P43 & 0.5 & $3 \& 4$ & 2000 & 0.15 & 125 & Sludge A & with High Sludge Ratios \\
\hline P44 & 0.25 & $3 \& 4$ & 500 & 0.15 & 125 & Sludge A & with High Sludge Ratios \\
\hline P45 & 0.25 & $3 \& 4$ & 1000 & 0.15 & 125 & Sludge A & with High Sludge Ratios \\
\hline P46 & 0.25 & $3 \& 4$ & 2000 & 0.15 & 125 & Sludge A & with High Sludge Ratios \\
\hline P47 & 0.25 & $3 \& 4$ & 3000 & 0.15 & 125 & Sludge A & with High Sludge Ratios \\
\hline P48 & 0.25 & $3 \& 4$ & 5000 & 0.15 & 125 & Sludge A & with High Sludge Ratios \\
\hline P49 & 0.125 & $3 \& 4$ & 1000 & 0.15 & 125 & Sludge A & with High Sludge Ratios \\
\hline P50 & 0.125 & $3 \& 4$ & 2000 & 0.15 & 125 & Sludge A & with High Sludge Ratios \\
\hline P51 & 0.125 & $3 \& 4$ & 3000 & 0.15 & 125 & Sludge A & with High Sludge Ratios \\
\hline P52 & 0.125 & $3 \& 4$ & 4000 & 0.15 & 125 & Sludge A & with High Sludge Ratios \\
\hline P53 & 0.125 & $3 \& 4$ & 6000 & 0.15 & 125 & Sludge A & with High Sludge Ratios \\
\hline P34 & 1 & $3 \& 4$ & 1000 & 0.15 & 125 & Sludge A & Repeat of P15 \\
\hline P35 & 2 & $3 \& 4$ & 100 & 0.15 & 125 & Sludge A & Repeat of P07 \\
\hline P36 & 2 & $3 \& 4$ & 100 & 0.15 & 125 & Sludge B & Repeat of P21 \\
\hline P37 & 0.5 & $3 \& 4$ & 100 & 0.15 & 125 & Sludge A & Repeat of P09 \\
\hline
\end{tabular}


The sludge added to the loop is quantified in terms of sludge-to-fiber mass ratio, $\eta$. The quantity of sludge is determined as:

$$
W_{\text {sludge }}=\eta \cdot W_{\text {fiber }}
$$

The required quantity of sludge was measured using an OHAUS CT6000 Class A Digital scale used also for fiber weight measurement. A container (15 $\mathrm{g}$ approximate weight) is placed on the scale and zeroed. Iron-oxide \#2008 is then added until desired weight is obtained ( $95 \%$ of final sludge weight). Iron-oxide $\# 9101-N$ ( $5 \%$ of final sludge weight) is then added to same container.

\subsubsection{Procedure for Head Loss Testing}

Procedures followed for head loss testing are described below step-by-step:

1. Loop is filled with fresh water and all manometer tubing and DP cells are bled.

2. The computer data acquisition and control program is started, which is used to monitor differential pressure (DP) cell output and also to maintain required approach velocities.

3. DP cells are checked by setting a static deflection between $0-3 \mathrm{ft}$ and verifying that the computer reads same pressure head.

4. $\quad$ Set pump to obtain approach velocity of about $1.5 \mathrm{ft} / \mathrm{s}$ and turn on heating tapes. Monitor water temperature until it reaches $120-125^{\circ} \mathrm{F}$.

5. Lower the water level in the 12 "downcomer to just above the tee junction with 4 " pipe, by draining water through a drain port at the top.

6. $\quad$ Sludge sample is then added within 1 minute (see Procedure $\mathrm{C}$ for weighing sludge

\footnotetext{
${ }^{7}$ Several experiments were carried out at lower temperatures. In such cases, heating tapes were not needed.

${ }^{8}$ This step is skipped in the case when no sludge is to be added to the loop.
}

samples), and allowed to circulate for about 1 minute.

7. Approach velocity is set to $0.15 \mathrm{ft} / \mathrm{s}$.

8. Pre-soaked insulation debris (see Procedure D for generating insulation debris) is then added within 5 seconds, the 12" downcomer filled to the top making sure that no insulation is caught in the top region, loop is sealed (top access over closed), and the stand pipe valve opened.

9. Flow loop is run at $0.15 \mathrm{ft} / \mathrm{s}$ until stable head loss is obtained. Four water samples (about 1 liter each) are taken ( 2 top and 2 bottom) and the flow is increased. This process is repeated through $1.5 \mathrm{ft} / \mathrm{s}$ (unless head loss exceeds $50 \mathrm{ft}$ at lower velocity), noting stable head loss at $0.25,0.5,0.75,1.0$, and $1.5 \mathrm{ft} / \mathrm{s}$.

10. After attaining the maximum velocity, the flow is lowered in steps to note the head losses at $1.0,0.75,0.5,0.25$, and $0.15 \mathrm{ft} / \mathrm{s}$.

11. Pump is then shut off and computer readout of DP cells are checked again against a known static deflection.

12. Model is then drained and the "cake" removed from the strainer plate and placed in an oven (set at $250^{\circ} \mathrm{F}$ ) for approximately two days.

13. The dried cake is weighed as a rough check for sludge mass balance.

14. The loop is cleaned thoroughly by flushing with fresh water repeatedly and made ready for next test.

\subsubsection{Procedure for Analyzing Water Samples}

The water samples drawn from the loop in step 9 of the above procedures for head loss testing were analyzed to estimate the concentration of the sludge in the water.

1. A clean and dry $0.45 \mu \mathrm{m}$ paper filter is weighed. 
2. Filter is then placed in glass filter system consisting of Schleicher and Schnell glass filter holder BGHT.

3. Water sample is added to filter system and a vacuum is applied to drain the water sample through the filter.

4. Volume of water sample that passed through the filter paper is noted using the graduations on the receiving flask.

5. Filter with strained particulates is removed, labeled and placed on a tray to air dry for one day.

6. Once dry, filter with sludge is weighed and difference from the clean dry filter noted as weight of sludge. The scale employed is A\&D Electronic Balance, model ER182A, with a rated capacity of $180 \mathrm{~g}$ and resolution of 0.1 g.

7. Measured concentration is weight of sludge divided by weight of water sample.

8. A correction is applied to the measured concentration based on calibration of the filter system. The correction equation used was developed based on ARL bench tests and is displayed in Figure 2-3.

\subsection{Test Results}

The head loss data were obtained for theoretical bed thicknesses in the range of $0.125^{\prime \prime}$ to $4.0^{\prime \prime}(0.32$ to $10.2 \mathrm{~cm}$ ); approach velocities in the range of 0.15 to $1.5 \mathrm{ft} / \mathrm{s}(0.05$ to $0.5 \mathrm{~m} / \mathrm{s})$; at temperatures of $75^{\circ} \mathrm{F}$ $\left(24^{\circ} \mathrm{C}\right)$ and $125^{\circ} \mathrm{F}\left(52^{\circ} \mathrm{C}\right)$; and for sludge-to-fiber mass ratios in the range of 0 to 60 (or $0 \%$ to $6000 \%$ ). The transient head loss curves for each of the tests were analyzed to obtain the stable head loss corresponding to each combination of the experimental parameters (nominal thickness, insulation class, sludge-to-fiber ratio added to the loop and water temperature). These stable head losses are presented in Tables 5-2 and 5-3 for pure NUKONTM fiber beds and mixed beds formed of NUKONTM and sludge. As indicated in Table 5-3, only a fraction of the sludge is filtered by the bed where as the remaining fraction continues to be suspended in the loop coater. The quantity of sludge trapped on the fiber bed when the stable head loss was attained was estimated from concentration measurements described in Section 5.1.4 as follows:

$$
M_{\text {filtered }}=M_{\text {added }}-C_{\text {sludge }} \cdot V_{\text {loop }}
$$

where,

$$
\begin{aligned}
\mathrm{M}_{\text {filtered }}= & \begin{array}{l}
\text { Mass of sludge trapped on the cake } \\
\text { where the stable head losses were } \\
\text { measured }(\mathrm{g})
\end{array} \\
\mathrm{M}_{\text {added }}= & \begin{array}{l}
\text { Mass of sludge added to the loop as } \\
\text { described in Section } 5.1 .2
\end{array} \\
\mathrm{C}_{\text {sludge }}= & \begin{array}{l}
\text { Concentration of sludge in the loop } \\
\text { water where the stable head losses were }
\end{array} \\
& \text { measured }(\mathrm{g} / \mathrm{l})
\end{aligned}
$$

\subsubsection{Pure Fiber Beds}

Figure 5-1 presents typical transient head loss traces for a pure fiber bed of theoretical thickness of $4^{\prime \prime}$ $(10 \mathrm{~cm})$ at a water temperature of $125^{\circ} \mathrm{F}\left(52^{\circ} \mathrm{C}\right)$. As shown in this figure, at the initial approach velocity where the debris bed was formed, the head loss climbed gradually to a steady value. During the tests, it could be seen that the fibrous bed built up gradually as the flocks of insulation were brought to the strainer by the flow. Once all the debris reached the strainer and the bed underwent compression, the head loss attained a stable value. This stable value was recorded and then the flow was increased in steps until a maximum of $1.5 \mathrm{ft} / \mathrm{s}(0.5 \mathrm{~m} / \mathrm{s})$ was reached or until the resultant head loss challenged the structural integrity of the test loop. As the flow was ramped up in steps, the head loss followed it closely increasing with velocity. At each velocity, the head loss was allowed to reach a stable value which was recorded.

Table 5-2 presents the measured stable head loss data for pure fiber beds. To characterize the bed and gain insights into the bed microscopic internal structure, portions of the fiber bed were magnified under a scanning electron microscope (see Figure 5-2). As illustrated in this figure, the beds are formed of randomly arranged fibers almost always perpendicular to the flow direction. This behavior suggests that the original shreds contain loosely 


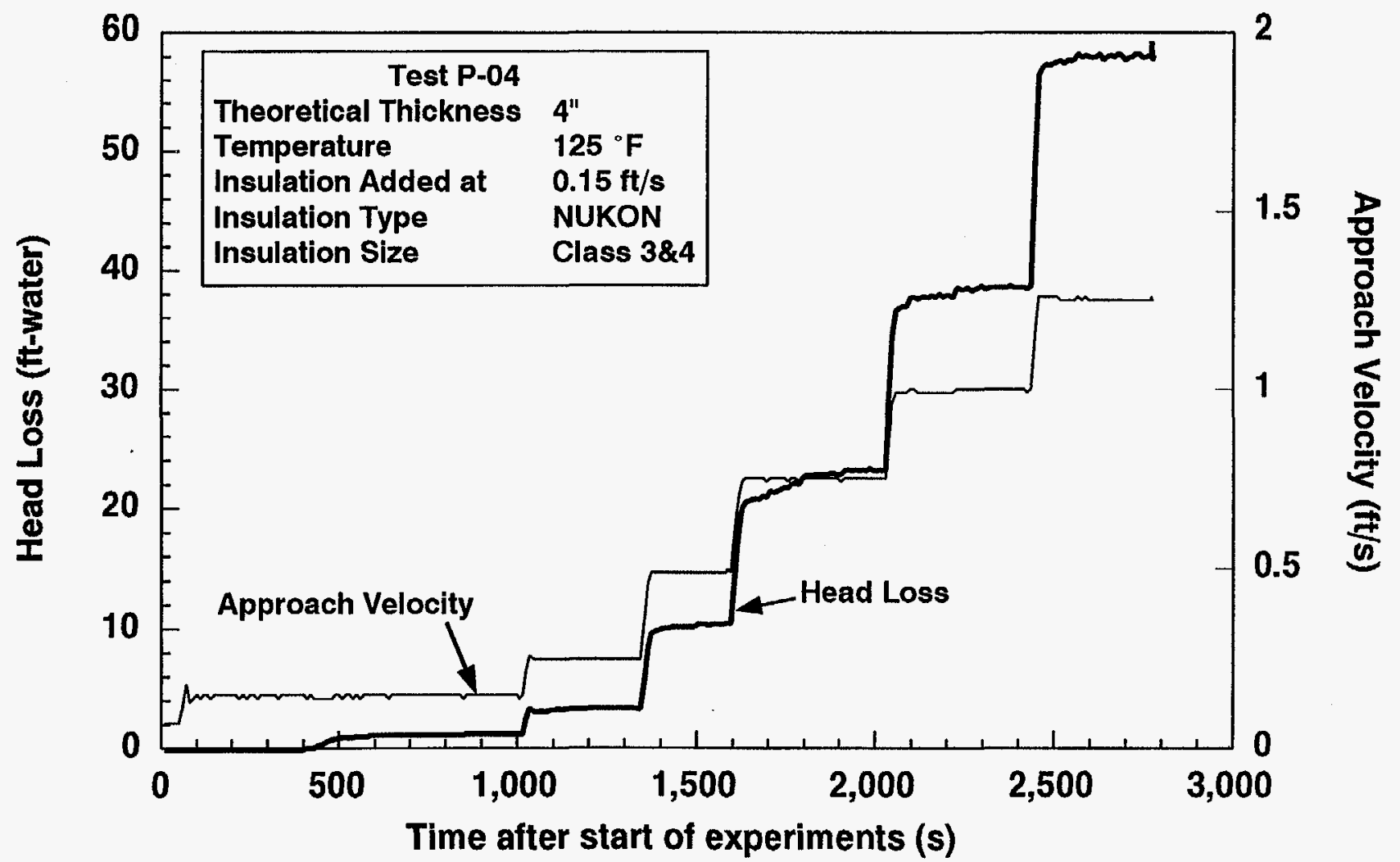


Head Loss Test Results and Analysis
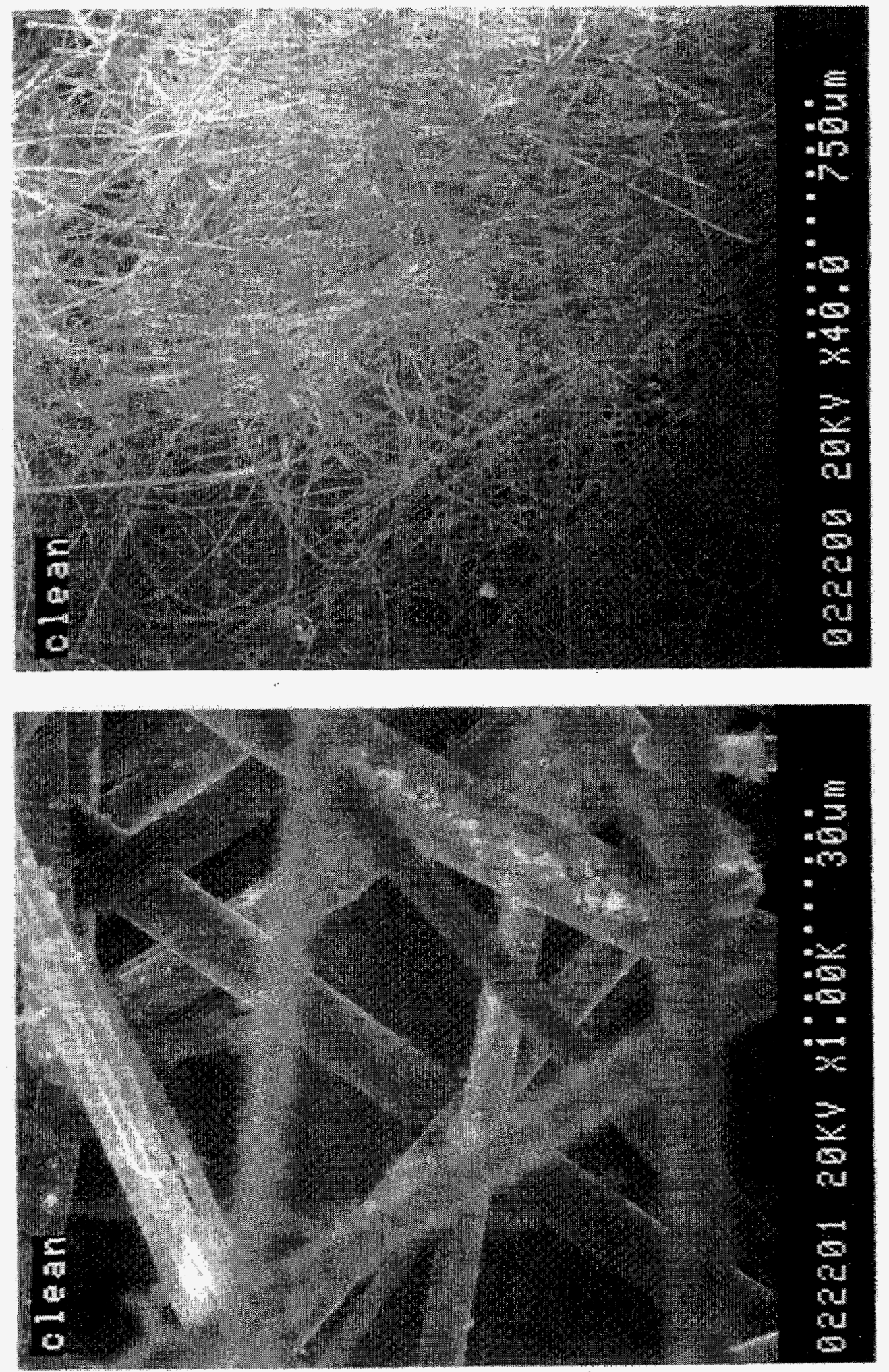
Table 5-2. Experimental Head Loss Data for Pure NUKON'M Fiber Beds

\begin{tabular}{|c|c|c|c|}
\hline \multirow{2}{*}{$\begin{array}{c}V_{\text {approach }} \\
\text { ft/s }\end{array}$} & \multicolumn{3}{|c|}{ ARL Data for $\Delta H_{\text {Loss }}$} \\
\hline & ft-wate & ft-water & ft-water \\
\hline \multicolumn{4}{|c|}{ P01 \& P02: 1" Theo. Thick; No Sludge; $125^{\circ} \mathrm{F}$} \\
\hline & P01 & $\mathrm{P} 02$ & Average \\
\hline 0.15 & 0.5 & 0.5 & 0.5 \\
\hline 0.25 & 1.0 & 1.0 & 1.0 \\
\hline 0.50 & 2.0 & 3.0 & 2.5 \\
\hline 0.75 & 4.0 & 7.0 & 5.5 \\
\hline 1.00 & 8.0 & 10.0 & 9.0 \\
\hline 1.50 & 14.0 & 19.0 & 16.5 \\
\hline \multirow{2}{*}{\multicolumn{4}{|c|}{ P05 \& E32: 2" Theo. Thick.; No Sludge; ${ }_{\text {E32 }} 50^{\circ} \mathrm{F}$}} \\
\hline & & & Average \\
\hline 0.15 & 2.0 & 1.3 & $1.7^{\circ}$ \\
\hline 0.25 & 4.0 & 3.0 & 3.5 \\
\hline 0.50 & 12.0 & 8.0 & 10.0 \\
\hline 0.75 & 25.0 & 16.0 & 20.5 \\
\hline 1.00 & 38.0 & 25.0 & 31.5 \\
\hline 1.50 & 57.0 & 47.0 & 52.0 \\
\hline \multirow{2}{*}{\multicolumn{4}{|c|}{ P03: $2^{\prime \prime}$ Theo. Thick.; No Sludge; $125^{\circ} \mathrm{F}$}} \\
\hline & & & Average \\
\hline 0.15 & 1.0 & & 1.0 \\
\hline 0.25 & 2.0 & & 2.0 \\
\hline 0.50 & 5.0 & & 5.0 \\
\hline 0.75 & 10.0 & & 10.0 \\
\hline 1.00 & 16.0 & & 16.0 \\
\hline 1.26 & 26.0 & & 25.0 \\
\hline 1.50 & 36.0 & & 36.0 \\
\hline \multirow{2}{*}{\multicolumn{4}{|c|}{ P04: 4" Theo. Thick.; No Sludge; $125^{\circ} \mathrm{F}$}} \\
\hline & & & \\
\hline 0.15 & 2.0 & & 2.0 \\
\hline 0.25 & 4.0 & & 4.0 \\
\hline 0.50 & 10.0 & & 10.0 \\
\hline 0.75 & 24.0 & & 24.0 \\
\hline 1.00 & 38.0 & & 38.0 \\
\hline 1.25 & 57.0 & & 57.0 \\
\hline \multirow{2}{*}{\multicolumn{4}{|c|}{ P40: $0.50^{\prime \prime}$ Theo. Thick.; No Sludge; $125^{\circ} \mathrm{F}$}} \\
\hline & & & $\begin{array}{c}\text { Average } \\
0.2\end{array}$ \\
\hline $\begin{array}{l}0.15 \\
0.25\end{array}$ & $\begin{array}{l}0.2 \\
0.3\end{array}$ & & 0.3 \\
\hline 0.50 & 0.9 & & 0.9 \\
\hline 0.75 & 1.7 & & 1.7 \\
\hline 1.00 & 3.0 & & 3.0 \\
\hline 1.50 & 6.2 & & 6.2 \\
\hline \multicolumn{4}{|c|}{ P42: $0.125^{\prime \prime}$ Theo. Thick.; No Sludge; $125^{\circ} \mathrm{F}$} \\
\hline 0.15 & 0.1 & & 0.1 \\
\hline 0.25 & 0.1 & & 0.1 \\
\hline 0.50 & 0.3 & & 0.3 \\
\hline 0.75 & 0.5 & & 0.5 \\
\hline 1.00 & 1.0 & & 1.0 \\
\hline 1.50 & 1.5 & & 1.5 \\
\hline
\end{tabular}


Table 5-3. Experimental Head Loss Data for NUKON ${ }^{\mathrm{TM}}$ Based Mixed Beds

\begin{tabular}{|c|c|c|c|c|c|c|c|c|c|}
\hline \multirow{2}{*}{ Test } & \multirow{2}{*}{$\begin{array}{c}\text { Nominal } \\
\text { Thickness } \\
\text { (inches) }\end{array}$} & \multicolumn{2}{|c|}{$\begin{array}{l}\text { Sludge to Fiber } \\
\text { Ratio }\end{array}$} & \multicolumn{6}{|c|}{ Head Loss (ft-water) } \\
\hline & & $\begin{array}{l}\text { Added } \\
(\%)\end{array}$ & $\begin{array}{c}\text { Filtered } \\
(\%)\end{array}$ & $\begin{array}{c}@ \\
0.15 \mathrm{ft} / \mathrm{s}\end{array}$ & $\begin{array}{c}@ \\
0.25 \mathrm{ft} / \mathrm{s}\end{array}$ & $\begin{array}{c}@ \\
0.50 \mathrm{ft} / \mathrm{s}\end{array}$ & $\begin{array}{c}@ \\
0.75 \mathrm{ft} / \mathrm{s}\end{array}$ & $\begin{array}{c}@ \\
1.00 \mathrm{ft} / \mathrm{s}\end{array}$ & $\stackrel{@}{1.50 \mathrm{ft} / \mathrm{s}}$ \\
\hline P07 & 2 & 100 & 84 & $T$ & 2 & 6 & 13 & 21 & $34(@ 1.25 \mathrm{ft} / \mathrm{s})$ \\
\hline P08 & 2 & 100 & 95 & 1 & 2 & 7 & 17 & 34 & $52(@ 1.25 \mathrm{ft} / \mathrm{s})$ \\
\hline P16 & 2 & 50 & 45 & 1 & 2 & 7 & 15 & 29 & 48 \\
\hline P19 & 2 & 50 & 35 & - & 2 & 5 & 15 & 30 & 46 \\
\hline $\mathrm{P} 12$ & 1 & 50 & 30 & - & 1 & 2 & 4 & 7 & 16 \\
\hline E34 & 1 & 100 & 83 & - & 1 & 4 & 8 & 13 & 25 \\
\hline P24 & 1 & 100 & 83 & - & 1 & 3 & 6 & 10 & 23 \\
\hline P26 & 1 & 100 & 83 & - & - & 3 & 6 & 12 & 22 \\
\hline P13 & 1 & 250 & 205 & - & 6 & 12 & 21 & 26 & 39 \\
\hline P14 & 1 & 500 & 383 & 4 & 12 & 31 & 51 & -- & -- \\
\hline P15 & 1 & 1000 & 843 & 53 & -. & -- & -- & - & -. \\
\hline $\mathrm{P} 09$ & 0.5 & 100 & 66 & -- & 0.7 & 1.5 & 3 & 5 & 9 \\
\hline P27 & 0.5 & 100 & 66 & -- & - & 1 & 2.5 & 4.5 & 10.3 \\
\hline P28 & 0.5 & 100 & 66 & -- & -- & 1.3 & 2.6 & 4.4 & 9.1 \\
\hline P29 & 0.5 & 100 & 66 & -- & -- & 1.5 & 3 & 5 & 11.7 \\
\hline P10 & 0.5 & 250 & 159 & -- & 1 & 2 & 5 & 9 & 19 \\
\hline P11 & 0.5 & 500 & 330 & 1 & 3 & 14 & 32 & 37 & -- \\
\hline P33R & 0.5 & 1000 & 1000 & 5 & 15 & 34 & 43 & -- & -- \\
\hline P43 & 0.5 & 2000 & 1274 & 10 & 18 & 50 & -- & -- & -- \\
\hline P44 & 0.25 & 500 & 292 & - & 2 & 5 & 8 & 12 & 16 \\
\hline P45 & 0.25 & 1000 & 622 & - & 4 & 6 & 10 & 13 & 18 \\
\hline P46 & 0.25 & 2000 & 1333 & - & 2 & 4 & 6 & 8 & 14 \\
\hline P47 & 0.25 & 3000 & 1697 & 3 & 4 & 6 & 10 & 16 & 24 \\
\hline P48 & 0.25 & 5000 & 2651 & 8 & 10 & 22 & 30 & 34 & 40 \\
\hline
\end{tabular}


attached fibers that are easily detached under the influence of head loss. This may explain why beds formed of classes $3 \& 4$ and classes $5 \& 6$ behave alike.

Within the range tested, the size class of the insulation debris shreds (i.e., $3 \& 4$ versus $5 \& 6$ ) has no significant effect on head loss. In all cases, head loss increased with both the bed thickness and the approach velocity. The data shows that head loss versus bed thickness is fairly linear, whereas headloss versus velocity is non-linear. This trend is shown in Figure 5-3. Note that experimental data collected for different theoretical thicknesses collapsed into a single line when plotted; this confirms the linearity of head loss with respect to fiber bed thickness. Any scatter that exists is within the randomness of the data. The data confirms that the water temperature has an important effect on head loss; the higher water temperature resulted in lower head loss for the same approach velocity.

\subsubsection{Mixed Beds}

Figures 5-4 and 5-5 are the transient head loss traces for the mixed beds of different sludge-to-fiber mass ratios. In both cases, the bed theoretical thickness is $0.25^{\prime \prime}(0.6 \mathrm{~cm})$, the operating temperature is $125^{\circ} \mathrm{F}$ $\left(52^{\circ} \mathrm{C}\right)$, and the same procedure was followed for debris introduction. In both cases, the resultant head losses are significantly larger than those corresponding to the pure fiber bed condition. However, the transient head loss behavior in these two cases is different, leading to the following conclusions:

1. At low head losses, the debris beds are fairly uniform and can be described as mixed beds where the sludge particles are intermixed with the fibers. Figure 5-6 presents a photograph of the mixed bed typically observed at low sludge-to-fiber mass ratios and/or low approach velocities, characterized by low compacting pressures. Such beds behaved very similarly to pure fiber beds in that head loss increased significantly for each corresponding increase in velocity. Additionally, the beds exhibited a certain amount of hysteresis effects similar to pure fiber beds. Visual observation of these beds suggests that they remained fairly uniform throughout the experiment. These beds are referred to as undamaged mixed beds hereafter. Portions of these beds were magnified under SEM to study the bed morphology (see Figure 5-7).

2. Large head losses across the beds can damage the debris bed by punching holes through the bed. A photograph of a typical damaged bed is presented in Figure 5-8. As shown, the damaged beds resemble a partially plugged strainer, and usually result in lower head losses. In Figure 5-5, such a transition occurred as the flow velocity was increased from $0.15 \mathrm{ft} / \mathrm{s}(0.05 \mathrm{~m} / \mathrm{s})$ to $0.25 \mathrm{ft} / \mathrm{s}(0.08$ $\mathrm{m} / \mathrm{s}$ ). This increase was instantaneously followed by an increase in head loss. Apparently the bed structure was unable to support such high losses, leading to the damage illustrated in Figure 5-8. As a result, the head losses decreased with time, ultimately reaching a much lower steady state value. This behavior occurred at each increasing velocity. Further increase in velocity appears to have little effect on the head loss. For example, in Figure 5-5 increasing velocity from $1 \mathrm{ft} / \mathrm{s}$ to $1.5 \mathrm{ft} / \mathrm{s}(0.3$ $\mathrm{m} / \mathrm{s}$ to $0.5 \mathrm{~m} / \mathrm{s}$ ) resulted in no notable increase in head loss.

The stable head loss data obtained from the experiments, including that for damaged beds, are listed in Table 5-3 for mixed beds of different fiber thicknesses and sludge-to-fiber mass ratios. Within the range of mixed beds tested, neither the insulation debris classes nor the sludge particle size appears to have significant effect on the head loss. In all cases, the head loss increased fairly linearly with respect to the fiber bed thickness. However, head loss strongly varied with approach velocity and sludge-to-fiber mass ratio. To illustrate head loss dependence on sludge-to-fiber mass ratio, Figure 5-9 plots the head loss for the mixed beds as a function of sludge-to-fiber mass ratio in the fiber bed for three flow velocities $(0.15,0.75$ and $1.5 \mathrm{ft} / \mathrm{s}$ or $0.05,0.23$ and $0.5 \mathrm{~m} / \mathrm{s}$ ) and different thicknesses.

\subsection{Measurement Uncertainties and Repeatability}

The measurement uncertainties in the flow, head loss and temperature were very small $(<5 \%)$. On the other hand, the uncertainties in concentration could be as high as $15 \%$ if a single sample was used (see Section 2.3.4). Considering that multiple 


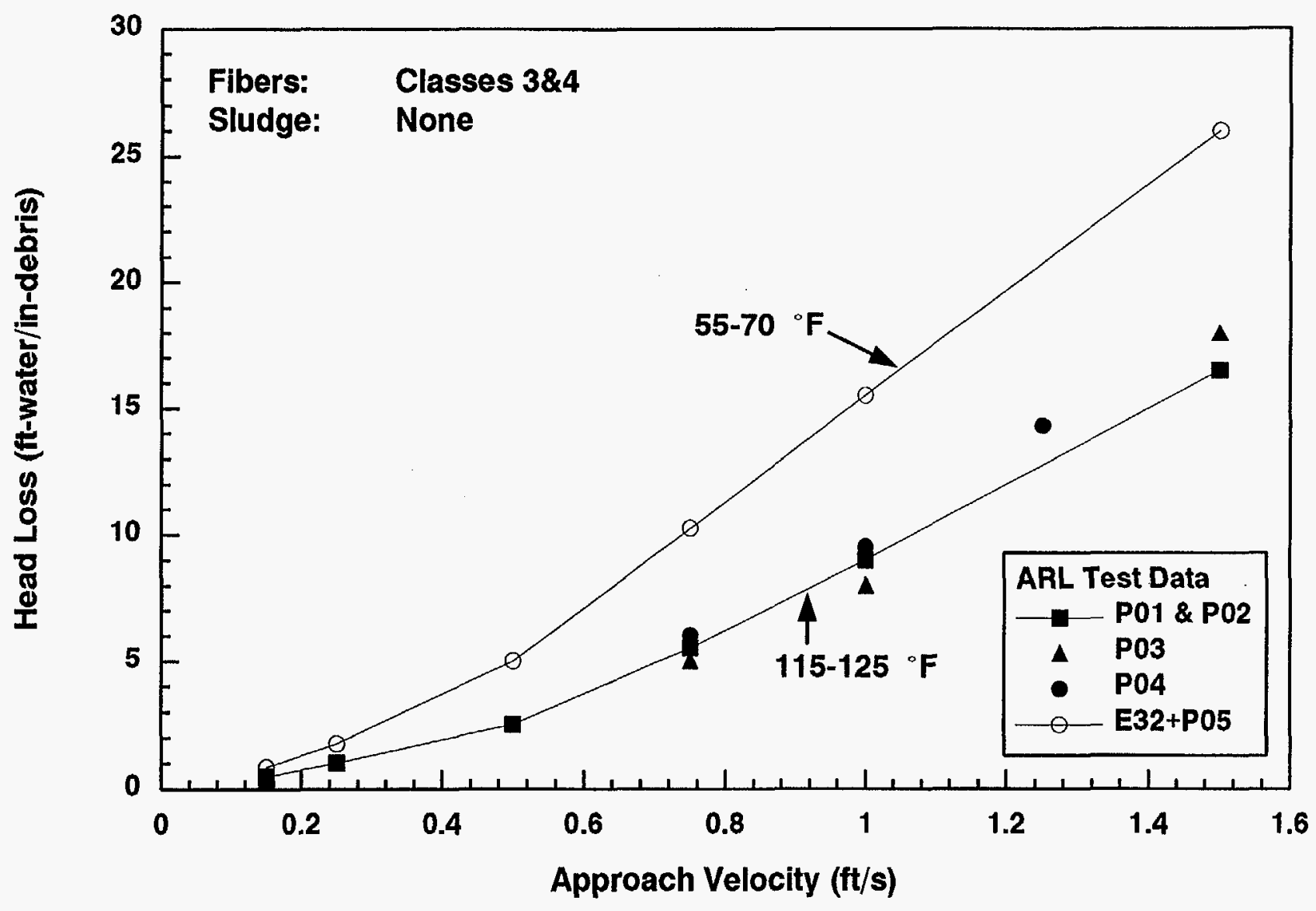

Figure 5-3. Experimental Data for Pure Fiber Beds Generated from ARL Tests 
Head Loss Test Results and Analysis

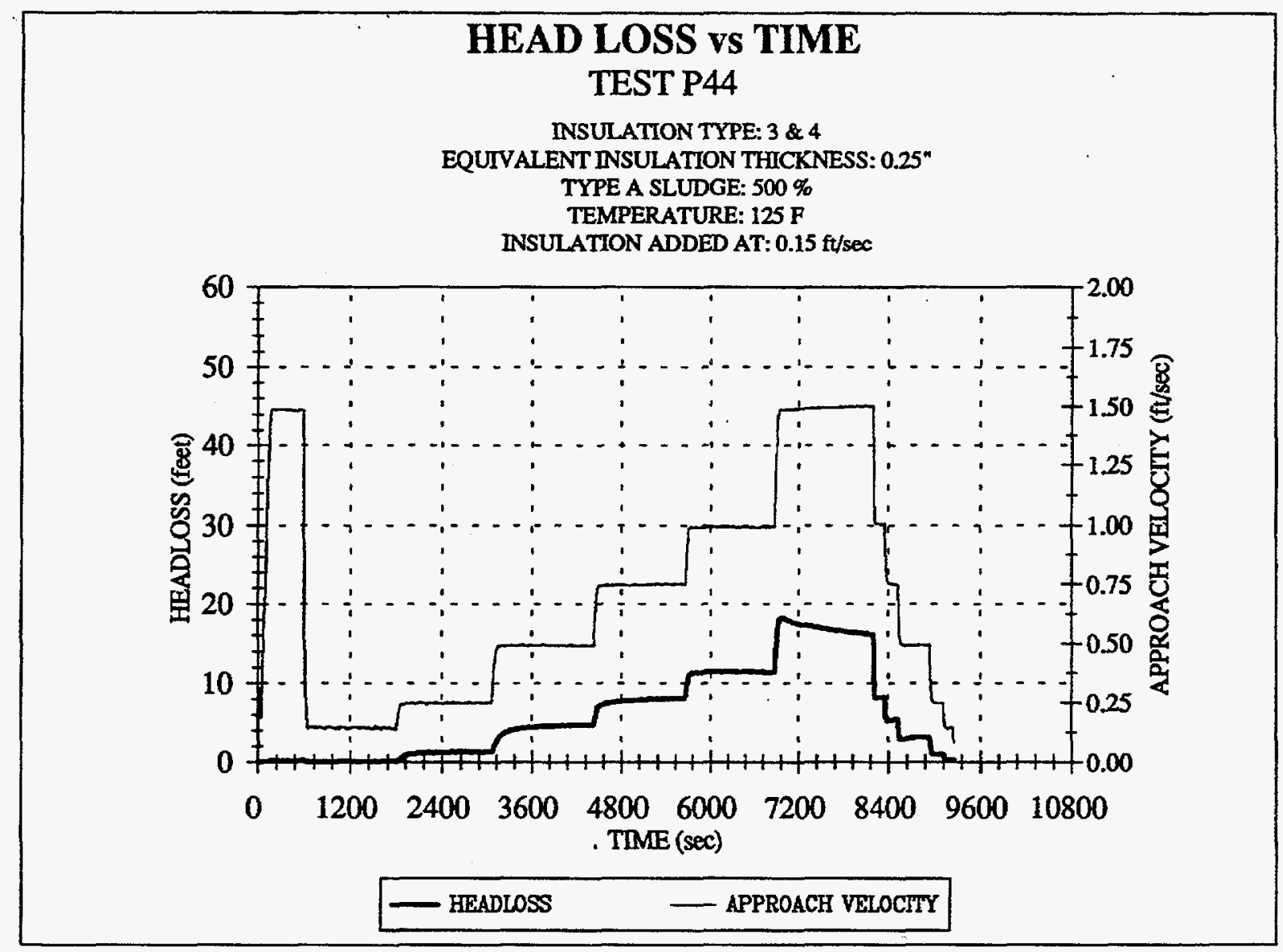

Figure 5-4. Head Loss vs. Time (Type A Sludge 500\%) 
Head Loss Test Results and Analysis

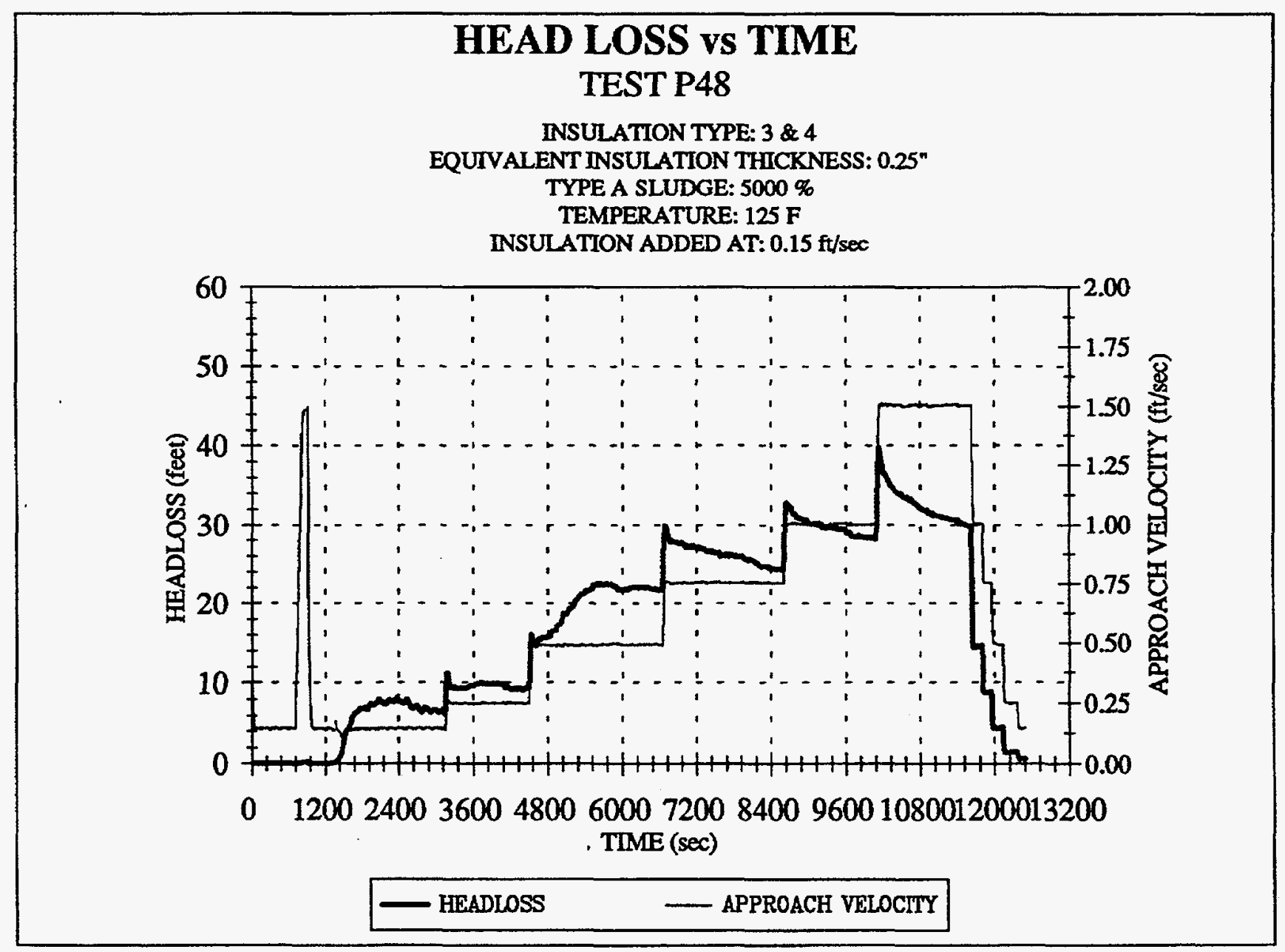

Figure 5-5. Head Loss vs. Time (Type A Sludge 5000\%) 


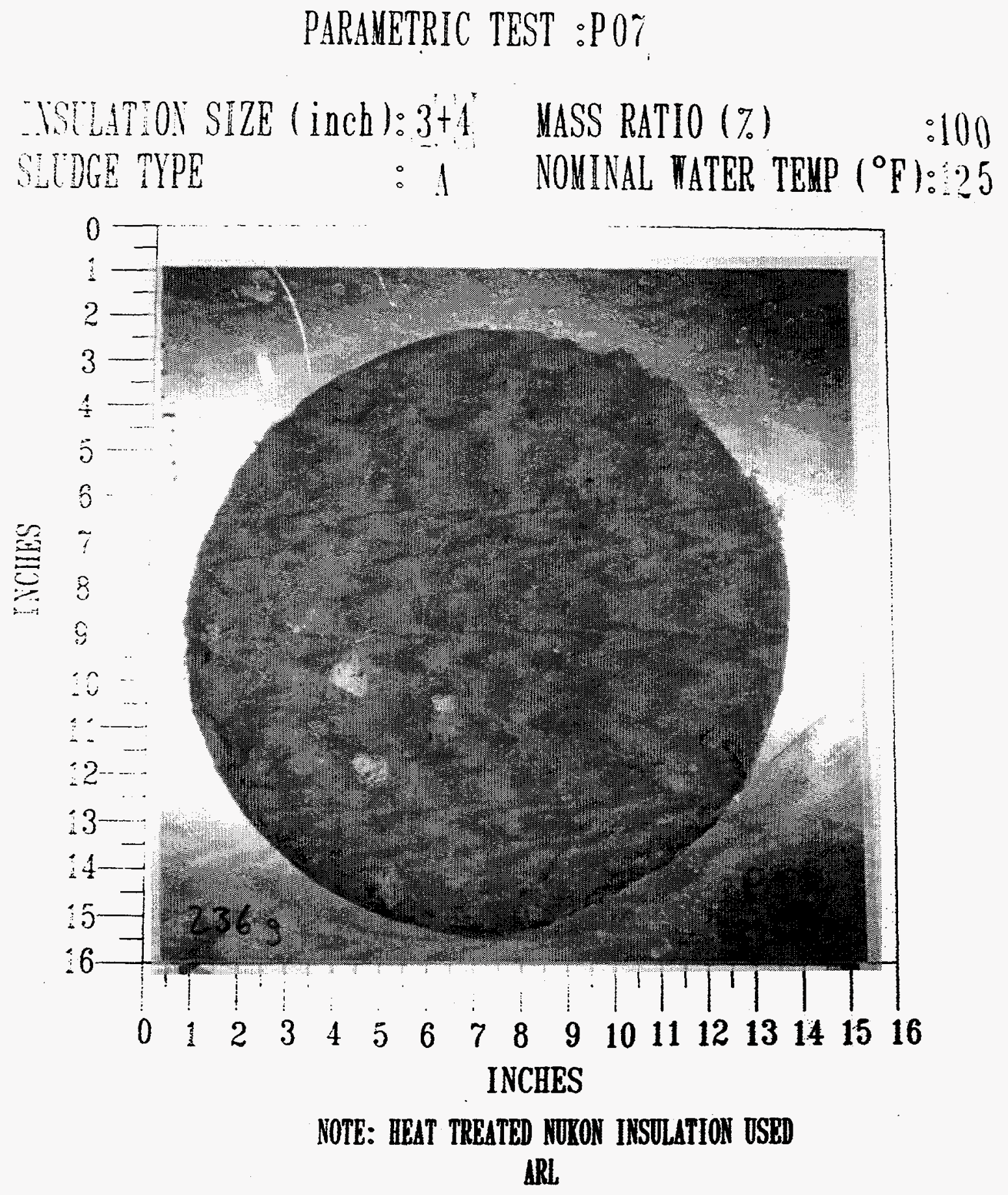

TYPICAL CAKE FOR TEST WITH LOW SLUDGE RATIO TEST P07: 1" CLASS 3\&4 DEBRIS / 100\% SLUDGE A / 125\%

Figure 5-6. Typical Cake for Test with Low Sludge-to-Fiber Ratio 
Head Loss Test Results and Analysis

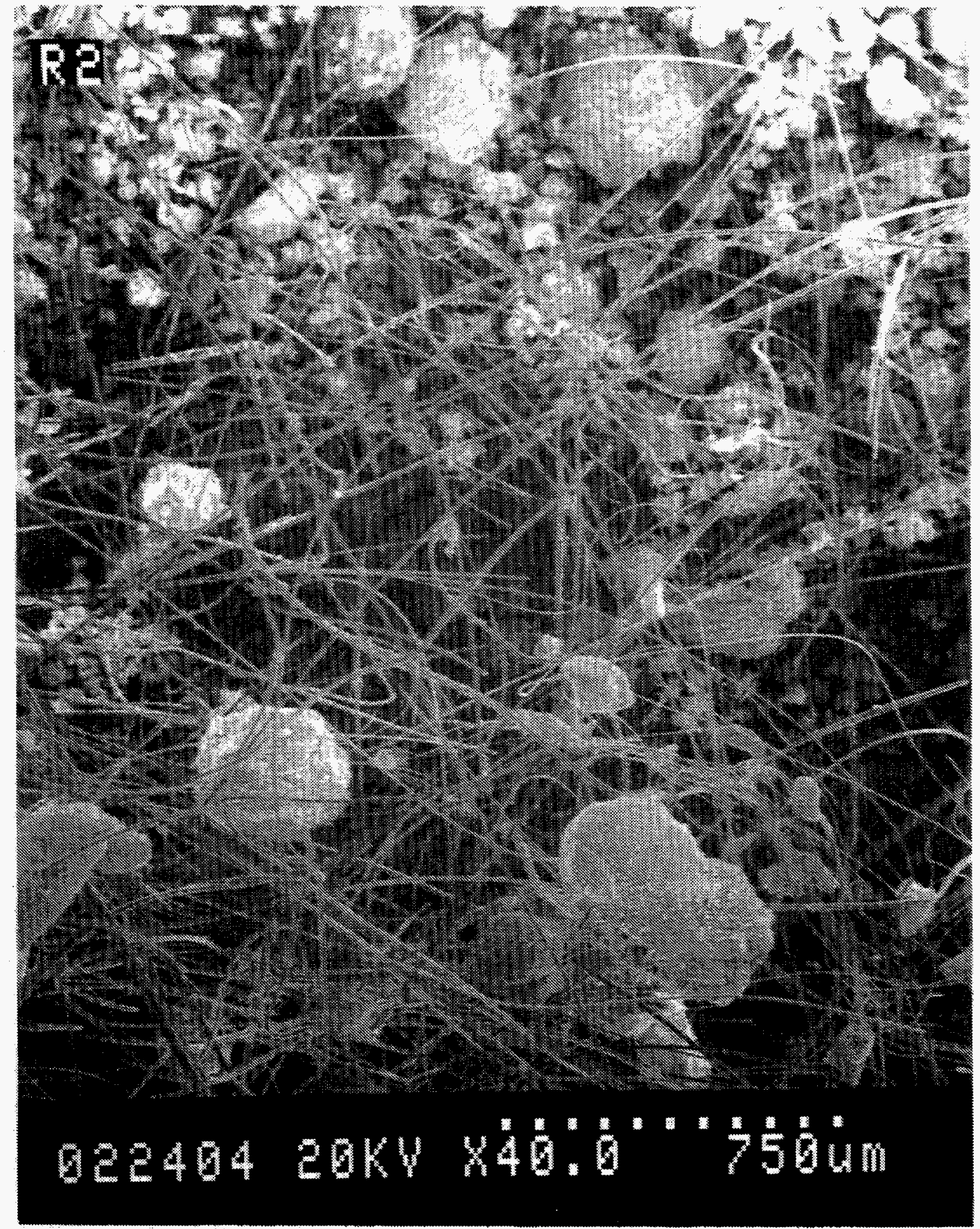

Figure 5-7. Scanning Electron Micrograph of a Mixed Bed 


\section{PARAETRIC TEST :P19}
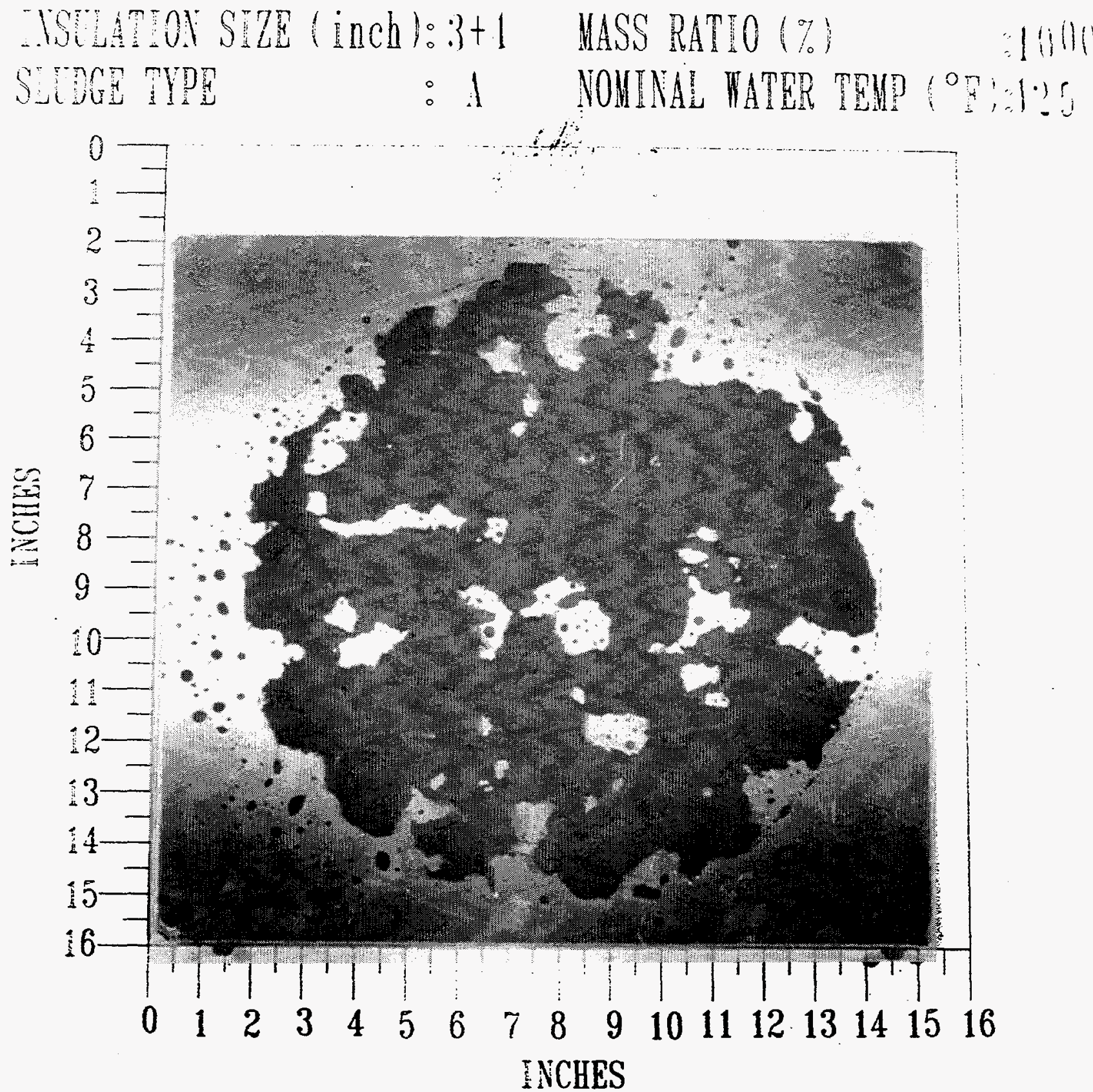

NOTE: AEAT TREATED NUKON INSULATION OSED

ARL

TYPICAL CAKE FOR TEST WITH SMALL THICKNESS TEST P49: 0.125" CLASS 3\&4 DEBRIS / 1000\% SLUDGE A / $125^{\circ} \mathrm{F}$

Figure 5-8. Typical Damaged Cake 


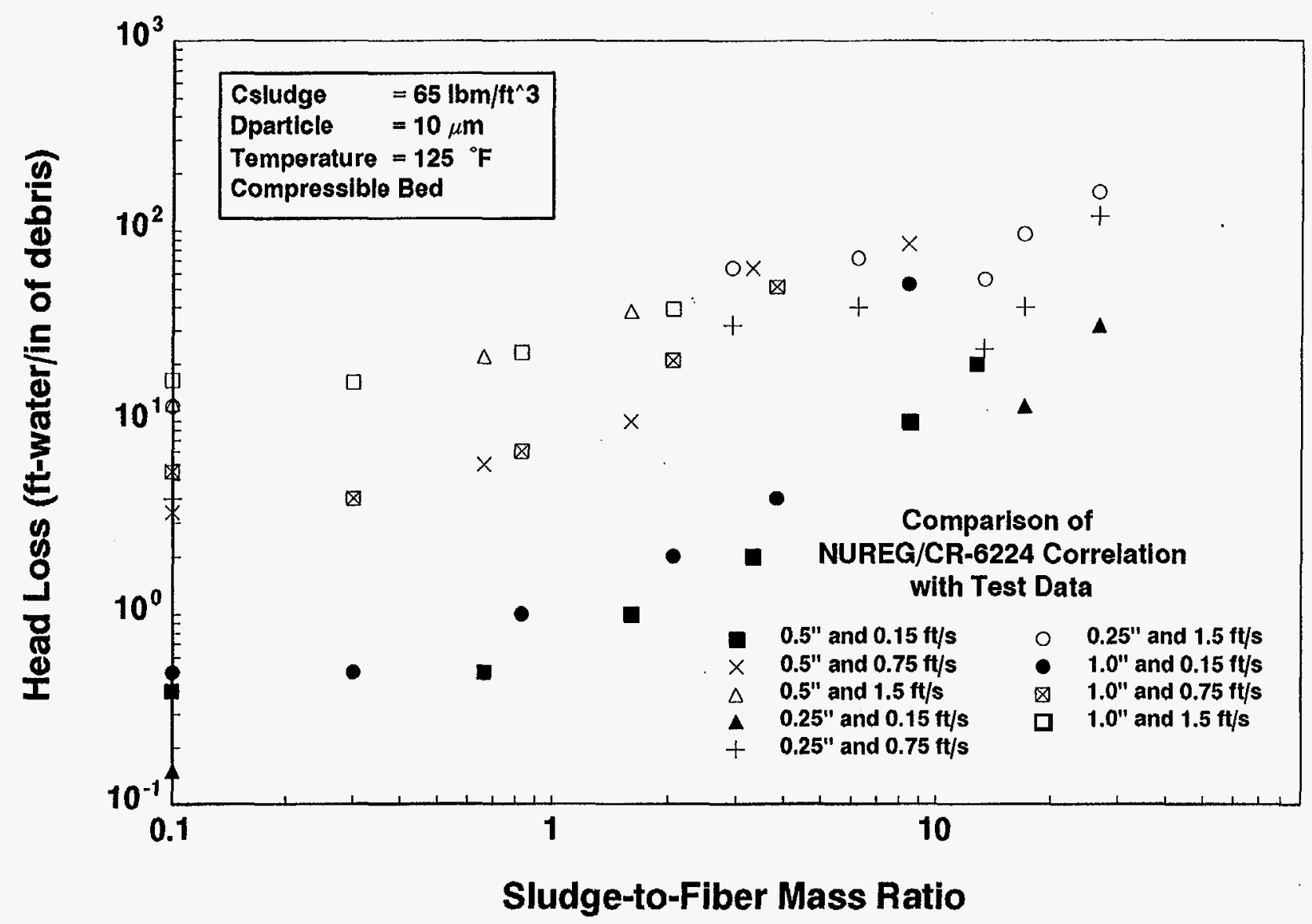

Figure 5-9. Experimental Head Loss Data for Selected Bed Thicknesses and Approach Velocities vs. Sludge-toFiber Mass Ratio 
samples were used to estimate concentration in most tests, the actual uncertainties associated with concentration measurements could be less than $\pm 10 \%$. In addition to these instrument uncertainties, experimental data obtained from the experiments suffered from large variations introduced by the random nature of the underlying processes (e.g., bed formation). To address this concern, several of the tests were repeated and the results are plotted in Figure 5-10. As shown in this figure, the data are repeatable within $\pm 20 \%$. This should be treated as the accuracy of the data and should be kept in mind when applying the data.

\subsection{Analysis and Discussions}

As previously stated, the primary objective of the head loss tests was to obtain data to validate the semi-theoretical head loss correlation discussed in Section 1.4. For compressible fiber beds formed on the strainer surface, Equation 1.18 can be rewritten as:

$$
\begin{aligned}
\frac{\Delta H}{\Delta L_{o}}= & 4.153 \times 10^{-5}\left[3.5 S_{v}^{2}\left(1-\varepsilon_{m}\right)^{1.5}\left[1+57\left(1-\varepsilon_{m}\right)^{3}\right] \mu U\right. \\
& \left.+0.66 S_{v} \frac{\left(1-\varepsilon_{m}\right)}{\varepsilon_{m}} \rho_{w} U^{2}\right]\left(\frac{\Delta L_{m}}{\Delta L_{o}}\right)
\end{aligned}
$$

where,

$$
\begin{array}{ll}
\mathrm{S}_{\mathrm{v}} & \text { is specific surface area }\left(\mathrm{ft}^{2} / \mathrm{ft}^{3}\right) \\
\mu & \text { is dynamic viscosity }(\mathrm{lbm} / \mathrm{s}-\mathrm{ft}) \\
\mathrm{U} & \text { is velocity (ft/s) } \\
\Delta \mathrm{H} & \text { is head loss (ft-water) } \\
\rho_{\mathrm{w}} & \text { is water density (lbm/ } \left.\mathrm{ft}^{3}\right) \\
\Delta \mathrm{L}_{\mathrm{o}} & \text { is the fiber bed theoretical thickness } \\
& \text { (in.) } \\
\Delta \mathrm{L}_{\mathrm{m}} & \text { is the actual bed thickness (in.) }
\end{array}
$$

The mixture porosity, $\varepsilon_{m}$, can be given as:

$$
\varepsilon_{m}=1-\left(1+\frac{\rho_{f}}{\rho_{\rho}} \eta\right)\left(1-\varepsilon_{o}\right) \frac{\Delta L_{o}}{\Delta L_{m}}
$$

where,

$\rho_{f} \quad$ is fiber density $\left(175 \mathrm{lbm} / \mathrm{ft}^{3}\right.$ or 2803 $\left.\mathrm{kg} / \mathrm{m}^{3}\right)$ $\rho_{\mathrm{p}} \quad$ is sludge particle density $\left(324 \mathrm{lbm} / \mathrm{ft}^{3}\right.$ or $5190 \mathrm{~kg} / \mathrm{m}^{3}$ )

$\eta \quad$ is sludge-to-fiber mass ratio trapped on the filter not added to the loop

$\varepsilon_{0} \quad$ is the theoretical fiber bed porosity

$\varepsilon_{\mathrm{o}}$ and $\Delta \mathrm{L}_{\mathrm{m}}$ (in $\mathrm{ft}$ ) can be calculated as:

$$
\begin{gathered}
\varepsilon_{o}=1-c_{o} / \rho_{f} \\
\Delta L_{m}=c_{o} / c \Delta L_{o}
\end{gathered}
$$

where,

$$
\begin{aligned}
& c_{o} \text { is the 'as-fabricated' packing density } \\
& \left(\mathrm{lbm} / \mathrm{ft}^{3}\right) \\
& \text { c is the actual packing density }\left(\mathrm{lbm} / \mathrm{ft}^{3}\right)
\end{aligned}
$$

For a given fiber mass, i.e., known theoretical thickness $\Delta \mathrm{L}_{o}$, Equation 5-5 has two unknowns: (a) the head loss across the bed, and (b) the actual bed thickness (or the actual packing density, $c$ of Eqn. 5-7b). For an incompressible bed, the actual bed thickness is the same as the theoretical bed thickness, and porosity can be estimated using Equation $5-7 \mathrm{a}$. The remaining variable, $\Delta \mathrm{H}$, can be calculated directly using Equation 5-5. For compressible beds the actual bed thickness is different from the theoretical thickness as a result of the compacting pressures. The experimental data were used to estimate the actual thickness.

\subsubsection{Data Analysis for Pure Fiber Beds $(\eta=0)$}

Figures 5-11 and 5-12 present comparison of the head loss data with Equation 5-2 predictions for water temperatures of $60^{\circ} \mathrm{F}$ and $125^{\circ} \mathrm{F}$, respectively.

The following NUKONTM specific information was used to evaluate several variables in the equation:

$$
\begin{aligned}
& \mathrm{S}_{\mathrm{v}}= 1.7142 \times 10^{5} \mathrm{ft}^{2} / \mathrm{ft}^{3}\left(5.6243 \times 10^{5} \mathrm{~m}^{-1}\right) \\
& \mathrm{D}_{\mathrm{f}}=2.333 \times 10^{-5} \mathrm{ft}^{\mathrm{f}}(\text { or } 7.112 \mu \mathrm{m}) \\
& \mathrm{c}_{\mathrm{o}}=2.4 \mathrm{lbm} / \mathrm{ft}^{3}\left(38.4 \mathrm{~kg} / \mathrm{m}^{3}\right) \\
& \vartheta=5.5582 \times 10^{-3} \mathrm{ft}^{3} / \mathrm{lbm} \text { or } 3.47 \times 10^{-4} \mathrm{~m}^{3} / \mathrm{kg} \\
& \varepsilon_{\mathrm{o}}=0.986
\end{aligned}
$$



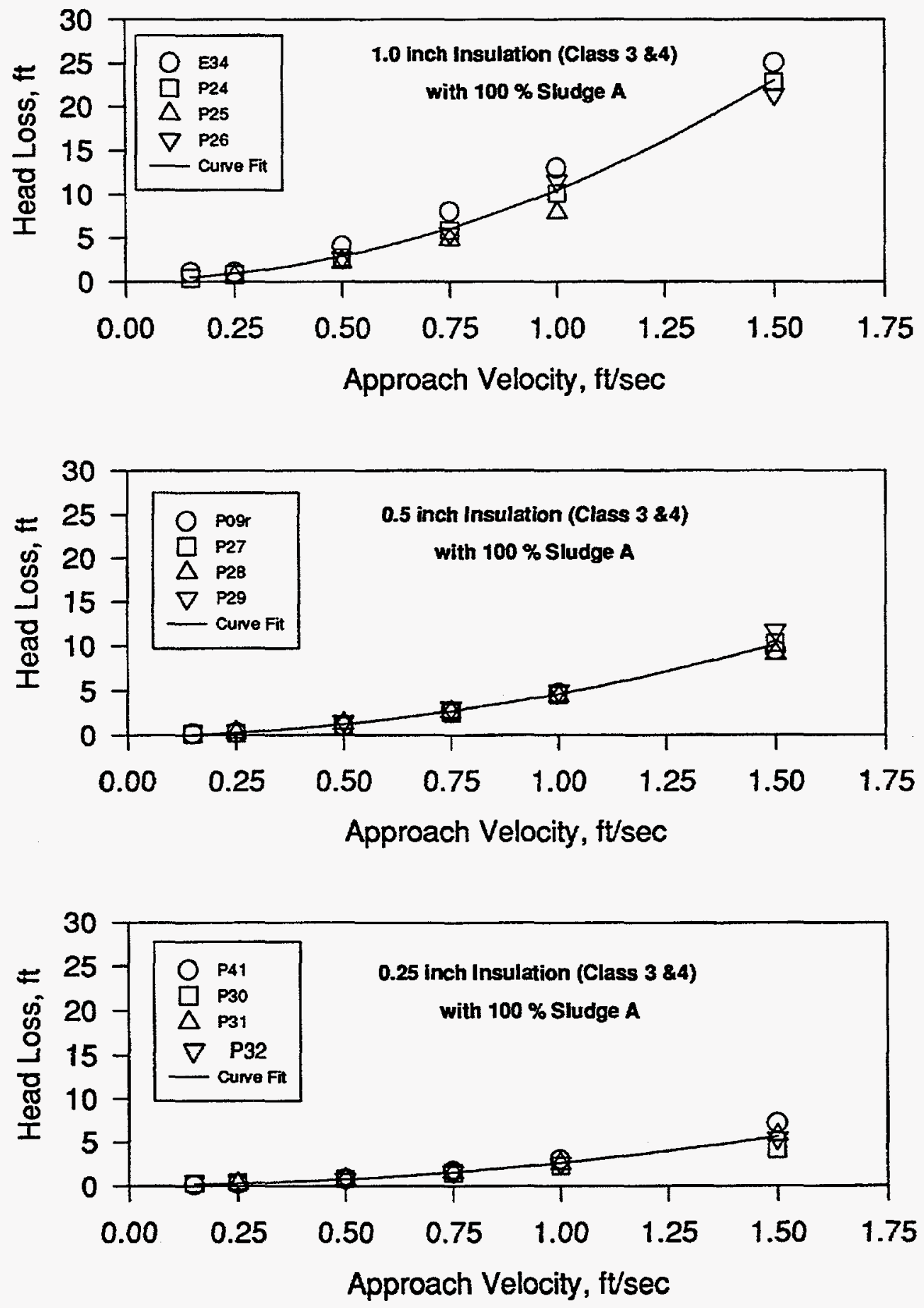

Figure 5-10. Check for Data Repeatability 


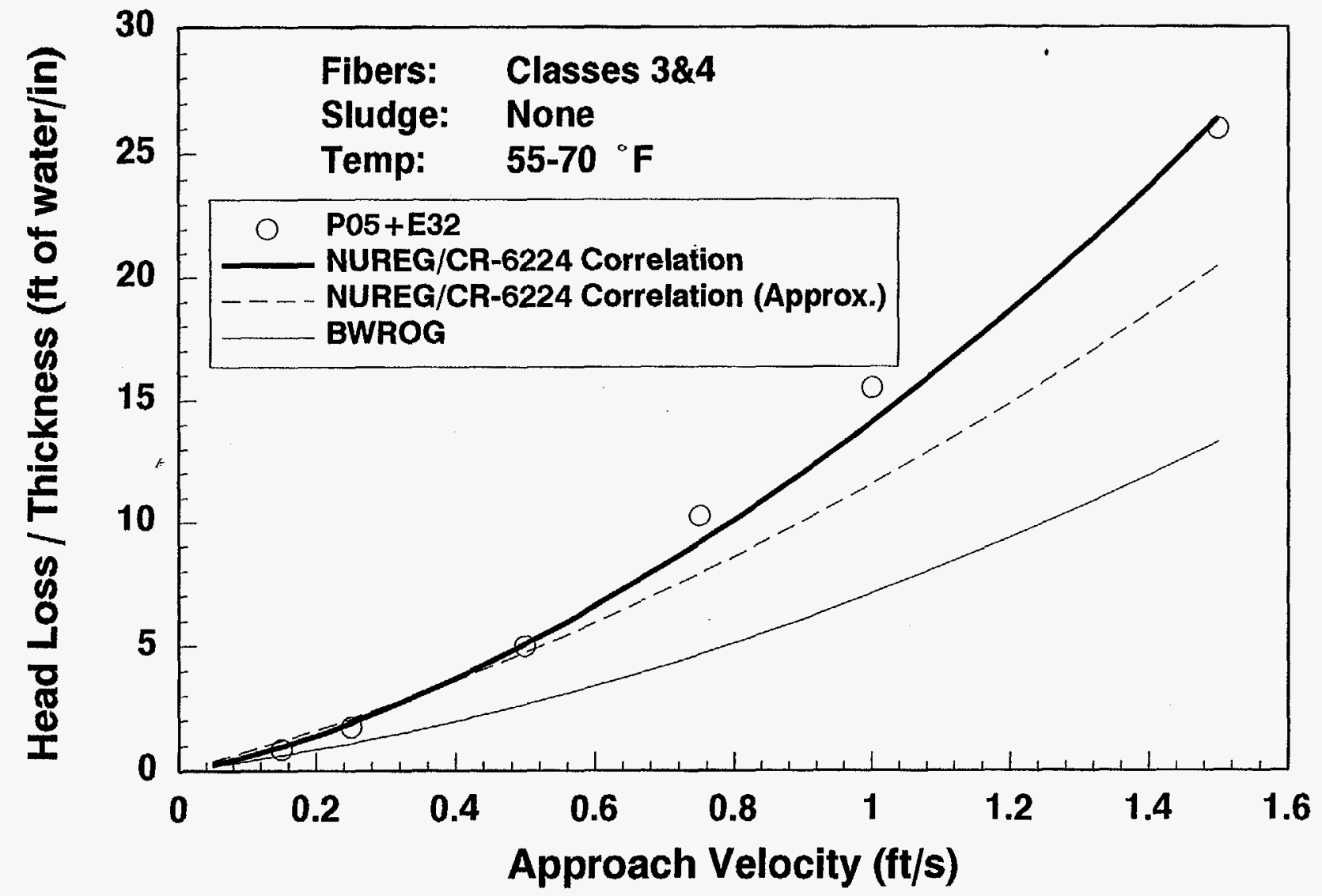

Figure 5-11. Comparison of Predictions of BLOCKAGE Head Loss Model (Equation 4-1) with ARL Head Loss Data for Pure Fiber Beds 


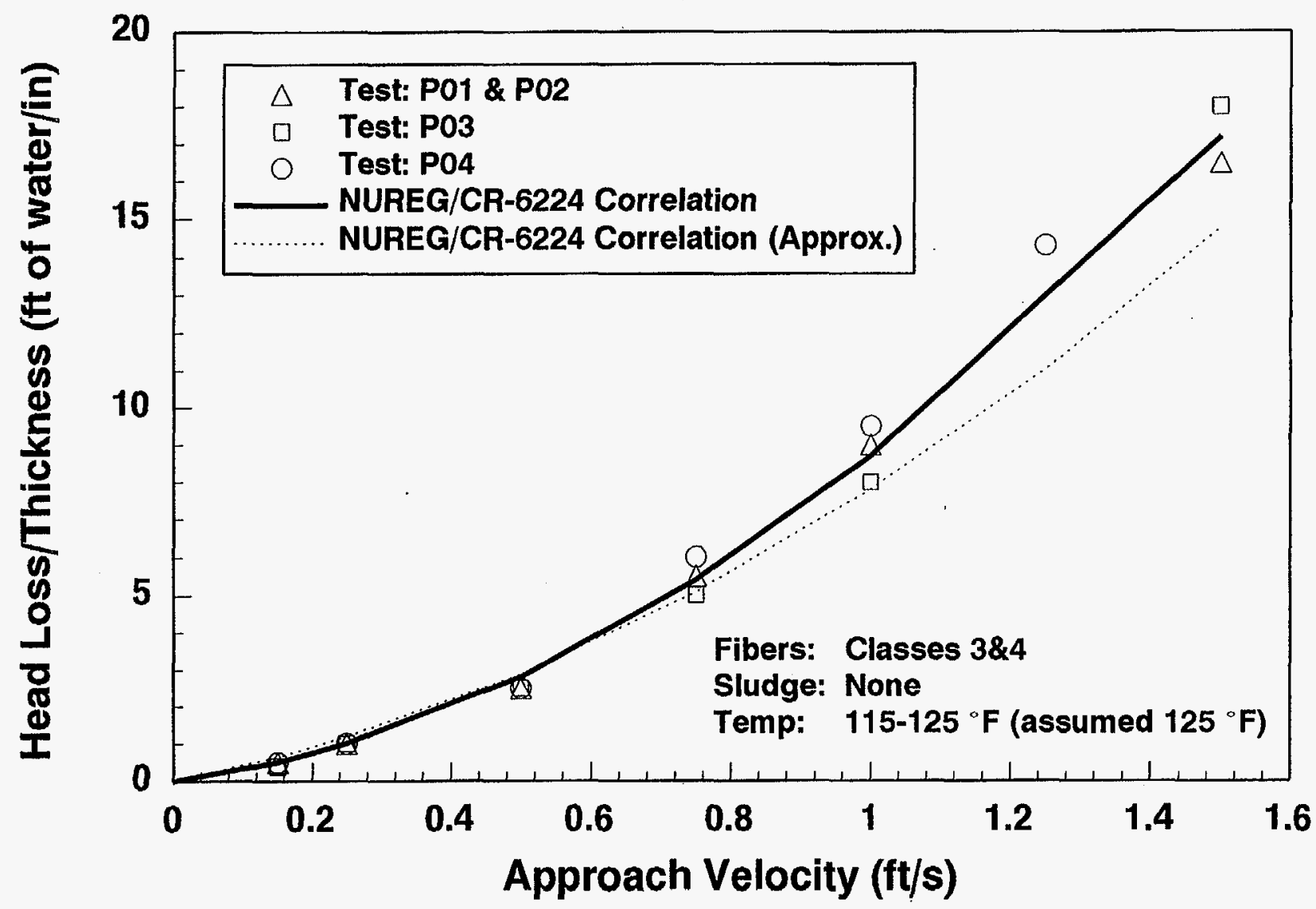

Figure 5-12. Comparison of Predictions of BLOCKAGE Head Loss Model (Equation 4-1) with ARL Head Loss Data for Pure Fiber Beds 
Head Loss Test Results and Analysis

In addition, water properties were obtained from available physical tables as functions of temperature. The bed compact density was calculated using the following equation, which was developed based on experimental measurements:

$$
c=1.3 c_{o}\left(\Delta H / \Delta L_{o}\right)^{0.38}
$$

where,

$$
c_{0} \quad \text { is } 2.4 \mathrm{lbm} / \mathrm{ft}^{3}
$$

$\Delta \mathrm{H}$ is head loss ( $\mathrm{ft}$-water)

$\Delta \mathrm{L}_{\mathrm{o}}$ is bed theoretical thickness (in.)

As evident from these figures, the measured data were within $\pm 20 \%$ of the correlation, verifying Equation 5-5 applicability to fiber beds consisting of classes $3 \& 4$ debris. It should be noted that the good agreement observed in this case is primarily due to the fact that the experiments were conducted in a controlled environment. Such agreement may not be possible for tests where the debris sizes and water temperatures vary from test to test.

Equation 5-5 was solved using an iterative method; to avoid the iterations, a simplified form of that equation was developed for some special cases. From visual observations, pure NUKON ${ }^{\mathrm{TM}}$ beds were compressed to about half their original thickness when subjected to head losses in the range of the reference plant NPSH (14 ft water or $4.18 \times 10^{4}$ $\mathrm{Pa}$ ). For such a case, assume the bed to be incompressible with a packing density twice that of the theoretical one. Under such an assumption, head loss can be estimated using Equation 5-5 and the following assumptions:

$$
\begin{aligned}
& \Delta L_{m}=0.5 \Delta L_{o}, \text { and } \\
& \varepsilon_{m}=1-2 c_{o} / \rho_{f}
\end{aligned}
$$

For NUKONTM Equation 5-5 can be reduced to:

$$
\frac{\Delta H}{\Delta L_{o}}=9712 \mu U+0.06 \rho U^{2}
$$

Using water thermo-physical properties, this equation can be re-written as:

$$
\frac{\Delta H}{\Delta L_{\circ}}=7.4 U+4.1 U^{2} \quad @ 60^{\circ} F
$$

$$
\frac{\Delta H}{\Delta L_{0}}=3.7 U+4.1 U^{2} \quad @ 120^{\circ} \mathrm{F}
$$

These two equations are also compared in Figures 5-11 and 5-12 with the experimental data. As evident from these figures, reasonable agreement was obtained at low velocities, which also correspond to low head loss gradients. At higher velocities, however, Equation 5-11b clearly underpredicts the head loss primarily because it does not account for bed compressibility associated with larger head loss gradients.

Also plotted in Figure 5-11 is the head loss correlation reported by the BWROG developed from the test column head loss data for NUKON ${ }^{\mathrm{TM}}$ [Ref. 5.2] . As noted in Reference 5.2, the data were obtained at ambient temperature using small NUKON ${ }^{\mathrm{T} M}$ shreds. This comparison suggests that this latter equation considerably underpredicts the data.

\subsubsection{Data Analysis for Mixed Beds $(0.45<$ $\eta<27$ )}

Since the amount of sludge on the fiber bed was known at the time the head loss measurement was made, application of the head loss model became direct. The following physical parameters were used:

$$
\begin{aligned}
& \mathrm{D}_{\mathrm{f}}=7.112 \mu \mathrm{m} \\
& \mathrm{S}_{v}=1.7142 \times 10^{5} \mathrm{ft}^{2} / \mathrm{ft}^{3}=5.6243 \times 10^{5} \\
& \rho_{\mathrm{f}}=174.8 \mathrm{lbm} / \mathrm{ft}^{3}\left(2800 \mathrm{~kg} / \mathrm{m}^{3}\right) \\
& \rho_{\mathrm{p}}=324 \mathrm{lbm} / \mathrm{ft}^{3}\left(5190 \mathrm{~kg} / \mathrm{m}^{3}\right) \\
& \mathrm{c}_{\text {sludge }}=65 \mathrm{lbm} / \mathrm{ft}^{3}\left(1041 \mathrm{~kg} / \mathrm{m}^{3}\right) \\
& \mathrm{c}_{\mathrm{o}}=2.4 \mathrm{lbm} / \mathrm{ft}^{3}\left(38.4 \mathrm{~kg} / \mathrm{m}^{3}\right)
\end{aligned}
$$

In addition, the following closure relationship was used for estimation of compressed bed actual thickness:

$$
\begin{array}{ll}
c=1.3 \mathrm{c}_{\mathrm{o}}\left(\Delta \mathrm{H} / \Delta \mathrm{L}_{\mathrm{o}}\right)^{0.38} & \mathrm{c} \leq 65 \mathrm{lbm} / \mathrm{ft}^{3} \\
c=65 \mathrm{Ibm} / \mathrm{ft}^{3} & \text { Otherwise. }
\end{array}
$$

Tables 5-4, 5-5, 5-6 and 5-7 provide a point-by-point comparison of the experimental data with the correlation in a tabular form. Also, Figure 5-13 compares experimental data, plotted as $\left(\Delta \mathrm{P}_{\text {mixed }}\right) /$ $\left(\Delta \mathrm{P}_{\text {fiber }}\right)$ versus the sludge-to-fiber ratio, with the correlation predictions for bed thicknesses ranging 
Head Loss Test Results and Analysis
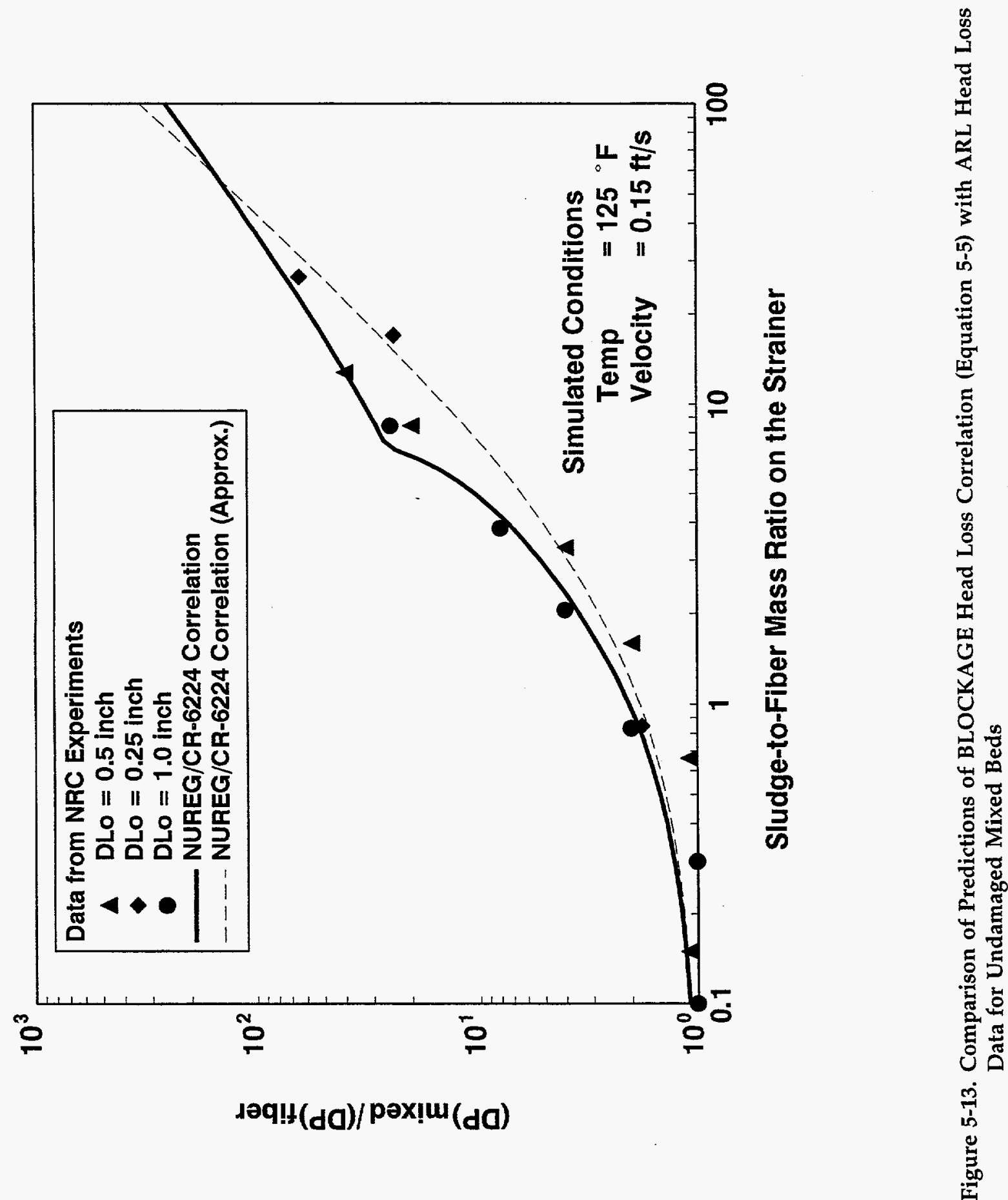
from $1 / 4^{\prime \prime}$ to $1 "$, an approach velocity of $0.15 \mathrm{ft} / \mathrm{s}$ and a water temperature of $125^{\circ} \mathrm{F}$. Good agreement was obtained over the entire range of comparison, particularly at higher fiber bed thicknesses where uniform beds are expected. The apparent large differences at low sludge-to-fiber mass ratios is attributable to associated experimental uncertainties which ranged up to $\pm 20 \%$ under these conditions. Once again, a simplified form of Equation 5-5 was obtained for the $\eta$ range of present interest as follows:

$$
\begin{aligned}
& \frac{\Delta H}{\Delta L_{o}}=10(1+0.54 \eta)^{1.5} U+4(1+0.54 \eta) U^{2} @ 60^{\circ} F \\
& \frac{\Delta H}{\Delta L_{o}}=5(1+0.54 \eta)^{1.5} U+4(1+0.54 \eta) U^{2} @ 120^{\circ} F
\end{aligned}
$$

Predictions of 5-13b are also plotted in Figure 5-13.

Similarly, good comparison was obtained for other bed thicknesses and approach velocities whenever the head loss gradient is less than about $50 \mathrm{ft}$ water/in (see Tables 5-4 through 5-7). For higher head loss gradients, which typically occurred at higher approach velocities ( $U>1 \mathrm{ft} / \mathrm{s}$ ) coupled with large sludge-to-fiber ratios ( $\eta>10)$, the correlation was found to overpredict the head loss. Figure 5-14 plots this data for an approach velocity of $1.5 \mathrm{ft} / \mathrm{s}$ : $\Delta \mathrm{L}_{\mathrm{o}}$ of $0.25^{\prime \prime}, 0.5^{\prime \prime}$ and $1 "$; and a temperature of $125^{\circ} \mathrm{F}$. As evident from this figure, the correlation reasonably bounds the data for all thicknesses at low sludge-to-fiber mass ratios; however, at high sludge-to-fiber mass ratios the correlation severely overestimates the head loss. This overprediction can be attributed to the fact that the model does not account for the bed being damaged by the high differential pressure. ${ }^{9}$. This does not pose a serious concern since in the BWR suppression pools the differential pressures are in the range of $5-25 \mathrm{ft}-$ water. In this range the model predictions are in good agreement with the experimental data.

\subsection{Application to NUREG/CR-6224}

The semi-theoretical model proposed for NUKON ${ }^{\mathrm{TM}}$ based debris beds shown in Equation 5-5 performs well for both pure beds $(\eta=0)$ and for mixed beds $(\eta>0)$ formed of (a) Sludge A, (b) Sludge B and (c) Mix $A$. This conclusion is further validated by comparing the equation predictions with the experimental data made available by other sources [Ref. 5.3 and 5.4]. These comparisons are presented in Appendix B of NUREG/CR-6224 [Ref. 5.5]. The comparison also suggests that such factors as (a) water temperature and (b) the bed compression can be adequately accounted for through the use of the semi-theoretical approach. Based on this study, the head loss model in BLOCKAGE was updated to include compressibility effects and was used in the analyses described in NUREG/CR-6224.

The head loss model was developed assuming a uniform debris layer on the strainer. The model predictions are in agreement with the experimental data for fiber bed thicknesses larger than 0.125 " $(0.318 \mathrm{~cm})$. Below these thicknesses the beds are expected to be highly non-uniform and, therefore, it is unlikely that the model predictions would be accurate. In this range, the model predictions should be interpreted as an upper bound for head loss.

Similarly, the model does not take into consideration the damage caused on the fiber bed by high pressure drops. As previously discussed, beds thinner than 0.5 " undergo irrecoverable damage at high sludge-to-fiber mass ratios caused by excessive head losses. The damaged beds resemble a partially covered strainer. In this case also, the model predictions are higher than the measured values, and the model predictions can be seen to be bounding rather than best-estimate. Note that in the present experiments damage was only observed for beds thinner than 0.5 ". No such damage was noted for beds thicker than $1 "$ in the head loss range of interest ( $<50 \mathrm{ft}$-water). Thus, this model limitation is only applicable for thin beds at high sludge-tofiber mass ratios.

\footnotetext{
${ }^{9}$ In the experiments it was observed that holes were punched through what appeared to be an initially uniform fiber bed by the shear forces resulting from high head loss (see Figure 4-8). Such effects were not incorporated into the present model.
} 
Table 5-4. Comparison Between Model Predictions and Test Data for 2" Nominal Thickness Beds

\begin{tabular}{|c|c|c|c|c|c|c|c|c|c|c|c|c|c|c|}
\hline \multirow{3}{*}{ Test } & \multicolumn{2}{|c|}{$\begin{array}{l}\text { Sludge to Fiber } \\
\text { Ratio }\end{array}$} & \multicolumn{12}{|c|}{ Head Loss (ft-water) } \\
\hline & \multirow{2}{*}{$\begin{array}{l}\text { Added } \\
(\%)\end{array}$} & \multirow{2}{*}{$\begin{array}{l}\text { Filtered } \\
(\%)\end{array}$} & \multicolumn{2}{|c|}{ (1) $0.15 \mathrm{ft} / \mathrm{s}$} & \multicolumn{2}{|c|}{ (19. $0.25 \mathrm{ft} / \mathrm{s}$} & \multicolumn{2}{|c|}{ (1) $0.50 \mathrm{ft} / \mathrm{s}$} & \multicolumn{2}{|c|}{ @ $0.75 \mathrm{ft} / \mathrm{s}$} & \multicolumn{2}{|c|}{ @ $1.00 \mathrm{ft} / \mathrm{s}$} & \multicolumn{2}{|c|}{$@ 1.50 \mathrm{ft} / \mathrm{s}$} \\
\hline & & & Data & Model & Data & Model & Data & Model & Data & Model & Data & Model & Data & Model \\
\hline $\mathrm{P} 03$ & 0 & 0 & 0.8 & 1 & 2 & 2.0 & 5 & 5.6 & 10 & 10.8 & 16 & 17.6 & 36 & 35 \\
\hline P16 & 50 & 45 & 1 & 1.4 & 2 & 2.8 & 7 & 8 & 15 & 15 & 29 & 24.0 & 48 & 47 \\
\hline $\mathrm{P} 07$ & 100 & 84 & 1 & 1.8 & 2 & 3.2 & 6 & 10.0 & 13 & 18 & 21 & 30.0 & & \\
\hline P08 & 100 & 95 & 1 & 2 & 2 & 4 & 7 & 11 & 17 & 20 & 34 & 33.0 & & \\
\hline E32 & 0 & 0 & 1.2 & 1.9 & 3.5 & 3.8 & 10 & 10.1 & 20.5 & 18.6 & 31.5 & 28.6 & 52 & 46 \\
\hline P19 & 50 & 35 & -- & 2.2 & 2 & 4.2 & 5 & 11.2 & 15 & 20.4 & 30 & 31.6 & 52.7 & 60.2 \\
\hline
\end{tabular}


Head Loss Test Results and Analysis

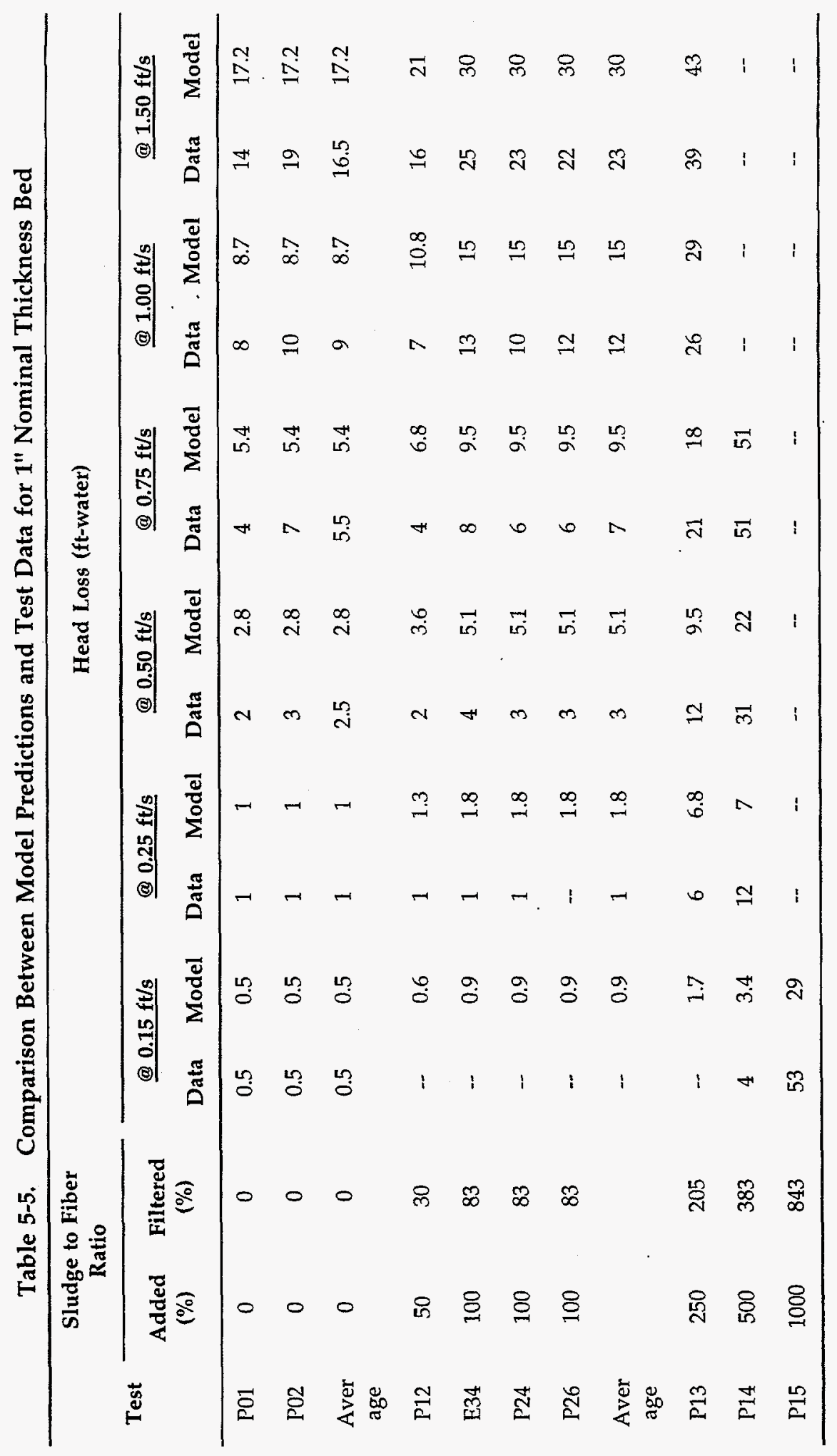


Table 5-6. Comparison Between Model Predictions and Test Data 0.5" Nominal Thickness Bed

\begin{tabular}{|c|c|c|c|c|c|c|c|c|c|c|c|c|c|c|}
\hline \multirow{3}{*}{ Test } & \multicolumn{2}{|c|}{$\begin{array}{l}\text { Sludge to Fiber } \\
\text { Ratio }\end{array}$} & \multicolumn{12}{|c|}{ Head Loss (ft-water) } \\
\hline & \multirow{2}{*}{$\begin{array}{c}\text { Added } \\
(\%)\end{array}$} & \multirow{2}{*}{$\begin{array}{l}\text { Filtered } \\
(\%)\end{array}$} & \multicolumn{2}{|c|}{ (a) $0.15 \mathrm{ft} / \mathrm{s}$} & \multicolumn{2}{|c|}{ (a) $0.25 \mathrm{ft} / \mathrm{s}$} & \multicolumn{2}{|c|}{ (@) $0.50 \mathrm{ft} / \mathrm{s}$} & \multicolumn{2}{|c|}{ @ $0.75 \mathrm{ft} / \mathrm{s}$} & \multicolumn{2}{|c|}{ (1.00 ft/s } & \multicolumn{2}{|c|}{ (10) $1.50 \mathrm{ft} / \mathrm{s}$} \\
\hline & & & Data & Model & Data & Model & Data & Model & Data & Model & Data & Model & Data & Model \\
\hline $\mathrm{P} 09$ & 100 & 66 & -- & 0.4 & -- & 0.8 & 2.0 & 2.2 & 3 & 4.2 & 5 & 6.7 & 10 & 13.5 \\
\hline $\mathrm{P} 27$ & 100 & 66 & -- & 0.4 & -- & 0.8 & 1 & 2.2 & 2.5 & 4.2 & 4.5 & 6.7 & 10.3 & 13.5 \\
\hline $\mathrm{P} 28$ & 100 & 66 & -- & 0.4 & -- & 0.8 & 1.3 & 2.2 & 2.6 & 4.2 & 4.4 & 6.7 & 9.1 & 13.5 \\
\hline P29 & 100 & 66 & -- & 0.4 & -- & 0.8 & 1.5 & 2.2 & 3 & 4.2 & 5 & 6.7 & 11.7 & 13.5 \\
\hline $\begin{array}{l}\text { Aver } \\
\text { age }\end{array}$ & 100 & 66 & -- & 0.4 & -- & 0.8 & 1.5 & 2.2 & 2.8 & 4.2 & 4.7 & 6.7 & 10.3 & 13.5 \\
\hline P10 & 250 & 159 & -- & 0.7 & 1 & 1.4 & 2 & 3.8 & 5 & 7.1 & 9 & 11.2 & 19 & 22 \\
\hline P11 & 500 & 330 & 1 & 1.4 & 3 & 2.8 & 14 & 8.3 & 32 & 18 & 37 & 35 & -- & -- \\
\hline P33R & 1000 & 1000 & 5 & 7 & 15 & 12 & 34 & 25 & 43 & 42 & -- & -- & -- & -. \\
\hline $\mathrm{P} 43$ & 2000 & 1274 & 10 & 9 & 18 & 17 & 50 & 35 & -- & - & -- & -- & -- & -- \\
\hline P40 & 0 & 0 & 0.2 & 0.2 & 0.3 & 0.4 & 1 & 1.1 & 1.7 & 2.1 & 3 & 3.5 & 7.2 & 7.1 \\
\hline
\end{tabular}


Table 5-7. Comparison Between Model Predictions and Test Data for 0.25" Theoretical Bed Thickness

\begin{tabular}{|c|c|c|c|c|c|c|c|c|c|c|c|c|c|c|}
\hline & \multicolumn{2}{|c|}{$\begin{array}{l}\text { Sludge to Fiber } \\
\text { Ratio }\end{array}$} & \multicolumn{12}{|c|}{ Head Loss (ft-water) } \\
\hline Test & \multirow{2}{*}{$\begin{array}{l}\text { Added } \\
(\%)\end{array}$} & \multirow{2}{*}{$\begin{array}{c}\text { Filtered } \\
(\%)\end{array}$} & \multicolumn{2}{|c|}{ @ $0.15 \mathrm{ft} / \mathrm{s}$} & \multicolumn{2}{|c|}{$@ 0.25 \mathrm{ft} / \mathrm{s}$} & \multicolumn{2}{|c|}{$@ 0.50 \mathrm{ft} / \mathrm{s}$} & \multicolumn{2}{|c|}{$@ 0.75 \mathrm{ft} / \mathrm{s}$} & \multicolumn{2}{|c|}{$@ 1.00 \mathrm{ft} / \mathrm{s}$} & \multicolumn{2}{|c|}{$@ 1.50 \mathrm{ft} / \mathrm{s}$} \\
\hline & & & Data & Model & Data & Model & Data & Model & Data & Model & Data & Model & Data & Model \\
\hline \multirow{6}{*}{ "ָ } & 0 & 0 & 0 & 0.08 & 0 & 0.2 & 0 & 0.5 & 1 & 1 & 2 & 1.6 & 3 & 3.2 \\
\hline & 500 & 292 & -- & 0.6 & 2 & 1.3 & 5 & 3.5 & 8 & 7 & 12 & 12.5 & 16 & 25 \\
\hline & 1000 & 622 & -- & 2 & 4 & 5 & 6 & 10.5 & 10 & 16 & 13 & 23 & 18 & 40 \\
\hline & 2000 & 1333 & - & 5 & 2 & 8.4 & 4 & 18.1 & 6 & 29.3 & 8 & 41.5 & 14 & 70 \\
\hline & 3000 & 1692 & 3 & 6 & 4 & 10.3 & 6 & 22 & 10 & 36 & 16 & 51 & 24 & 86 \\
\hline & 5000 & 2651 & 8 & 9 & 10 & 15 & 22 & 32 & 30 & 52 & 34 & 75 & 40 & 127 \\
\hline
\end{tabular}




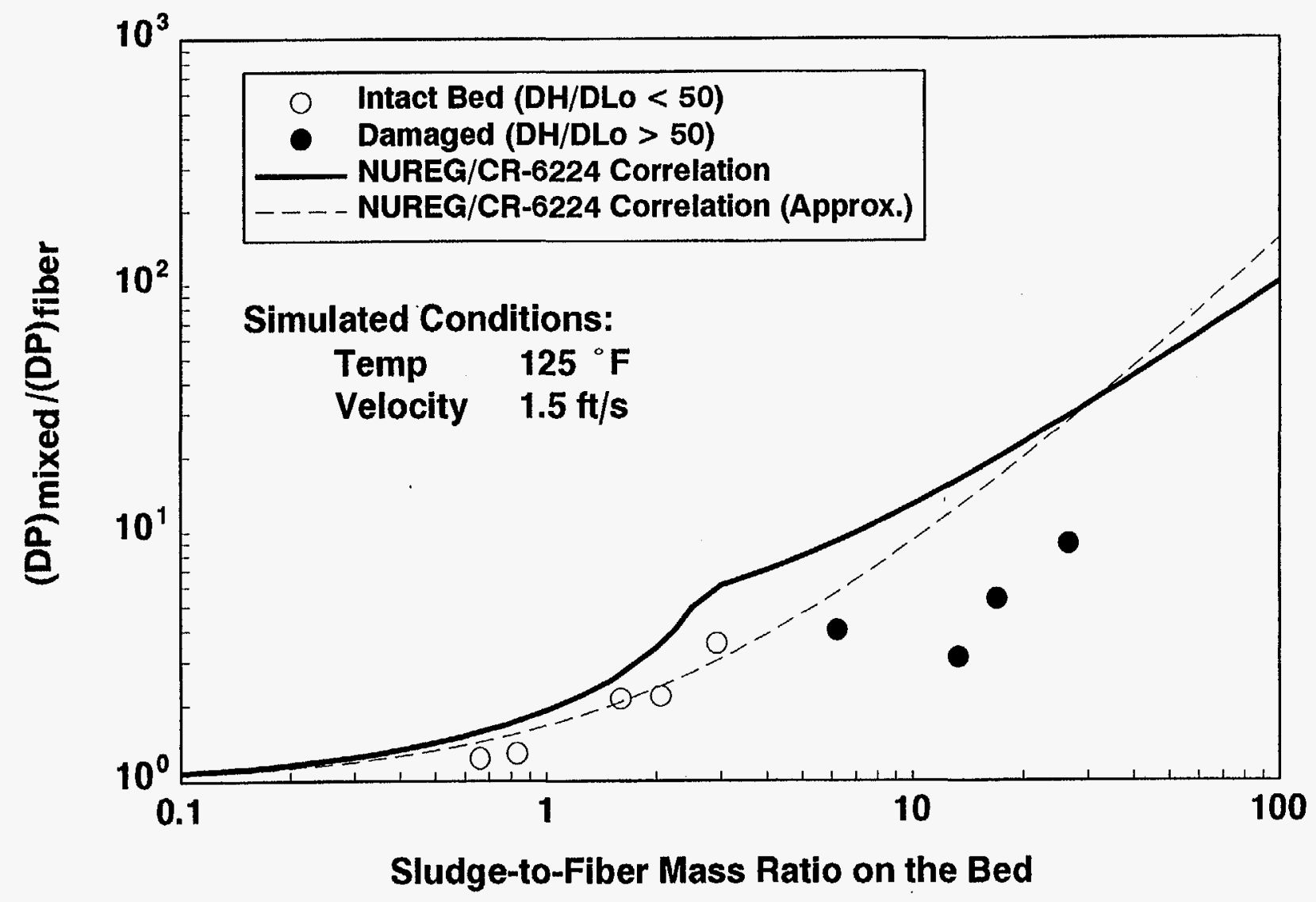

Figure 5-14. Comparison of Predictions of BLOCKAGE Head Loss Correlation (Equation 5-5) with ARL Head Loss Data for Undamaged and Damaged Mixed Beds 


\section{References for Section 5}

5.1 P. Murthy, M. Padmanabhan, F.J. Weber, G.E. Hecker, "Head Loss of Fibrous Insulation Debris and Sludge for BWR Suction Strainers," Alden Research Laboratory, Inc., 1995.

5.2 BWR Owners' Group, "Interim Report of the BWR Owners' Group ECCS Suction Strainer Committee," BWROG-94157, December 1994.

5.3 D. N. Brocard, "Buoyancy, Transport, and Head Loss of Fibrous Reactor Insulation," Alden Research Laboratory, published as Sandia National Laboratories Report No. SAND82-7205, Rev, NUREG/CR-2982, Rev. 1, July 1983.
5.4 B. J. Pernino and G. Hecker, "Head Loss Tests with Blast-Generated NUKON ${ }^{\mathrm{TM}}$ Insulation Debris," ARL/140-93/M670F, 1993.

5.5 G. Zigler, et al, "Parametric Study of the Potential for BWR ECCS Strainer Blockage Due to LOCA Generated Debris," Revised Draft Report, NUREG/CR-6224 (SEA No. 93554-06-A:1), April 1995. 



\subsection{Filtration Efficiency Test Results and Analysis}

Head loss across a debris bed is dependent on the quantity of sludge and fiber trapped on the strainer. In the case of fibers, nearly $100 \%$ of the debris approaching the strainer would be trapped, as confirmed by visual observations and limited concentration measurements. On the other hand, not all the sludge approaching the strainer would be trapped; in fact, a considerable fraction of the sludge might penetrate the strainer on the first approach. A set of filtration tests were conducted as part of the present program to estimate (a) the once-through filtration efficiency of the debris bed which relates to the fraction of the debris approaching the strainer that would be trapped during the first pass, and (b) the cumulative or saturation filtration efficiency which relates the total fraction of sludge added to the loop that is ultimately filtered by the debris bed after a large number of passes through the bed.

The same closed loop set-up used in the head loss tests was used to measure the filtration efficiency. As noted previously, the closed loop facility does not provide the ideal set-up for measuring filtration efficiency. However, the filtration efficiencies can be inferred from the concentration measurements obtained several times within one flushing cycle after the fiber cake forms on the strainer. The flushing cycle is defined as the time taken for the water to flow through the loop once.

\subsection{Experimental Procedure}

The experimental procedure for fibrous debris generation and sample preparation were the same as those described in Sections 5.1.1 and 5.1.2. Step-bystep descriptions of the procedures followed for conducting the test are described below.

1. Loop is filled with fresh water and all manometer tubing and DP cells are bled.

2. The computer data acquisition and control program is started, which is used to monitor differential pressure (DP) cell output and also to maintain required approach velocities.

3. DP cells are checked by setting a static deflection between $0-3 \mathrm{ft}$ and verifying that the computer reads same pressure head.
4. Set pump to obtain approach velocity of about $1.5 \mathrm{ft} / \mathrm{s}$ and turn on heating tapes. Monitor water temperature until it reaches $120-125^{\circ} \mathrm{F}$.

5. Lower the water level in the 12" downcomer to just above the tee junction with $4^{\prime \prime}$ pipe, by draining water through a drain port at the top. The drained water is saved to be added back into the loop in Step 9 below.

6. Sludge sample is then added within 1 minute (see Section 5.1.2 for weighing sludge samples), and allowed to circulate for about 1 minute.

7. Approach velocity is set to the value specified for the test $(0.15,0.25$ or $0.5 \mathrm{ft} / \mathrm{s})$.

8. Collect one water sample, about one liter each at top and bottom locations.

9. Pre-soaked insulation debris (see Section 5.1.1 for generating insulation debris) is then added within 5 seconds, the 12" downcomer filled to the top using the water saved in Step 5 above making sure that no insulation is caught in the top region, loop is sealed (top access cover closed), and the stand pipe valve opened. Note the time at which the insulation is added.

10. Collect water samples (about one liter each at top and bottom locations) at 20 second intervals, starting from 20 seconds after adding the insulation and continue for an elapsed time equal to 240 seconds. Thereafter, collect five additional samples at intervals of about 40 seconds.

11. Flow loop is run at the set approach velocity until stable head loss obtained. The velocity is increased in steps to $1.5 \mathrm{ft} / \mathrm{s}$ (unless head loss exceeds $50 \mathrm{ft}$ at lower velocity), noting stable head loss at each of the next higher value in the sequence of $0.25,0.5,0.75,1.0$, and $1.5 \mathrm{ft} / \mathrm{s}$.

12. After attaining the maximum velocity, the flow is lowered in steps to note the head losses at 1.0, 0.75, 0.5, 0.25, and $0.15 \mathrm{ft} / \mathrm{s}$. 
13. Pump is then shut off and computer readout of DP cells are checked again against a known static deflection.

14. Model is then drained and the "cake" removed from the strainer plate and placed in an oven (set at $250^{\circ} \mathrm{F}$ ) for approximately two days.

15. The dried cake is weighed as a rough check for sludge mass balance.

16. Perform concentration analysis of collected samples.

17. The loop is cleaned thoroughly by flushing with fresh water repeatedly and made ready for next test.

Water samples collected in Step 10 above were analyzed to estimate the sludge concentration following the procedures described in Section 5.1.4.

\subsection{Derivation of Filtration Efficiency}

The concentration measurements were used to obtain the filtration efficiencies. Figure 6-1 presents the concentration profiles for top and bottom samples for Test P27. In this test, the sludge was added to the loop initially, and then allowed to circulate for several minutes to attain uniform concentration. As evident from the figure, water samples drawn during this initial phase suggest that uniform concentration was attained in the loop, and that the concentration was very close to the theoretical value of $0.075 \mathrm{~g} / 1^{10}$. At 0 seconds, a premeasured quantity $\left(\Delta \mathrm{L}_{\circ}=0.5^{\prime \prime}\right)$ of classes $3 \& 4$ fibers was added to the loop, all at once. The actual time at which the insulation cake formed could not be directly measured from the experiment since the water was very murky. However, based on previous experiments, it was estimated that the bed would form in 80 seconds as illustrated in Figure 61. Until that point, the concentration of sludge in the water samples drawn above and below the strainer was essentially the same, confirming that filtration is minimal during the time when the bed is

\footnotetext{
${ }^{10}$ Theoretical estimate is based on the fact that in test P27, $39 \mathrm{~g}$ of sludge was added to a loop water column of $520 \mathrm{l}$.
}

being formed. However, as expected, this trend reversed once the bed was formed on the strainer. Due to filtration of sludge by the fiber bed, the concentration below the bed was found to be substantially lower than that above the bed; this trend was especially evident during the first flushing cycle. Thereafter, the concentrations both above and below the strainer decreased steadily with time, ultimately reaching a stable value of about $0.027 \mathrm{~g} / \mathrm{l}$. After that point, change in concentration was minimal, indicating that the filter bed had reached an equilibrium. It is likely that this equilibrium was a result of bed structure and the particle size distribution.

The concentration profiles, such as those illustrated in Figure 6-1, were used to estimate the bed filtration efficiency as a function of time. A complete listing of these transient concentration profiles for all of the filtration tests (P24 through P32) are provided in Reference 6.1. Two types of filtration efficiencies were measured from the concentration data: once-through efficiency and cumulative efficiency. The once-through efficiency is a measure of the fraction of the sludge that is filtered by the debris bed during the first pass and is defined as:

$$
e_{\text {once-through }}=\frac{C_{\text {top }}-C_{\text {bottom }}}{C_{\text {top }}}
$$

where,

$$
\begin{aligned}
& \mathrm{e}_{\text {once-through }} \text { is once-through efficiency } \\
& \mathrm{C}_{\text {top }} \quad \begin{array}{l}
\text { is sludge concentration above the bed } \\
(\mathrm{g} / 1)
\end{array} \\
& \begin{array}{ll}
\mathrm{C}_{\text {bottom }} \quad \begin{array}{l}
\text { is sludge concentration below the bed } \\
(\mathrm{g} / \mathrm{l})
\end{array}
\end{array}
\end{aligned}
$$

On the other hand, the cumulative efficiency is a measure of the fraction of the total sludge added to the loop that is filtered by the debris bed as a function of time and is defined as:

$$
e_{\text {cumulative }}=\frac{M_{\text {total }}-M_{\text {cake }}}{M_{\text {total }}}
$$

where, 


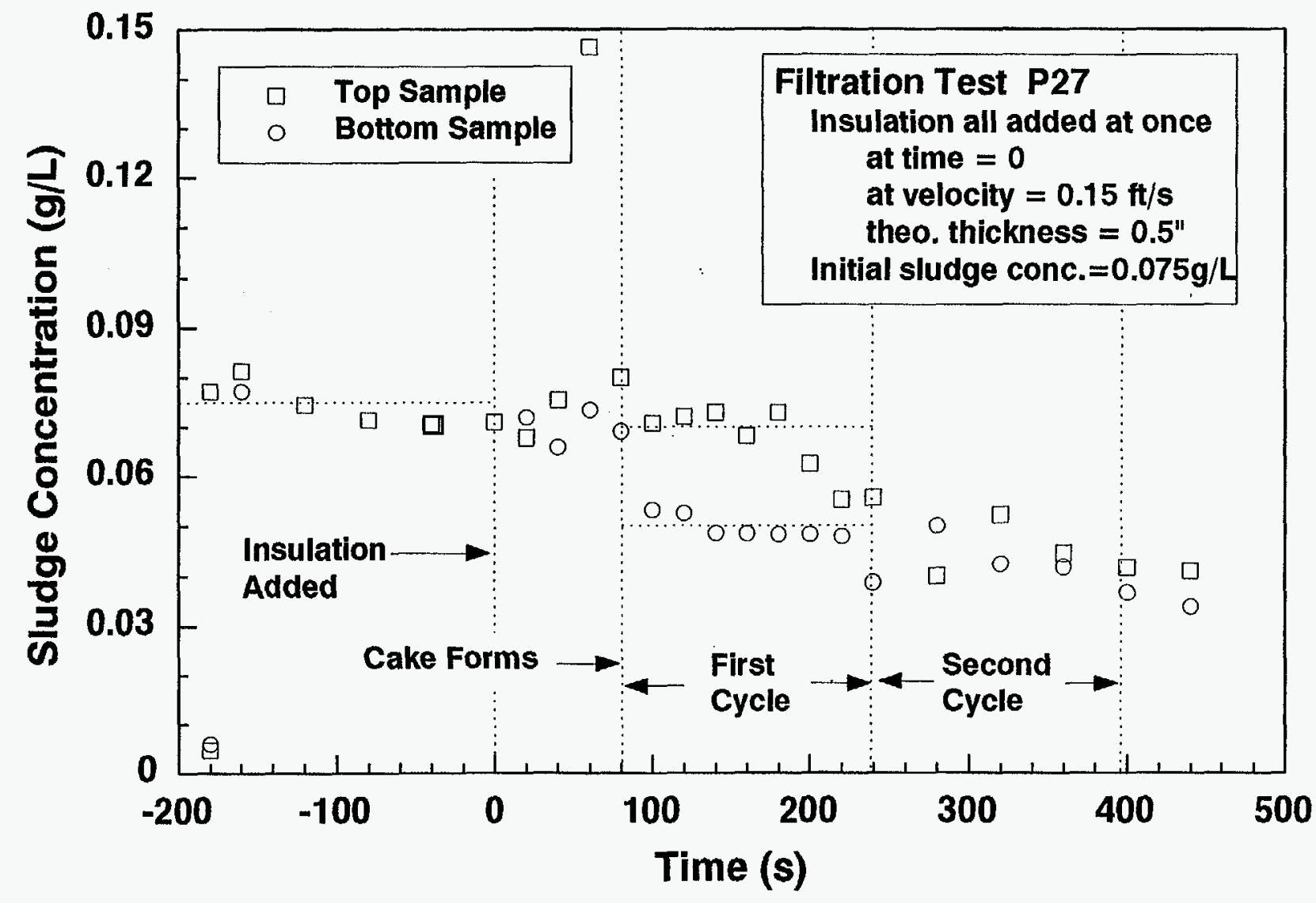

Figure 6-1. Loop Water Concentration as a Function of Time. Data Collected From Two Sampling Ports Located at Top and Bottom of the Strainer Simultaneously 
$\mathrm{e}_{\text {cumulative }}$ is cumulative filtration efficiency $M_{\text {total }} \quad$ is total sludge added to the loop ( $g$ )

$\mathrm{M}_{\text {cake }} \quad$ is total sludge filtered by the cake ( $\mathrm{g}$ )

Figure 6-2 presents estimated once-through filtration efficiencies for a $0.5^{\prime \prime}(1.3 \mathrm{~cm})$ thick fiber bed at 0.15 $\mathrm{ft} / \mathrm{s}(0.05 \mathrm{~m} / \mathrm{s})$ as a function of time. As evident from this figure, two alternatives exist for estimating the once-through filtration efficiency. In the first case, instantaneous concentrations both upstream and downstream of the strainer can be used to estimate once-through efficiency as a function of time. The efficiencies obtained using this method may reach as high as $33 \%$ during the first cycle and level to about $15 \%$ during the subsequent cycles. However, the trends exhibited varied from experiment to experiment suggesting that large experimental uncertainties are associated with these estimates. To minimize these variations, it was decided to obtain the filtration efficiency estimates based on time-averaged concentrations. These timeaveraged concentrations for the first cycle are illustrated in Figure 6-1 for Test P27. The oncethrough efficiencies obtained from these timeaveraged values are plotted in Figure 6-2 for both the first and second cycles. Both the instantaneous efficiencies and time averaged efficiencies suggest that filtration efficiency reaches a maximum value during the first cycle and decreases with every subsequent cycle. Based on SEM images of the sludge particles leftover in the water below the strainer, it was concluded that this decrease in efficiency is a reflection of shift in sludge particle distribution towards the smaller sizes $(<1 \mu \mathrm{m})$; i.e., the fraction of micron size particles contained in the water after a few flushing cycles is significantly lower than that in the sludge originally added to the loop. Since such a shift in particle size is not expected in the case of an open-loop arrangement, such as the BWR suppression pool, it is possible that the filtration efficiency in the open loop may not decrease with time. As a result, the once-through filtration efficiencies for the first cycle were interpreted to be the filtration efficiency corresponding to a once-through arrangement. These once-through filtration efficiency estimates are plotted in Figure 6-3 for several bed thicknesses and approach velocities.

Within the range tested, the once-through filtration efficiencies are fairly independent of both the approach velocity and fiber bed thickness. In all cases, the maximum efficiency attained was about $45 \%$. Note, however, that this estimate of $45 \%$ is associated with large experimental uncertainties involved with concentration measurements. Based on a bounding analysis, it was estimated that a maximum possible upper bound for the oncethrough efficiency is $50 \%$.

Figure 6-2 also presents the cumulative filtration efficiencies for Test P27. As shown in this figure the cumulative filtration efficiency increased steadily with time, ultimately reaching an asymptotic value of $66 \%$. These asymptotic values are plotted as functions of theoretical thickness in Figure 6-4. As evident from this figure the cumulative efficiency varies from $50 \%$ to $95 \%$ as the thickness increases from $1 / 8$ " to $2 "$. Beyond 2" the cumulative filtration efficiency was about $95 \%$. 


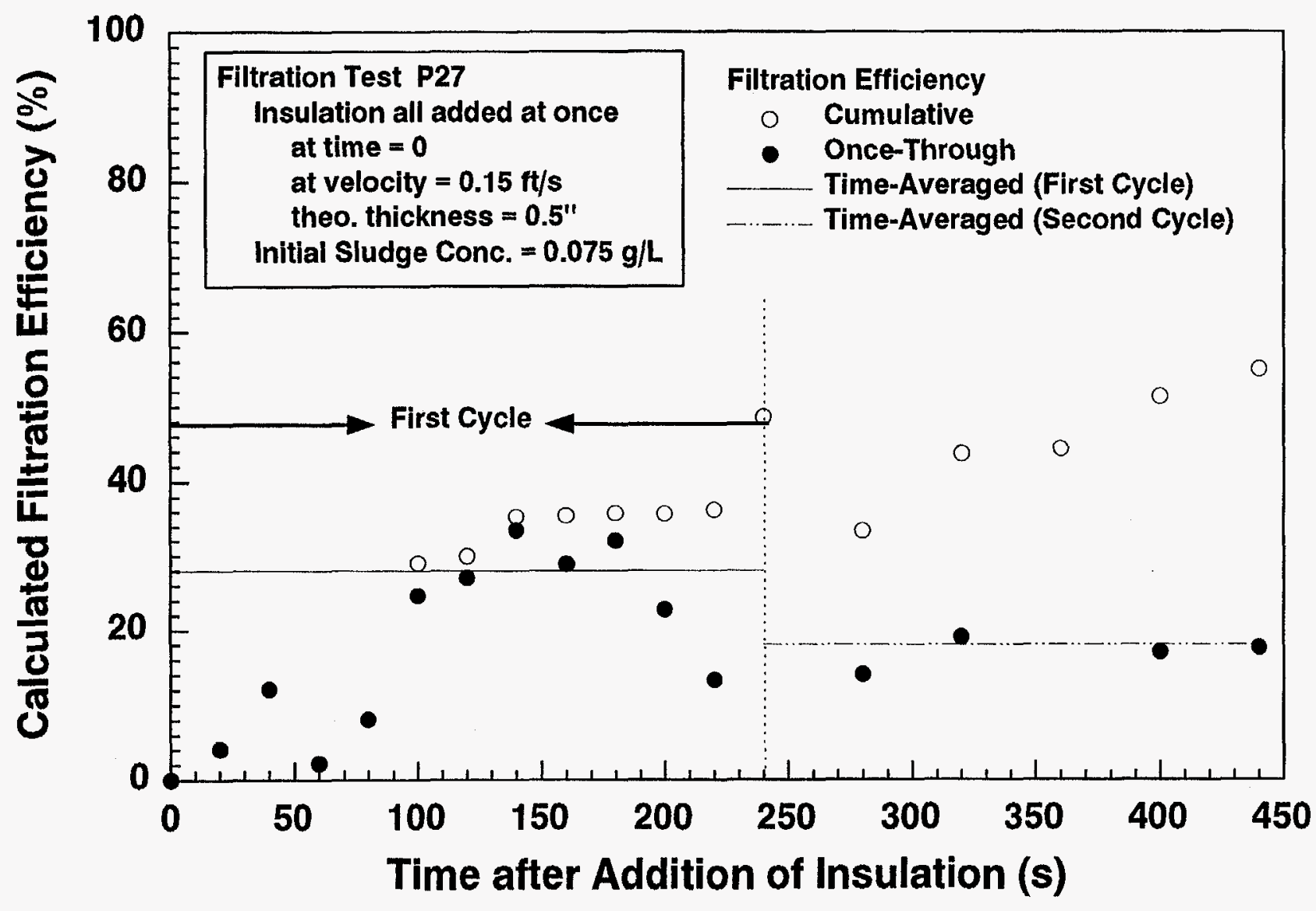

Figure 6-2. Cumulative and Once-Through Filtration Efficiency Measured From Test P27 


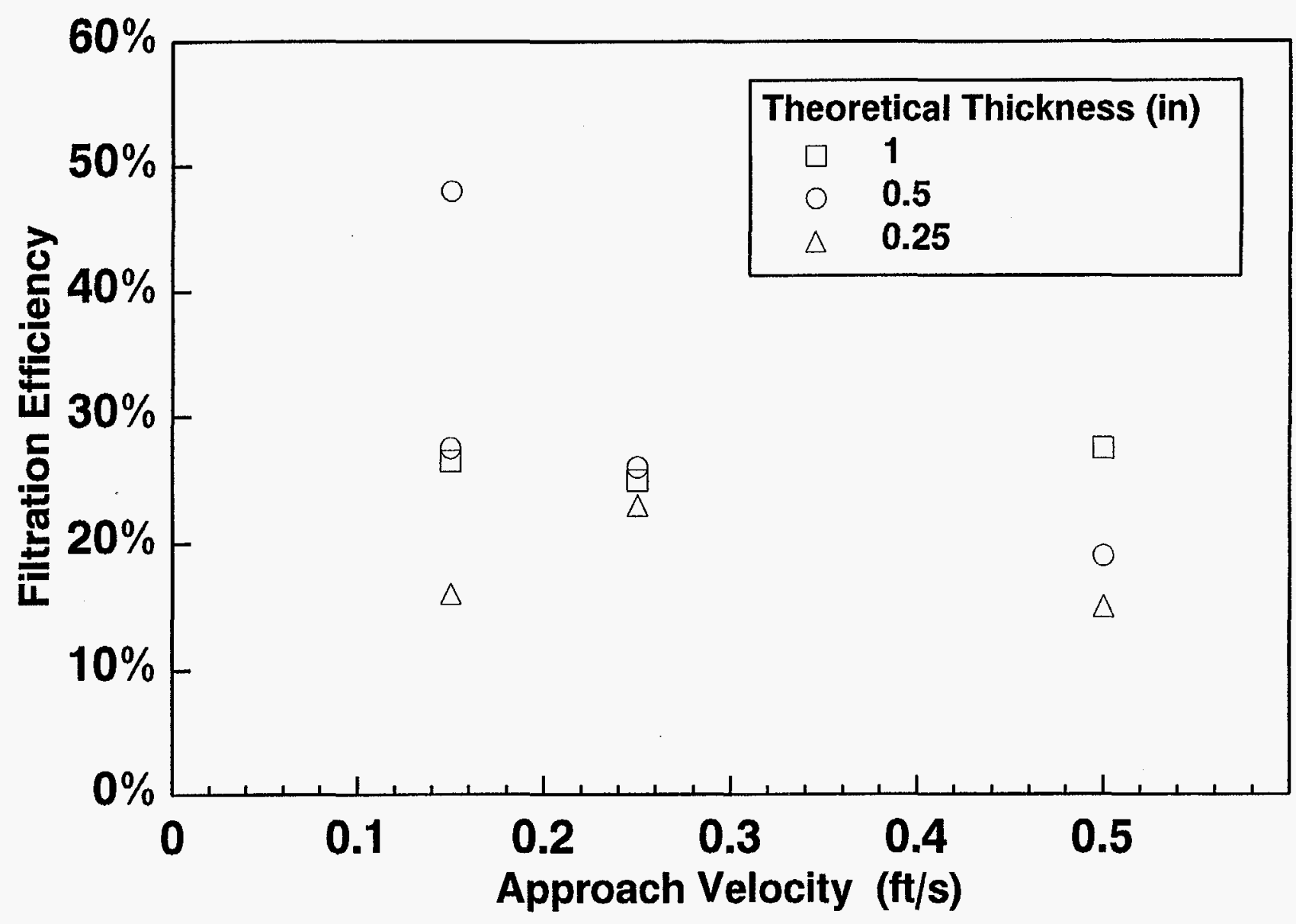

Figure 6-3. Filtration Efficiency vs. Approach Velocity 


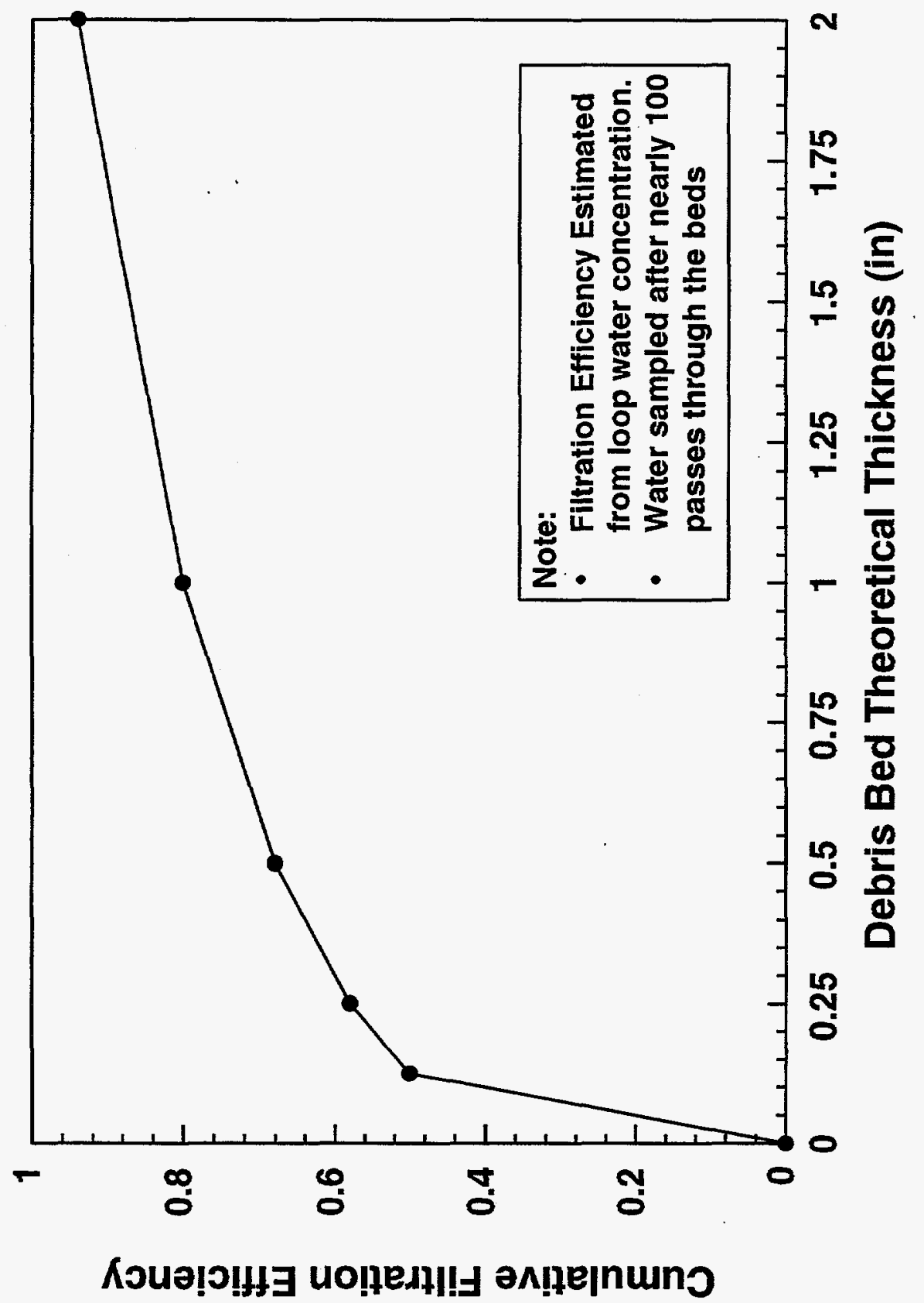

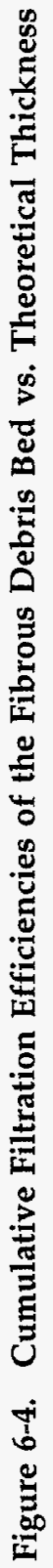


Filtration Efficiency Test Results and Analysis

\section{References for Section 6}

6.1 P. Murthy, M. Padmanabhan, F.J. Weber, G.E. Hecker, "Head Loss of Fibrous Insulation

Debris and Sludge for BWR Suction

Strainers," Alden Research Laboratory, Inc., 1995. 


\subsection{Summary and Significant Findings}

A series of controlled experiments were conducted at ARL under NRC sponsorship to obtain head loss and filtration characteristics of debris beds formed of NUKON ${ }^{\mathrm{TM}}$ fibrous fragments. A thermally insulated closed loop test set-up was selected to conduct experiments at elevated temperatures typical of suppression pools. A flat-plate strainer with a hole arrangement typical of strainers found in most U.S. BWRs was used to simulate the ECCS suction strainer. This test set-up was selected because it maximizes the amount of data that can be obtained. Being smaller in volume minimized time was required to clean the set-up between each test. Also, the set-up could be insulated appropriately to operate at elevated temperatures. Finally, its design permitted sustaining larger head losses which allowed for broader range of operating parameters. However, it does have the following short-comings:

1. Its usage to obtain accurate/reliable filtration data are somewhat limited by the fact that the flushing time scales are very small.

2. The transient head loss curves obtained are not prototypical of BWR suppression pool conditions and hence can not be used to validate transient predictions of BLOCKAGE.

3. Finally, usage of a flat plate strainer raises questions on the applicability of the data to assess strainer designs other than uniform strainers that are presently in use (i.e., the data may not be directly applicable for assessment of non-uniform passive strainers, especially at low fiber bed thicknesses).

A leaf shredder was used to generate the fibrous fragments that are judged to closely resemble the LOCA generated NUKON ${ }^{\mathrm{TM}}$ debris in the reference plant. A total of three particulate mixes, termed as Sludge A, Sludge B and Mix A, were used to simulate the particulate debris that are expected to reach the ECCS suction strainer after a LOCA.

The stable head losses across the strainers were measured using DP cells and the sludge concentration measurements were used to estimate the quantity of sludge contained in debris cake at the time the stable value is reached. Exploratory tests were effectively used to finalize the procedure used to introduce the debris into the loop. The insights gained from these exploratory tests related to debris introduction can be summarized as follows:

1. The approach velocity at which the debris bed forms does not significantly effect the head loss across the bed. As a result, it was possible in the experiments to form the debris bed at the lowest velocity $(0.15 \mathrm{ft} / \mathrm{s})$ and increase the velocity in preselected steps until a velocity of $1.5 \mathrm{ft} / \mathrm{s}$ was reached. This procedure maximized the head loss data that could be obtained from each test.

2. Once the bed is compacted under the influence of head loss, it does not fully recover to the original state. As a result, the head loss data obtained for precompressed beds was discarded from the correlation development.

3. The head loss was very sensitive to the method by which sludge and fibrous debris were introduced into the test loop. It is essential that experiments closely simulate, as much as possible, the actual conditions that prevail in the BWR suppression pool (i.e., the fiber and sludge debris intermixed with the water approach the strainer simultaneously). In this study, two methods were used to simulate these conditions, both of which provided very similar results.

The head loss data were obtained for theoretical fiber bed thicknesses of $0.125^{\prime \prime}$ to $4.0^{\prime \prime}$; approach velocities of 0.15 to $1.5 \mathrm{ft} / \mathrm{s}$; temperatures of $75^{\circ} \mathrm{F}$ and $125^{\circ} \mathrm{F}$; and sludge-to-fiber nominal concentration ratios of 0 to 60 . Within the range tested, the data exhibited the following trends:

1. The debris cakes, with or without sludge, were compressible under the influence of head loss resulting from flow through the cake. Visual observations suggest that the compaction was higher for pure fiber beds and was somewhat lower for sludge beds. The SEM images of the beds suggest that the fibers were aligned perpendicular to the flow, but in a random manner in the horizontal direction; i.e., the beds are best described as random beds normal to the flow. In the case 
of mixed beds, the sludge particles were primarily seen to be intermixed with the fibers, leading to formation of random mixed beds. The beds appear to be uniform, although this could not be confirmed for all depths.

2. The fibrous debris size difference (classes $3 \& 4$ versus classes $5 \& 6$ ) does not appear to play a significant role in the head loss. This result is likely a direct reflection of the minimal structural differences between classes $3 \& 4$ and classes $5 \& 6$. Attempts to generate very small size classes using the leaf shredder resulted in 'kernels' which are not prototypical of LOCA generated debris. Although, kernels induced larger head losses, it is not clear if those head losses resulted from the structure of the kernels or the smaller size of the debris.

3. Water temperature plays a significant role in determining the head loss. Increasing the water temperature decreases the head loss, most likely due to the associated decrease in water viscosity. No other effects of water temperature appear to play a significant role.

4. Particulate debris significantly increases the head loss across a debris bed. In some cases, a 100-fold increase in head loss was noted, corresponding to an increase in sludge-tofiber mass ratio of 10 . Head loss differences between Sludge A, Sludge B and Mix-A appear to be marginal, maybe because the particle size distributions in all these mixes are similar.

For test conditions where the beds are fairly uniform, the head loss data were predictable within an acceptable accuracy range by the semi-theoretical model. The model was equally applicable for both pure fiber beds and the mixed beds. Typically, the model predictions overestimated the head losses for very thin beds $\left(\Delta \mathrm{L}_{\mathrm{o}}<0.125^{\prime \prime}\right)$ and/or for thin beds at high sludge-to-fiber mass ratios. This overestimation is attributable to the non-uniformity of the debris beds. In this range, the correlation can be interpreted to provide upper bound estimates. Based on these findings, usage of the semitheoretical model in BLOCKAGE provides a reasonable approach for modeling head loss across the fiber beds.

The concentration measurements obtained during the first flushing cycle were used to estimate the filtration efficiencies of the debris beds. The measurements were conducted for thicknesses ranging from 0.25 to 1 in; over a velocity range of 0.15 to $0.5 \mathrm{ft} / \mathrm{s}$; and a sludge concentration between $0.05 \mathrm{~g} / 1$ to $0.15 \mathrm{~g} / 1$. The results of these tests suggest the following:

1. Once-through filtration efficiencies were typically $20-50 \%$ over the range of parameters tested. These efficiencies were weakly dependent on the approach velocity and the fiber bed thickness. However, these findings should not be extrapolated beyond the range of measurement because it is very likely that fiber beds thinner than $0.25^{\prime \prime}$ would possess much lower filtration efficiencies.

2. The data suggest that cumulative filtration efficiency increases with the number of loops circulated and finally reaches a stable value. Typically the saturation or cumulative filtration efficiency was found to be a strong function of the bed thickness, ranging from nearly $90 \%$ to $50 \%$, while the fiber bed thickness was varied between 1 in to 0.125 in.

The filtration efficiencies measured from these experiments should be regarded as approximate. In general, they suggest that only a fraction of the debris would ultimately be filtered by the thin debris cakes regardless of the number of times the particles pass through the bed. Based on these insights, a simplified filtration model was developed and incorporated into BLOCKAGE. 
Appendix A

Instrument Calibration Sheets 

Summary and Significant Findings

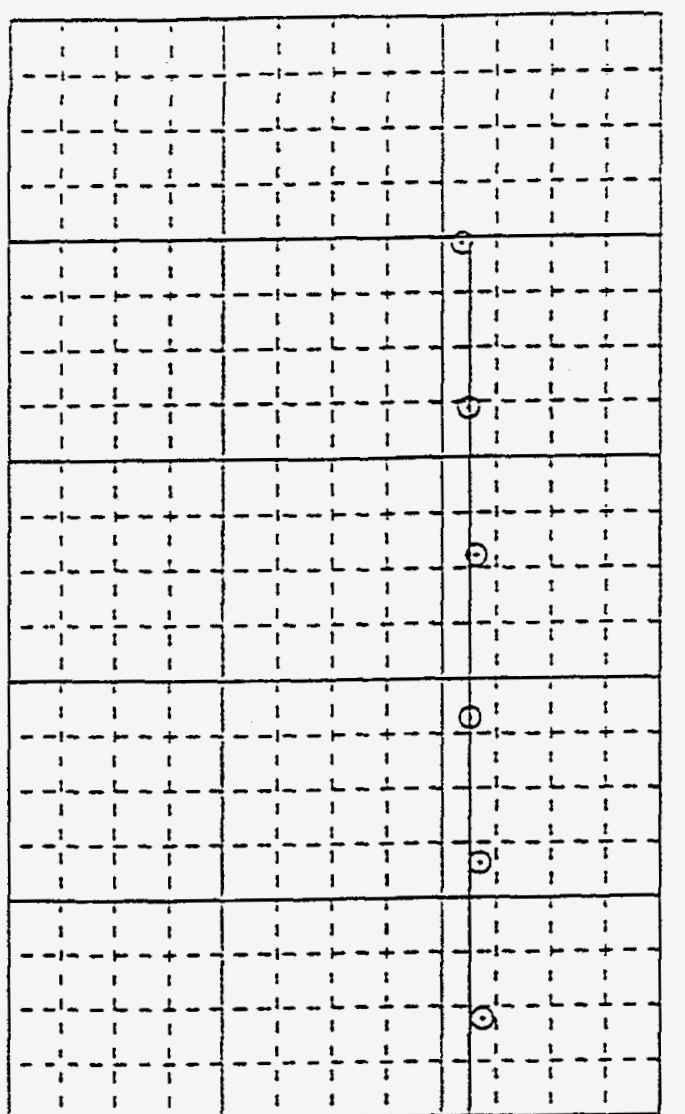

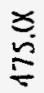

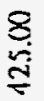

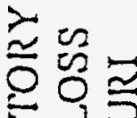

¿

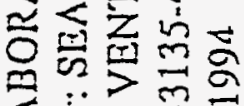

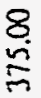

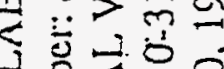

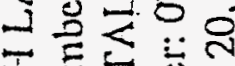

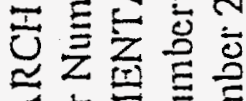

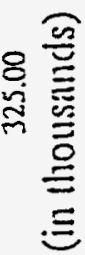

8

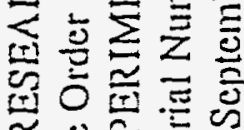

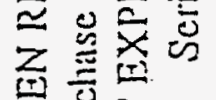

$\frac{3}{2}=$

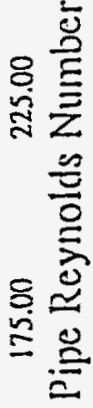

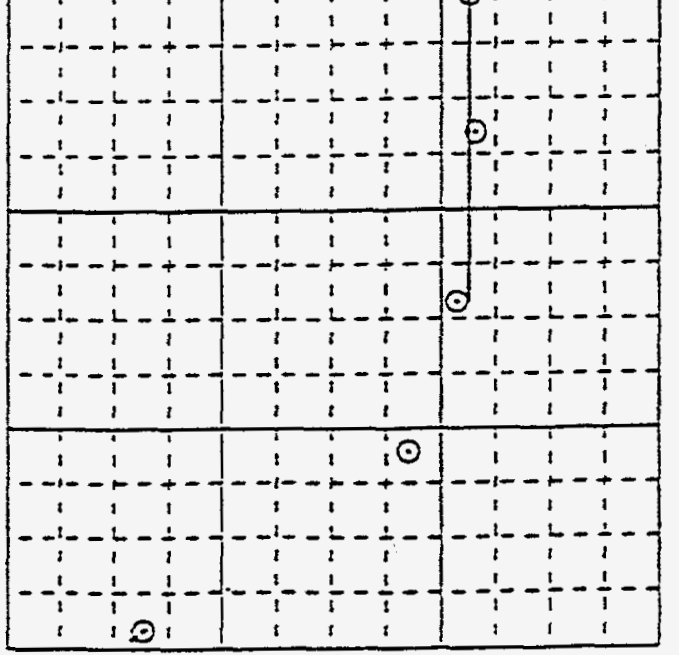

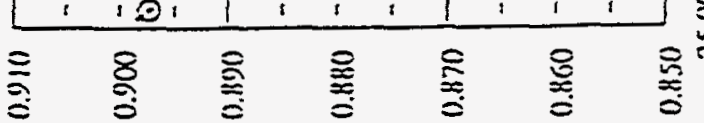

ญ.

$\underset{8}{8}$

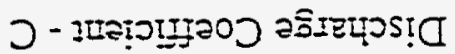

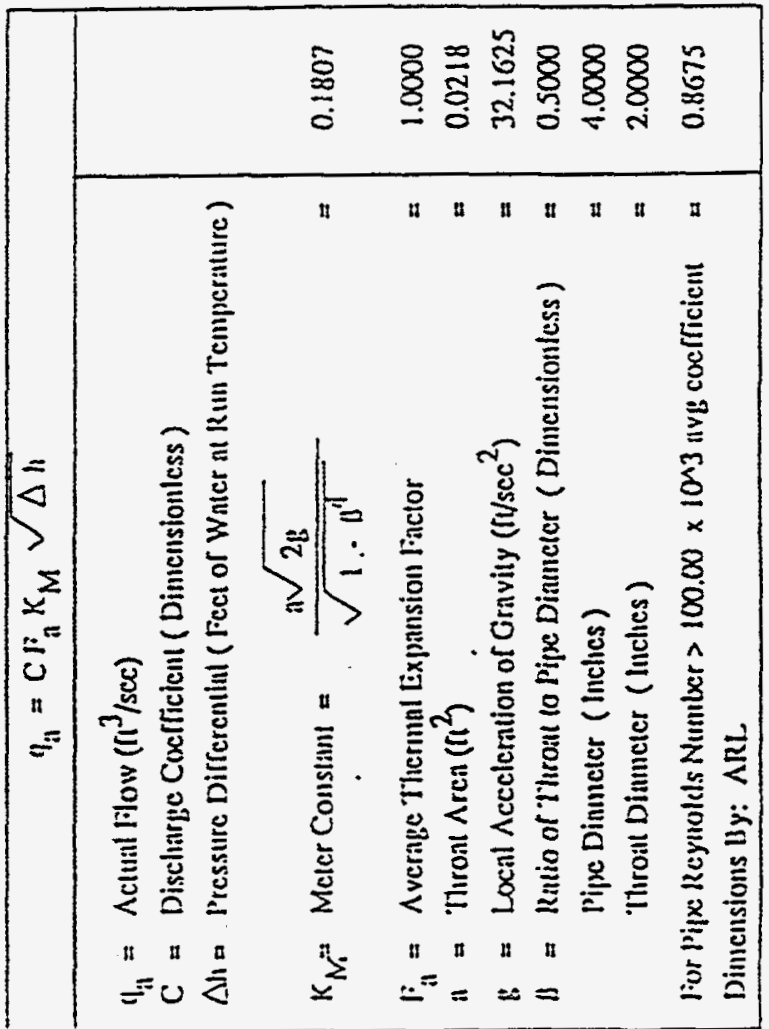




\begin{tabular}{|c|c|c|c|c|c|c|c|c|c|}
\hline "U1" & $\begin{array}{l}\text { Linc } \\
\text { Temin } \\
\text { Dep I: }\end{array}$ & $\begin{array}{c}\text { Air } \\
\text { Tcmip } \\
\text { Deg }{ }^{\prime}\end{array}$ & $\begin{array}{c}\text { Nal } \\
\text { Weigllt } \\
\text { II. }\end{array}$ & $\begin{array}{l}\text { Rum } \\
\text { Duration } \\
\text { secs. }\end{array}$ & $\begin{array}{c}\text { Oulput } \\
\text { [see } \\
\text { nolc] }\end{array}$ & $\begin{array}{l}\text { Fow } \\
\text { CrS }\end{array}$ & $\begin{array}{l}\text { HLinc } \\
\text { FrH20 }\end{array}$ & $\begin{array}{l}\text { Pipe } \\
\text { Rey. } \\
\times 10 \% 5\end{array}$ & Coel \\
\hline $\begin{array}{l}1 \\
2 \\
3 \\
1 \\
5\end{array}$ & $\begin{array}{l}68 \\
681 \\
68 \\
68 \\
68\end{array}$ & $\begin{array}{l}68 \\
68 \\
68 \\
68 \\
68\end{array}$ & $\begin{array}{l}1063 \\
2058 \\
2053 \\
2046 \\
1066\end{array}$ & $\begin{array}{l}161.507 \\
111.907 \\
166.231 \\
396.509 \\
132.311\end{array}$ & $\begin{array}{l}1.531 \sim \\
3.310 \sim \\
8.061 \sim \\
3.017 \sim \\
5.777 \sim\end{array}$ & $\begin{array}{c}0.4042 \\
0.2952- \\
0.1983 \\
8.2891 \mathrm{E}-02 \\
0.4936\end{array}$ & $\begin{array}{l}6.659 \\
3.539 \\
1.582 \\
0.261 \\
9.921\end{array}$ & $\begin{array}{l}1.1234 \\
1.0398 \\
0.6986 \\
0.2919 \\
1.7384\end{array}$ & $\begin{array}{l}0.8660) \\
0.8686 \\
0.8730 \\
0.8973 \\
0.8673\end{array}$ \\
\hline $\begin{array}{c}6 \\
7 \\
8 \\
9 \\
10\end{array}$ & $\begin{array}{l}68 \\
68 \\
68 \\
68 \\
68\end{array}$ & $\begin{array}{l}68 \\
68 \\
68 \\
68 \\
68\end{array}$ & $\begin{array}{l}6073 \\
8080 \\
8081 \\
8085 \\
8083\end{array}$ & $\begin{array}{l}159.364 \\
181.852 \\
161.600 \\
141.661 \\
129.594\end{array}$ & $\begin{array}{l}7.791 \sim \\
3.360 \sim \\
3.792 \sim \\
4.238 \sim \\
1.795 \sim\end{array}$ & $\begin{array}{l}0.6122 \\
0.7022 \\
0.8033 \\
0.8979 \\
1.002\end{array}$ & $\begin{array}{l}15.197 \\
20.126 \\
26.324 \\
32.813 \\
40.921\end{array}$ & $\begin{array}{l}2.1561 \\
2.4730 \\
2.8290 \\
3.1619 \\
3.5287\end{array}$ & $\begin{array}{l}0.8691 \\
0.8663 \\
0.8665 \\
0.8674 \\
0.8669\end{array}$ \\
\hline $\begin{array}{l}11 \\
12\end{array}$ & $\begin{array}{l}68 \\
68\end{array}$ & $\begin{array}{l}68 \\
68\end{array}$ & $\begin{array}{l}8090 \\
8087\end{array}$ & $\begin{array}{l}118.519 \\
107.948\end{array}$ & $\begin{array}{l}5.316 \sim \\
6.028 \sim\end{array}$ & $\begin{array}{l}1.096 \\
1.203\end{array}$ & $\begin{array}{l}18.931 \\
58.857\end{array}$ & $\begin{array}{l}3.8619 \\
1.2381\end{array}$ & $\begin{array}{l}0.8676 \\
0.8682\end{array}$ \\
\hline
\end{tabular}


v. 00 csioss ouA

Calibration of BLif I ransmitter

5. $7 \pi 75$

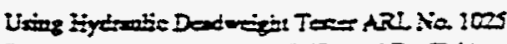

Dove: 28995

Centroud Bycasa

Reare Sal O-SO PSI

Tempesere 75 \&

\begin{tabular}{|c|c|c|c|c|c|c|c|c|c|}
\hline \multicolumn{6}{|c|}{ 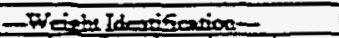 } & \multirow{2}{*}{$\begin{array}{l}\text { Tenter } \\
\text { PSI }\end{array}$} & \multirow{2}{*}{$\begin{array}{l}\text { Rexiog } \\
\text { voles }\end{array}$} & \multirow{2}{*}{$\begin{array}{l}\text { Celeatured } \\
\text { PSI }\end{array}$} & \multirow{2}{*}{$\begin{array}{l}P=x \\
\text { Exror }\end{array}$} \\
\hline & 24 & 5 & 10 & $20 A$ & 208 & & & & \\
\hline 1 & & & & & & 0000 & -20074 & & \\
\hline 2 & 1 & & & & & $5 m$ & 0604 & $\leq 0007$ & nam! \\
\hline 3 & 1 & 1 & & & & 10005 & 16381 & 90005 & 0.149 \\
\hline 4 & 1 & & $I$ & & & 15.005 & 26002 & 14.9833 & 0.157 \\
\hline 5 & 1 & 1 & 1 & & & 2000 & 3.5704 & 19.9317 & 0.129 \\
\hline 6 & 1 & & & I & & 25.007 & 4551 & 24.9823 & 0.009 \\
\hline 7 & 1 & 1 & & ! & & 30009 & 55226 & 29.9828 & 0.088 \\
\hline 8 & 1 & & 1 & 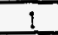 & & 35.009 & 6.4967 & 34.9962 & 0.05 \\
\hline 9 & 1 & 1 & 1 & $i$ & & 40.011 & 7.4698 & 400045 & 0.017 \\
\hline 10 & 1 & & & 1 & 1 & 45.0?1 & 8.4447 & 45.0000 & -0.024 \\
\hline i1 & 1 & & & 1 & 1 & 45.011 & 8.4447 & $45 . \mathrm{mmo}$ & -0.044 \\
\hline 12 & 1 & 1 & 1 & 1 & & 40.011 & 7.4731 & 402014 & -0.025 \\
\hline 13 & 1 & & 1 & 1 & & 35000 & 65018 & 35,0225 & $=0038$ \\
\hline 14 & 1 & 1 & & 1 & & 30000 & 55202 & 300173 & $-2 \mathrm{~mm}$ \\
\hline 15 & 1 & & & 1 & & 25007 & 45585 & 25,0200 & -2055 \\
\hline 16 & 1 & 1 & I & & & 20007 & 35861 & $20016 ?$ & $-0,04$ \\
\hline 17 & 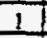 & & 1 & & & 15.005 & 26153 & 15.0198 & -0.006 \\
\hline 18) & 1 & 1 & & & & 10005 & 1.645 & 100050 & -0206 \\
\hline 19 & 1 & & & & & 5.003 & 0.6743 & 5.0501 & $0 \leq 53$ \\
\hline 201 & & & & & & 0.000 & 02954 & & \\
\hline$x=$ & $z$ & & & & & & & Slope: & 5.146677 \\
\hline$x$ & ค1 & & ז & & & & & Sed ET: & $\begin{array}{l}\text { 1.S5Ges5? } \\
0.0178608\end{array}$ \\
\hline
\end{tabular}

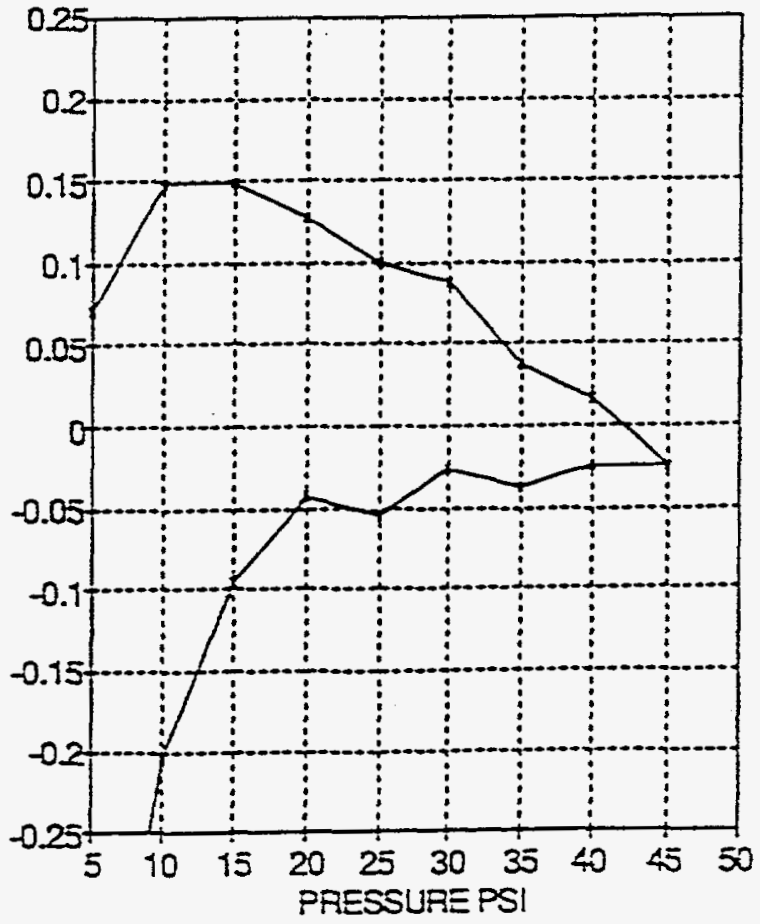


Summary and Significant Findings

v1.00 csiors catt

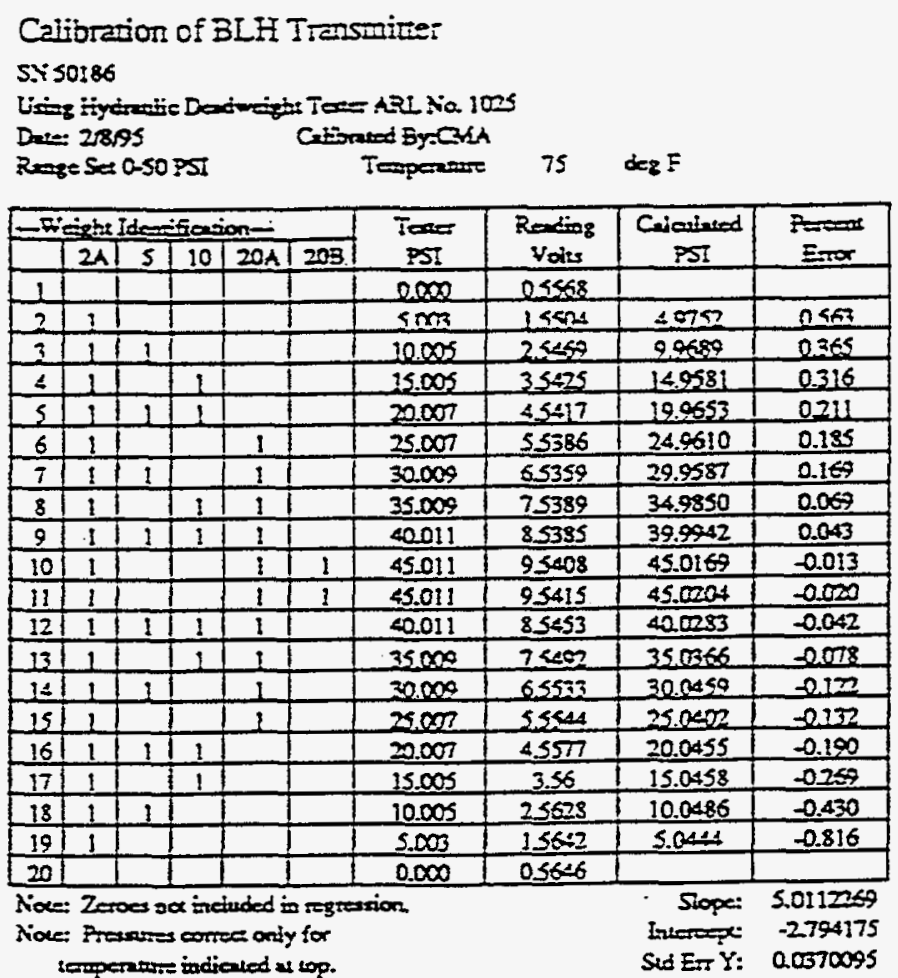

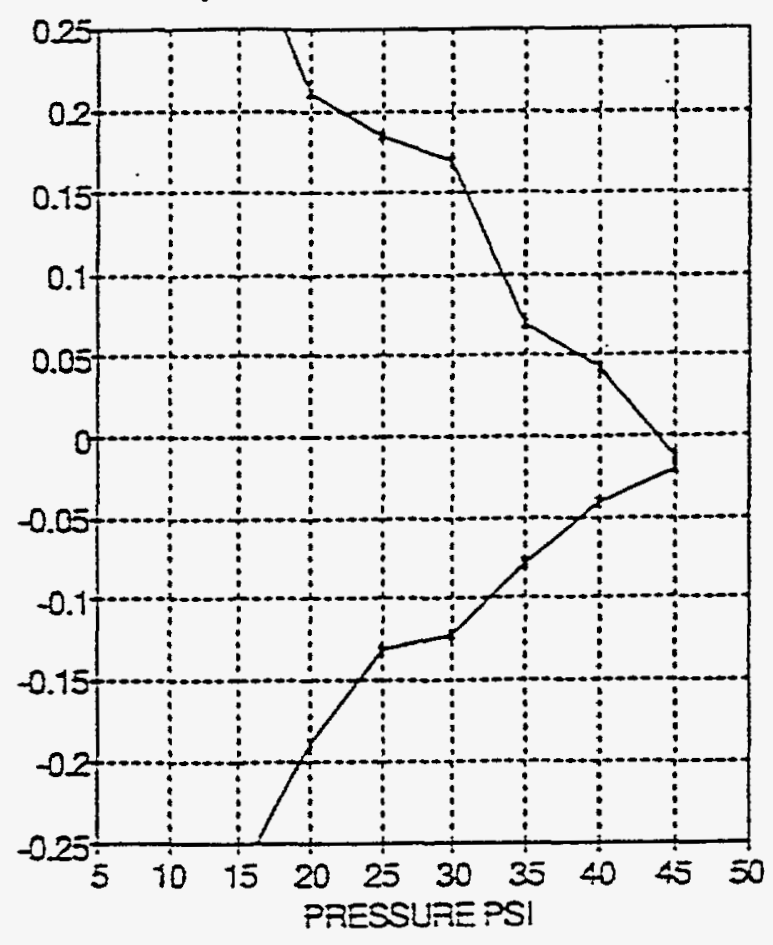


Calitration of BLF Transminter

ARL tia: mso s.i sots6

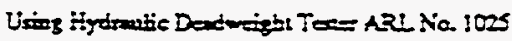

RemeSelo-SOPSI Temperare 75 F

Fie: HONSOA. FO

\begin{tabular}{|c|c|c|c|c|c|c|c|c|c|}
\hline \multicolumn{6}{|c|}{ Wsidentiforion- } & \multirow{2}{*}{$\begin{array}{c}\text { Tearr } \\
\text { PSI }\end{array}$} & \multirow{2}{*}{$\begin{array}{l}\text { Rexios } \\
\text { Voles }\end{array}$} & \multirow{2}{*}{$\begin{array}{c}\text { Caierinted } \\
\text { PSI }\end{array}$} & \multirow{2}{*}{$\begin{array}{l}\text { Iytror } \\
\text { Extror }\end{array}$} \\
\hline & $2 A$ & 5 & 10 & $30 \mathrm{~A}$ & 203 & & & & \\
\hline 1 & & & & & & 0000 & 0178 & & \\
\hline 2 & 1 & & & & & sor & 11742 & 50330 & $=0 \sin$ \\
\hline 3 & 1 & 1 & & & & 10.005 & 2.1663 & 100584 & -0.330 \\
\hline 4 & 1 & & 1 & & & 15.005 & 3.1576 & 15.5589 & 0724 \\
\hline 5 & 1 & 1 & 1 & & & 20001 & 4.1557 & 20,052 & -0.080 \\
\hline 6 & 1 & & & I & & 25.007 & 5.0987 & 24.8505 & 0.710 \\
\hline 7 & 1 & 1 & & 1 & & 30.009 & 6.0579 & 29.8708 & 0.462 \\
\hline 8 & 1 & & 1 & 1 & & 35.009 & 7.075 & 34.7997 & 0.601 \\
\hline 9 & 1 & 1 & 1 & 1 & & $<0.011$ & 8.0703 & 39.8209 & 0.478 \\
\hline 10 & 1 & & & 1 & $i$ & 45.011 & 9.1601 & 45.3177 & -0.577 \\
\hline III & 1 & & & 1 & 1 & 45.011 & 9.1557 & 45.2955 & $-0.6 \times 9$ \\
\hline 12 & 1 & 1 & 1 & 1 & & 40.011 & 8.1242 & $40 \cos 22$ & -0.203 \\
\hline 13 & 1 & & 1 & 1 & & 35000 & 70004 & 34.8723 & 0391 \\
\hline 14 & 1 & 11 & & 1 & & 30009 & 60890 & 208054 & 0.615 \\
\hline 151 & 1 & & & 1 & & 25007 & $5.11 \pi$ & 240263 & 0,32 \\
\hline 16 & 1 & 1 & 1 & & & 30.007 & 4.1581 & 20.0857 & $-0.39 i$ \\
\hline 17 & 1 & & 1 & & & 15.005 & 3.1679 & 15.0908 & $-0 \leq 568$ \\
\hline 18 & 1 & 1 & & & & 10.005 & 2.1792 & 10.1054 & -0.572 \\
\hline 19 & 1 & & & & & 5.000 & 1.1809 & $3.06 \pi$ & $-17 \sqrt{3}$ \\
\hline 201 & & & & & & 0.000 & 0.1826 & & \\
\hline Fot & & & & & & & & 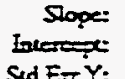 & $\begin{array}{l}5.3443665 \\
-0.889239 \\
0.1584159\end{array}$ \\
\hline
\end{tabular}

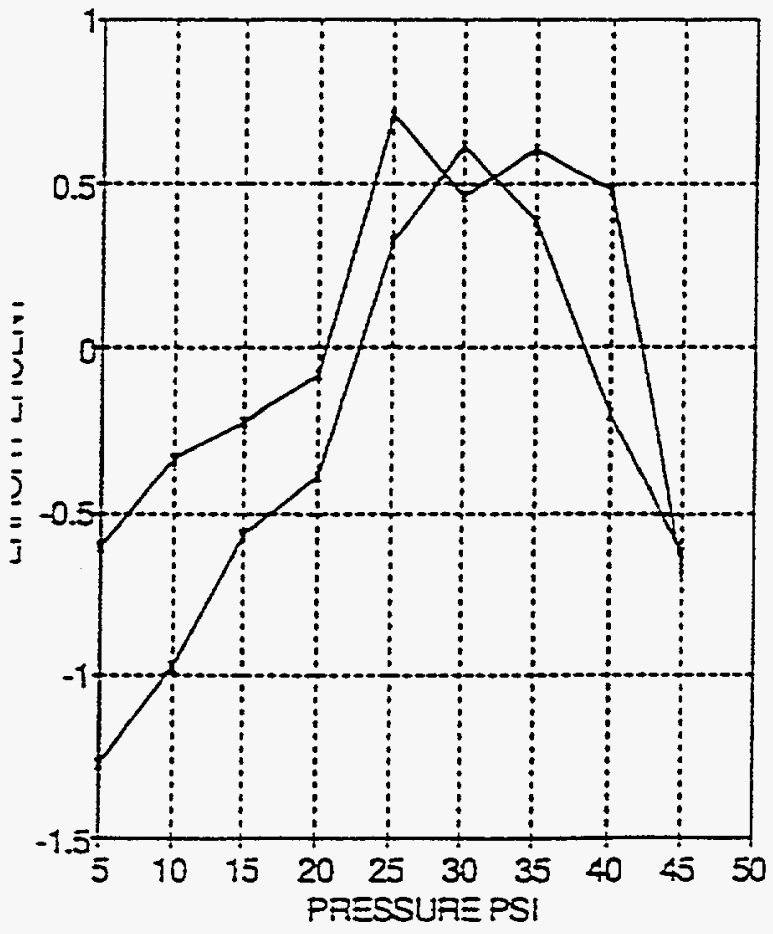


Summary and Significant Findings

v1.000snors oxt

Calibration of BLF Transmizer

ARLXia: $5:$ TाTा

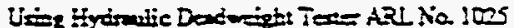

Dode: 2395 Cajioned By.CMA

Rere Sel 0.50 PSI Tempereme 75 dez F

Be: FONSOA.FO

\begin{tabular}{|c|c|c|c|c|c|c|c|c|c|}
\hline \multicolumn{6}{|c|}{ - } & \multirow{2}{*}{$\begin{array}{c}\text { Tener } \\
\text { PSI }\end{array}$} & \multirow{2}{*}{$\begin{array}{c}R=\text { dises } \\
\text { Voliss }\end{array}$} & \multirow{2}{*}{$\begin{array}{l}\text { Cuiesherod } \\
\text { PSI }\end{array}$} & \multirow{2}{*}{ Enex } \\
\hline & 24 & $s$ & 101 & $20 \mathrm{~A}$ & 203 & & & & \\
\hline 1 & & & & & & 0,000 & 0,0014 & & \\
\hline 2 & 1 & & & & & $5 \mathrm{moz}$ & $n 0018$ & $5 \pi<4$ & $\cap \cap 49$ \\
\hline 3 & 1 & 1 & & & & 10005 & 19978 & 100417 & $\Rightarrow 0,05$ \\
\hline 4 & 1 & & 11 & & & 15.005 & 2.5251 & 15.0048 & 0.002 \\
\hline 5 & 1 & 1 & 11 & & & 32.007 & 3.892 & 19.0958 & 0.057 \\
\hline 6 & 1 & & & 1 & & 25.007 & 4.8522 & 24.9527 & 0218 \\
\hline 7 & 1 & 1 & & 1 & & 30.009 & 5.5213 & 29.9546 & 0.181 \\
\hline 8 & 1 & & 11 & 1 & & 35.009 & 6.7553 & 34.5306 & 077 \\
\hline 9 & 1 & $i$ & 11 & 1 & & 40.011 & 7.75688 & 39.9454 & 0.164 \\
\hline 10 & 1 & & & 1 & 1 & 45.011 & 8.7612 & 45.1300 & -0.254 \\
\hline 11 & 1 & & & 1 & 1 & 45.011 & 8.7597 & 45.1227 & -0.257 \\
\hline 121 & 1 & 1 & 11 & 1 & & 40.011 & $7 . \pi 19$ & 40.0233 & -0.051 \\
\hline 13 & 1 & & 1 & 1 & & 35000 & 67094 & 340573 & 0.118 \\
\hline 141 & 1 & 1 & 1 & 1 & & 30000 & 58109 & 29.0174 & 0.206 \\
\hline 15 & 1 & & & 1 & & 25,007 & $\leq 958$ & 249800 & 0,008 \\
\hline 16 & 1 & 1 & 11 & & & 20.007 & 3.8981 & 20.0273 & -0.101 \\
\hline 17 & 1 & & 1 & & & 15.005 & 2.9302 & 15.0311 & -0.173 \\
\hline 18 & 1 & 1 & & & & 10.005 & 19638 & 10.0427 & -0.373 \\
\hline 19 & 1 & & & & & 5.003 & 0.9943 & 5.0383 & -0.69 \\
\hline 20 & & & & & & 0.000 & 0.0553 & & \\
\hline
\end{tabular}

Nole: Zeroes nox included in restrasion

Tioce: Prownes correc only for

Siope: 5.161866

Lemperavrs indioued as uop

$-0.094164$

Sut E-T: $\quad 0.0578691$

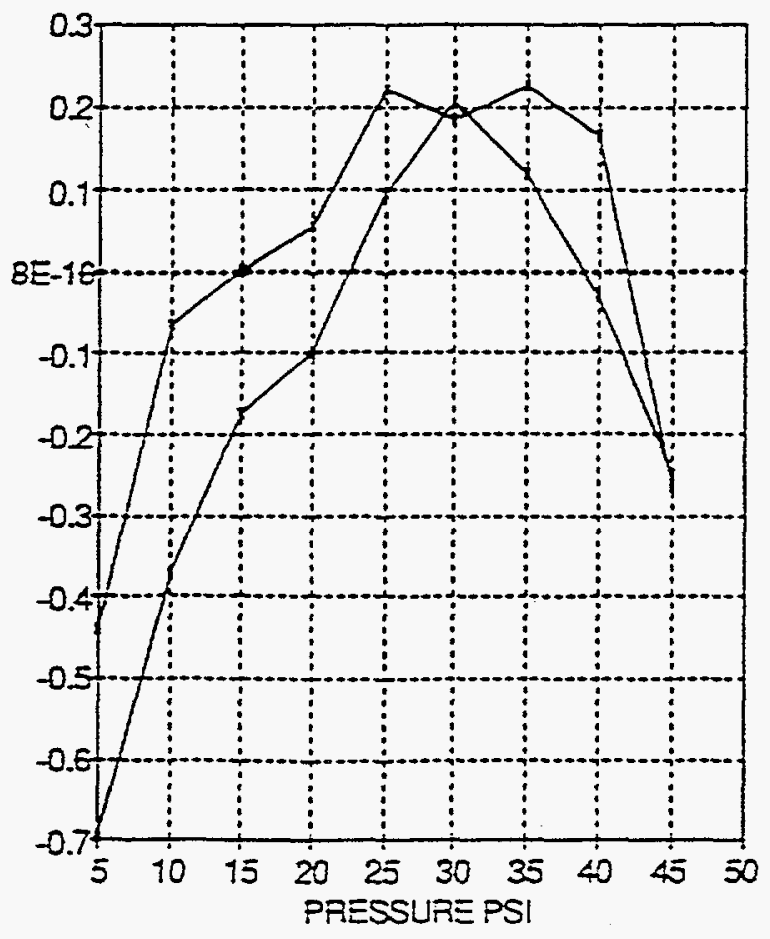

Revisoned 


\section{Calioraton OE BLFX-DUCER}

$S \equiv R$ No.: $\pi \pi 17$

Usi=g Hychive Deacw joit Teser ARL No. 1025

Dare: $9 / 28 / 94$ Calizateo उy:CMA

Razge Set 0-50 PSI Terpeazir 76.6 $\quad \mathrm{i}=\mathrm{g}$ F

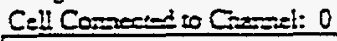

\begin{tabular}{|c|c|c|c|c|c|c|c|c|c|c|}
\hline \multicolumn{7}{|c|}{-Waight Id-iffetion- } & \multirow{2}{*}{$\begin{array}{l}\text { Tes:= } \\
\text { PSI }\end{array}$} & \multirow{2}{*}{$\begin{array}{l}\text { Readis } \\
\text { Vaits }\end{array}$} & \multirow{2}{*}{$\begin{array}{c}\text { Colerbisted } \\
\text { PSI }\end{array}$} & \multirow{2}{*}{$\begin{array}{c}\text { Pect: } \\
\text { Etror }\end{array}$} \\
\hline 1 & 11 & $2+1$ & 231 & 5 & 101 & $20 \mathrm{~A}$ & & & & \\
\hline 1 & & & & & $I$ & & 0.000 & 0.0516 & & \\
\hline 2 & & 1 & & & 1 & & 5.005 & 1.0215 & 5.0111 & -0.159 \\
\hline$\frac{3}{3}$ & & 11 & & ! & 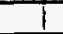 & & 10.005 & 1.9995 & 10.0021 & 0.051 \\
\hline 4 & & 1 & i & & $!$ & & 15.005 & 2.9565 & 14.9879 & 0.114 \\
\hline 5 & & 1 & & 1 & 1 & & 20.007 & 3.9256 & 19.9897 & 0.086 \\
\hline$\frac{6}{6}$ & & 1 & & & & 1 & 25.007 & 4.898 & 24.9982 & 0.033 \\
\hline 71 & & 1 & & 1 & & 1 & 30.009 & 5.868 & 20.9095 & 0.030 \\
\hline 81 & & 11 & & & 11 & 1 & 35.008 & 6.8396 & $35.009 !$ & $-0.00 ?$ \\
\hline 91 & 11 & & & 1 & 11 & I & 39.010 & 7.6168 & 39.0163 & -0.016 \\
\hline 101 & 11 & & & 1 & 11 & 1 & 39.010 & 7.6175 & 39.0199 & -0.025 \\
\hline III & & 1 & & & 11 & 1 & 35.008 & 6.8409 & 35.0158 & -0.021 \\
\hline 12 & & 11 & & 1 & 1 & $!$ & 30.009 & 5.8599 & 30.0093 & -0.005 \\
\hline 131 & & 11 & & & 1 & 1 & 25.007 & $4.90 !$ & 25.0137 & -0.029 \\
\hline 14 & & 11 & & 1 & 11 & & 20.007 & 3.9278 & 19.9959 & 0.056 \\
\hline 15 & & 11 & & & 11 & & 15.005 & 2.9598 & $15.00<9$ & 0.001 \\
\hline 161 & & 11 & & 1 & & & 10.005 & 1.9916 & 10.0129 & $-0.0 \pi$ \\
\hline 171 & & 11 & & & & & 5.003 & 1.0234 & 5.0209 & .0353 \\
\hline 181 & & 7 & & & 1 & & 0.000 & 0.0512 & & \\
\hline & Slope: & 5.1559834 \\
\hline \multicolumn{9}{|c|}{ 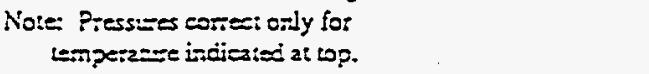 } & $\begin{array}{l}\text { interesp: } \\
\text { Sid ETY: }\end{array}$ & $\begin{array}{l}-0.255774 \\
0.0105519\end{array}$ \\
\hline
\end{tabular}

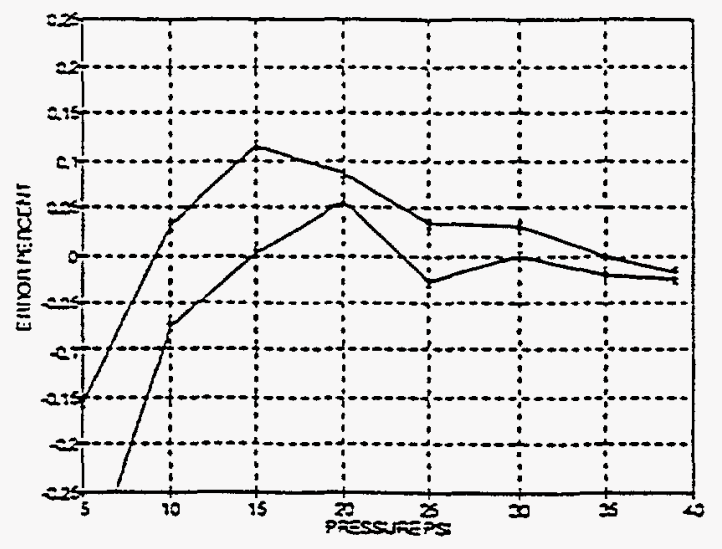

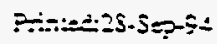

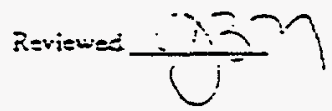


Summary and Significant Findings

V1.1001/035SCN!A

Calibretion of BLF X-DUCER

$S \equiv R$ No.: 50185

Usisg Hy:

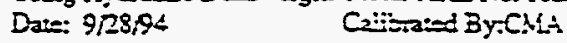

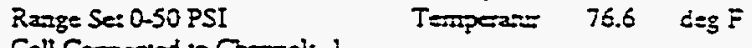

Cell Co:

\begin{tabular}{|c|c|c|c|c|c|c|c|c|c|c|}
\hline \multicolumn{7}{|c|}{$-W_{\text {giott Id-rifletion- }}$} & \multirow{2}{*}{$\begin{array}{c}\text { Tes:e } \\
\text { PSI }\end{array}$} & \multirow{2}{*}{$\begin{array}{l}\text { Read:s } \\
\text { Yolss }\end{array}$} & \multirow{2}{*}{$\begin{array}{c}\text { Calcilated } \\
\text { PSI }\end{array}$} & \multirow{2}{*}{$\begin{array}{l}\text { Peen: } \\
\text { Efor }\end{array}$} \\
\hline & 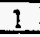 & $2 \mathrm{~A}$ & $23 !$ & 5 & 10 & $20 \mathrm{~A}$ & & & & \\
\hline$!$ & & & & & & & 0.000 & 02666 & & \\
\hline 2 & & 11 & & & & & 5.005 & 1.2582 & 4.9923 & 0.217 \\
\hline 3 & & 1 & & 1 & & & 10.005 & 22534 & 9.9783 & 0.259 \\
\hline 4 & & 11 & & & 1 & & 15.005 & 3.2548 & 14.9953 & 0.064 \\
\hline 5 & & 11 & & 1 & 1 & & 20.007 & $4.2 \leqslant 98$ & 19.9803 & 0.134 \\
\hline 6 & & 1 & & & & 1 & 25.007 & 5.2457 & 24.9748 & 0.127 \\
\hline 7 & & 1 & & 1 & & 1 & 30.009 & 6.2459 & 29.9858 & 0.076 \\
\hline 8 & & 11 & ! & & 1 & 1 & 35.008 & 7.2486 & $35.00 \leq 4$ & 0.011 \\
\hline 9 & 1 & & & 1 & 1 & 1 & 39.010 & 8.0488 & 39.0134 & -0.009 \\
\hline 101 & 1 & & & 1 & 1 & 1 & 39.010 & 8.0482 & 39.0104 & .0 .001 \\
\hline 111 & & 1 & & & 1 & 1 & 35.008 & 7.2524 & 35.0231 & -0.043 \\
\hline 121 & & 1 & & 1 & & 1 & 30.009 & 6.2547 & 30.0249 & -0.055 \\
\hline 131 & & 1 & & & & 1 & 25.007 & 52581 & 25.0319 & -0.101 \\
\hline 14 & & 1 & & i & 1 & & 20.007 & 4.2565 & 20.0139 & -0.034 \\
\hline 151 & & 1 & & & 1 & & 15.005 & 3.2621 & 15.0319 & -0.179 \\
\hline 161 & & 1 & & 1 & & & 10.005 & 22518 & 10.0204 & -0.152 \\
\hline 17 & & 1 & & & & & 5.003 & 1.2649 & 5.0259 & -0.453 \\
\hline 181 & & & & & & & 0.000 & 0.26 & & \\
\hline
\end{tabular}

Note: Zeroes not ineluded in regression.

Nole: ?t=sties contest oniy fo:

Slope: 5.0100266

temperatre incieated at top.

Hiterept: .131131

Sid E-Y: 0.020447 !

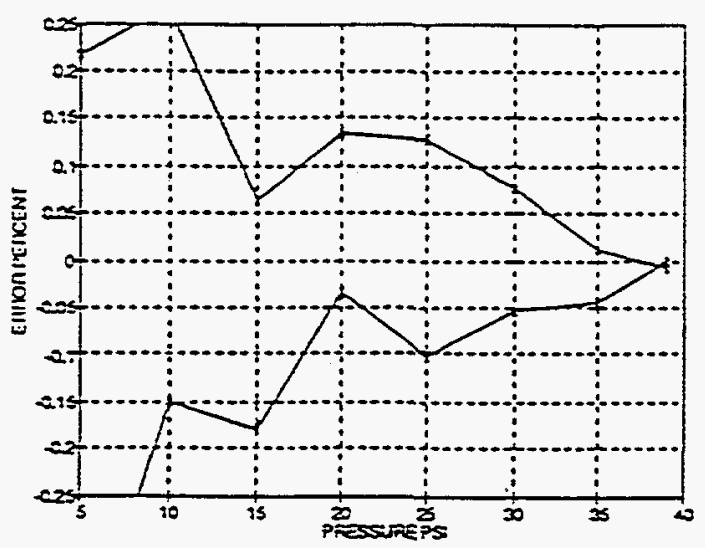




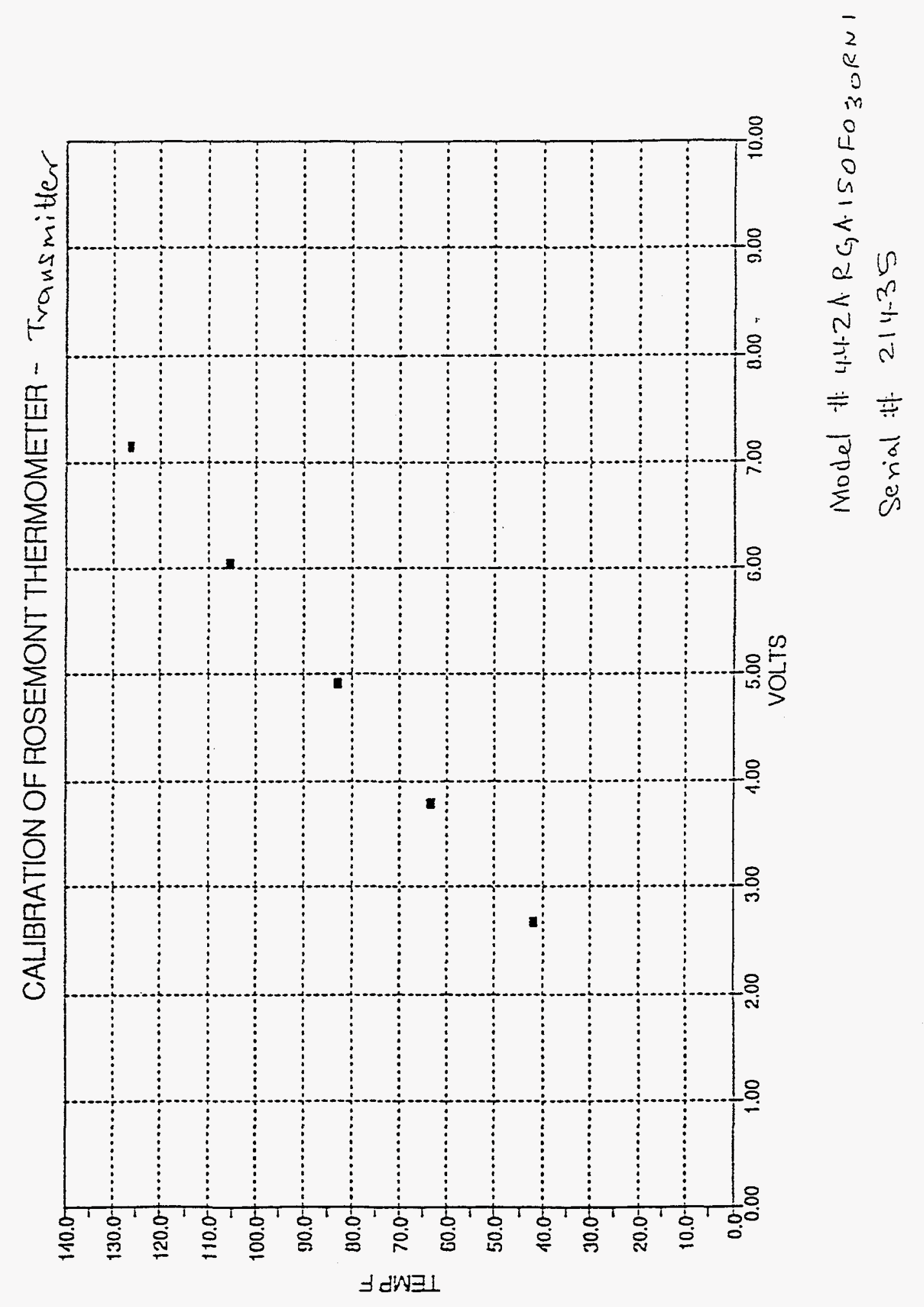


Summary and Significant Findings

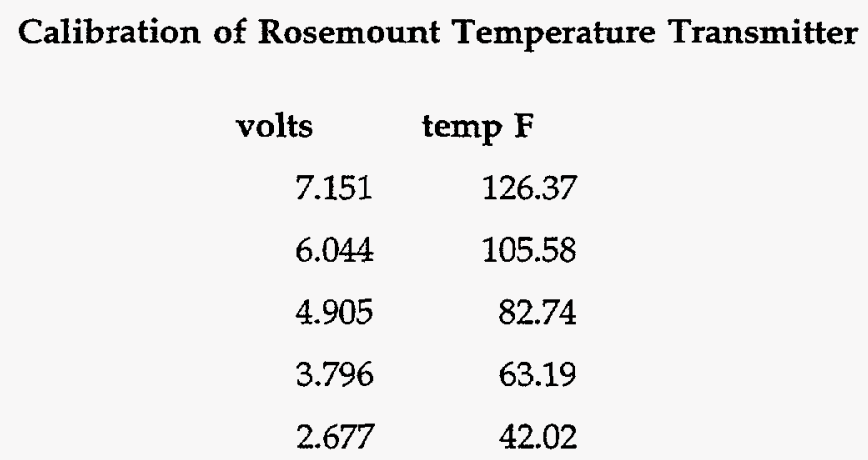

Regression Output:

Constant
Std Err of Y Est
R Squared
No. of Observations
Degrees of Freedom

X Coefficient(s)
Std Err of Coef.

$-8.68532$

0.685024

0.999684

5

3

Model \# 442ARGA150F030RNT

Serial \# 21435 


\section{Appendix B}

Simulated BWR Sludge Characterization 



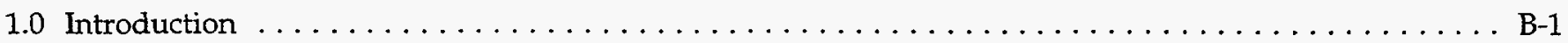

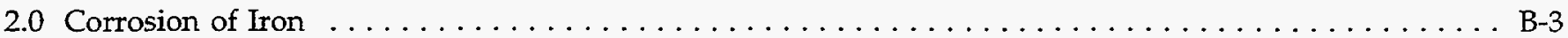

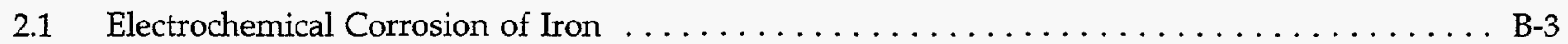

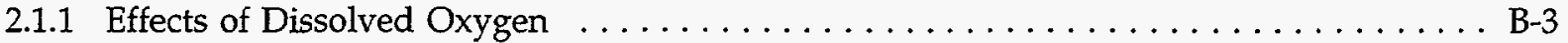

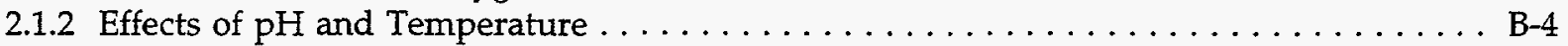

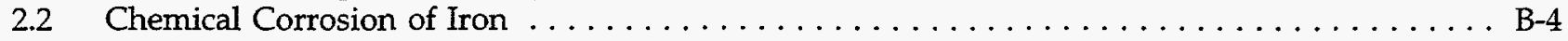

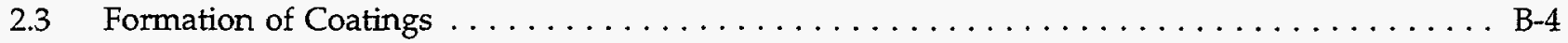

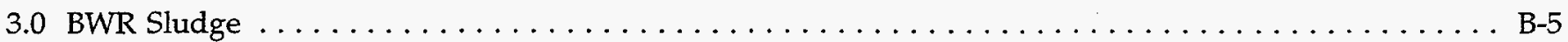

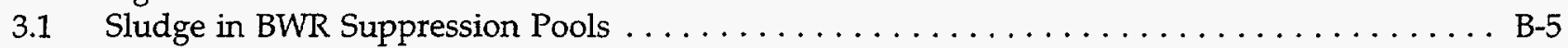

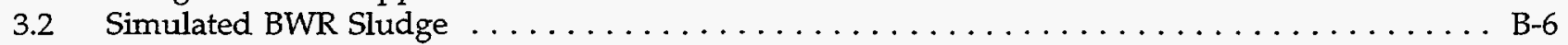

4.0 Samples Analyzed and Characterization Techniques . . . . . . . . . . . . . . . . . . . B-9

4.1 Samples for Sludge Particle Characterization $\ldots \ldots \ldots \ldots \ldots \ldots \ldots \ldots \ldots \ldots \ldots \ldots$. . . . . . . . . . . . .

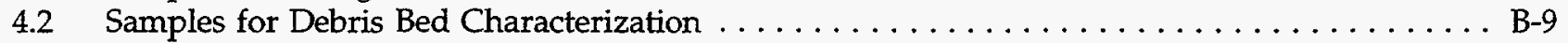

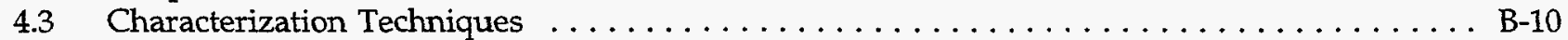

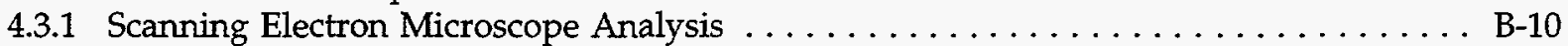

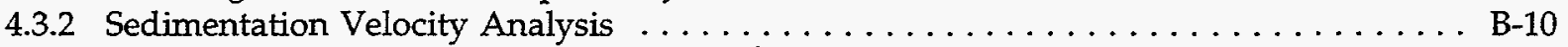

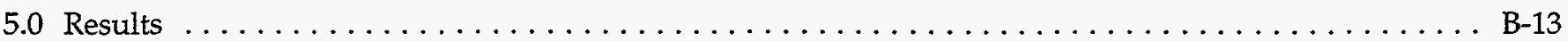

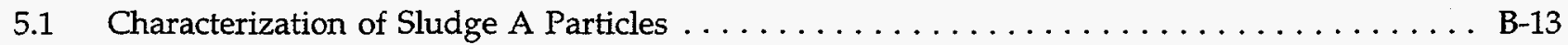

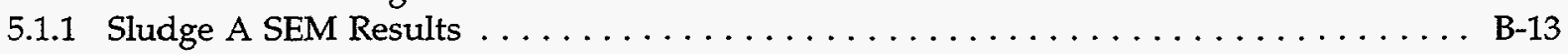

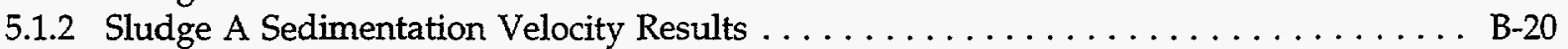

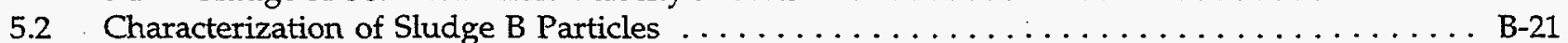

5.2.1 Sludge B SEM Results . . . . . . . . . . . . . . . . . . . . . . . B-21

5.2.2 Sludge B Sedimentation Velocity Results $\ldots \ldots \ldots \ldots \ldots \ldots \ldots \ldots \ldots \ldots$. $\ldots \ldots$

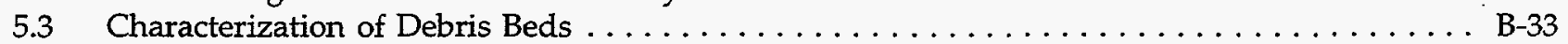

5.3 .1 Clean Fiber Bed SEM Results . . . . . . . . . . . . . . . . . . . . . B-33

5.3.2 Lightly Loaded Mixed Bed SEM Results $\ldots \ldots \ldots \ldots \ldots \ldots \ldots \ldots \ldots \ldots \ldots$. . . . . . . . . . .

5.3.3 Heavily Loaded Mixed Bed SEM Results . . . . . . . . . . . . . . . . . . B-39

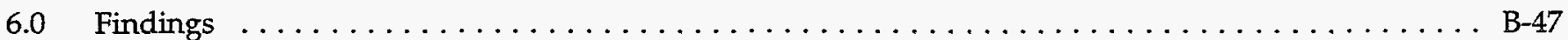

6.1 Findings of the Sludge Particles Characterization $\ldots \ldots \ldots \ldots \ldots \ldots \ldots \ldots \ldots \ldots \ldots \ldots$

6.2 Findings of the Debris Bed Characterization $\ldots \ldots \ldots \ldots \ldots \ldots \ldots \ldots \ldots \ldots \ldots \ldots \ldots$

References for Appendix B . . . . . . . . . . . . . . . . . . . 

B-1. SEM Photograph of Sludge A as a Dry Powder (Sample 1-0) at $750 \mu \mathrm{m}$ Bar

Magnification. .......................................... B-14

B-2. SEM Photograph of Sludge A as a Dry Powder (Sample 1-0) at $30 \mu \mathrm{m}$ Bar Magnification. . . . . . . . . . . . . . . . .

B-3. SEM Photograph of Sludge A as a Dry Powder (Sample 1-0) at $1 \mu \mathrm{m}$ Bar Magnification. . . . . . . B-16

B-4. SEM Photograph of Sludge A as Collected in a Filter Paper from the Test Loop Without Fiber Bed (Sample 1-5). $750 \mu \mathrm{m}$ Bar Magnification. . . . . . . . . . . . . . . . . . . . . B-17

B-5. SEM Photograph of Sludge A as Collected in a Filter Paper from the Test Loop With Fiber Bed (Sample 1-6). $750 \mu \mathrm{m}$ Bar Magnification. . . . . . . . . . . . . . . . . B-18

B-6. SEM Photograph of Sludge A as Collected in a Filter Paper From the Test Loop With Fiber Bed (Sample 1-6). $1 \mu \mathrm{m}$ Bar Magnification. . . . . . . . . . . . . . . . . . . . . B-19

B-7. Mass-Particle Size Frequency Distribution of Sludge A as a Dry Powder (Sample 1-0) Without Surfactant.

B-8. Mass-Particle Size Cumulative Distributions of Sludge A as a Dry Powder (Sample 1-0)

Without Surfactant.

B-9. Mass-Particle Size Frequency Distribution of Sludge $\mathrm{A}$ as a Dry Powder (Sample 1-0)

With Surfactant. . . . . . . . . . . . . . . . . . . . . . . . . . . . .

B-10. Mass-Particle Size Cumulative Distribution of Sludge A as a Dry Powder (Sample 1-0)

B-11. Mass-Particle Size Frequency Distribution of Sludge $A$ in the Water in the Test Loop

(Samples 1-2, 1-3, 1-4, and 1-4 [US]).

B-12. Mass-Particle Size Cumulative Distribution of Sludge $A$ in the Water in the Test Loop

(Samples 1-2, 1-3, 1-4, and 1-4 [US]).

B-13. Average of the Mass-Particle Size Frequency Distribution of Sludge $\mathrm{A}$ in the Test Loop.

(Samples 1-2, 1-3, 1-4, and 1-4 [US]).

B-14. Average of the Mass-Particle Size Cumulative Distribution of Sludge $A$ in the Test Loop.

(Samples 1-2, 1-3 1-4, and 1-4 [US]).

B-15. SEM Photograph of Sludge B as a Dry Powder (Sample 2-0) at $750 \mathrm{\mu m}$ Bar Magnifi-

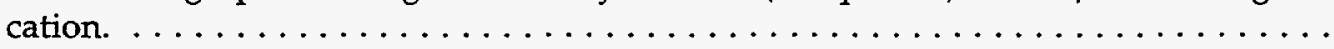

B-16. SEM Photograph of Sludge B as a Dry Powder (Sample 2-0) at $30 \mu \mathrm{m}$ Bar Magnifi-

B-17. SEM Photograph of Sludge B as a Dry Powder (Sample 2-0) at 1 um Bar Magnifi-

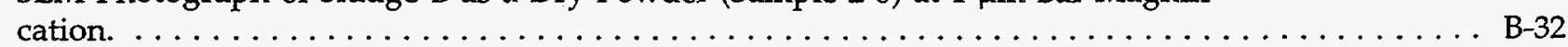

B-18. Mass-Particle Size Frequency Distribution of Sludge B as a Dry Powder (Sample 2-0). . . . . . . B-34

B-19. Mass-Particle Size Cumulative Distribution of Sludge B as a Dry Powder (Sample 2-0). . . . . . . B-35

B-20. SEM Photograph of a Clean Fiber Bed (Sample 3-0) at $750 \mu \mathrm{m}$ Bar Magnification. . . . . . . . . . B-36

B-21. SEM Photograph of a Clean Fiber Bed (Sample 3-0) at $30 \mu \mathrm{m}$ Bar Magnification. . . . . . . . . . B-37

B-22. SEM Photograph of a Clean Fiber Bed (Sample 3-0) at 1 $\mathrm{um}$ Bar Magnification. . . . . . . . . . . . B-38

B-23. SEM Photograph of a Lightly Loaded Mixed Bed (Sample 3-1) at $750 \mu \mathrm{m}$ Bar Magnification.

B-24. SEM Photograph of a Lightly Loaded Mixed Bed (Sample 3-1) at 30 um Bar Magnifi-

B-25. SEM Photograph of a Lightly Loaded Mixed Bed (Sample 3-1) at 1 . 4 m Bar Magnifi-

B-26. SEM Photograph of a Heavily Loaded Mixed Bed (Sample 3-2) at 750 .

B-27. SEM Photograph of a Heavily Loaded Mixed Bed (Sample 3-2) at 250 . $\ldots \ldots \ldots \ldots \ldots$

B-28. SEM Photograph of a Heavily Loaded Mixed Bed (Sample 3-2) at 30 um Bar Magnifi-

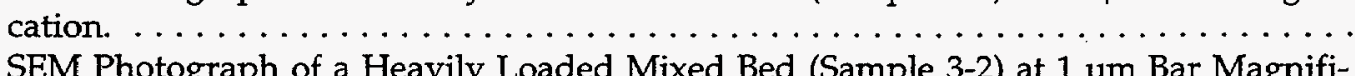

B-29. SEM Photograph of a Heavily Loaded Mixed Bed (Sample 3-2) at $1 \mu \mathrm{m}$ Bar Magnification. 


\section{List of Tables}

B-1. BWR Suppression Pool Sludge Particle Size Distribution $\ldots \ldots \ldots \ldots \ldots \ldots \ldots \ldots \ldots \ldots \ldots . \ldots . \ldots$

B-2. BWROG Recommended Particle Size Distribution for Simulated Sludge . . . . . . . . . . . B 6

B-3. Sludge A Particle Size Distribution According to Manufacturer's Specifications. . . . . . . . . . . . B-6

B-4. Summary of Samples and Characterization Analyses. . . . . . . . . . . . . . . . B-11

B-5. Dry Powder Sludge A Particle Size Distribution. Sedimentation Velocity Analysis Without Surfactant.

B-6. Dry Powder Sludge A Particle Size Distribution. Sedimentation Velocity Analysis With Surfactant. . . . . . . . . . . . . . . . . . . . . . . . . . . . . . . . B B-21

B-7. Dry Powder Sludge B Sedimentation Velocity Analysis. . . . . . . . . . . . . . . B-33 


\subsection{Introduction}

Several instances of clogging of the strainers at the suction of the pumps of the Emergency Core Cooling System (ECCS) have occurred at U.S. plants. Of particular interest are the clogging incidents in 1992 and 1993 at the Perry Nuclear Plant, a BWR-6 Mark III containment. In these incidents, ECCS pump suction strainers experienced mechanical deformation due to high pressure losses. As determined in the evaluation of these events [Ref. 1], the high strainer pressure losses resulted from the accumulation of a combination of fibrous debris and particulate matter (primarily iron oxide). In these cases, the fibrous debris was produced by filters that had been inadvertently dropped in the suppression pool. The main conclusion of the analysis of the Perry events is that fibrous material deposited on the surface of the ECCS pump suction strainers can act as a filter media, capturing fine particles present in the suppression pool. This combined effect of fibers and particulate debris results in pressure losses significantly higher than those which typically occur with fiber beds alone.

The fine particles in the Perry suppression pool were found to be primarily iron oxides produced by direct oxidation of the pool and carbon steel piping systems which are connected to the suppression pool. In addition to corrosion products, some other miscellaneous debris materials were found in the pool, including Griffolyn, Herculite, tape, and plastic. The situation of having iron oxides and some other foreign materials in the suppression pool is not unique to the Perry plant and, as a matter of fact, is a common condition of several BWRs [Ref. 2]. These corrosion products and debris materials are commonly referred to as sludge, and its characteristics like composition, quantity, density and size distribution are site specific. At issue is, however, the potential for having high pressure losses in the ECCS pump suction strainers due to the accumulation of iron oxide particles in fibrous materials. This circumstance has prompted several activities, both by the U.S. Nuclear Regulatory Commission as well as the BWR Owners' Group (BWROG), to characterize the behavior of iron oxide particles similar to those expected to be in the sludge present in the floor of BWR's suppression pools.

Perhaps the most important single parameter in determining the behavior of sludge particles is the size distribution. The mechanisms by which these particles are deposited or filtered in a fibrous bed strongly depend on the relative size of the particles in comparison with the diameter of the fibers. This relative size will affect the filtration efficiency, i.e., the fraction of sludge mass being deposited on the fibers, as well as the morphology of the deposits in the fibers. The nature of this morphology, in turn, may affect the pressure drop in the ECCS strainers. As a matter of fact, several tests conducted by the BWROG indicate that fine particle produce, when combined with fibrous materials, lower head losses than the corresponding head losses for a coarser distribution of particles [Ref. 3]. Therefore, determining the general characteristics of the sludge, including its particle size distribution, is important in the assessment of head loss measurements.

The objective of this report is to present the results of various analyses conducted to characterize two types of simulated BWR sludge and their deposition on NUKON ${ }^{\mathrm{TM}}$ insulation fibrous materials during typical tests carried out at the Alden Research Laboratories, Inc. (ARL) to measure head losses. In general, this characterization consists in determining the shape, state of agglomeration, and size distribution of the iron oxide particles used to simulate the sludge in the head loss experiments; in addition, the morphology of the deposition of these sludge particles on fibrtous beds will be investigated. Section 2 of this report presents the iron corrosion processes expected to produce the iron oxide particles in suppression pools. The simulated BWR sludge is described in Section 3, whereas the sludge particles and debris beds analyzed are described in Section 4. The type of analysis performed on each sample and the corresponding results are presented in Section 5. Finally, Section 6 presents the significant findings from these analyses. 



\subsection{Corrosion of Iron}

There are two distinguishable types of corrosion: chemical and electrochemical. Chemical corrosion, such as that in non-electrolytes or dry gases, is controlled by the kinetics of heterogeneous reactions and is not accompanied by the generation of electric currents. Electrochemical corrosion occurs with generation of currents, such as the case of corrosion of metals with electrolytes. This is a widespread type of corrosion, and includes the action of natural waters and most aqueous solutions on metal surfaces.

\subsection{Electrochemical Corrosion of Iron}

On a piece of metal subjected to electrochemical corrosion there are both anodic and cathodic sites which are continually shifting. Some portions of the surface attract electrons away from others because of the presence of impurities, strains, or other influences that change the reactivity of the metal. This is the reason why iron corrodes in some areas more than others. At an anodic site an oxidation process occurs, which is the loss of electrons, and the metal goes into solution as a result of a reaction given by:

$$
\mathrm{Fe}-2 \text { electrons } \Rightarrow \mathrm{Fe}^{2+}
$$

As part of the formation of rust at a cathodic site, water is being reduced to hydroxide ions and dihydrogen as follows:

$$
2 \mathrm{H}_{2} \mathrm{O}+2 \text { electrons } \Rightarrow 2 \mathrm{HO}^{-}+\mathrm{H}_{2}
$$

In the corrosion of iron in a neutral media there occurs an additional reaction of the anodic products with the hydroxyl ions formed at the cathode sites:

$$
\mathrm{Fe}^{2+}+2 \mathrm{OH}^{-}=\mathrm{Fe}(\mathrm{OH})_{2} \quad \text { (Ferrous hydroxide) }
$$

The ferrous hydroxide formed has a comparatively high solubility. In the presence of oxygen in the solution, a further reaction takes place, the oxidation of ferrous hydroxide to ferric hydroxide:

$$
\begin{gathered}
4 \mathrm{Fe}(\mathrm{OH})_{2}+2 \mathrm{H}_{2} \mathrm{O}=4 \mathrm{Fe}(\mathrm{OH})_{3} \quad \text { (Ferric hydroxide) } \\
2 \mathrm{Fe}(\mathrm{OH})_{2}+\frac{1}{2} \mathrm{O}_{2}+\mathrm{H}_{2} \mathrm{O} \\
\Rightarrow \mathrm{Fe}_{2} \mathrm{O}_{3} \cdot \mathrm{H}_{2} \mathrm{O}
\end{gathered}
$$

Hydrated ferric oxide has a yellow color and is much less soluble than ferrous hydroxide in solution. It is important to note that secondary formation of the insoluble iron corrosion products ferrous hydroxide and hydrated ferric oxide does not suppress the process of electrochemical rusting. The formation of rust proceeds not directly on the anodic site but in the solution adjacent to the corroding surface. Therefore adhesion to the surface and protective properties of rust are weak. For this reason, the rate of corrosion of iron changes little with time in distilled water with access of oxygen and also in a number of natural waters.

The poor protective properties of rust can also be explained by the fact that the more soluble ferrous hydroxide initially forms directly on the surface of iron, and only after the oxidation of the hydroxide, does the highly insoluble ferric hydrate precipitate. Under atmospheric corrosion, rust does form in more intimate contact with the iron surface, with better adherence, thereby providing considerable protective action. Rust formed in the corrosion of iron and low-alloy steels consists of a mixture of ferric and ferrous hydroxides. Depending on conditions and time of formation of rust, its composition can fluctuate considerably. The older the rust and the easier the access of oxygen, the greater the content of the hydrated ferric oxide.

\subsubsection{Effects of Dissolved Oxygen}

At ordinary temperatures, oxygen and moisture are the basic factors necessary for the corrosion of iron in a neutral media. Both must be present simultaneously, because oxygen alone or water free of dissolved oxygen does not corrode iron to any practical extent. Iron corrodes in natural waters at a rate according to the concentration of dissolved oxygen. Water in contact with iron continues to corrode only until the dissolved oxygen is consumed. The rate of corrosion is roughly limited by the rate of diffusion of the dissolved oxygen to 
the metal surface, and thus the reason for the high corrosion rate at or near the water line.

\subsubsection{Effects of $\mathrm{pH}$ and Temperature}

The corrosion rate of iron is also dependent on the $\mathrm{pH}$ level of water. At a value of $\mathrm{pH}$ greater than needed for hydrogen evolution $(\mathrm{pH}=4)$, the corrosion rate is constant up to a $\mathrm{pH}$ of 9.5. Once hydrogen evolution begins, a protective layer of ferrous hydroxide is formed on the iron surface formed by the initial corrosion reaction. In this range, the surface of iron is always in contact with the saturated solution of ferrous hydroxide. Corrosion continues as rapidly as the dissolved oxygen can diffuse through the protective layer. This layer is continually being renewed by the corrosion process and will continue based on the availability of dissolved oxygen. At $\mathrm{pH}$ levels above 9.5, the increase in alkalinity extends its effect to the iron surface and decreases the corrosion rate rendering the iron passive. This decreases the permeability of the dissolved oxygen and consequently the rate of formation of the corrosion product layer. At $\mathrm{pH}$ levels below 4, in the acid region, the alkaline corrosion product layer is dissolved and the acid reacts directly with the iron surface.

The corrosion rate is also influenced by the temperature of water. Increased temperature increases the corrosion rate by allowing the dissolved oxygen to penetrate further into the ferrous hydroxide layer.

\subsection{Chemical Corrosion of Iron}

The oxidation of iron results in three simple oxides that can be found in the scale formed on iron. Often the scale consists of three different layers composed of $\mathrm{FeO}, \mathrm{Fe}_{3} \mathrm{O}_{4}$, and $\mathrm{Fe}_{2} \mathrm{O}_{3}$. These layers are situated such that the oxide with the lowest oxygen content, $\mathrm{FeO}$, is next to the metal, then the intermediate iron oxide, $\mathrm{Fe}_{3} \mathrm{O}_{4}$, and finally the highest iron oxide, $\mathrm{Fe}_{2} \mathrm{O}_{3}$, at the external surface.

Ferrous oxide, $\mathrm{FeO}$, forms a cubic lattice and is stable only at temperatures above $570^{\circ} \mathrm{C}$. It does not form at lower temperatures. When the scale is cooled, it decomposes according to:

$$
4 \mathrm{FeO} \Rightarrow \mathrm{Fe}+\mathrm{Fe}_{3} \mathrm{O}_{4}
$$

Ferrous-Ferric Oxide, $\mathrm{Fe}_{3} \mathrm{O}_{4}$ or black magnetite, has a cubic lattice, with unit cell containing eight $\mathrm{Fe}_{3} \mathrm{O}_{4}$ groups. Magnetite is stable from ambient temperature to the melting point of iron. By heating magnetite to $400^{\circ} \mathrm{C}$, the magnetic properties decay and $\mathrm{Fe}_{2} \mathrm{O}_{3}$ is formed according to:

$$
2 \mathrm{Fe}_{3} \mathrm{O}_{4}+\mathrm{O} \Rightarrow 3 \mathrm{Fe}_{2} \mathrm{O}_{3}
$$

Ferric oxide, $\mathrm{Fe}_{2} \mathrm{O}_{3}$ or Hematite, has a rhombohedral structure. The unit cell contains two $\mathrm{Fe}_{2} \mathrm{O}_{3}$ groups. Hematite exists within a wide temperature range, but partially dissociates above $1100^{\circ} \mathrm{C}$.

\subsection{Formation of Coatings}

The formation of coatings of iron oxides on the surface of iron is dependent on temperature and is inversely proportional to the square root of the formation time. Although this coating, known as mill scale, may be protective when first formed, a limited thickness is reached at which point the coating cracks exposing the surface to further localized corrosion in the form of pitting. Internal stresses during formation of the oxide and the thermal cycling of the oxide and metal can cause fragmentation which also exposes the metal surface to further corrosion. 


\subsection{BWR Sludge}

\subsection{Sludge in BWR Suppression Pools}

Several BWR plants have reported sediments on the suppression pool floor. The analyses of these sedimented material showed that it consists primarily of steel corrosion products, mostly iron oxides, although some plants have also observed other constituents, like organic matter, in the sediments. This particulate material is commonly referred to as sludge but, since steel corrosion products constitute more than $99 \%$ (by mass) of the suppression pool sludge, in this report the terms sludge and corrosion products will be used indistinctly.

The makeup of corrosion products in BWR suppression pools is plant specific, but it is generally characterized as iron oxide. By some estimates [Ref. 4], the amount of sludge may vary from $30 \mathrm{~kg}$ to $2300 \mathrm{~kg}$, depending on the plant cleanup procedures. The oxides produced in these pools are considered to be a product from direct corrosion in the pool as well as corrosion particles from piping systems that are periodically flushed and drained into the pool. These corrosion products can potentially contain all the iron oxide compounds described in Section 2. Information obtained from suppression pool cleaning companies indicates that the typical trend involving the particle size of the corrosion products is a function of the elapsed time, the theory being that the longer the elapsed time from the last cleaning, the larger the particle size. This is believed to be the result of the natural agglomeration of the more amorphous gelatinous material as well as the mill scale particles that flake off over the course of time. In those areas where large amounts of particles have been settled for longer periods of time, the agglomerates will have a larger equivalent size. Based on the rudimentary filtration methods used by the suppression pool cleaning companies, the general consensus among these companies is that the mean particle size of the agglomerated iron oxide particles in the suppression pools is about $25 \mu \mathrm{m}$. Since the cleaning companies removed many layers of sludge, collected at different depths from several plants, this particle size can be considered a rough average of the sludge particle size.

A better characterization of the sludge particles in BWR suppression pools was conducted by the BWROG, which evaluated, using LASER light scattering, the particle size distribution of the sludge samples obtained from five BWR suppression pools, including Mark I, II and III containments. It is believed that these sludge samples consist of nearly $100 \%$ iron oxides. The data from these samples is summarized in Table B-1 [Ref. 3].

As it can be seen in this table, despite the differences among the particle size distributions in the samples from the surveyed plants, the median equivalent diameter is less than $10 \mu \mathrm{m}$ in all cases. It is interesting to note the discrepancy between these sludge particle size determinations and the 25 $\mu \mathrm{m}$ mean size estimated by the suppression pool cleaning companies. The BWR owners' group characterization using LASER light scattering is

Table B-1. BWR Suppression Pool Sludge Particle Size Distribution

\begin{tabular}{|c|c|c|c|c|c|c|}
\hline Plant & Cont. Type & $0-1 \mu \mathrm{m}$ & $0-5 \mu \mathrm{m}$ & $0-10 \mu \mathrm{m}$ & 10-75 $\mu \mathrm{m}$ & $>75 \mu \mathrm{m}$ \\
\hline A & III & $\begin{array}{l}65 \% \\
75 \%\end{array}$ & & $\begin{array}{l}100 \% \\
100 \%\end{array}$ & & $0 \%$ \\
\hline B & II & & $94 \%$ & $99.5 \%$ & $0.5 \%$ & $0 \%$ \\
\hline C & III & $8 \%$ & $88 \%$ & $97 \%$ & $3 \%$ & $0 \%$ \\
\hline $\mathrm{D}$ & I & $14 \%$ & $85 \%$ & $97 \%$ & $3 \%$ & $0 \%$ \\
\hline $\mathrm{E}$ & III & $\begin{array}{l}18 \% \\
14 \% \\
15 \%\end{array}$ & $\begin{array}{l}75 \% \\
65 \% \\
65 \%\end{array}$ & $\begin{array}{l}86 \% \\
82 \% \\
80 \%\end{array}$ & $\begin{array}{l}14 \% \\
18 \% \\
20 \%\end{array}$ & $0 \%$ \\
\hline
\end{tabular}


more accurate than the estimated average particle size based on filtration methods used by the cleaning companies, but the specific conditions at which the BWROG samples were taken are not known at the present time. In particular, it is important to have an idea about both the depth in the sludge layer at which the BWROG samples were obtained, as well as the time elapsed from the last pool cleaning at each plant. According to the hypothesis of particle agglomeration as a function of time, it could be possible to obtain agglomerates from the top surface of the sludge layer smaller in size than those obtained from the bottom; in addition, smaller agglomerates could be obtained if the suppression pools are cleaned more frequently.

\subsection{Simulated BWR Sludge}

The information in Table B-1 was used by the BWROG to suggest the sludge particle size distribution in Table B-2 to be used in the head loss experiments conducted at ARL.

Table B-2. BWROG Recommended Particle Size Distribution for Simulated Sludge [5].

\begin{tabular}{ccc}
\hline $\begin{array}{c}\text { Size Range } \\
(\boldsymbol{\mu m})\end{array}$ & $\begin{array}{c}\text { Average Size } \\
(\boldsymbol{\mu m})\end{array}$ & $\begin{array}{c}\text { Percentage by Mass } \\
(\%)\end{array}$ \\
\hline $0-5$ & 2.5 & 81 \\
$5-10$ & 7.5 & 14 \\
$10-75$ & 42.5 & 5 \\
\hline
\end{tabular}

A survey was conducted among some companies capable of providing several powders with the recommended particle size distribution. None of the surveyed companies was able to provide iron oxide powders with the required particle size distribution. Although it was recognized that some ceramic powders could be provided with exactly the suggested particle size distribution, it was decided to use iron oxide powders to better simulate the sludge observed in BWR suppression pools.

Black iron oxide, $\mathrm{Fe}_{3} \mathrm{O}_{4}$, was supplied by Hansen Engineering, Inc. according to the following particle size distributions:

$\begin{array}{cccccc}\mathrm{Fe}_{3} \mathrm{O}_{4} & <2 & 2-5 & 5-10 & 10-35 & >35 \\ \text { Type } & \mu \mathrm{m} & \mu \mathrm{m} & \mu \mathrm{m} & \mu \mathrm{m} & \mu \mathrm{m} \\ \# 2008 & 5 \% & 80 \% & 15 \% & 0 \% & 0 \% \\ \# 9101-\mathrm{N} & \sim 0 \% & \sim 0 \% & \sim 0 \% & 82 \% & -18 \%\end{array}$

It is important to note that the method used to determine the particle size distribution of powder \#2008 is not accurately known, whereas the particle size distribution of powder \#9101-N was apparently measured by screen analysis. Knowledge of the method used in determining the particle size distribution is of relevance because the various measurement processes result in different particle sizes; for example, the transport and deposition behavior of particles is better characterized by defining a diameter in terms of the particle terminal settling velocity, a case in which all particles having similar settling velocities are considered to be of the same size, regardless of their actual size or shape. This situation has to be considered when comparing the results obtained from different techniques used to characterize particle size distributions.

To simulate the particle size distribution suggested by the BWROG, it was decided to mix $95 \%$ of black iron \#2008 and $5 \%$ of black iron \#9101-N, resulting in the so called Sludge $A$. The estimated particle size distribution for this mix is given in Table B-3.

Table B-3. Sludge A Particle Size Distribution According to Manufacturer's Specifications.

\begin{tabular}{cc}
\hline $\begin{array}{c}\text { Size Range } \\
(\boldsymbol{\mu m})\end{array}$ & $\begin{array}{c}\text { Percentage by Mass } \\
(\%)\end{array}$ \\
\hline$<2$ & 4.75 \\
$2-5$ & 76 \\
$5-10$ & 14.25 \\
$10-35$ & 4.1 \\
$35-75$ & 0.9 \\
\hline
\end{tabular}

To have an idea about the behavior of a coarser mix of sludge, it was decided to conduct some head loss experiments using $100 \%$ of black iron $\# 9101-N$. This mix is called Sludge B.

The debris generated during a loss of coolant accident (LOCA) in a BWR can incorporate some 
other particles in addition to the fibrous insulation materials. Examples of these additional materials include calcium silicate particles, produced by the impingement of the jet of steam and water from the break on the calcium silicate insulation materials used in systems such as the Reactor Core Isolation Cooling (RCIC) and the Reactor Water Clean-up (RWCU), concrete dust and paint chips, generated by the destruction of paint coverings on structures in the drywell. These non-fibrous materials may be transported to the suppression pool and eventually to the ECCS strainers, contributing to the pressure drop. To better understand the effects of these additional materials on the pressure drop increase, it was decided to conduct some experiments using a combination of iron oxide (Sludge A) and additional $11 \%$ in weight of unqualified paint chips; since this mixture includes simulated particles from materials in the drywell, it was decided to designate it Mix A to distinguish this simulated debris material from the sludge already present in the suppression pool before the LOCA. 



\subsection{Samples Analyzed and Characterization Techniques}

Several tests were conducted to measure the head losses due to accumulation of NUKON ${ }^{\mathrm{TM}}$ fibrous materials and sludge particles on a plate simulating ECCS strainers. In general, these tests consisted of dropping sludge particles and NUKONTM fibrous shreds into an experimental facility in which water was circulating through the plate at different flow velocities. To obtain a better characterization about the sludge particles and their deposition on NUKON ${ }^{\mathrm{TM}}$ fiber beds, the following samples were collected during some of the typical tests.

\subsection{Samples for Sludge Particle Characterization}

The characterization of the sludge consisted in determining the shape, state of agglomeration, and particle size distribution of Sludge A and Sludge B. In the case of Sludge A, both samples from the dry mix produced with the manufacturer's powders as well as samples collected from the test loop while the particles were circulating in the water were analyzed; for Sludge B, only samples from the dry powder supplied by the manufacturer were analyzed. The following paragraphs describe each of the samples collected for analysis.

Sample 1.0. Dry powder from Sludge A, i.e., as it was after mixing the iron oxide powders from Hansen Engineering, Inc., specifications \#2008 and \#9109-N, as described in Section 3, and before dropping it into the test facility.

Sample 1-1. Specimen of water collected from the port located after the plate (Port 2) while the Sludge A particles were circulating in the test loop at 1.5 $\mathrm{ft} / \mathrm{s}(0.5 \mathrm{~m} / \mathrm{s})$.

Sample 1-2. Same as above; taken to verify repeatability of the collection process.

Sample 1-3. Specimen of water collected from the port located before the plate (Port 1) while the Sludge A particles were circulating in the test loop at $1.5 \mathrm{ft} / \mathrm{s}(0.5 \mathrm{~m} / \mathrm{s})$.

Sample 1-4. Specimen of water collected from Port 2 while the Sludge A particles were circulating in the test loop at $1.5 \mathrm{ft} / \mathrm{s}(0.5 \mathrm{~m} / \mathrm{s}) ; 0.05 \%$ in weight of surfactant (sodium meta-phosphate) was added to the collected water to investigate the state of agglomeration after the specimen was collected.

Sample 1-5. Specimen of Sludge A particles deposited on a $0.45 \mu \mathrm{m}$ pore size filter paper. The particles came from a test in which $35 \mathrm{~g}$ of Sludge A were dropped in the test loop without any fibrous material.

Sample 1-6. Specimen of Sludge A particles deposited on a $0.45 \mu \mathrm{m}$ pore size filter paper. The particles came from test P09, in which the mass of Sludge A was the same as the mass of the NUKONTM fiber shreds in the test loop. The nominal fiber bed thickness was 1 inch $(2.5 \mathrm{~cm})$ and the approximate temperature in the water was $52^{\circ} \mathrm{C}$ $\left(125^{\circ} \mathrm{F}\right)$. The filter paper was taken at a flow velocity of $0.15 \mathrm{ft} / \mathrm{s}(0.05 \mathrm{~m} / \mathrm{s})$.

Sample 2-0. Dry powder from Sludge B, i.e., the iron oxide powder, specification \#9109-N, supplied by Hansen Engineering, Inc., as it was before dropping it into the test facility.

\subsection{Samples for Debris Bed Characterization}

The characterization of the debris bed formed on the perforated plate consisted of determining its morphology, i.e., the mode of deposition of the sludge particles on the fibers. It is important to note, however, that the debris beds were not collected for the specific purpose of making this characterization and, therefore, the handling of the debris beds may have affected their characteristics in the test loop; in particular, the beds removed at the end of the head loss tests were dried in an oven at about $121^{\circ} \mathrm{C}\left(250^{\circ} \mathrm{F}\right)$ for approximately two days. It is possible that this drying process may have modified not only the morphology of the deposited particles, but also their chemical composition.

Sample 3-0. Specimen from a clean fiber bed, i.e., the bed formed during test POI in which only NUKONTM fiber shreds were added to the experimental loop. The nominal fiber bed thickness was 1 inch $(2.54 \mathrm{~cm})$ and the approximate water temperature was $52^{\circ} \mathrm{C}\left(125^{\circ} \mathrm{F}\right)$.

Sample 3-1. Specimen of a mixed bed, i.e., a fiber bed loaded with Sludge A particles. In this case, the 
bed came from test P26, in which the same mass of Sludge $\mathrm{A}$ as the mass of fibers was added to the experimental loop. The nominal fiber bed thickness was 1 inch $(2.54 \mathrm{~cm})$ and the water temperature was about $52^{\circ} \mathrm{C}\left(125^{\circ} \mathrm{F}\right)$.

Sample 3-2. Specimen of mixed bed heavily loaded with sludge, i.e., the debris bed formed when a mass of Sludge A particles ten times greater than the mass of fibers was added to the loop. The bed came from test P33, in which the nominal fiber bed thickness was 0.5 inches $(1.27 \mathrm{~cm})$ and the water temperature was $52^{\circ} \mathrm{C}\left(125^{\circ} \mathrm{C}\right)$.

\subsection{Characterization Techniques}

The main objectives of these analyses were to determine the shape, state of agglomeration, and particle-size distribution of the $\mathrm{Fe}_{3} \mathrm{O}_{4}$ used to simulate suppression pool sludge, and to investigate the morphology of the debris beds formed during the head loss experiments. The techniques selected to achieve these objectives were Scanning Electron Microscope (SEM) with minimal sample modification and Sedimentation Velocity analysis. Specifically, SEM analysis allows the determination of the shape and state of agglomeration of the sludge particles providing, in addition, qualitative information about their size distribution. SEM was also the technique employed to obtain information about the morphology of the debris beds. Quantitative estimation of the particle-size distribution with SEM is, however, a tedious process that requires the analysis of several images and, therefore, the more efficient technique of sedimentation velocity analysis was used to obtain the quantitative particle-size distribution (by mass) of Sludge A and Sludge B.

\subsubsection{Scanning Electron Microscope Analysis}

The determination of the shape and state of agglomeration by microscopy is a well established technique; the properties are characterized in terms of the absorbed, back scattered, and secondary electrons from the primary beam. In these analyses, all of the samples were coated with a thin layer of carbon to avoid electrical charge due to the electron beam. This coating is a standard procedure that does not cause any artifacts. In the case of the dry powder samples from Sludge $A$ and Sludge B, i.e., Samples 1-0 and 2-0 respectively, the coated particles were dropped directly onto the SEM stub. The samples from the filter papers, i.e., Samples 1-5 and 1-6, were prepared by cutting the filter papers into several pieces and mounting some of these pieces onto the SEM stub using conductive paste. The debris bed samples, i.e., Samples 3-0, 3-1, and 32 , were also prepared by cutting out a piece from each bed and mounting it on the SEM stub using conductive paste.

All specimens were analyzed over the whole area at low magnification $(750 \mu \mathrm{m}$ bar) to determine how representative the photographed region was compared to other regions; this same procedure was carried out at the higher magnifications to verify that the photographed regions were representative. Photographs were taken of each sample at magnifications corresponding to scale bars of 750 $\mu \mathrm{m}, 30 \mu \mathrm{m}$, and $1 \mu \mathrm{m}$. This choice of magnifications provided information at the length scales corresponding to agglomerates (750 $\mu \mathrm{m}$ and $30 \mu \mathrm{m}$ bars) and primary particles ( $1 \mu \mathrm{m}$ bar).

\subsubsection{Sedimentation Velocity Analysis}

A quantitative characterization of the particle size distribution, by mass, can be obtained by measurements of the sedimentation velocity of the particles in water. This technique provides useful information about the particle size distribution, by mass, in the range from 1 to $100 \mu \mathrm{m}$. For agglomerates larger than $100 \mu \mathrm{m}$, sedimentation velocity analysis requires dispersing the particles in a container from which the liquid is withdrawn and inserted into an analysis chamber. The particles are easily dispersed into the water using a surfactant, sodium meta-phosphate, with ultra-sonication. This will separate the particles and provide better information about the actual primary size distribution and the strength of the forces holding the agglomerates together. In some cases, a magnetic stirring bar can be used to further disperse the particles; in these analyses, however, this method of dispersion was not used because the magnetic properties of the iron oxide particles cause attraction to the stirring bar.

The techniques used to characterize the analyzed samples are summarized in Table B-4. 
Appendix B

Table B-4. Summary of Samples and Characterization Analyses.

\begin{tabular}{|c|c|c|c|}
\hline Sample & Sample Description & \multicolumn{2}{|c|}{ Analysis Technique } \\
\hline & Sludge Particles & & \\
\hline $1-0$ & Dry powder of Sludge A & SEM & Sedimentation Velocity \\
\hline $1-1$ & Sludge A suspended in water; Port $2^{1}$ & & Sedimentation Velocity \\
\hline $1-2$ & Sludge A suspended in water; Port 2 & SEM & Sedimentation Velocity \\
\hline $1-3$ & Sludge A suspended in water; Port $1^{2}$ & SEM & Sedimentation Velocity \\
\hline $1-4$ & Sludge A suspended in water; Port 2 (Surfactant added) & SEM & Sedimentation Velocity \\
\hline $1-5$ & Sludge A deposited on filter paper; no fibrous shreds & SEM & \\
\hline $1-6$ & Sludge A deposited on filter paper; fibrous shreds added & SEM & \\
\hline $2-0$ & Dry powder of Sludge B & SEM & Sedimentation Velocity \\
\hline & Debris Beds & & \\
\hline 3-0 & Clean fiber bed & SEM & \\
\hline 3-1 & Mixed bed; sludge-to-fiber mass ratio: 1 & SEM & \\
\hline $3-2$ & Mixed bed; sludge-to-fiber mass ratio: 10 & SEM & \\
\hline
\end{tabular}

${ }^{1}$ Port 2: After the perforated plate

2 Port 1: Before the perforated plate 



\subsection{Results}

The objectives of the SEM analyses were to obtain qualitative information about the shape, size, and state of agglomeration of the iron oxide particles used to simulate suppression pool sludge, and to gain a qualitative description about the deposition of these particles on NUKON ${ }^{\mathrm{TM}}$ fiber beds. The objective of the sedimentation velocity analyses was to determine quantitatively the particle size distribution, by mass, of the sludge particles.

\subsection{Characterization of Sludge A Particles}

Sludge A was the mixture of iron oxide particles used to simulate suppression pool sludge in the majority of the head loss tests and, therefore, most of the characterization efforts corresponded to this type of sludge. Specifically, both samples from dry powders as well as samples of the sludge particles collected while circulating in the water in the test facility, were analyzed with SEM and sedimentation velocity.

\subsubsection{Sludge A SEM Results}

As indicated in Table B-4, all of the samples from Sludge A, with the exception of Sample 1-1 which was identical to Sample 1-2, were analyzed by SEM. The following paragraphs summarize the most significant results from these analyses.

Several specimens of the dry powder from Sludge $\mathrm{A}$, as it was before dropping it into the test loop, were prepared for SEM analyses; all showed similar results. Typical SEM photographs of this sample are included as Figures B-1, B-2, and B-3. The photograph at the lower magnification $(750 \mu \mathrm{m})$ in Figure B-1, shows large agglomerates with dimensions on the order of $100 \mu \mathrm{m}$ and smaller; in some cases even agglomerates of about $375 \mu \mathrm{m}$ are visible. As indicated in Figure B-1, these agglomerates are approximately spherical. The photograph at the next magnification $(30 \mu \mathrm{m})$ in Figure B-2, shows nearly spherical particles and agglomerates on the order of 5 to $30 \mu \mathrm{m}$. These particles are found between the larger agglomerates and can be observed as small features on the 750 $\mathrm{mm}$ photograph in Figure B-1. The primary particles are dense are relatively smooth, while the agglomerates are rough and porous. The photograph at the highest magnification $(1 \mu \mathrm{m})$ in
Figure B-3, indicates that the rough and porous agglomerates consist of much smaller spherical primary particles of less than $1 \mu \mathrm{m}$. These primary particles are agglomerated extensively, and the spread of the size distribution is broad; an appreciable fraction of the particles by number is observed for all sizes between 0.1 and $0.9 \mu \mathrm{m}$.

The SEM photographs of Sample 1-0 indicate that the particles in the dry powder of Sludge $A$ are extensively agglomerated; although the SEM results do not provide the quantitative particle size distribution of Sludge A, they suggest that the large agglomerates observed produce a particle mass-size distribution significantly larger than the particle size distribution recommended by the BWROG in Table B-2 and, consequently, also larger than the particle size distribution according to the iron oxide supplier specifications. However, it is not possible to determine from these results what is the state of agglomeration when the sludge particles are suspended in the water circulating in the test loop; to get this information, Samples 1-5 and 1-6 were analyzed. The SEM photograph of Sample 1-5 in Figure B-4, shows that the Sludge A particles, collected in a $0.45 \mu \mathrm{m}$ pore size paper while circulating in the test loop without fibrous materials, are considerably less agglomerated than the particles in the dry powder of Sludge $A$; it is believed that the dispersion of the large agglomerates occurred when they passed through the impeller of the pump used in the head loss experiments. Figure B-5 shows the SEM photograph of a specimen from Sample 1-6, which corresponds to the Sludge A particles collected on a $0.45 \mu \mathrm{m}$ pore size filter paper while they were circulating in the test loop at 0.15 $\mathrm{ft} / \mathrm{s}(0.05 \mathrm{~m} / \mathrm{s})$ in the presence of a fiber bed. This photograph shows very few agglomerates and almost none of about $100 \mu \mathrm{m}$, suggesting that, in addition of having dispersion in the circulating water, larger agglomerates were deposited on the fiber bed. In all of the cases analyzed for the Sludge A particles collected while circulating in the test loop, the primary particles observed at the highest magnification $(1 \mathrm{\mu m})$ were similar in size to those observed in the corresponding samples for dry powders from Sludge A, i.e., primary particles in the size range from 0.1 to $0.5 \mu \mathrm{m}$; this typical result is illustrated in Figure B-6, which shows the SEM photograph, at $1 \mu \mathrm{m}$ bar magnification, of a specimen from Sample 1-6. This result suggests that 
Appendix B

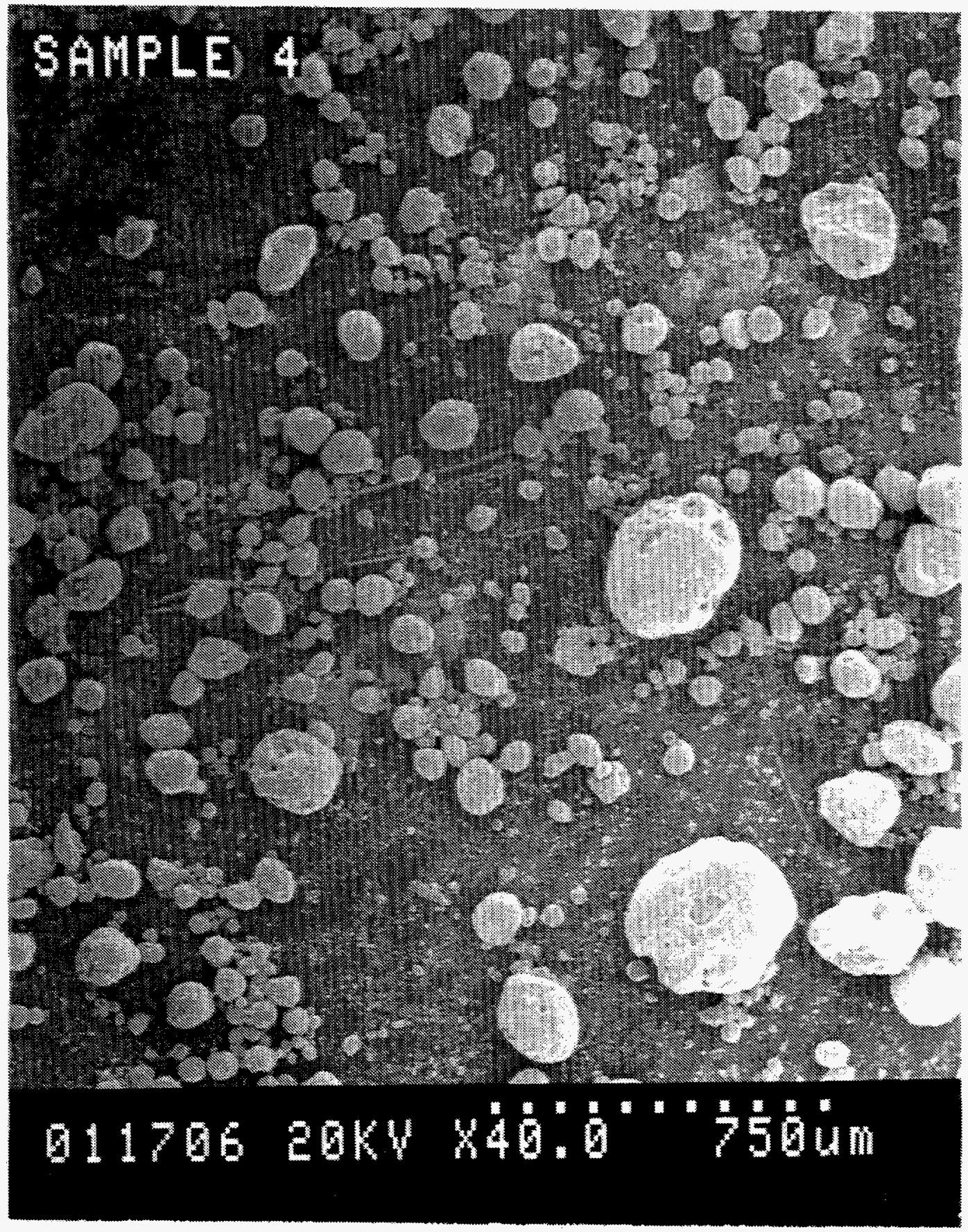

Figure B-1. SEM Photograph of Sludge $A$ as a Dry Powder (Sample 1-0) at 750 um Bar Magnification. 
Appendix B

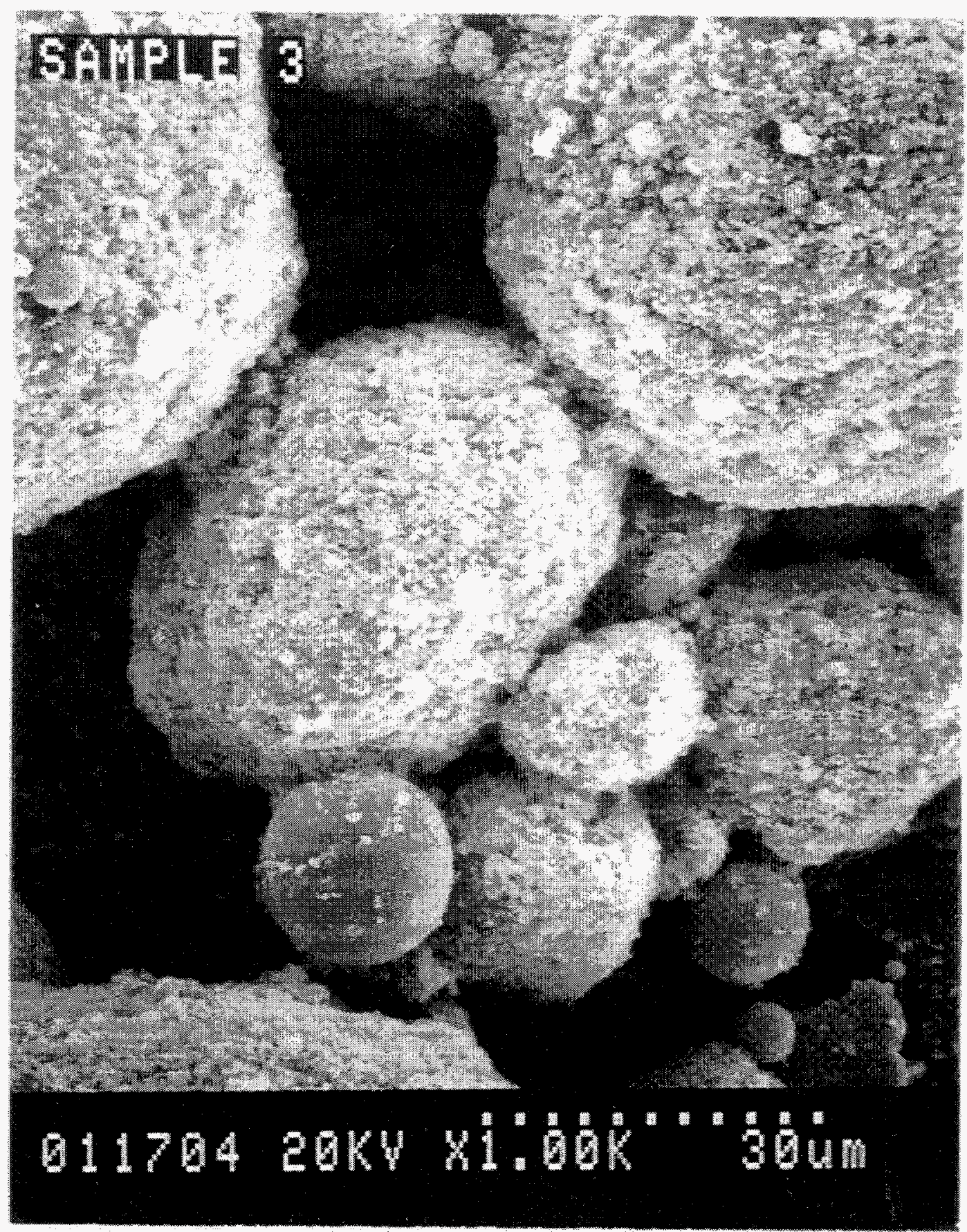

Figure B-2. SEM Photograph of Sludge A as a Dry Powder (Sample 1-0) at $30 \mu \mathrm{m}$ Bar Magnification. 
Appendix B

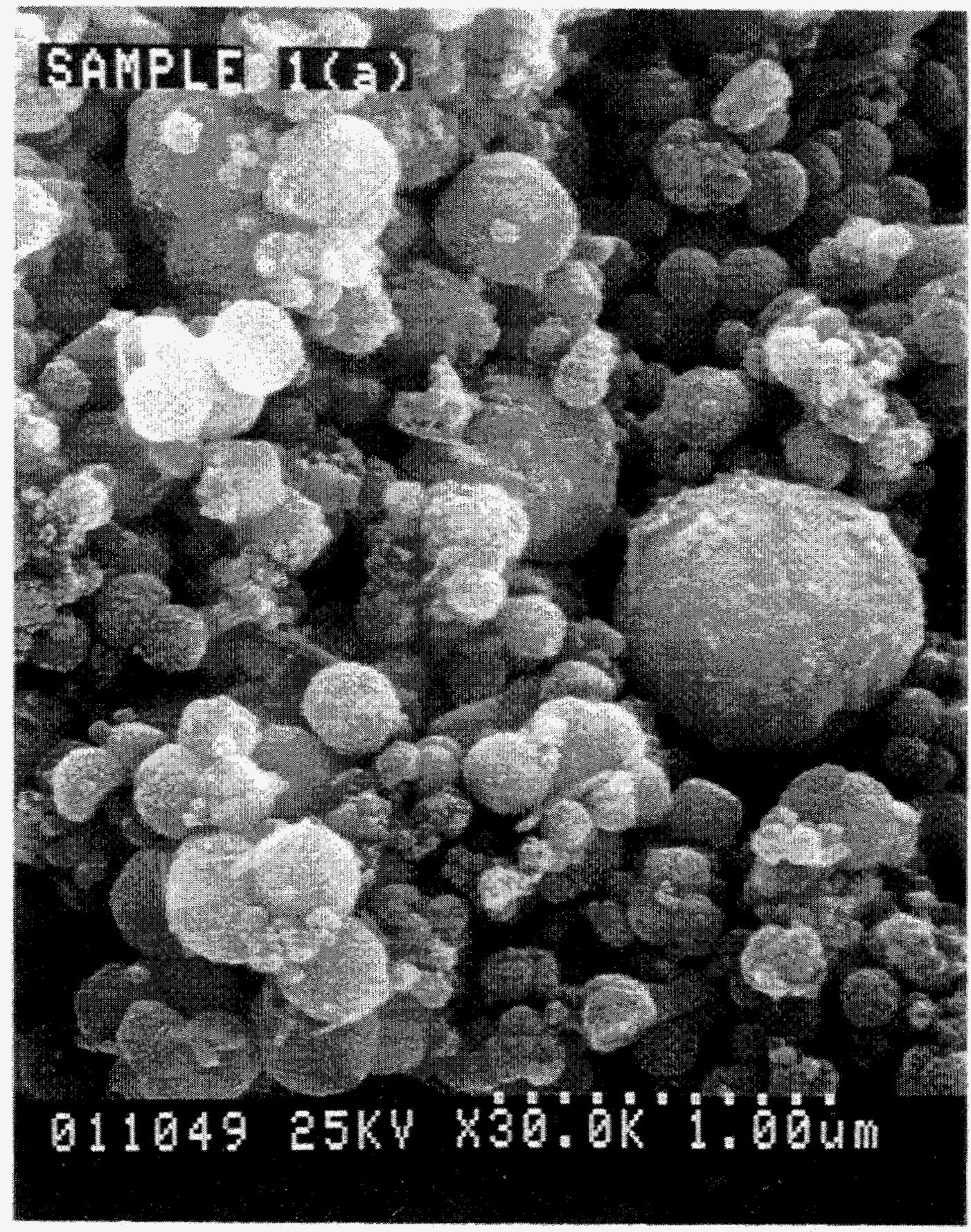

Figure B-3. SEM Photograph of Sludge A as a Dry Powder (Sample 1-0) at $1 \mu \mathrm{m}$ Bar Magnification. 
Appendix B

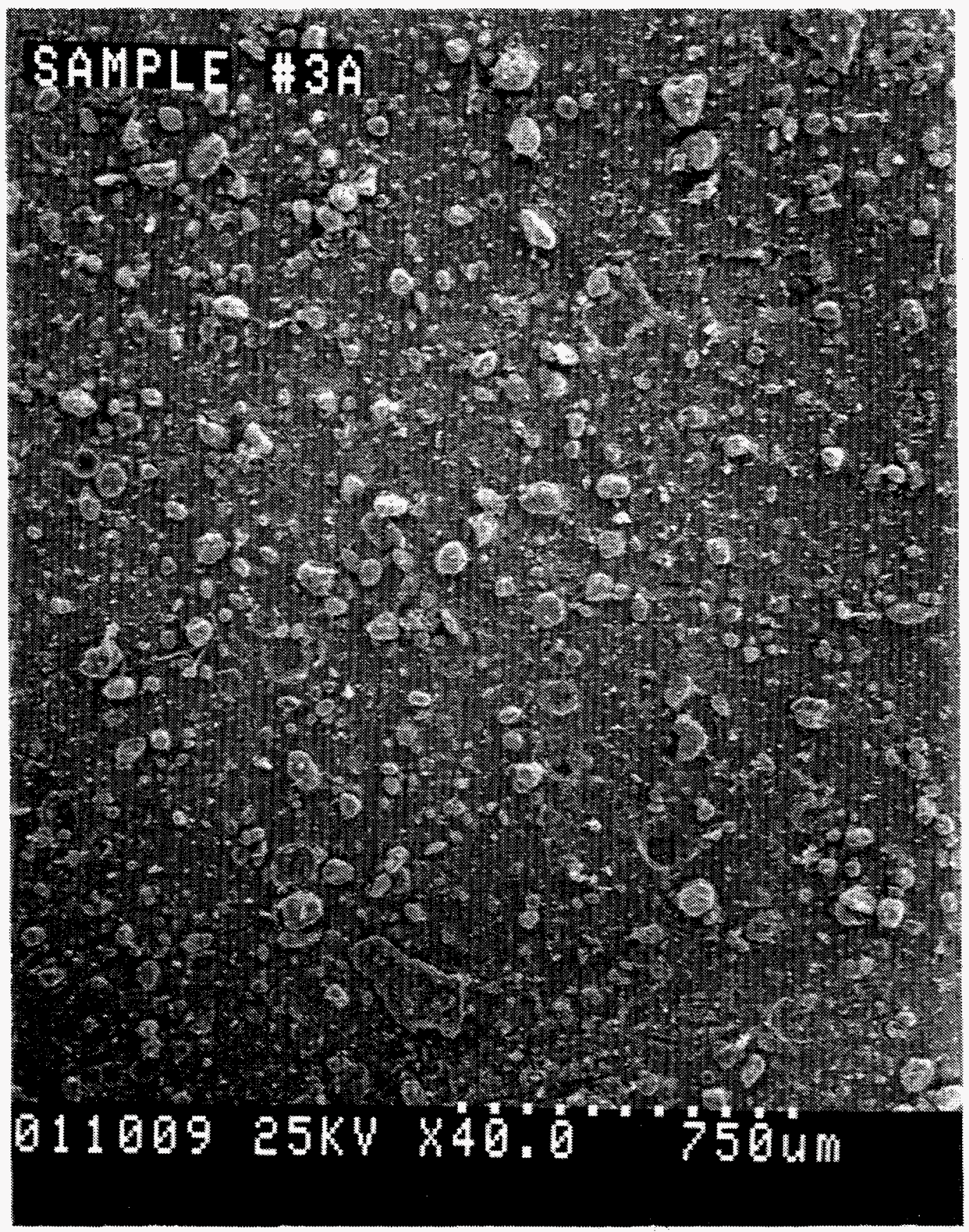

Figure B-4. SEM Photograph of Sludge A as Collected in a Filter Paper from the Test Loop Without Fiber Bed (Sample 1-5). 750 um Bar Magnification. 


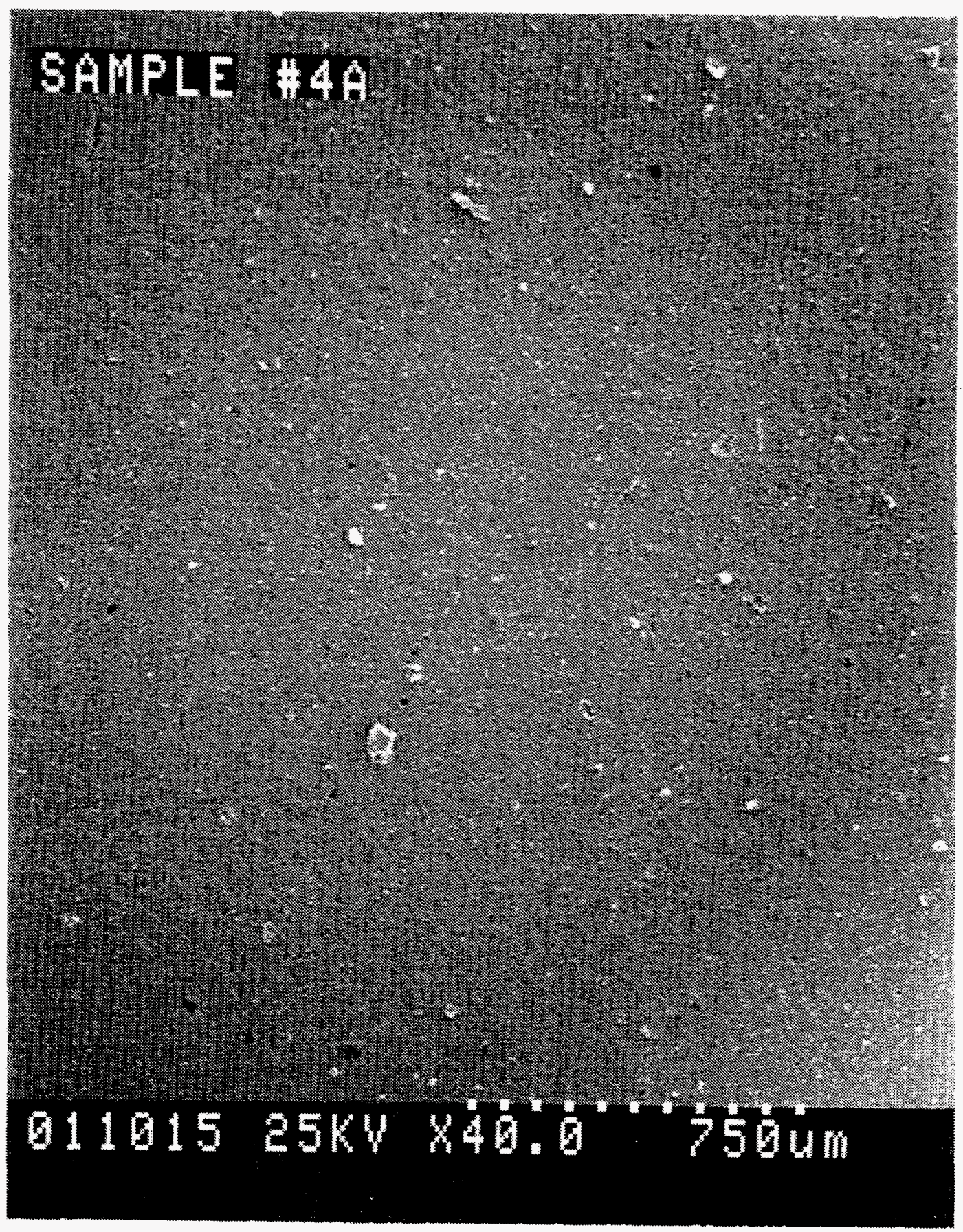

Figure B-5. SEM Photograph of Sludge A as Collected in a Filter Paper from the Test Loop With Fiber Bed (Sample 1-6). $750 \mu \mathrm{m}$ Bar Magnification. 
Appendix B

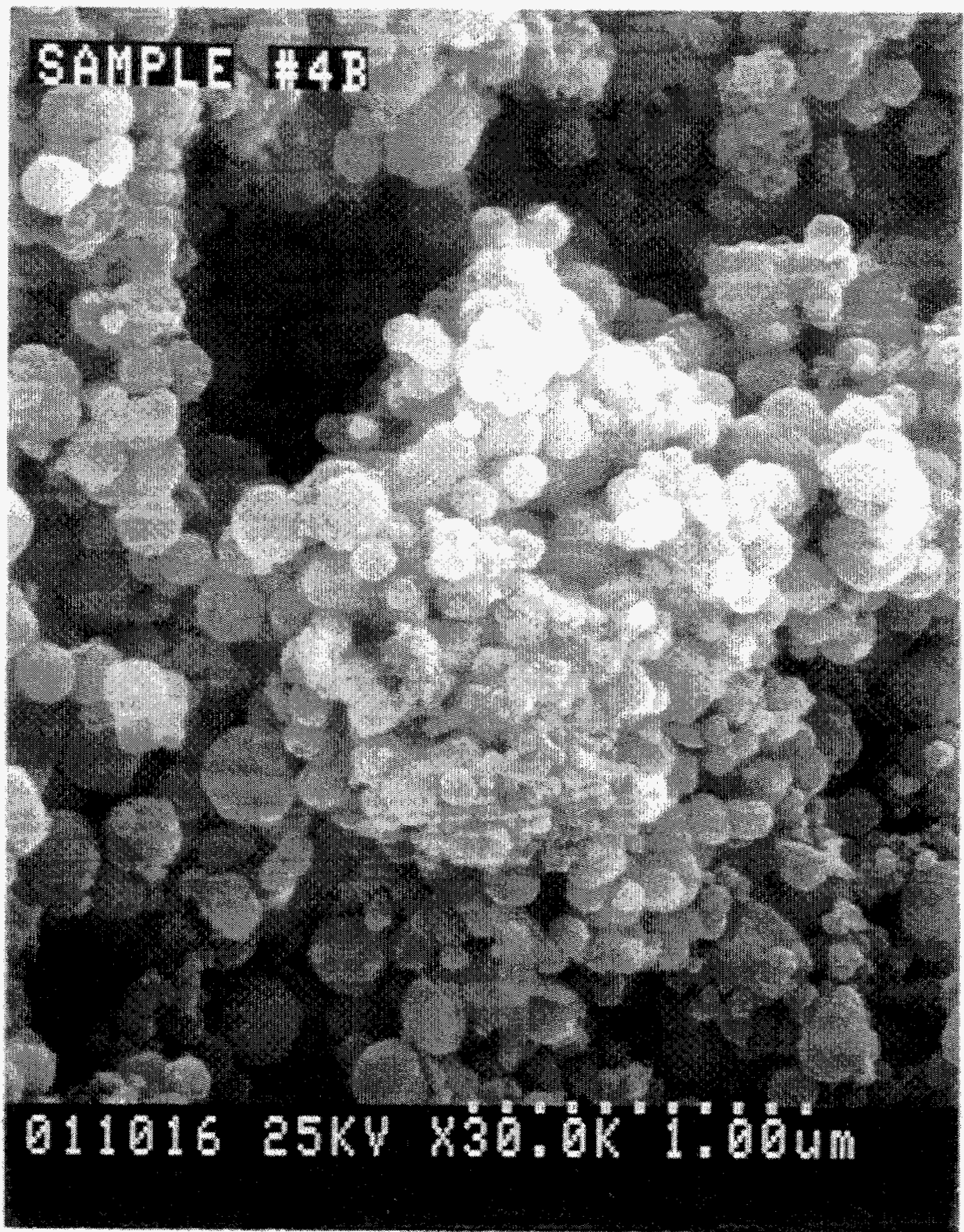

Figure B-6. SEM Photograph of Sludge A as Collected in a Filter Paper From the Test Loop With Fiber Bed (Sample 1-6). 1 pm Bar Magnification. 
these smaller primary particles cannot be dispersed in the test loop.

\subsubsection{Sludge A Sedimentation Velocity Results}

The qualitative results from the SEM analyses showed that Sludge $\mathrm{A}$ as a dry powder, before dropping it into the water in the test loop, was composed of large agglomerates of nearly spherical particles with a very broad size distribution. The SEM results also showed that, when the Sludge A particles are circulating in the water in the test loop, considerable dispersion of the agglomerates occurs.

To obtain the quantitative characterization of the particle size distribution, both in the dry state as well as when the particles are circulating in water, several samples of Sludge A particles were analyzed by sedimentation velocity measurements. The results from these analyses are summarized in the following paragraphs.

Specimens from Sample 1-0, particles from Sludge A as a dry powder, were so agglomerated that the sedimentation velocity measurements, initially conducted in the absence of surfactant and without ultra-sonication, gave meaningless results.

Consequently, it was decided to analyze a specimen from this sample using ultra-sonication but without surfactant. In this case, the agglomerates were dispersed using the ultra-sonication process for about 10 minutes. The results for the frequency and cumulative particle size distributions (by mass) from this analysis are presented in Table B-5; the corresponding plots are presented in Figure B-7, for the frequency particle size distribution, and Figure B-8 for the cumulative particle size distribution. The mass-mode, or maximum in the mass particle population, occurs at about $8.4 \mu \mathrm{m}$; the massmedian, i.e., the equivalent diameter above which $50 \%$ of the mass exists, occurs at about $7.6 \mu \mathrm{m}$.

To investigate the dispersion effect of adding a surfactant, $0.05 \%$ in mass of sodium-meta-phosphate was added to a specimen of Sample $1-0$. In this case, the specimen was also ultra-sonicated for about 15 minutes. The measured particle size distribution by mass is presented in Table B-6, which includes both the frequency and cumulative distributions. The same results are showed graphically in Figures B-9 and B-10 respectively. The mass-mode in this case
Table B-5. Dry Powder Sludge A Particle Size Distribution. Sedimentation Velocity Analysis Without Surfactant.

\begin{tabular}{ccc}
\hline $\begin{array}{c}\text { Equivalent } \\
\text { Diameter } \\
(\mu \mathrm{m})\end{array}$ & $\begin{array}{c}\text { Cumulative } \\
\text { Mass Fraction } \\
(\%)\end{array}$ & $\begin{array}{c}\text { Mass } \\
\text { Fraction } \\
(\%)\end{array}$ \\
\hline 100.00 & -93 & 7.6 \\
80.00 & -93 & 0 \\
60.00 & -93 & 0 \\
50.00 & 93 & 0 \\
40.00 & 93 & 0 \\
30.00 & 92.9 & 0.2 \\
25.00 & 92.6 & 0.4 \\
20.00 & 91.7 & 0.9 \\
15.00 & 88.5 & 3.2 \\
10.00 & 70.5 & 18.0 \\
8.00 & 53.7 & 16.7 \\
6.00 & 34.5 & 19.2 \\
5.00 & 26.1 & 8.4 \\
4.00 & 18.8 & 7.8 \\
3.00 & 11.9 & 6.8 \\
2.00 & 5.3 & 6.7 \\
1.50 & 2.7 & 2.6 \\
1.00 & 1.0 & 1.7 \\
\hline
\end{tabular}

MEDIAN DIAMETER: $\quad 7.61 \mu \mathrm{m}$

MODAL DLAMETER: $\quad 8.42 \mu \mathrm{m}$

occurs at about $5.4 \mu \mathrm{m}$; the mass-median of the particle size distributions is approximately $5 \mu \mathrm{m}$.

The comparison of the data in Tables B-5 and B-6 suggests that the measured particle size distribution is very sensitive to the method used to disperse the agglomerated particles. Unfortunately, it is not possible to determine from these analyses how much energy is needed to break down the large agglomerates $(>100 \mu \mathrm{m})$ initially present in the Sludge A; this is critical because many of the relevant properties of the particles in the test loop, including filtration efficiency and pressure drop, will depend on the agglomerate size and not on the primary particle size. To obtain quantitative information about the extent of dispersion of the agglomerated Sludge A particles introduced by the pump and heater in the head loss testing facility, several samples of Sludge $A$, suspended in the water and circulating at $1.5 \mathrm{ft} / \mathrm{s}(0.5 \mathrm{~m} / \mathrm{s})$, were collected and examined using sedimentation velocity 
Table B-6. Dry Powder Sludge A Particle Size Distribution. Sedimentation Velocity Analysis With Surfactant.

\begin{tabular}{ccc}
\hline $\begin{array}{c}\text { Equivalent } \\
\text { Diameter } \\
(\mu \mathrm{m})\end{array}$ & $\begin{array}{c}\text { Cumulative } \\
\text { Mass Fraction } \\
(\%)\end{array}$ & $\begin{array}{c}\text { Mass Fraction } \\
(\%)\end{array}$ \\
\hline 100.00 & 98.6 & 1.5 \\
80.00 & 98.6 & 0 \\
60.00 & 98.6 & 0 \\
50.00 & 98.4 & 0.2 \\
40.00 & 97.5 & 0.9 \\
30.00 & 95.4 & 2.1 \\
25.00 & 94.2 & 1.2 \\
20.00 & 92.9 & 1.2 \\
15.00 & 90.2 & 2.8 \\
10.00 & 82.7 & 7.4 \\
8.00 & 75.9 & 6.9 \\
6.00 & 61.4 & 14.5 \\
5.00 & 50.5 & 10.9 \\
4.00 & 38.4 & 12.2 \\
3.00 & 26.1 & 12.3 \\
2.00 & 13.2 & 13.0 \\
1.50 & 6.5 & 6.7 \\
1.00 & 2.7 & 3.8 \\
0.80 & 2.4 & 0.3 \\
0.60 & 2.4 & 0 \\
0.50 & 2.1 & 0.3 \\
0.40 & 1.8 & 0.3 \\
\hline & & \\
\hline & & \\
\hline
\end{tabular}

MEDIAN DIAMETER: $\quad 4.95 \mu \mathrm{m}$

MODAL DIAMETER: $5.42 \mu \mathrm{m}$

analysis; these are Samples 1-2, 1-3, and 1-4 described in Section 4.

The specimen from Sample 1-2 had to be dispersed with ultra-sonication for about 4 minutes because, without this dispersion process, the measured results were meaningless. The specimen from Sample 1-3, unlike Sample 1-2, did not require ultrasonication to provide useful measurements.

Similarly, the analyzed specimen from Sample 1-4 gave useful measurements without ultra-sonication. For comparison purposes, however, it was decided to analyze another specimen from Sample 1-4 after ultra-sonication for about 4 minutes; hereafter, the results for this specimen are denoted by 1-4 (US).

The frequency particle size distribution, by mass, measured for Samples 1-2, 1-3, 1-4, and 1-4 (US) are presented in Figure B-11; the corresponding cumulative particle size distributions are presented in Figure B-12. As indicated in Figures B-11 and B12 , all of the analyzed specimens gave, within the limits of error of this technique, the same particle size distribution for Sludge $\mathrm{A}$. This is an encouraging result, because shows that the collected samples are representative of the Sludge A particles while circulating in the water in the test loop. The averages and standard deviations of the measured values for the frequency and cumulative particle size distributions, by mass, are presented in Figures B-13 and B-14 respectively. As indicated in Figure $\mathrm{B}-13$, the average mass-mode is $2.26 \mu \mathrm{m}$, whereas the average mass-median is $2.38 \mu \mathrm{m}$. Figure B-14 also presents the comparison between the measured particle size distribution of Sludge $A$ and the particle size distribution recommended by the BWROG; for all practical purposes, Sludge A in the test loop represents fairly well the suggested particle size distribution.

\subsection{Characterization of Sludge B Particles}

Sludge B is composed of $100 \%$ of the iron oxide powder provided by the manufacturer according to specification \#9101- $\mathrm{N}$ and, since was used only in three of the head loss experiments, the characterization efforts were concentrated just in analyzing the particles from the dry powder before dropping the sludge into the test loop. Both SEM and sedimentation velocity analyses were used to typify Sludge B particles.

\subsubsection{Sludge B SEM Results}

Specimens of Sample 2-0, dry powder from Sludge $B$ as supplied by the manufacturer, were prepared for SEM analyses. Figures B-15, B-16, and B-17 present typical SEM photographs of this sample. Figure B-15, the SEM photograph at the lower magnification of $750 \mu \mathrm{m}$ bar, shows very few particles or agglomerates above $100 \mu \mathrm{m}$ and practically none above $150 \mu \mathrm{m}$. The SEM photograph at $30 \mu \mathrm{m}$ bar magnification in Figure B16 , shows that Sludge B contains a large number of nearly spherical particles between 1 and $30 \mu \mathrm{m}$. In contrast with the SEM results for Sludge A, this photo suggest that the Sludge $B$ particles do not 
Appendix $B$

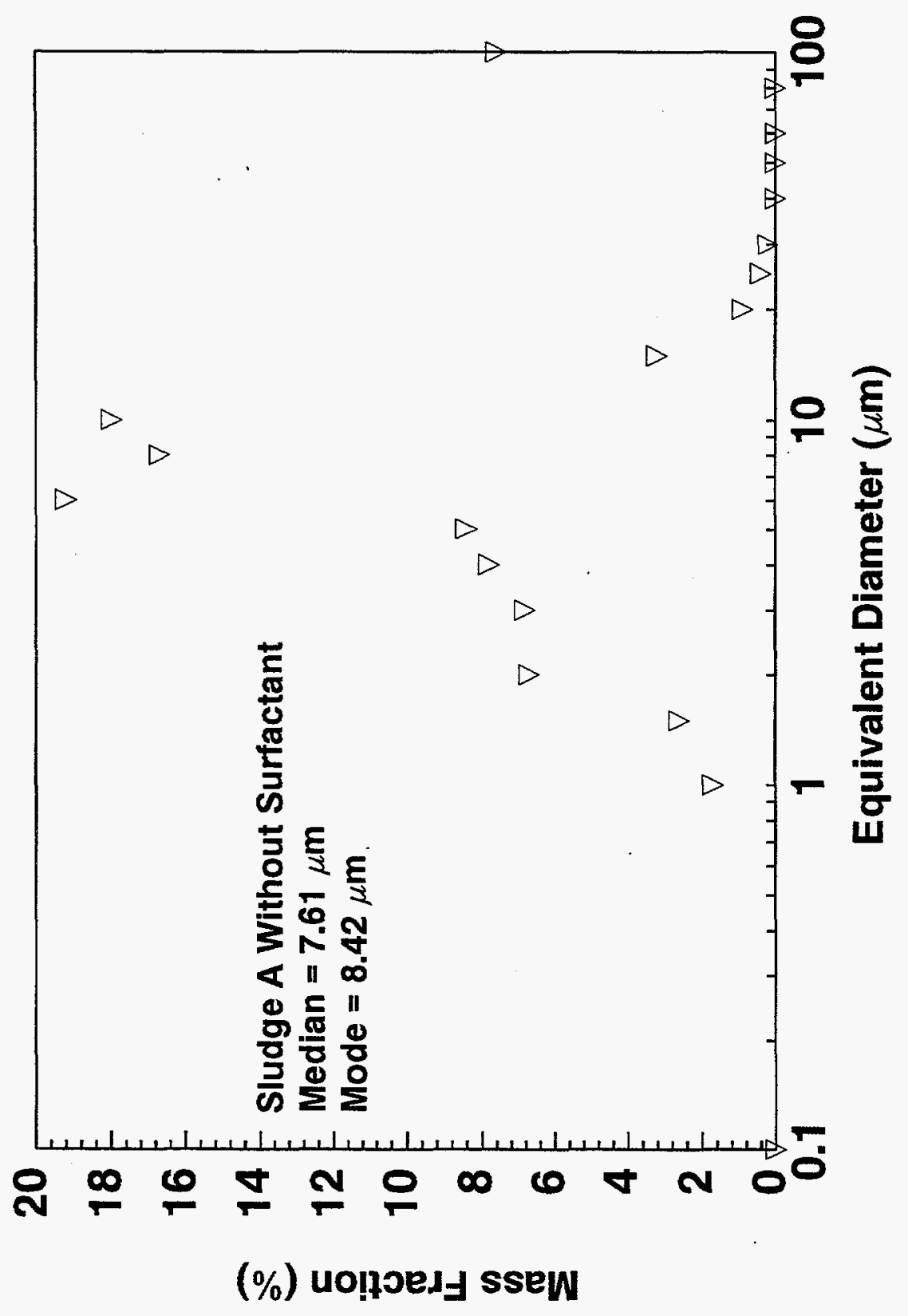

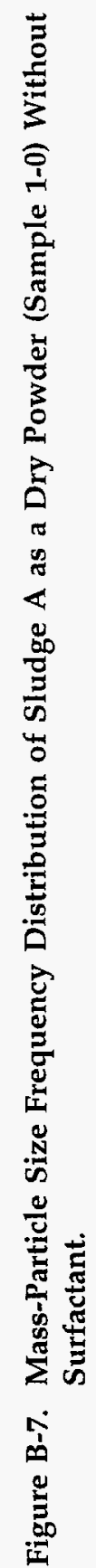




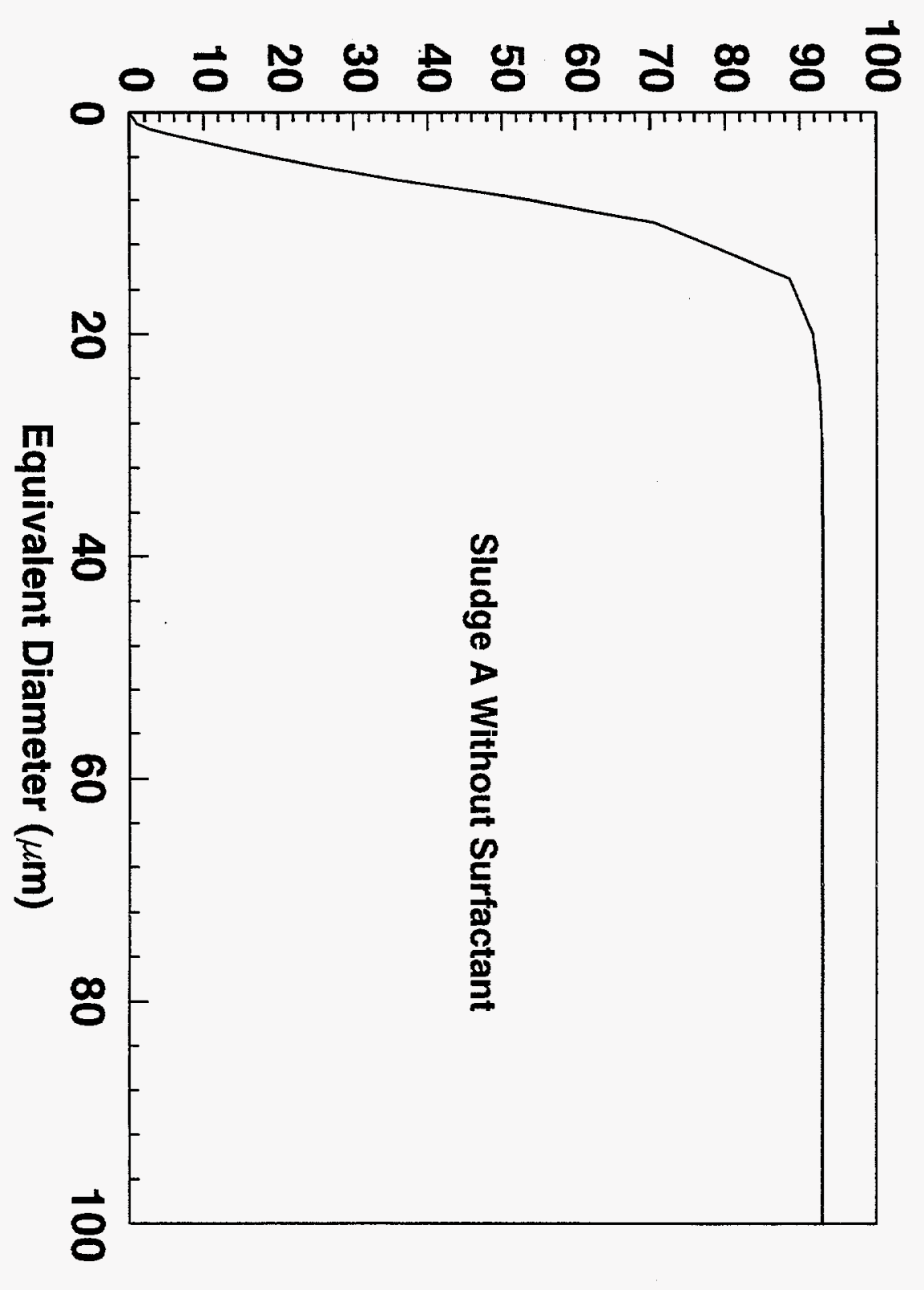




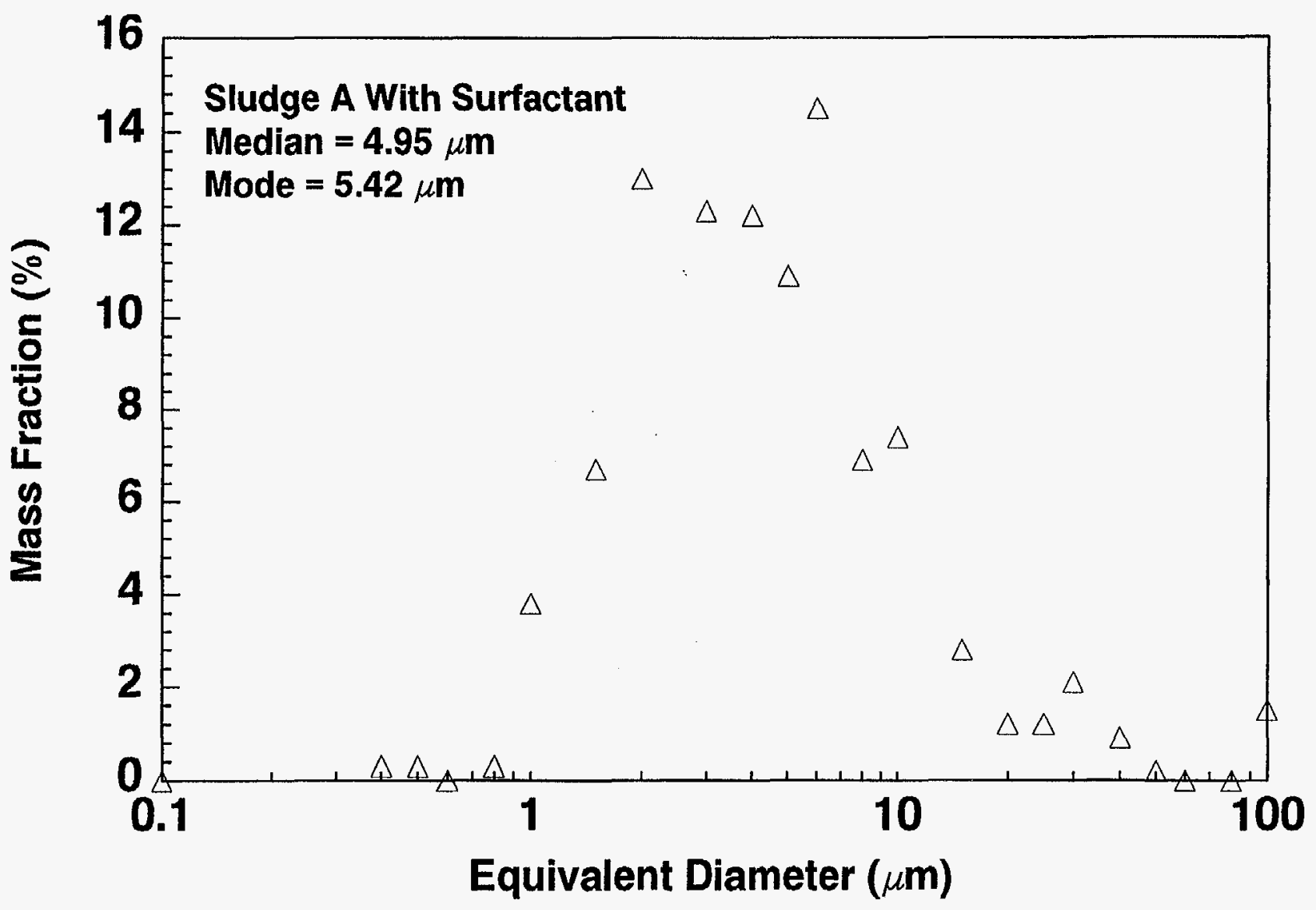

Figure B-9. Mass-Particle Size Frequency Distribution of Sludge A as a Dry Powder (Sample 1-0) With Surfactant. 

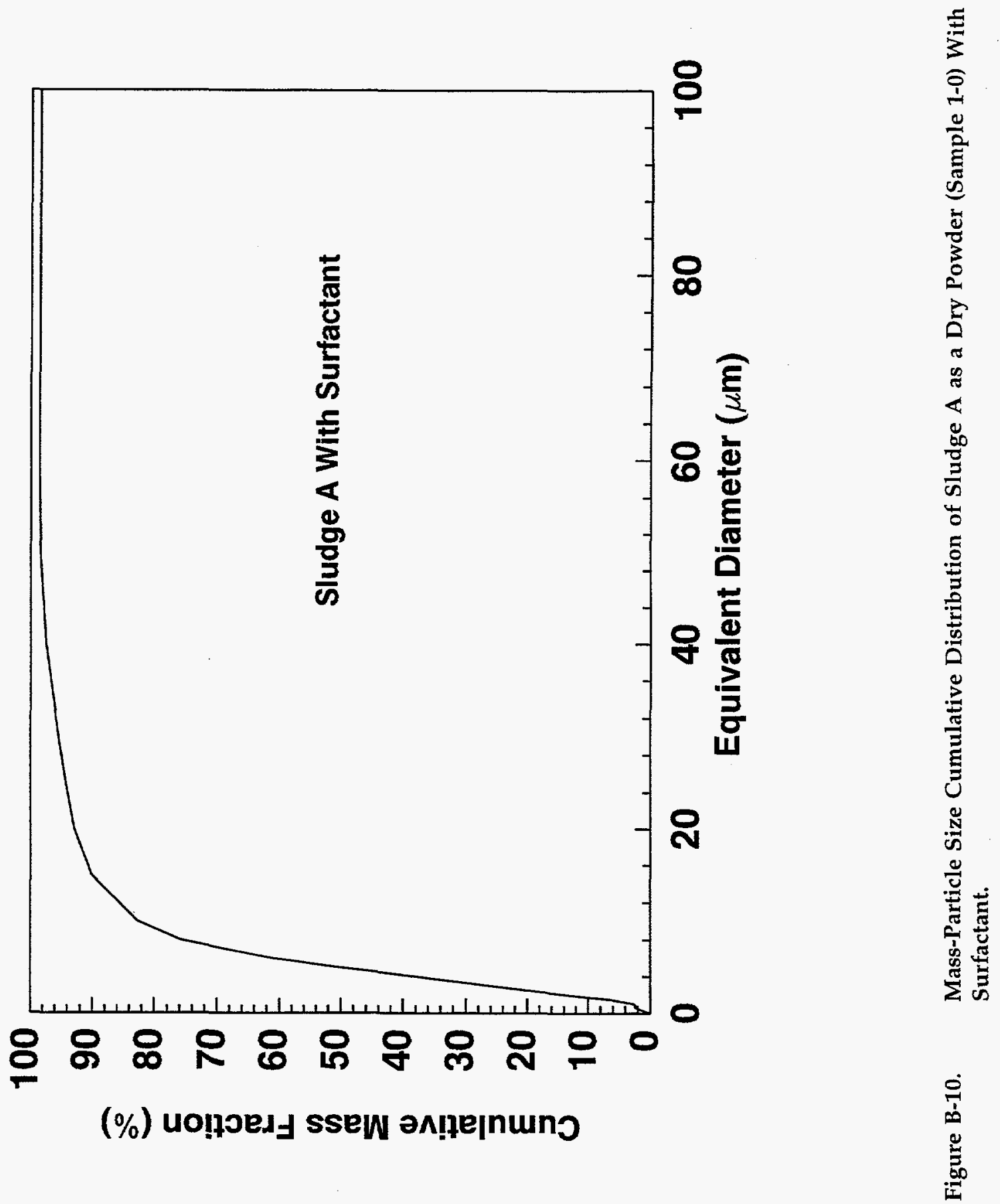
Appendix B

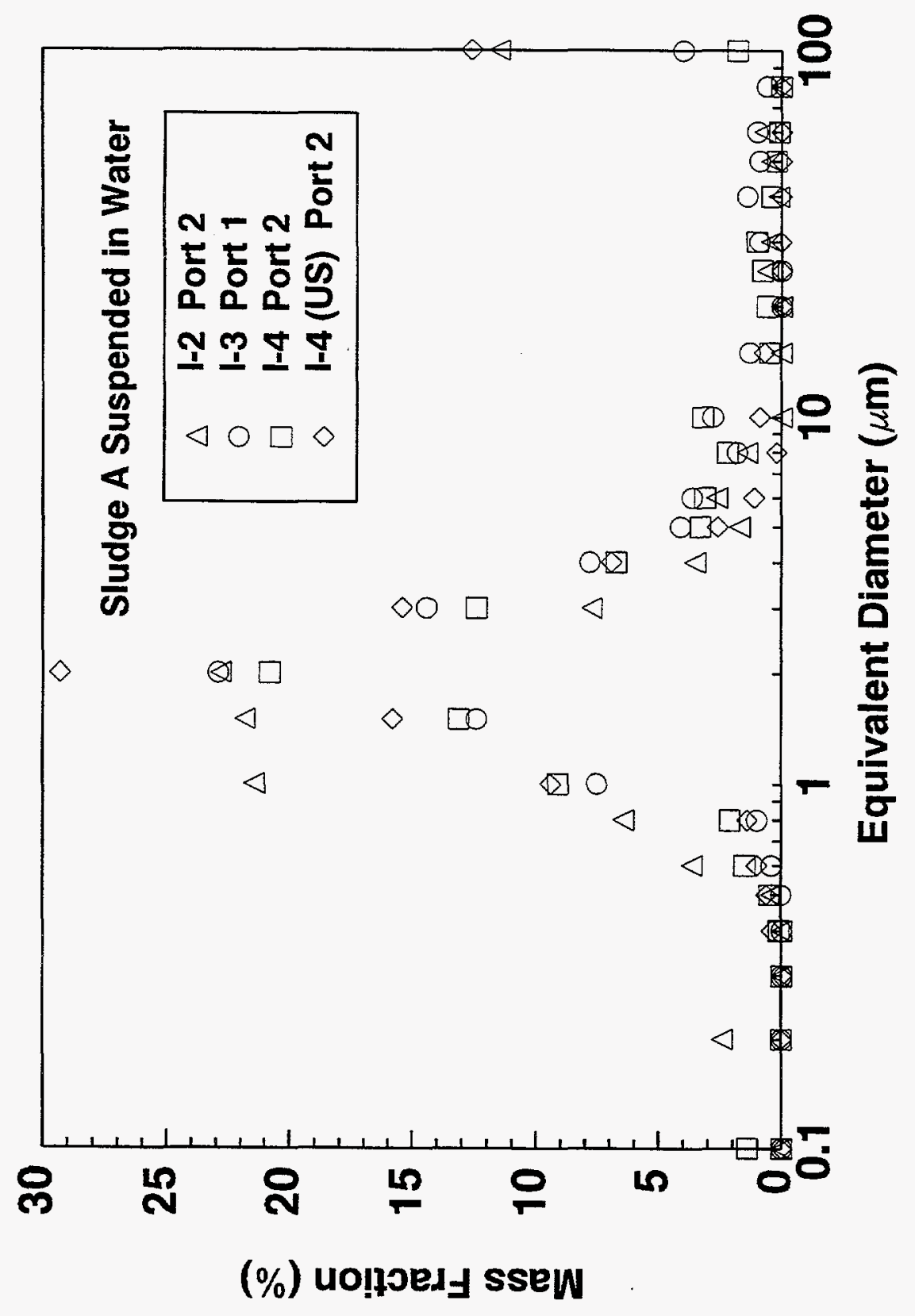



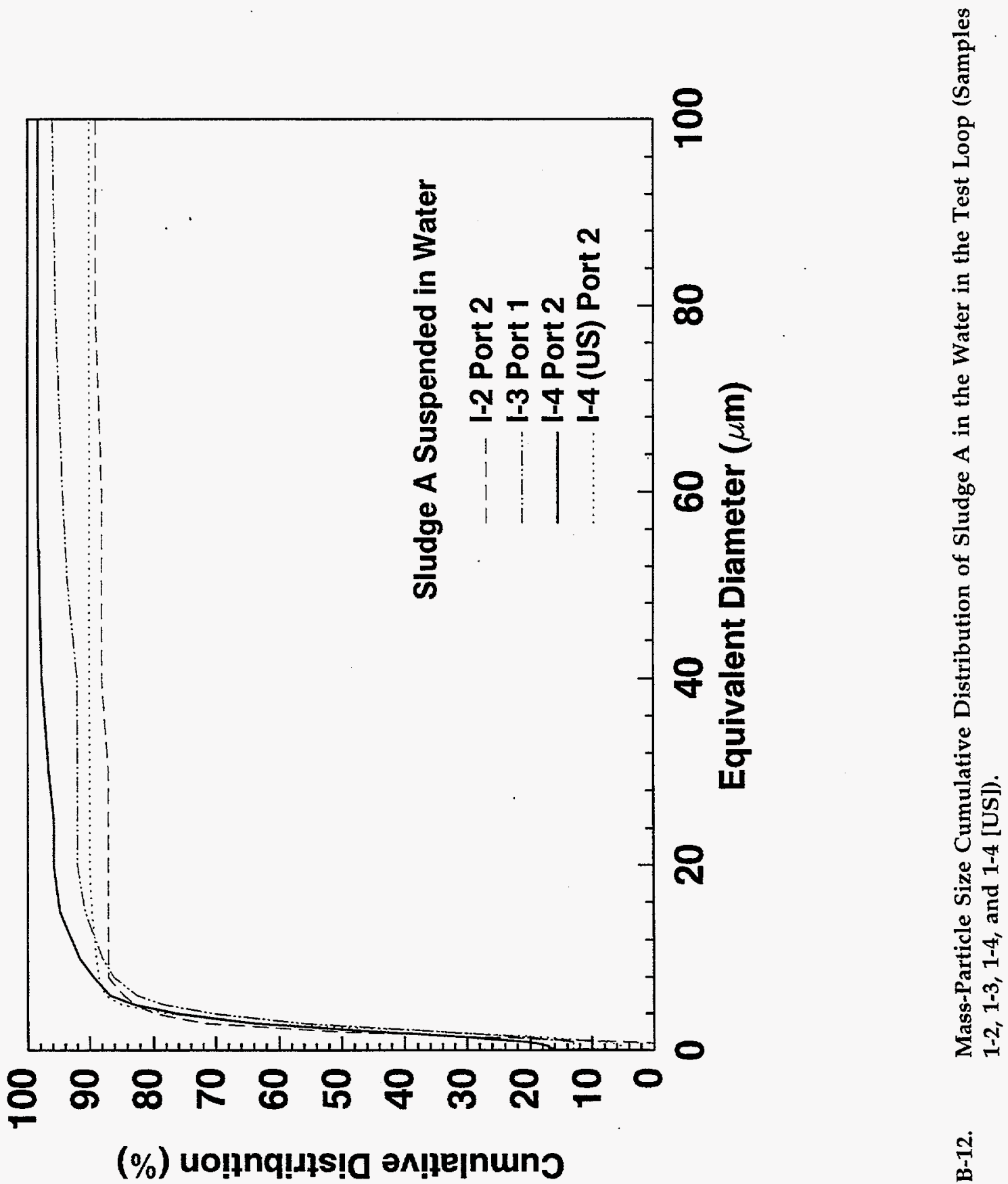
Appendix B

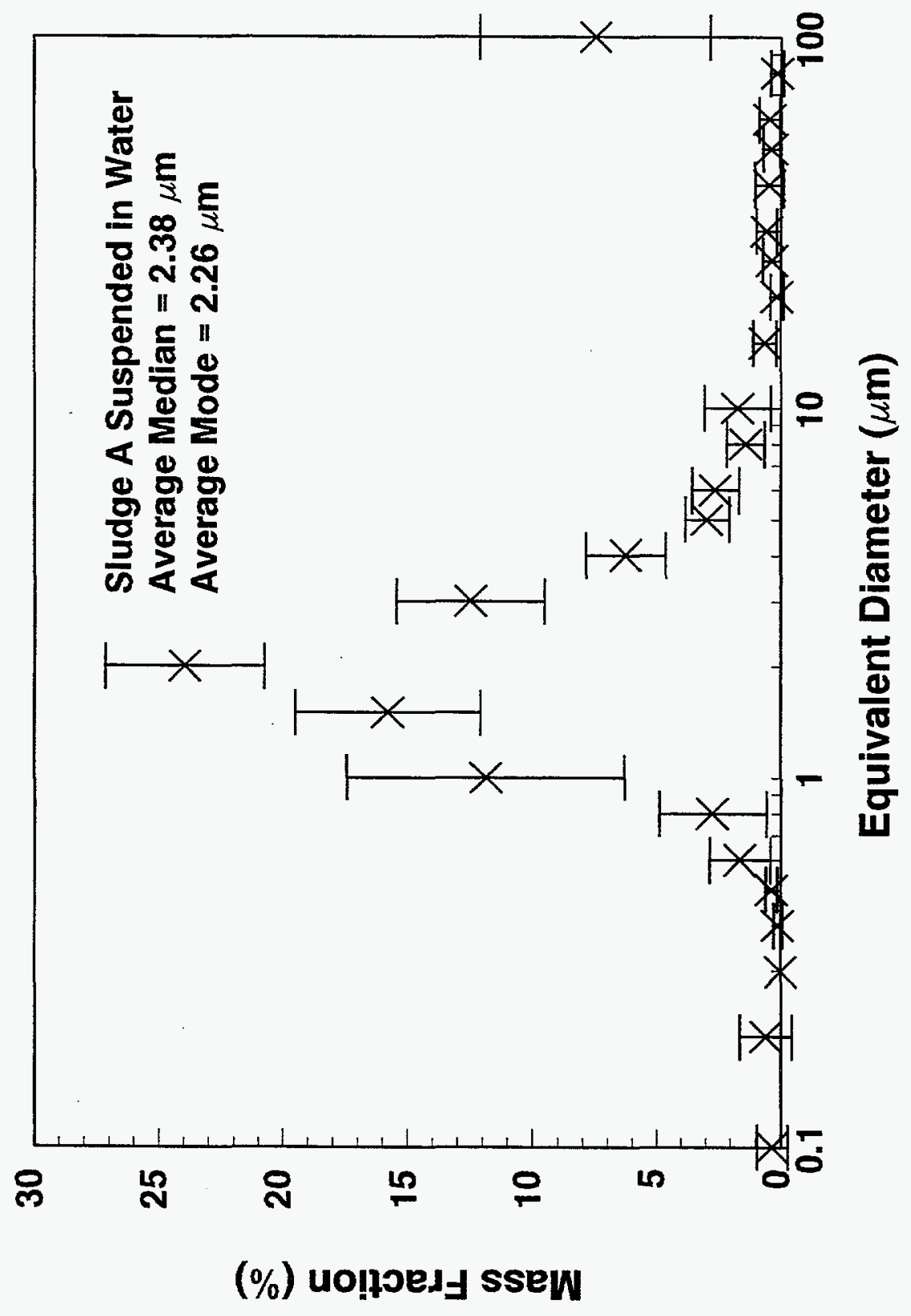

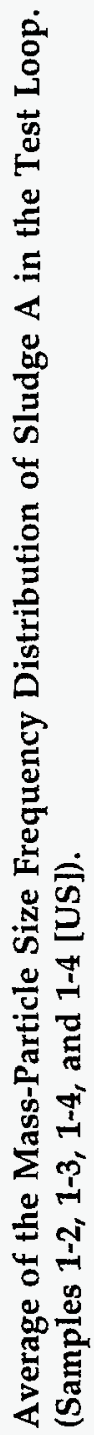

党 

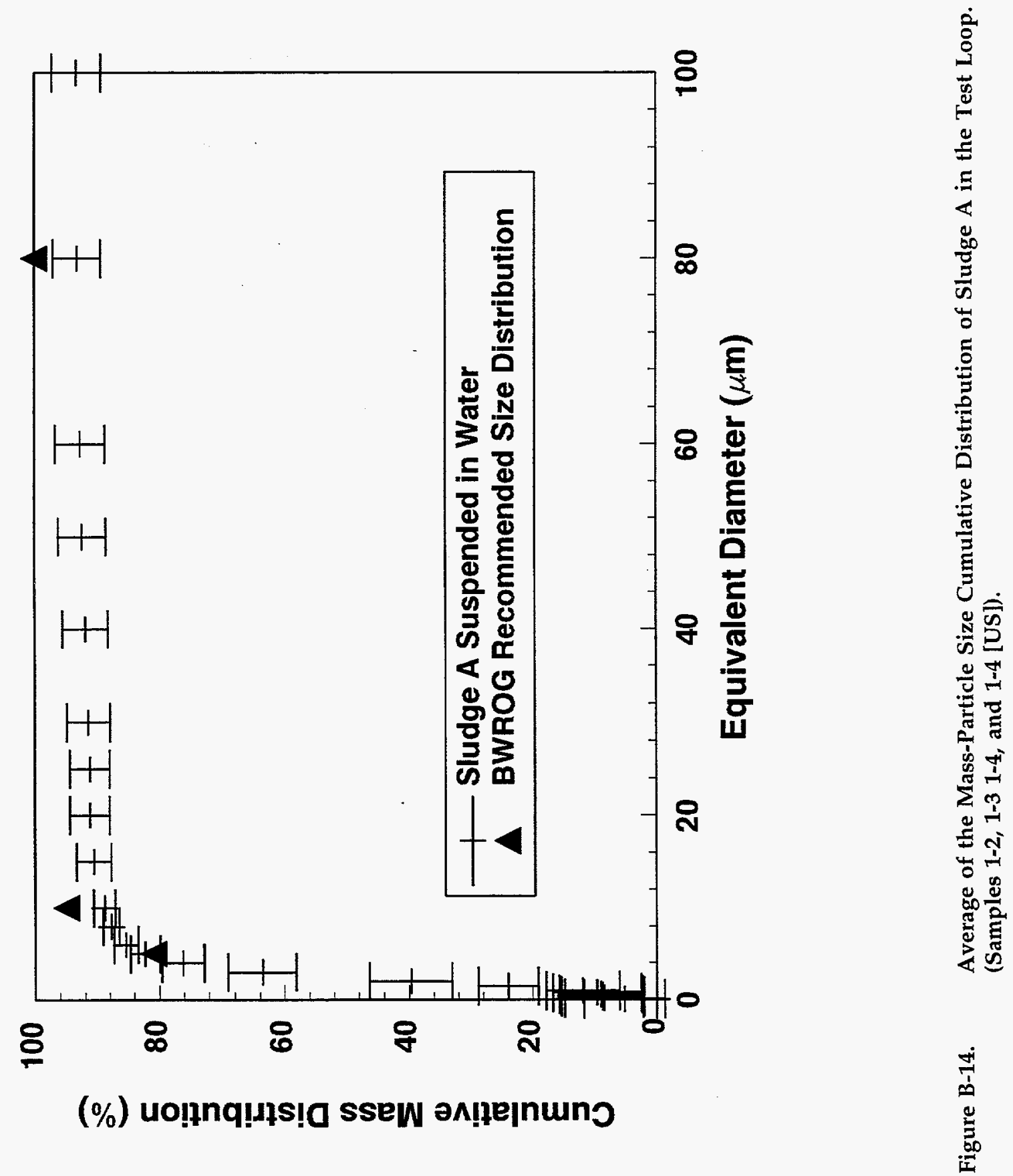
Appendix B

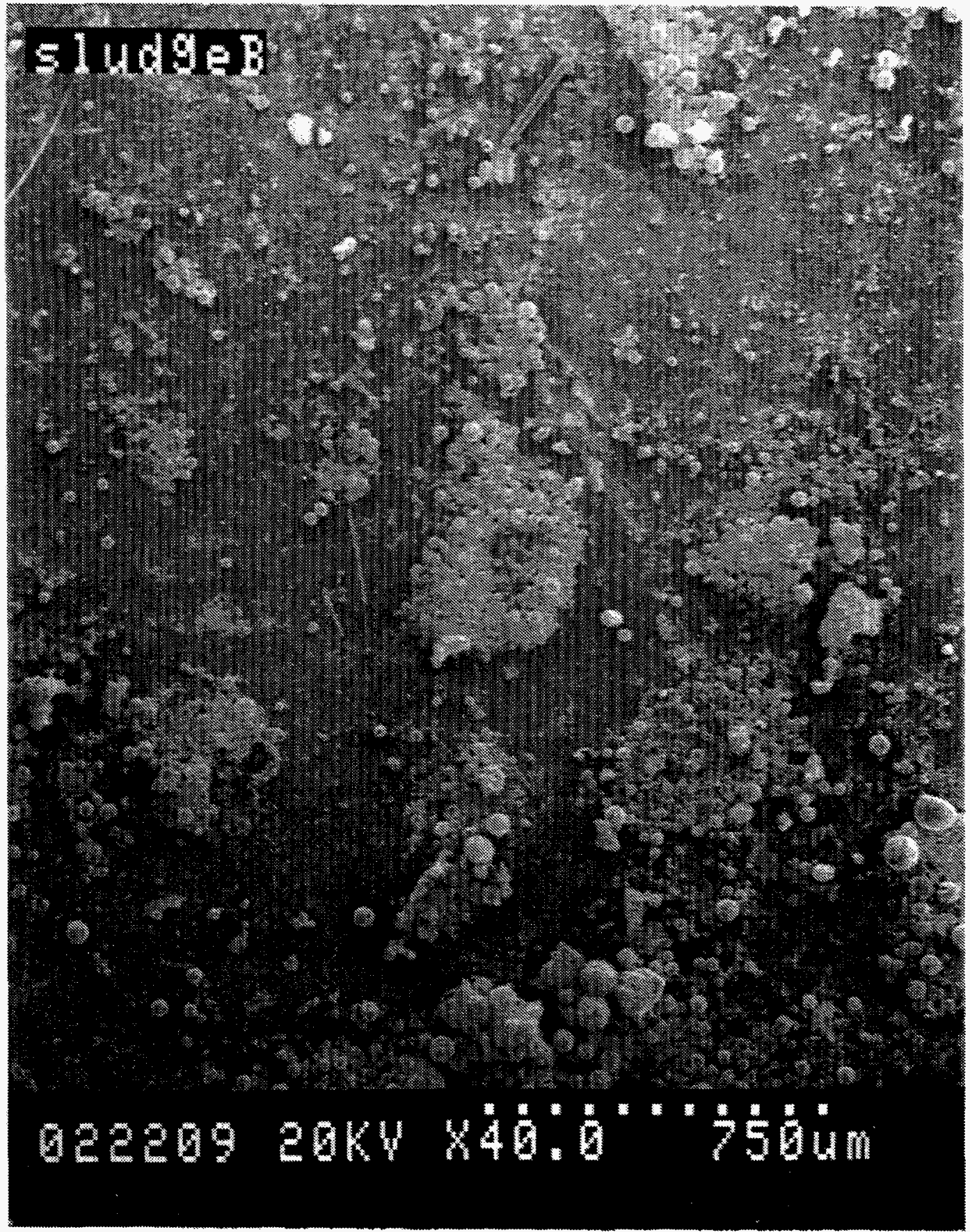

Figure B-15. SEM Photograph of Sludge B as a Dry Powder (Sample 2-0) at $750 \mu \mathrm{m}$ Bar Magnification. 
Appendix B

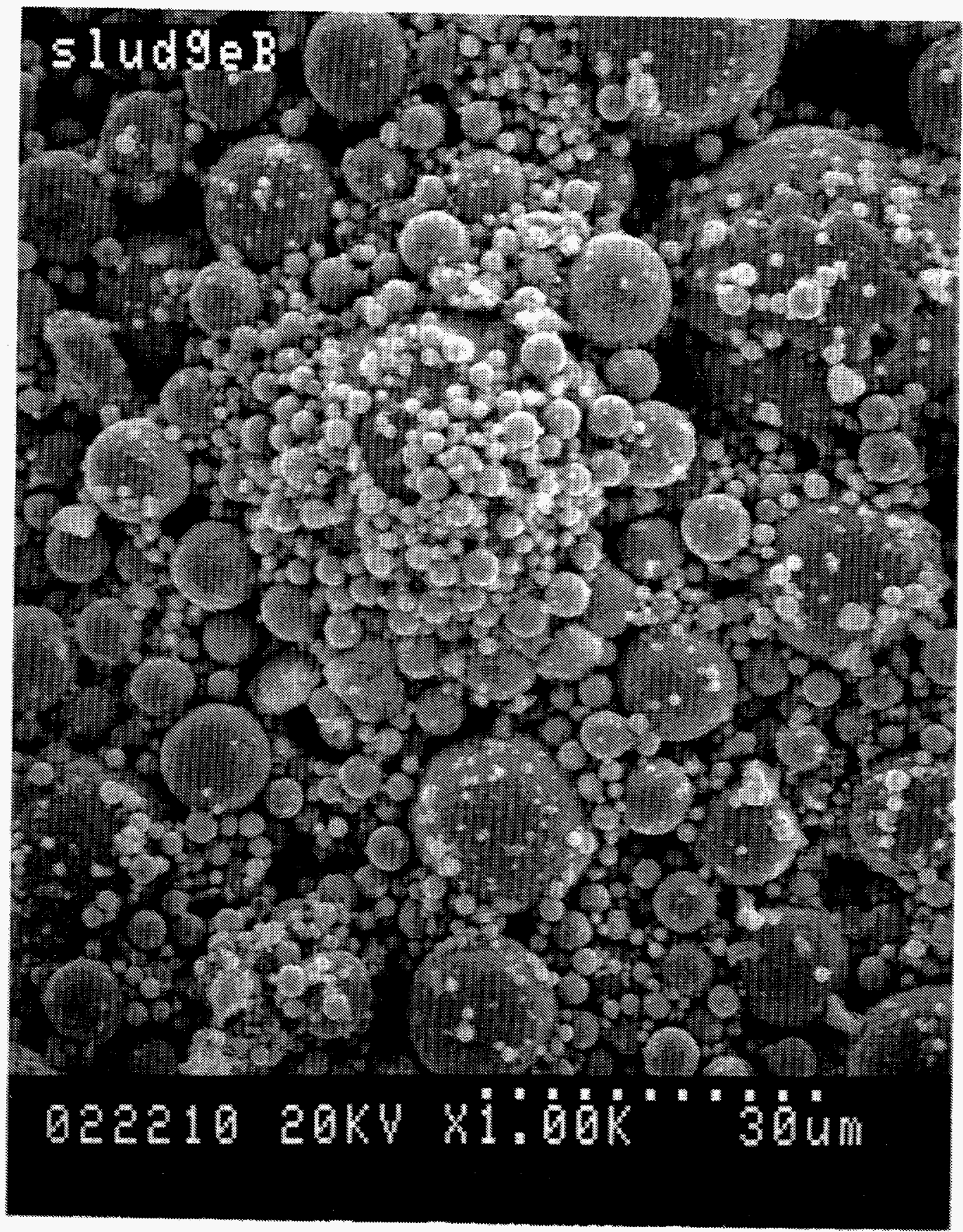

Figure B-16. SEM Photograph of Sludge B as a Dry Powder (Sample 2-0) at $30 \mu \mathrm{m}$ Bar Magnification. 


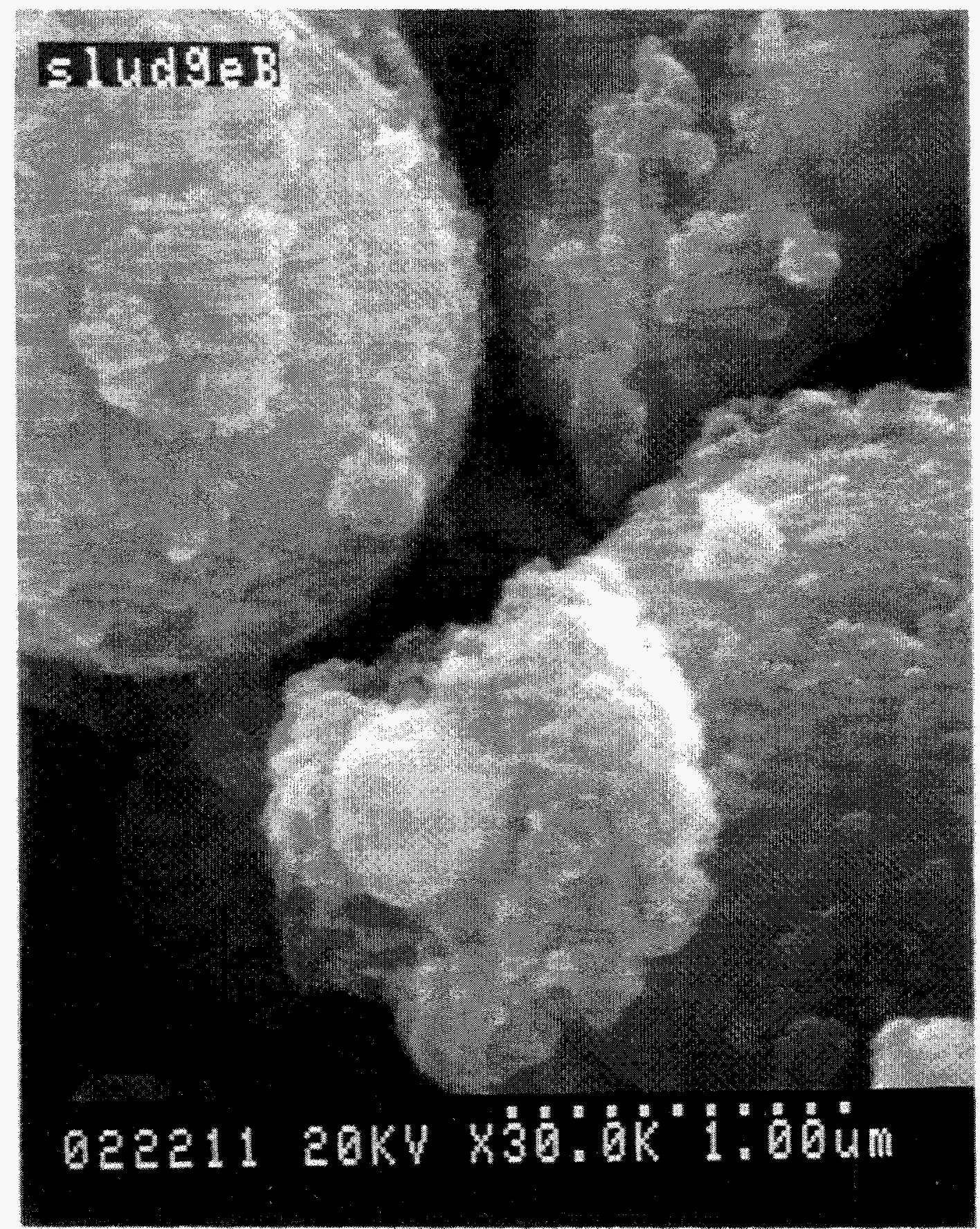

Figure B-17. SEM Photograph of Sludge B as a Dry Powder (Sample 2-0) at 1 um Bar Magnification. 
seem to form stable agglomerates. The highest magnification SEM photograph, $1 \mu \mathrm{m}$ bar, presented in Figure B-17, shows that Sludge B has very few particles below roughly $1 \mu \mathrm{m}$. Overall, these SEM photographs indicate that the spread of the Sludge B particle size distribution is not as broad as in the case of Sludge A.

\subsubsection{Sludge B Sedimentation Velocity Results}

The qualitative results from the SEM analyses showed that Sludge B, as a dry powder, was composed of primary particles in the range from 1 to $30 \mu \mathrm{m}$, and agglomerates of about $100 \mu \mathrm{m}$. To obtain the quantitative particle size distribution, by mass, a specimen from Sample 2-0, Sludge B as a dry powder, was analyzed by sedimentation velocity measurements.

The specimen for analysis was dispersed by ultrasonication for about 5 minutes in the presence of surfactant (sodium meta-phosphate). The frequency and cumulative particle size distributions, by mass, measured for Sludge B are presented in Table B-7; the same results are plotted in Figures B-18 and B19 , for the mass based frequency and cumulative particle size distributions respectively. The massmode of the this particle population occurs at about $3.6 \mu \mathrm{m}$; the mass-median is about $8.8 \mu \mathrm{m}$.

According to the manufacturer's specifications, Sludge $B$ should have about $82 \%$, by mass, of particles in the range from 10 to $35 \mu \mathrm{m}$, and trace amounts below $10 \mu \mathrm{m}$. The results of the sedimentation velocity analysis indicate that the screen analysis method, apparently used by the manufacturer to determine the particle size distribution of Sludge B, was not adequate to characterize particles below $10 \mu \mathrm{m}$.

\subsection{Characterization of Debris Beds}

The morphology of the particulate deposits on the fiber beds has an important effect in their filtration efficiency, i.e., in the fraction of the entering particulate mass that is retained by the debris bed and, therefore, it also affects the pressure losses at the suction of the ECCS's pumps. To have a better knowledge about this morphology, it was decided to
Table B-7. Dry Powder Sludge B Sedimentation Velocity Analysis.

\begin{tabular}{ccc}
\hline $\begin{array}{c}\text { Equivalent } \\
\text { Diameter } \\
(\mu \mathrm{m})\end{array}$ & $\begin{array}{c}\text { Cumulative } \\
\text { Mass Fraction } \\
(\%)\end{array}$ & $\begin{array}{c}\text { Mass } \\
\text { Fraction } \\
(\%)\end{array}$ \\
\hline 100.00 & 76.3 & 23.7 \\
80.00 & 76.2 & 0 \\
60.00 & 76.2 & 0.1 \\
50.00 & 76.2 & 0 \\
40.00 & 76 & 0 \\
30.00 & 76 & 0 \\
25.00 & 75.9 & 1.2 \\
20.00 & 71.6 & 4.3 \\
15.00 & 65.5 & 6.1 \\
10.00 & 56.2 & 9.2 \\
8.00 & 45.2 & 11.0 \\
6.00 & 31.3 & 13.9 \\
5.00 & 22.5 & 8.8 \\
4.00 & 7.6 & 14.9 \\
3.00 & 0 & 21.8 \\
2.00 & 0 & 14.6 \\
1.50 & 0 & 0 \\
1.00 & 0 & 6.1 \\
0.80 & 0 & 5.1 \\
0.60 & 0 & 0 \\
0.50 & 0 & 0 \\
\hline
\end{tabular}

MEDIAN DIAMETER: $\quad 8.76 \mu \mathrm{m}$

\section{MODAL DIAMETER: $\quad 3.65 \mu \mathrm{m}$}

examine with SEM analysis several specimens from debris beds samples collected during some of the head loss experiments. Specimens from Samples 3$0,3-1$, and 3-2, representing, respectively, a clean fiber bed, a mixed bed lightly loaded, and a mixed bed heavily loaded, were analyzed. A summary of the most significant results is presented in the following sections.

\subsubsection{Clean Fiber Bed SEM Results}

Sample 3-0 consists of a clean fiber bed, taken from the test facility without any sludge particles, and serves as a control to compare the results when sludge was added into the test loop. Figures B-20, B-21, and B-22 present the SEM photographs of a specimen from this sample at magnifications of 750 $\mu \mathrm{m}, 30 \mu \mathrm{m}$, and $1 \mu \mathrm{m}$ bars respectively. Figure B-20 shows that the fibers form a fairly uniform 
Appendix B

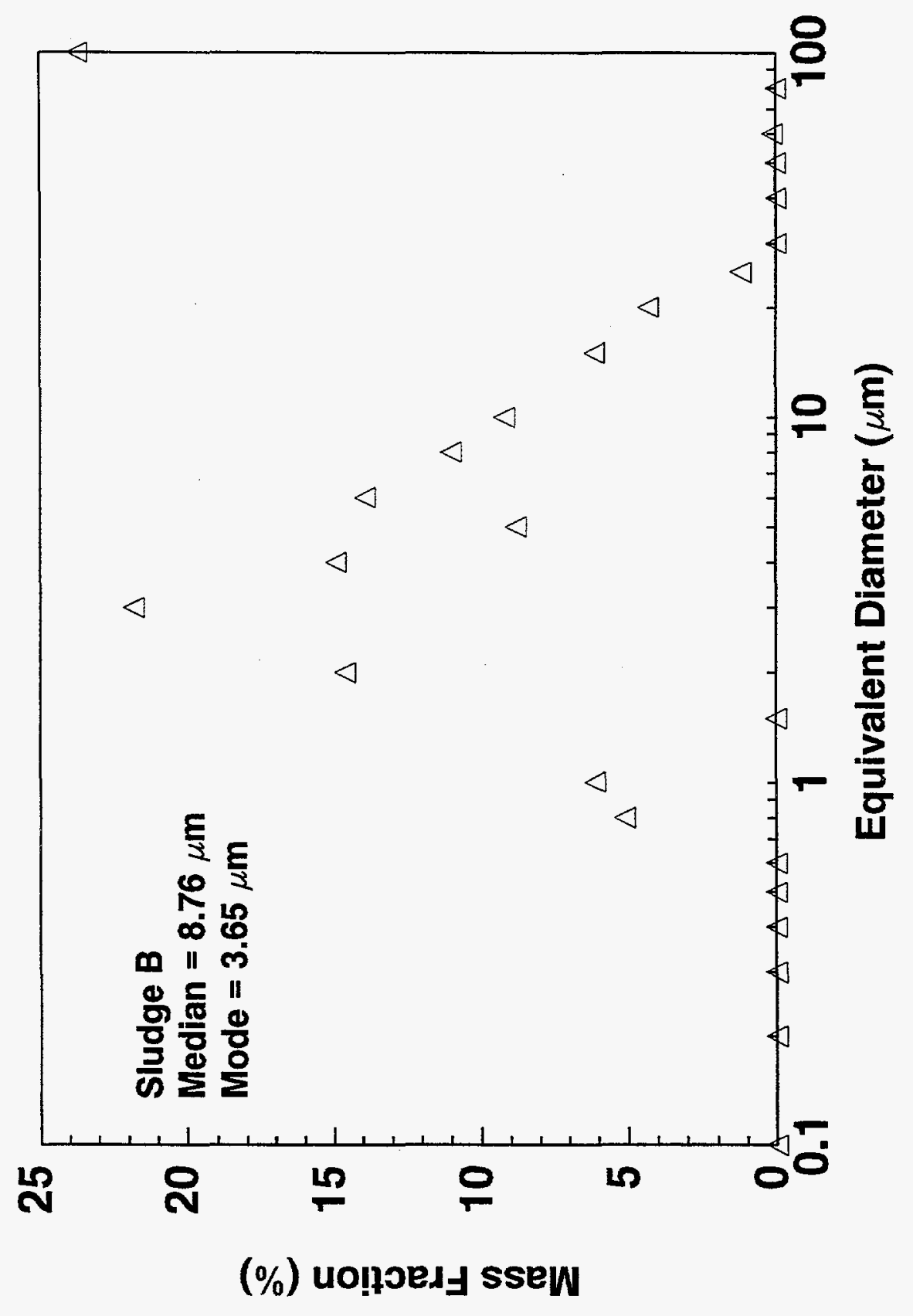

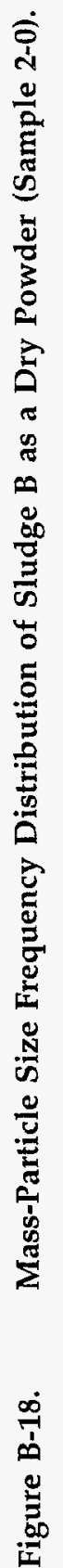


Appendix B

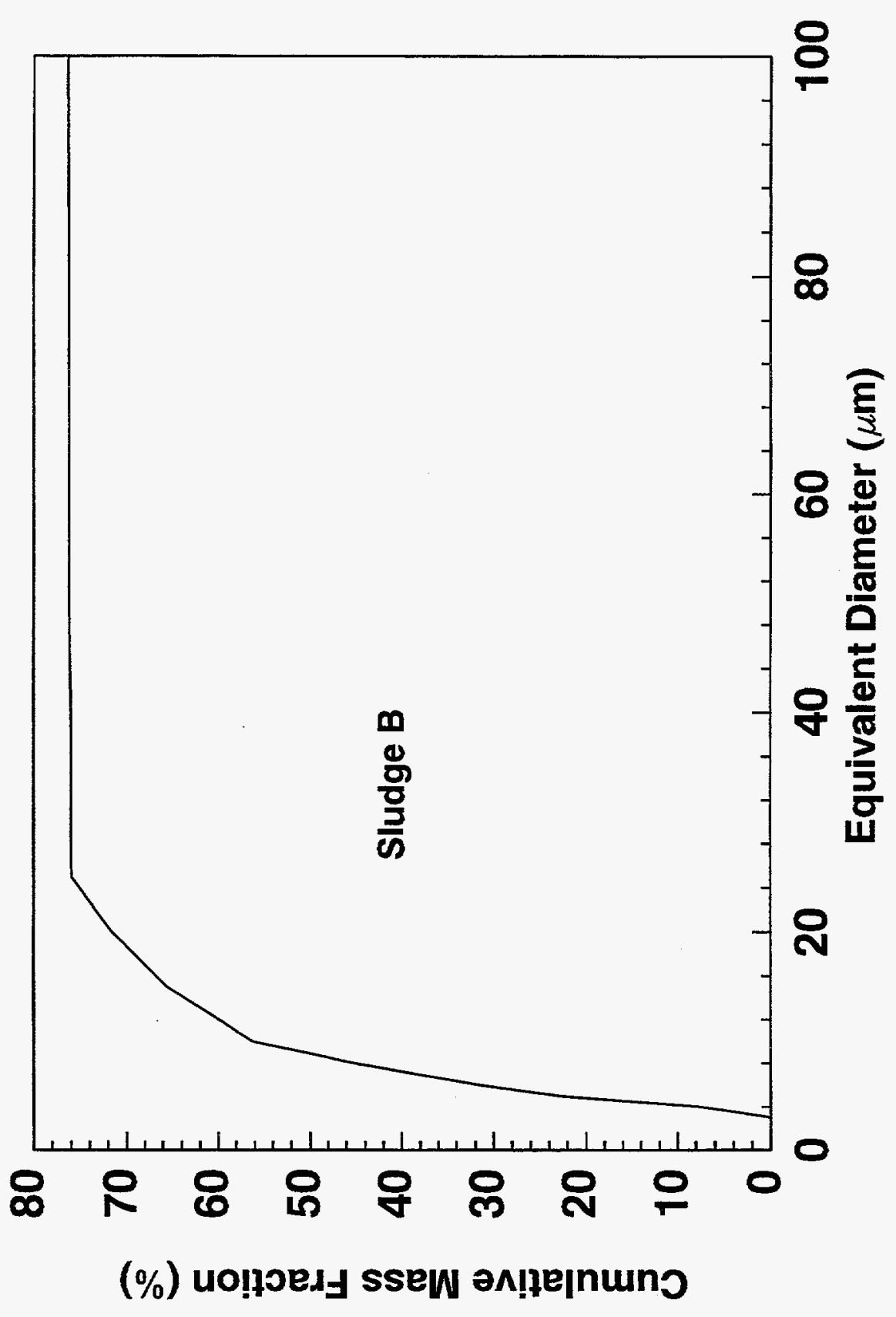

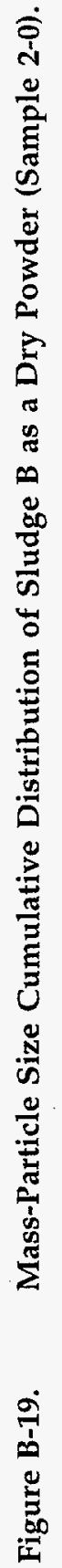


Appendix B

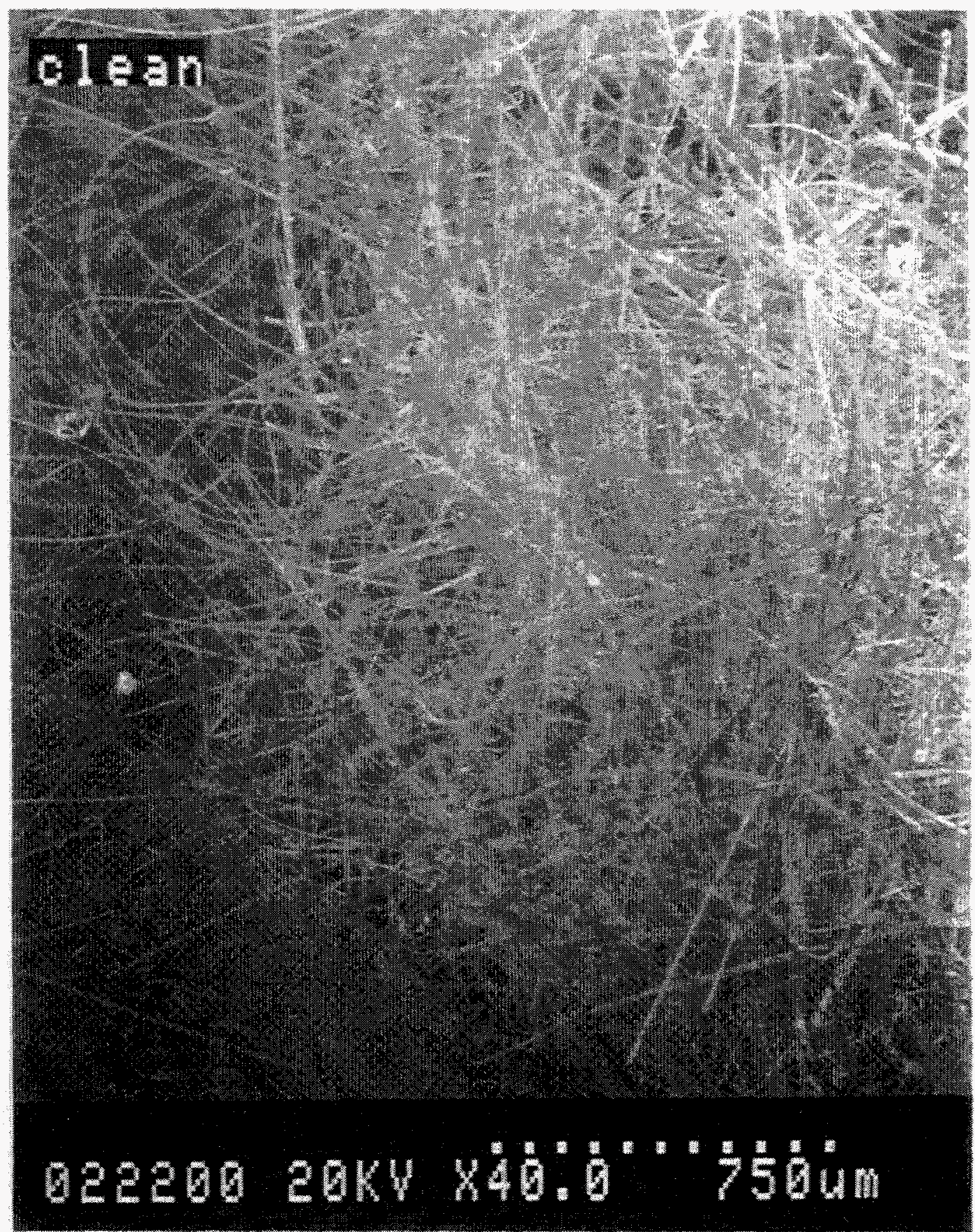

Figure B-20. SEM Photograph of a Clean Fiber Bed (Sample 3-0) at $750 \mu \mathrm{m}$ Bar Magnification. 
Appendix B

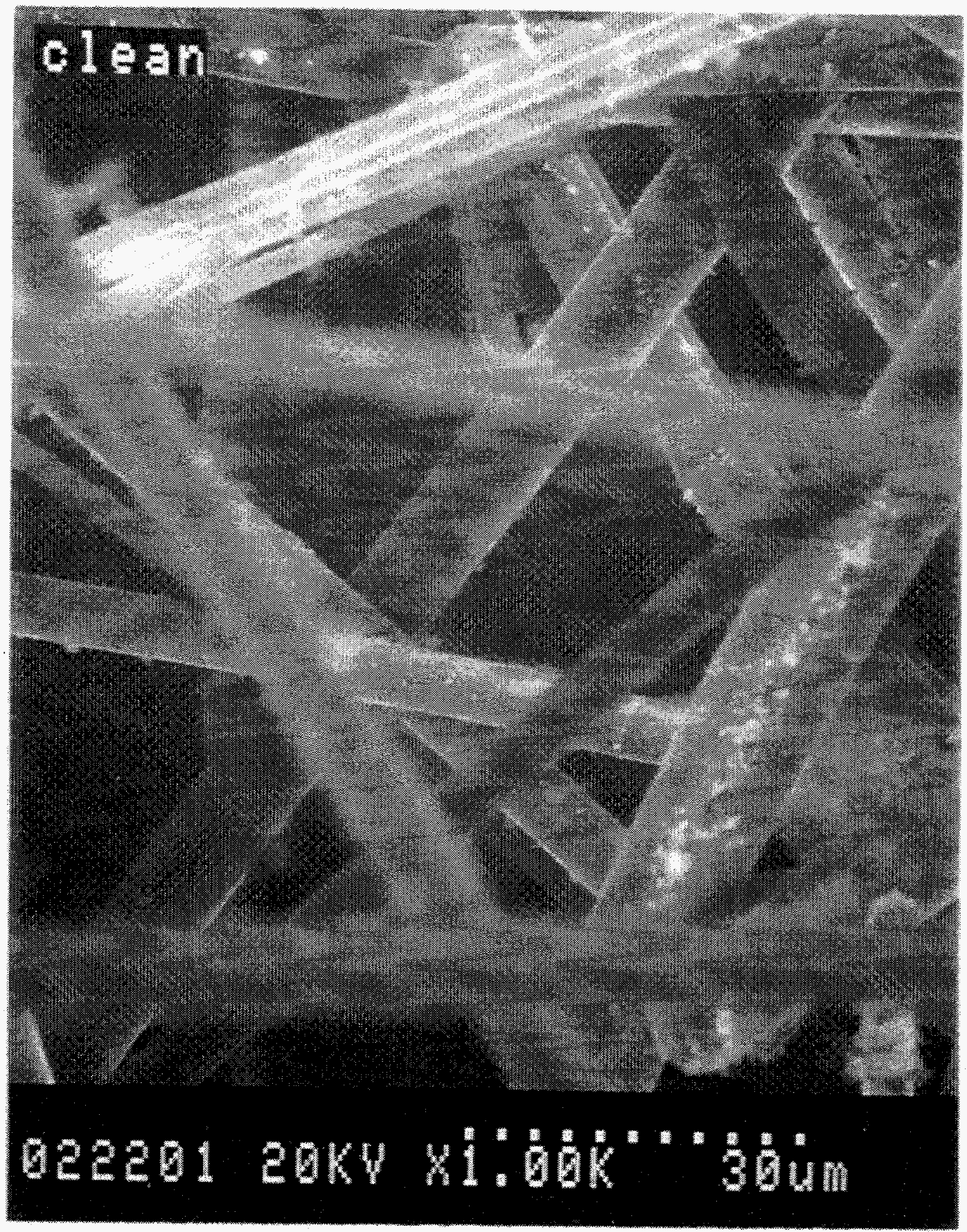

Figure B-21. SEM Photograph of a Clean Fiber Bed (Sample 3-0) at $30 \mu \mathrm{m}$ Bar Magnification. 
Appendix B

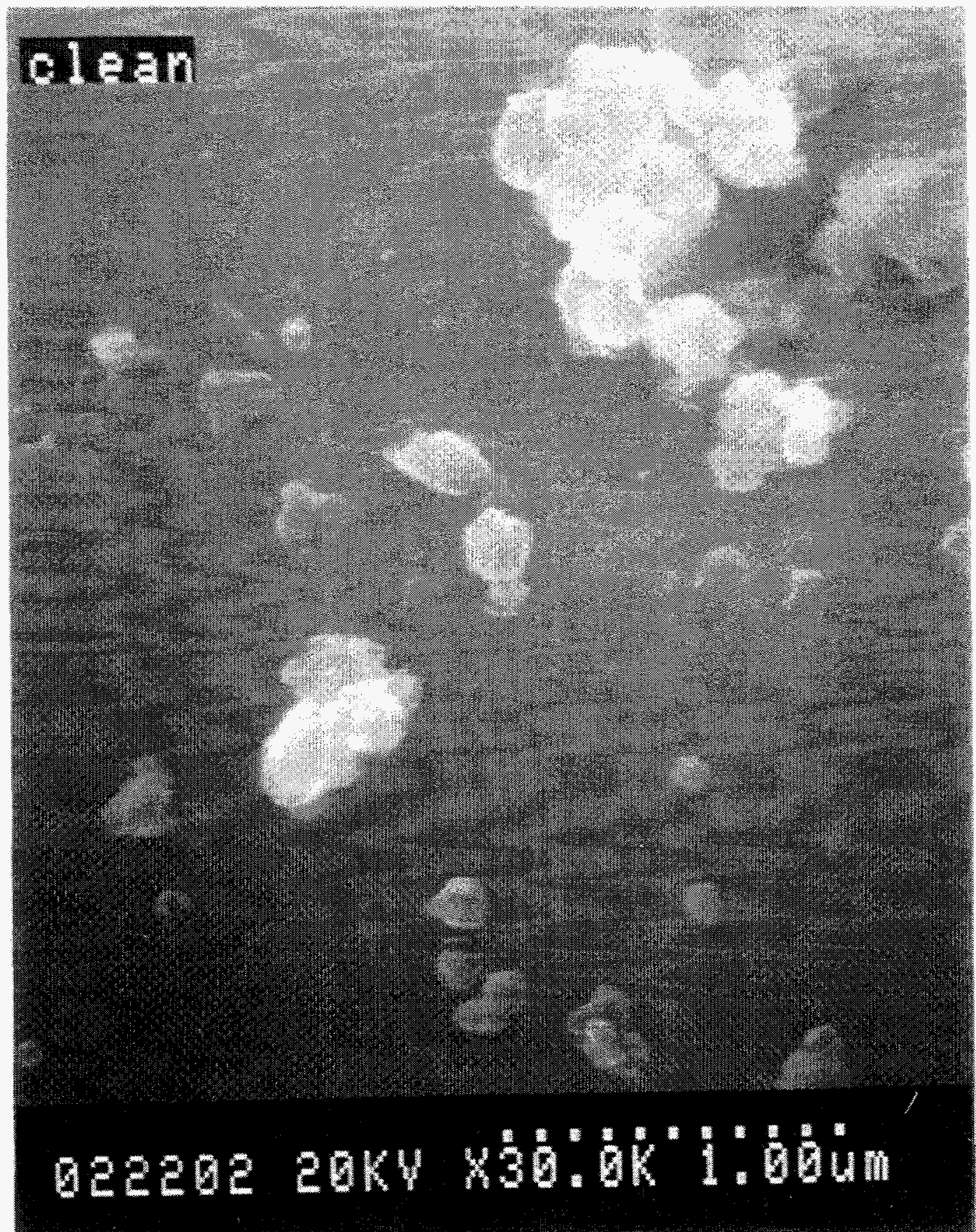

Figure B-22. SEM Photograph of a Clean Fiber Bed (Sample 3-0) at 1 mm Bar Magnification. 
structure; in addition, Figure B-20 suggest that the fibers in the bed are arranged in a perpendicular direction with respect to the water flow in the test facility. Figure B-21, SEM at $30 \mu \mathrm{m}$ bar magnification, shows that the fibers are about $7 \mu \mathrm{m}$ in diameter with very few particles deposited on their surfaces; the SEM photograph at the highest magnification of $1 \mu \mathrm{m}$ bar, presented in Figure B-22, shows these particles in more detail. The nature of these deposits, however, can not be inferred from these pictures, but they can be chemical products used in the production of the fibers; alternatively, they can be sludge particles deposited on the test facility surfaces during previous tests, and removed by the water flow for ulterior deposition on these fibers.

\subsubsection{Lightly Loaded Mixed Bed SEM Results}

Sample 3-1, a fiber bed loaded with Sludge A particles, came from a test in which the same mass of Sludge $A$ as the mass of fibers was added to the test loop. Figures B-23, B-24, and B-25 present the SEM photographs of a specimen from this sample. Figure B-23 is the lowest magnification $(750 \mu \mathrm{m})$ SEM photograph, and shows a fairly uniform arrangement of fibers with some large particles or agglomerates intermixed with the fibers. Figure B24, a medium magnification SEM photograph (30 $\mu \mathrm{m})$, shows that numerous small particles are deposited on the surface of the fibers. As indicated by the highest magnification SEM photograph (1 $\mu \mathrm{m})$ in Figure B-25, the dimensions of these particles are on the order of 0.1 to $0.5 \mu \mathrm{m}$.

\subsubsection{Heavily Loaded Mixed Bed SEM Results}

The heavily loaded mixed bed from which Sample 3-2 was collected, was produced when a mass of Sludge A particles ten times greater than the mass of fibers was added to the test loop. Specimens for SEM analyses were selected from three regions in this debris bed sample: periphery, halfway from edge to center, and center. In general, the SEM photographs showed similar results for these three regions. Typical SEM photographs are presented in
Figures B-26, B-27, B-28, and B-29.

Figure B-26 presents a SEM photograph at the lowest magnification $(750 \mu \mathrm{m})$, and shows a relatively uniform arrangement of fibers with large agglomerates intermixed with the fibers; the dimensions of these agglomerates range from less than $100 \mu \mathrm{m}$ to about $250 \mu \mathrm{m}$. The next highest magnification photo $(250 \mu \mathrm{m})$ in Figure B-27, suggests that a significant blockage of the channels within the fibers is produced by these agglomerates. The SEM photo at a $30 \mu \mathrm{m}$ bar magnification in Figure B-28, shows particles and agglomerates, with dimensions on the order of $30 \mu \mathrm{m}$ and smaller, covering the surface of the fibers. The highest magnification SEM photo (at $1 \mu \mathrm{m}$ bar) in Figure B29 , shows that the primary particles covering the surface of the fibers have dimensions less than 1 $\mu \mathrm{m}$.

In general, these SEM photographs show that the spread of particle size is broad; an appreciable number of agglomerated and primary particles are observed for all sizes between 0.1 and $250 \mu \mathrm{m}$. In addition, the SEM analyses of the debris beds show non-uniform deposition of the particles on the fibers. This could have been the result of the debris bed drying, transport, and sample preparation for analysis; this possibility is supported by the observation that particles fell off during the preparation of the specimen for SEM examination unless great care was taken.

The SEM photos of the heavily loaded bed, presented in Figures B-26 and B-27, suggest a blocking mode of particle deposition [Ref. 6], in which the agglomerated particles are lodged within the pore constrictions of the bed in such a way that the flow channels become clogged. The SEM photographs at high magnification, presented in Figures B-28 and B-29, show numerous sub-micron particles deposited on the surfaces of the fibers, suggesting also some particle deposition by smooth coating [Ref. 7]. Since the agglomerates represent by far most of the particle mass, it is believed that the dominant type of particle deposition in the examined case is of the blocking mode. 
Appendix B

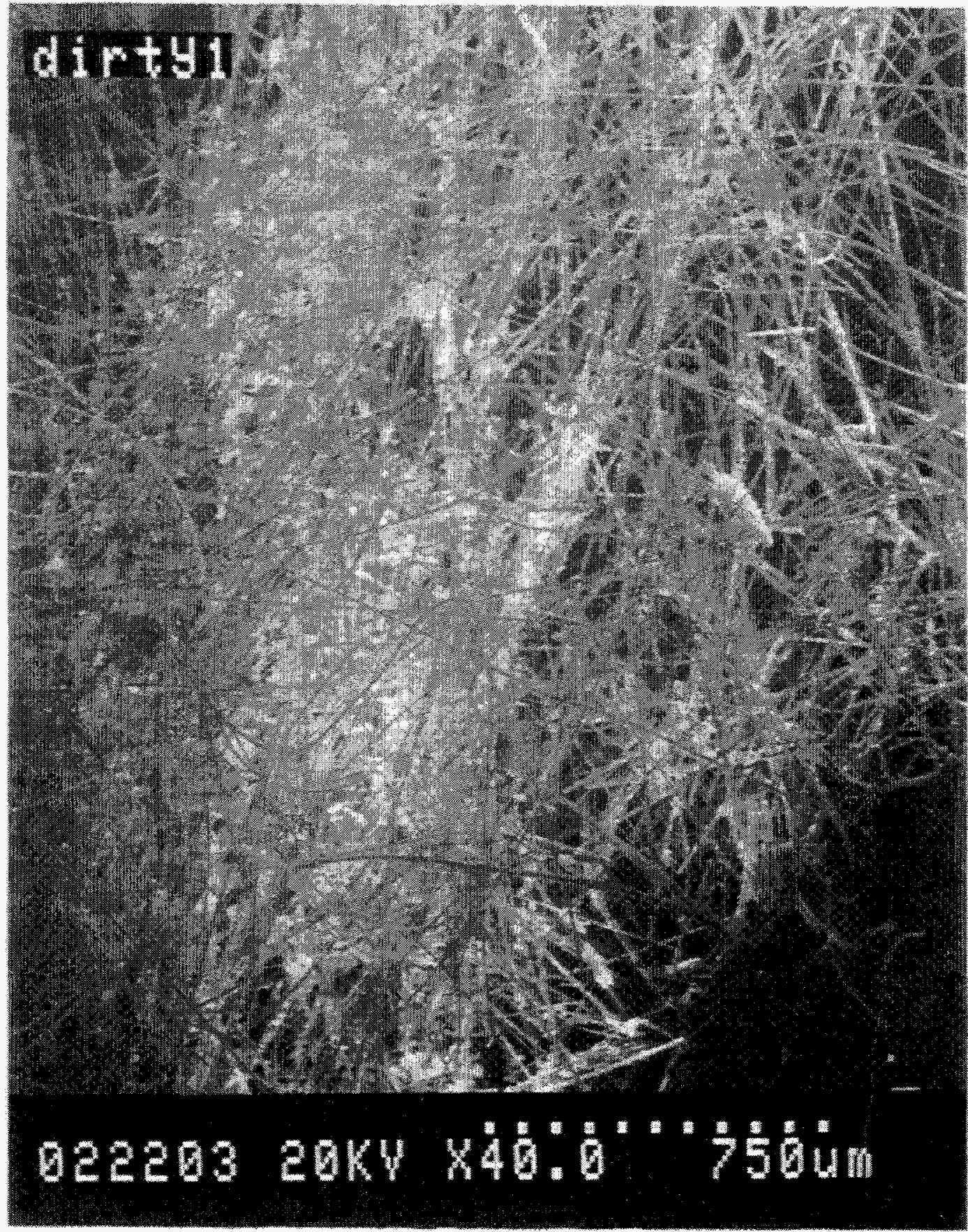

Figure B-23. SEM Photograph of a Lightly Loaded Mixed Bed (Sample 3-1) at 750 um Bar Magnification. 
Appendix B

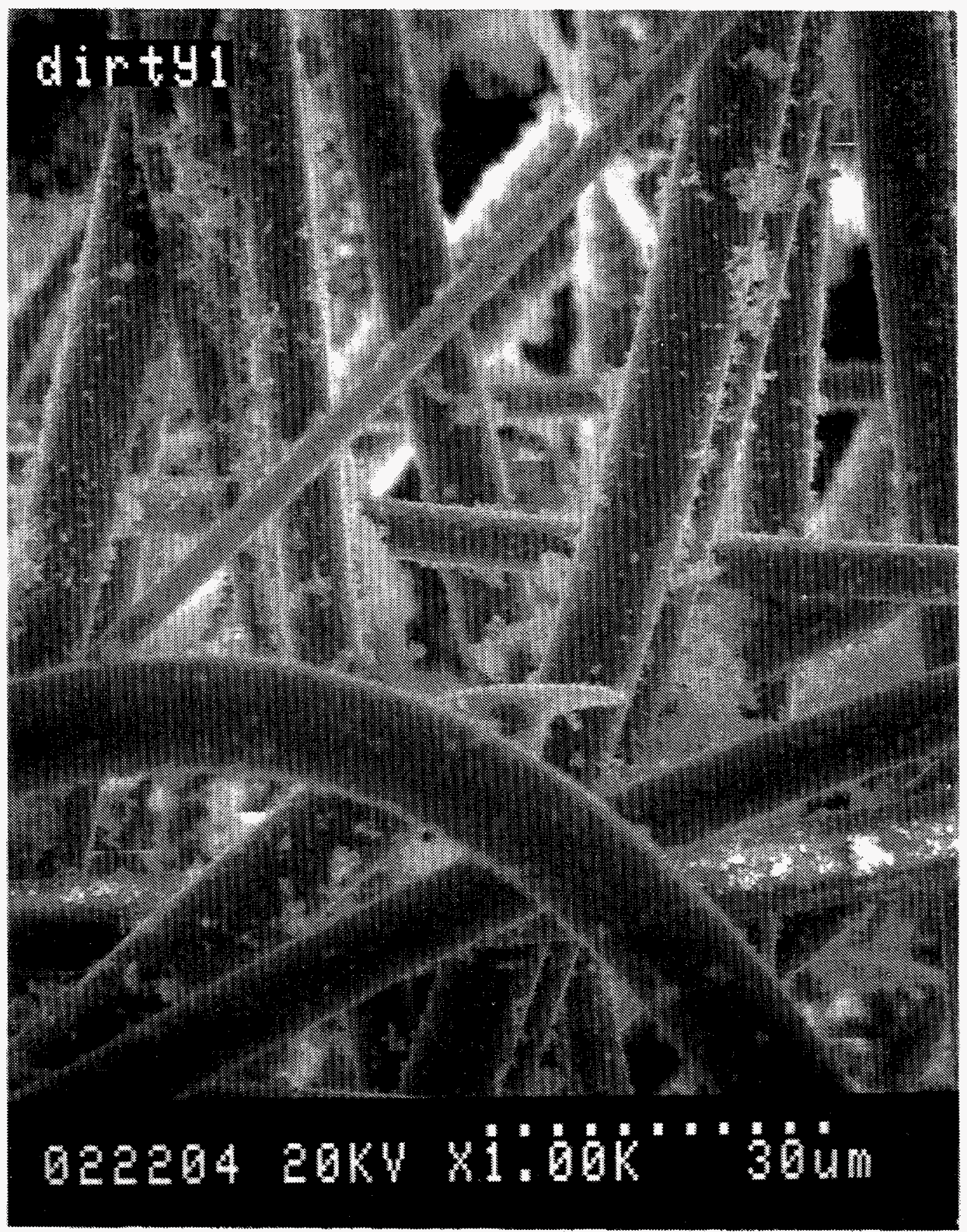

Figure B-24. $\quad$ SEM Photograph of a Lightly Loaded Mixed Bed (Sample 3-1) at $30 \mu \mathrm{m}$ Bar Magnification. 
Appendix B

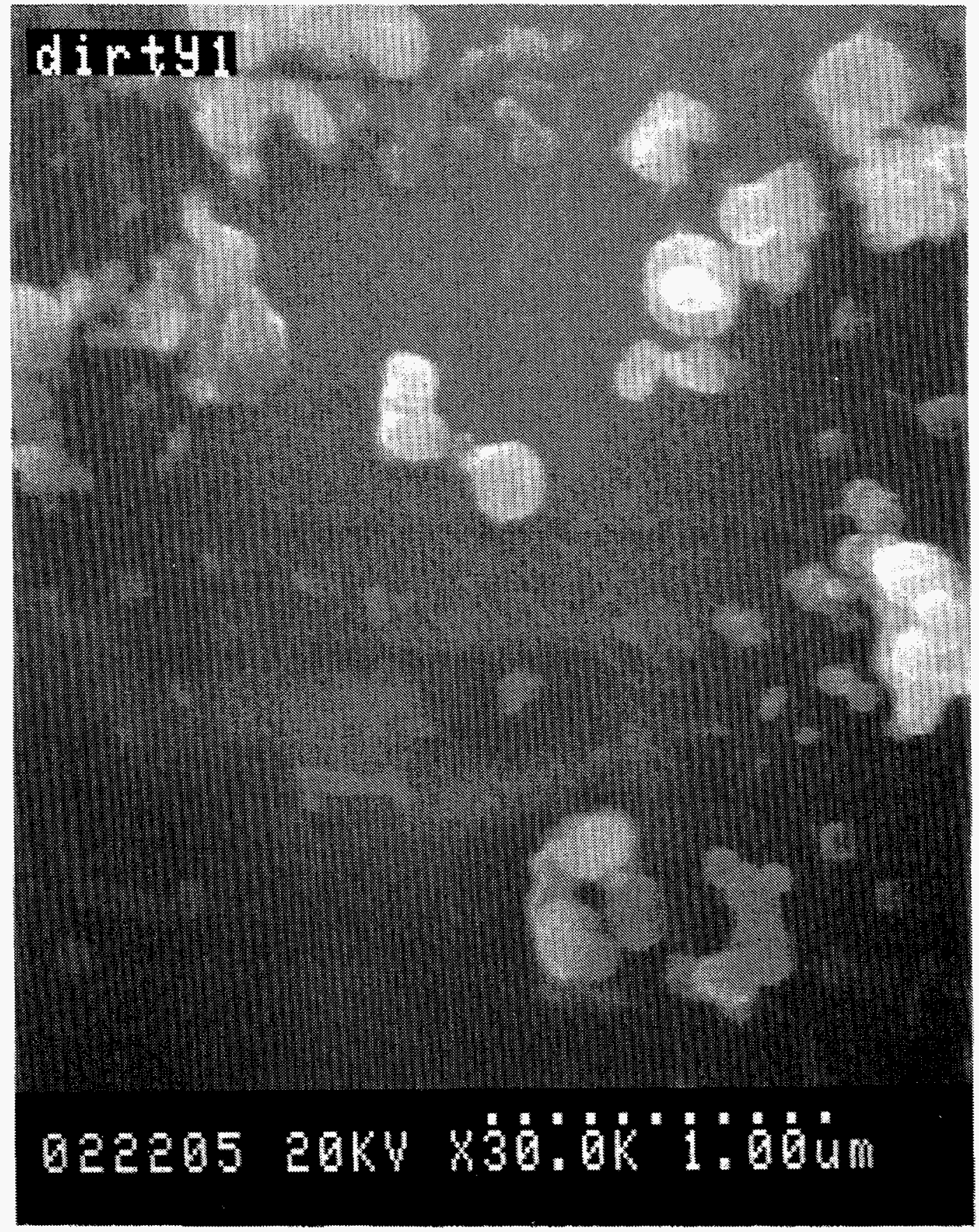

Figure B-25. SEM Photograph of a Lightly Loaded Mixed Bed (Sample 3-1) at 1 $\mu \mathrm{m}$ Bar Magnification. 
Appendix B

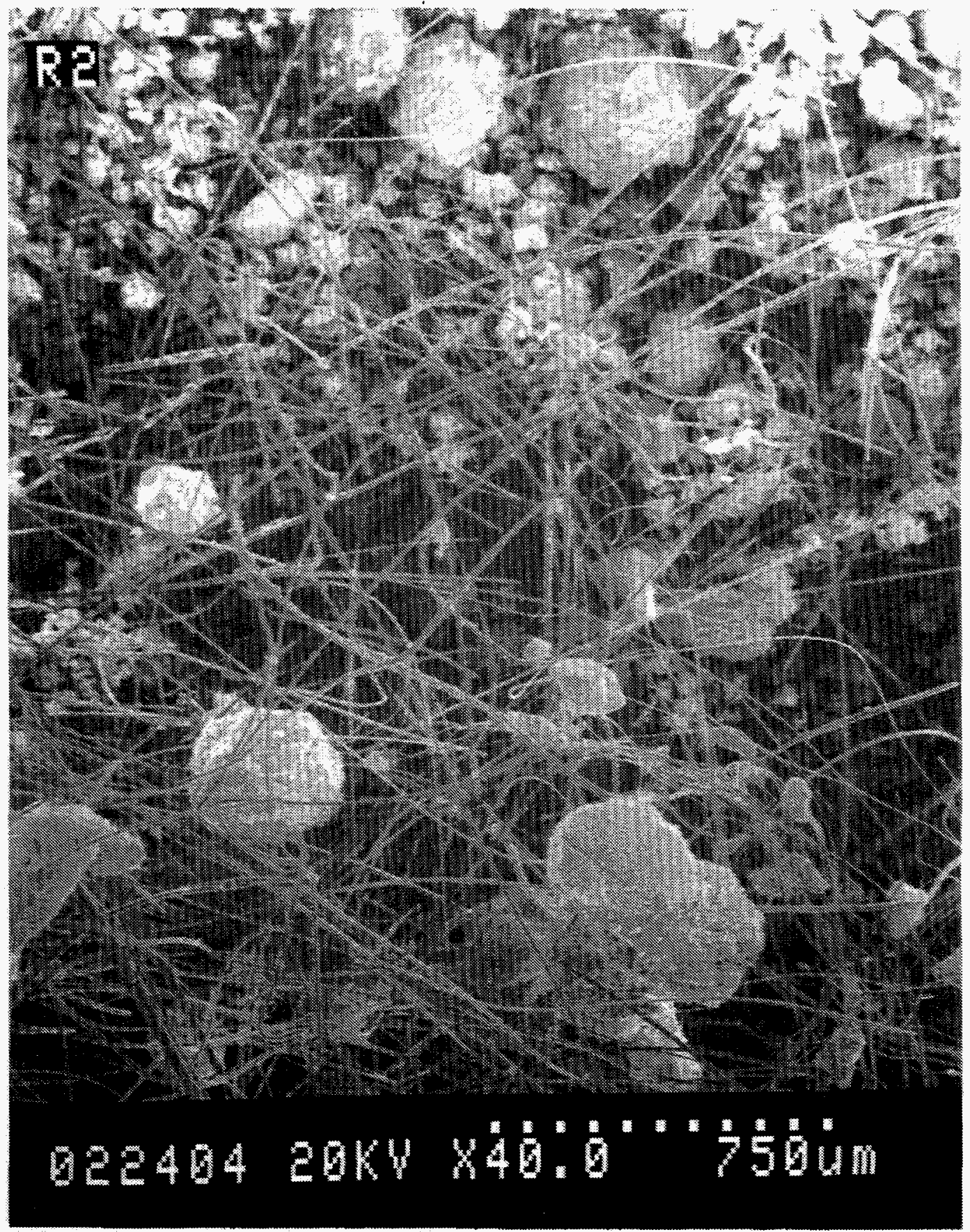

Figure B-26. SEM Photograph of a Heavily Loaded Mixed Bed (Sample 3-2) at 750 um Bar Magnification. 


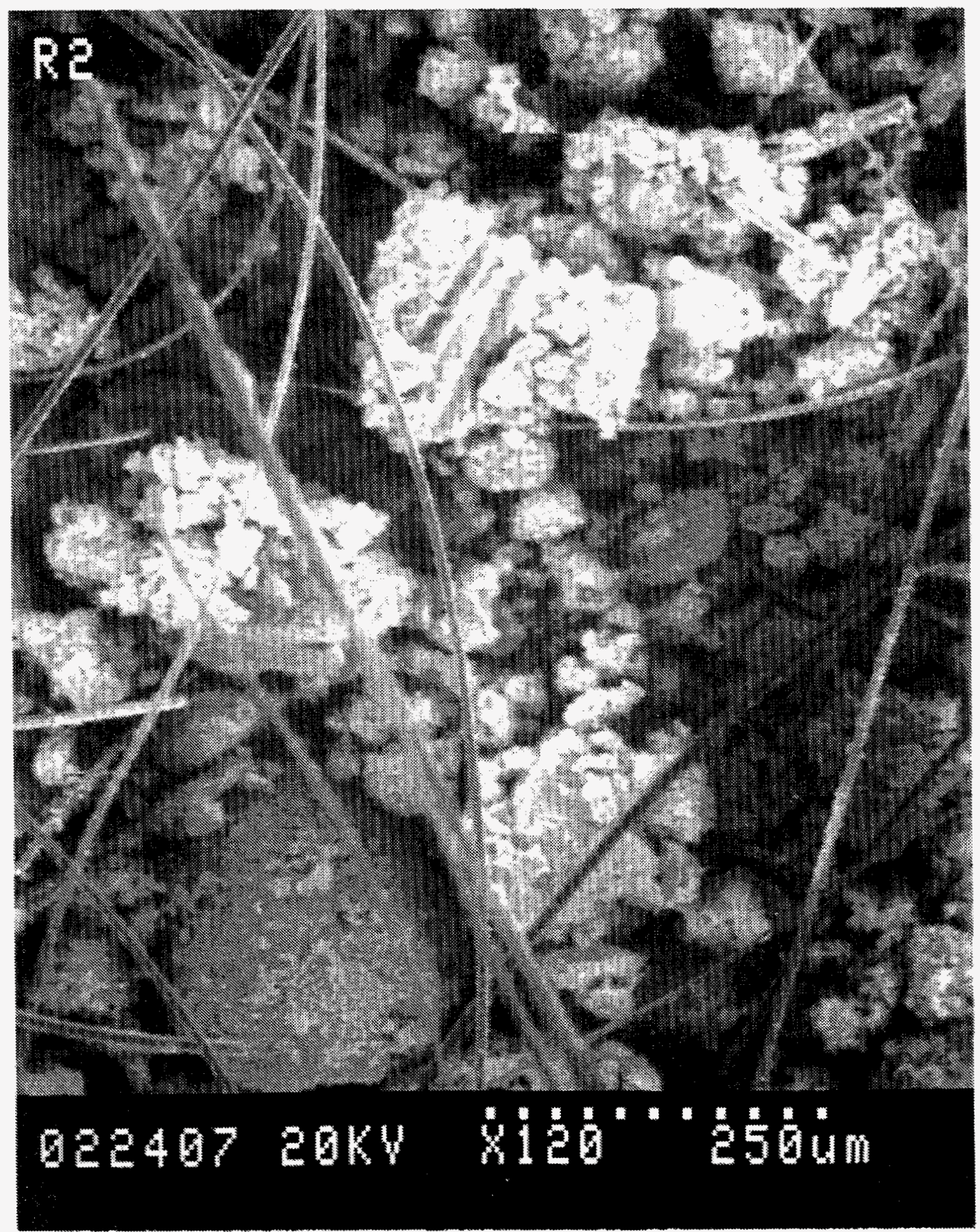

Figure B-27. SEM Photograph of a Heavily Loaded Mixed Bed (Sample 3-2) at $250 \mu \mathrm{m}$ Bar Magnification. 
Appendix B

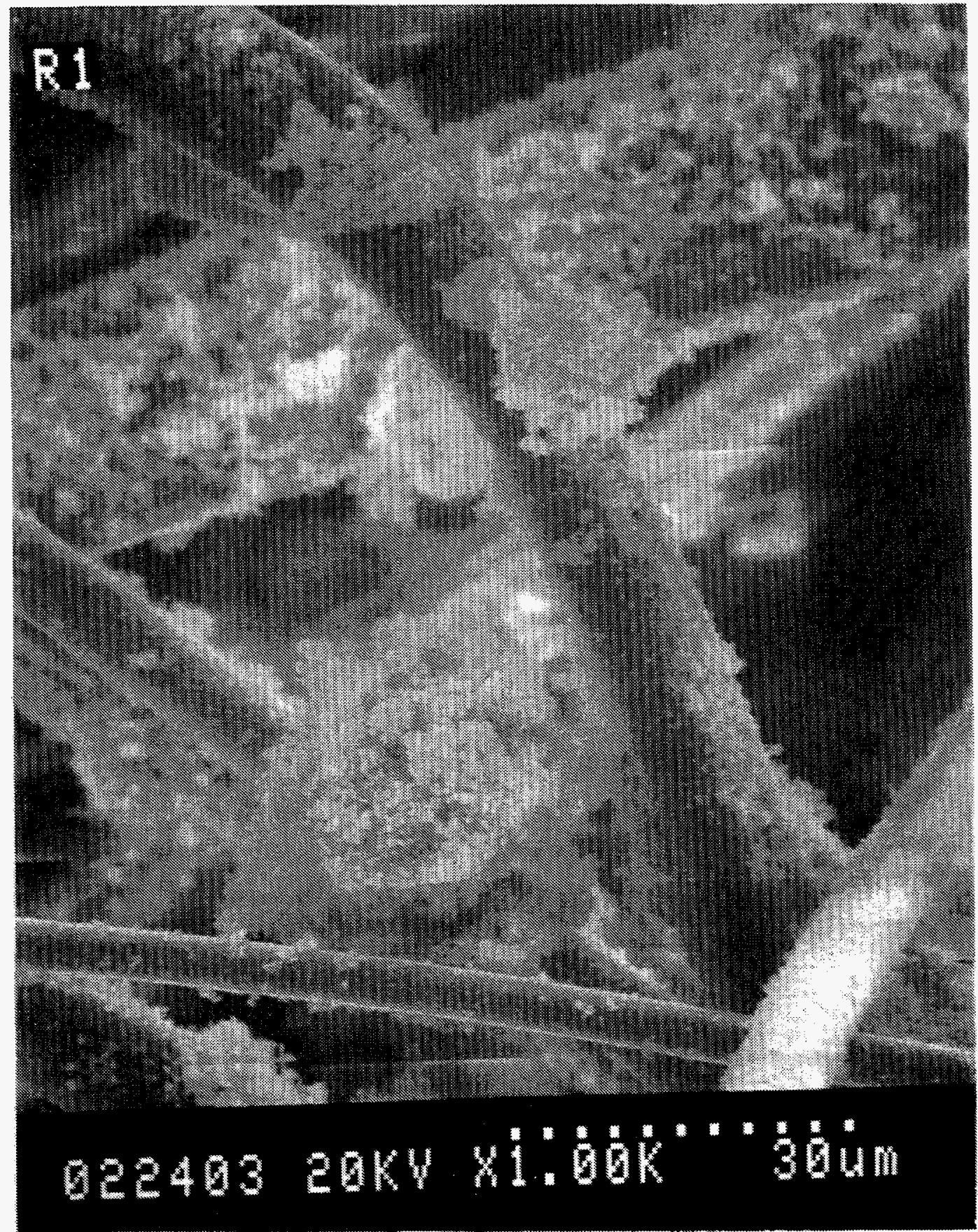

Figure B-28. SEM Photograph of a Heavily Loaded Mixed Bed (Sample 3-2) at $30 \mu \mathrm{m}$ Bar Magnification. 
Appendix B

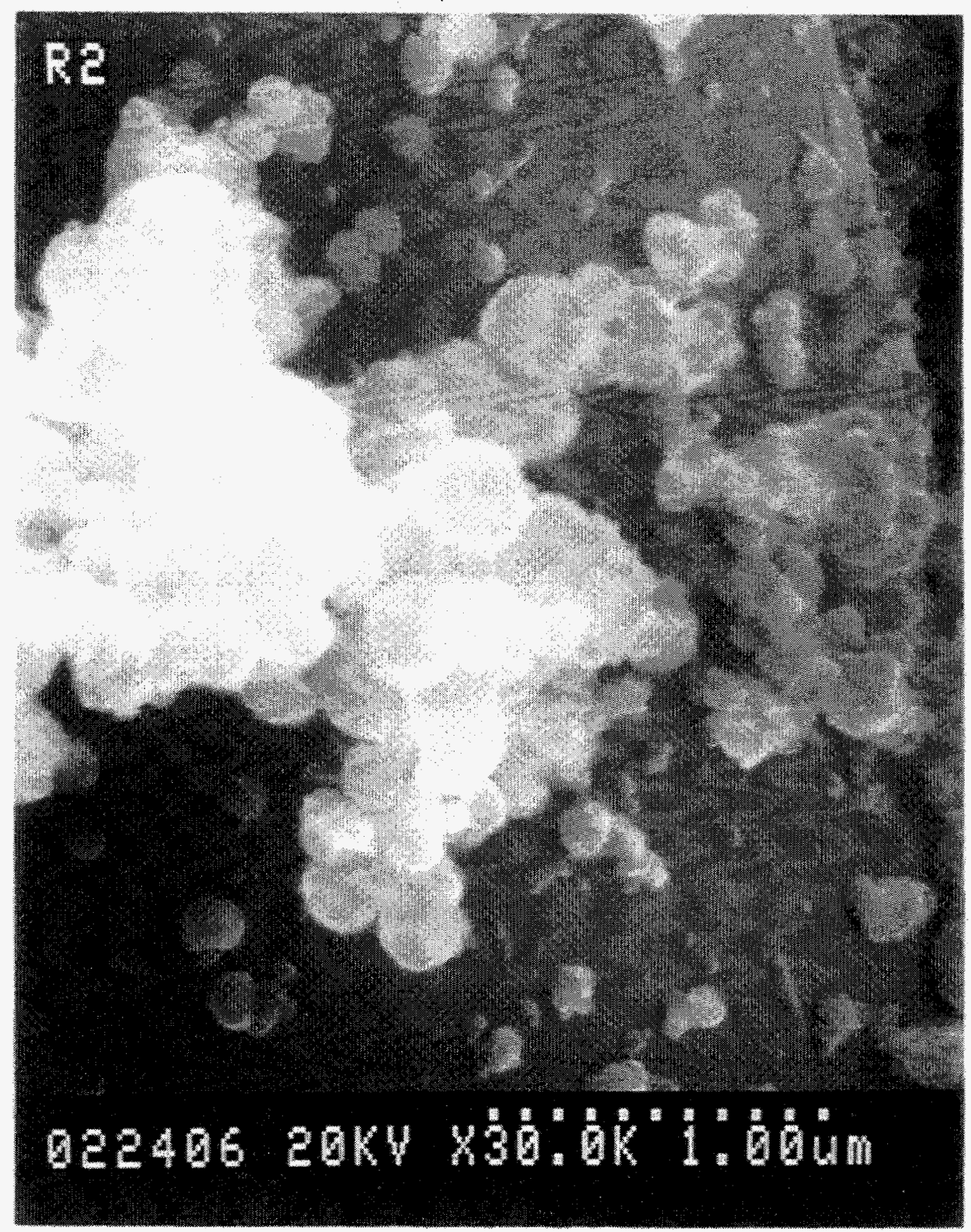

Figure B-29. SEM Photograph of a Heavily Loaded Mixed Bed (Sample 3-2) at 1 um Bar Magnification. 


\subsection{Findings}

The objectives of these characterization analyses were to determine the shape, state of agglomeration, and size distribution of the iron oxide particles used in the head loss experiments to simulate the sludge found in the suppression pools of several BWRs; in addition, the morphology of the deposition of these particles on NUKON ${ }^{\mathrm{TM}}$ fiber beds was investigated.

To achieve these objectives, SEM analyses were used to determine the shape, state of agglomeration, and to obtain a qualitative estimation of the size distribution of the iron oxide particles; the quantitative size distribution was estimated with sedimentation velocity analysis. The morphology of deposition of these particles on NUKON ${ }^{\mathrm{TM}}$ fiber beds was investigated using SEM analyses.

Sludge A was used in the majority of the head loss tests and, therefore, was characterized both in the dry state, i.e., before dropping it into the head loss test facility, as well as while circulating in the water in the test loop; Sludge B was characterized only in the dry state, as supplied by the manufacturer, before dropping it into the test facility. To determine the morphology of the debris bed formed in the head loss experiments, samples from clean and mixed fiber beds, both lightly and heavily loaded with Sludge A particles, were characterized using SEM.

\subsection{Findings of the Sludge Particles Characterization}

The SEM analyses of Sludge A showed that it is composed of nearly spherical particles extensively agglomerated; in the dry state, the spread of the size distribution is broad, with an appreciable number of primary and agglomerated particles observed for all sizes between $0.1 \mu \mathrm{m}$ and $375 \mu \mathrm{m}$. The SEM analyses of the Sludge A particles, collected while circulating in the water in the head loss test loop without fibrous materials, suggested that significant dispersion of the large agglomerates, i.e., greater than $100 \mu \mathrm{m}$, occurred when they passed through the pump's impeller; furthermore, the SEM analyses of the Sludge A particles collected while circulating in the water in the presence of NUKON ${ }^{\mathrm{TM}}$ fibrous shreds, showed that a considerable fraction of the large agglomerates is deposited on the fiber beds. In general, these results suggest that the particle size distribution of the Sludge A particles is very sensitive to the method used to disperse the agglomerated particles.

The sedimentation velocity analyses of the Sludge A particles circulating in the water in the head loss test loop at $1.5 \mathrm{ft} / \mathrm{s}(0.5 \mathrm{~m} / \mathrm{s})$, indicate that the size distribution, by mass, represents fairly well the particle size distribution recommended by the BWROG. On the other hand, the sedimentation velocity analyses show that, without the dispersion introduced by the impeller of the pump in the head loss facility, the large agglomerates observed in Sludge A produce a particle mass-size distribution significantly larger than the recommended by the BWROG; this finding confirms the corresponding conclusion derived as part of the Suppression Pool Experiments [Ref. 8].

With respect to Sludge $B$, the SEM analyses showed that, in the dry state, it is composed of nearly spherical agglomerated particles; the spread of the size distribution is not as broad as in the case of the Sludge A particles. The sedimentation velocity analyses showed that the mass-median diameter of the Sludge B particle population occurs at about 8.8 $\mu \mathrm{m}$, indicating a smaller size distribution than the particle size distribution according to the manufacturer's specifications, i.e., $82 \%$, by mass, of particles in the size range between 10 and $35 \mu \mathrm{m}$. In general, these results suggest that Sludge $B$ is not significantly different from Sludge $A$, a finding that may explain why the head losses measured for this type of particles were similar to the corresponding head losses for Sludge A particles.

\subsection{Findings of the Debris Bed Characterization}

The SEM of the debris bed formed during the head loss experiments showed that, in all cases, the fibers form a fairly uniform structure arranged in a perpendicular direction with respect to the water flow in the test facility. In the case of the mixed beds, these analyses showed large agglomerates, between 100 and $250 \mu \mathrm{m}$, intermixed with the fibers. Higher magnification SEM photographs, indicated that the size distribution of the particles deposited on the fiber surfaces and channel structures is broad, showing an appreciable number of primary particles and agglomerates between 0.1 and $250 \mu \mathrm{m}$. 
Appendix B

These analyses suggest that the deposition of sludge particles is by smooth coating, in the case of primary particles, and by channel blocking in the case of agglomerates; since the agglomerates represent by far most of the particle mass, it is believed that the blocking mode is the dominant type of particle deposition in the head loss experiments. 


\section{References for Appendix B}

[1] Interim Report of the BWR Owners' Group ECCS Suction Strainer Committee, BWROG, December 1994, p. 18

[2] "Debris in Containment and the Residual Heat Removal System," NRC Information Notice 94-57, August 12, 1994.

[3] "Summary of Current and Potential Future BWR Owners' Group Activities Regarding Resolution of ECCS Suction Strainer Issue," International Working Group Meeting, October 1994.

[4] Zigler, G., et al, "Parametric Study of the Potential for BWR ECCS Strainer Blockage Due to LOCA Generated Debris," NUREG/CR-6224, Draft Report for Comment, USNRC, August 1994, p. 4-24.
[5] 'BWR Owners' Group ECCS Suction Strainer Committee Suppression Pool Sludge Particle Size Distribution," Letter from General Electric to A.W. Serkiz, USNRC, Dated September 13, 1994.

[6] Tien, C. and Paytakes, A.C., "Advances in Deep Bed Filtration" in AIChE Journal, Vol 25, No. 5., 1979, p. 750

[7] Reference [6], pp. 750-751.

[8] Souto, F. J., and Rao, D.V., "Experimental Investigation of Sedimentation of LOCA Generated Fibrous Debris and Sludge in BWR Suppression Pools," NUREG/CR-6368, USNRC, November, 1995. 


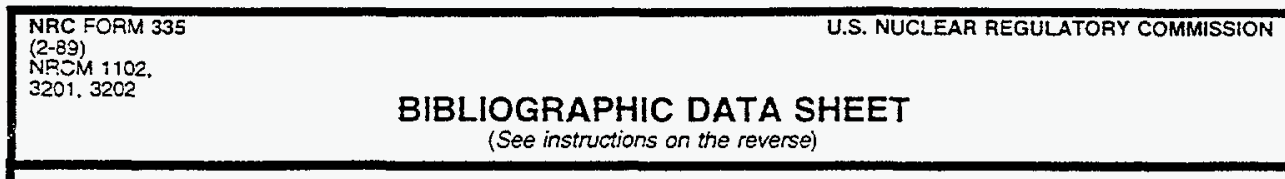

2. TITLE AND SUBTTLE
- REPORT NUMBER

(Aseligned by NRC, Add Yol., Supp., Fov, and Addendum Numbers, it any)

NUREG/CR-6367

SEA 95-554-06-A:8

Experimental Study of Head Loss and Filtration for LOCA Debris

\begin{tabular}{|c|r|}
\hline 3. & DATE REPORT PUBLISHED \\
\hline MONTH & YEAR \\
February & 1996 \\
\hline
\end{tabular}

4. FIN OR GRANT NUMBER

L1854, W6459

5. AUTHOR(S)

6. TYPE OF REPORT

D. V. Rao and F. J. Souto

7. PERIOD COVERED (Inclusive Dates)

8. PERFORMING ORGANIZATION - NAME AND ADDRESS (If NRC, provide DIVislon, Office or Reglon, U.S. Nuclear Regufatony Commission, and malling address; if contractor, provide name and molling address.)

Science and Engineering Associates, Inc.

6100 Uptown Blvd. NE

Albuquerque, NM 87110

9. SPONSORING ORGANIZATION - NAME AND ADDRESS (If NRC, type "Same as above"; "l coneractor, provido NRC OIVIslon, Ottlee or Reglon, U.S. Nuclear Comm/ssion and malling address.)

Division of Engineering Technology

Office of Nuclear Regulatory Research

U.S. Nuclear Regulatory Commission

Washington, DC 20555-0001

10. SUPPLEMENTARY NOTES

M. L. Marshal 7, Jr., A. W. Serkiz, NRC Project Managers

11. ABSTRACT (200 words or less)

A series of controlled experiments were conducted to obtain head loss and filtration characteristics of debris beds formed of NUKON'M fibrous fragments, and obtain data to validate the semi-theoretical head loss model developed in NUREG/CR-6224. A thermally insulated closed-loop test set-up was used to conduct experiments using beds formed of fibers only and fibers intermixed with particulate debris. A total of three particulate mixes were used to simulate the particulate debris. The head loss data were obtained for theoretical fiber bed thicknesses of $0.125^{\prime \prime}$ to 4.0"; approach velocities of 0.15 to $1.5 \mathrm{ft} / \mathrm{s}$; temperatures of $75^{\circ} \mathrm{F}$ and $125^{\circ} \mathrm{F}$; and sludge-to-fiber nominal

concentration ratios of 0 to 60 . Concentration measurements obtained during the first flushing cycle were used to estimate the filtration efficiencies of the debris beds. For test conditions where the beds are fairly uniform, the head loss data were predictable within an acceptable accuracy range by the semi-theoretical model. The model was equally applicable for both pure fiber beds and the mixed beds. Typically the model over-predicted the head losses for very thin beds and for thin beds at high sludge-to-fiber mass ratios. This is attributable to the nonuniformity of such debris beds. In this range the correlation can be interpreted to provide upper bound estimates of head loss.

12. KEY WORDSIDESCRIPTORS (Lst word or phrases that will assist recearchiors in locating the roport)

BWR Suction Strainers

Loss of NPSH

Head Loss Correlations

\begin{tabular}{|cc|}
\hline $\begin{array}{c}\text { 13. } \\
\text { AVAILABILTY STATEMENT } \\
\text { Unlimited }\end{array}$ \\
\hline 14. & SECURITY CLASSIFICATION \\
\hline & $\begin{array}{l}\text { (This Page) } \\
\text { Unclassified }\end{array}$ \\
\hline & $\begin{array}{l}\text { (This Report) } \\
\text { Unclassified }\end{array}$ \\
\hline 15. NUMBER OF PAGES \\
\hline 16. PRICE \\
\hline
\end{tabular}

NRC FORM $335(2-89)$ 